\title{
3. Ebenen gesellschaftlicher Tiefenwirkung
}

\subsection{Die Hofierung der "Totgeschwiegenen": Grimm und Kolbenheyer im Spiegel der rechtsgerichteten Presse nach 1918}

\subsubsection{Selektive Wahrnehmung und Larmoyanz: Totschwei- gen und totgeschwiegen werden im politisierten Buchmarkt der Weimarer Republik}

\begin{abstract}
Aber so geht es eben. Die deutsche Öffentlichkeit, gemeint sind die deutsch redigierten Zeitungen und Zeitschriften, kann sich nicht genugtun, alles mögliche Schöne und Gute über die jüdische Literatur zu verkünden, während die jüdisch geführten Zeitungen totschweigen und - wird ihnen ein deutscher Dichter, den sie nicht kaptiviert haben, zu wirksam - diesen von irgendeinem Lausjungen auf das hämischste bespeien lassen. Und was tun die deutsch geführten Zeitungen und Zeitschriften? Sie lassen es ruhig geschehen. ${ }^{1}$
\end{abstract}

Klub Der totgeschwiegenen Dichter - Die Literatur der Weimarer Republik, so der Befund von Siegfried Lokatis, zerfiel infolge des von „Gewerkschaften, Verbänden, Parteien und konfessionellen Organisationen“ getragenen „Durchbruch [s] zum Massenbuchhandel“ in zwei sich wechselseitig „befehdende und voneinander abgeschottete literarische Teilöffentlichkeiten“2. In kaum zu übertreffender Deutlichkeit wird diese Zerrissenheit von dem Ergebnis einer im Jahr 1929 durchgeführten Umfrage der Deutschen Dichter-Gedächtnis-Stiftung unterstrichen. Gefragt wurde nach jenen „neuesten Werk[en]“ der deutschen Literatur, die es „wert“ seien, „dem Gedächtnis des Volks erhalten zu bleiben“. Nach der Auswertung aller eingereichten Antworten, in denen insgesamt 936 Buchtitel Erwähnung fanden, rangierte Hans Grimms Volk ohne Raum an erster Stelle - unmittelbar gefolgt von Erich Maria Remarques Antikriegsroman Im Westen nichts Neues. ${ }^{3}$ Kolbenheyers Paracelsus-Trilogie landete auf dem sechsten Platz.

Sowohl die Exponenten der politischen Rechten als auch der politischen Linken warnten während der Weimarer Republik in dramatisierenden Worten vor der Bücherproduktion der jeweils anderen Seite. Diese Warnungen lassen sich zunächst als eine rhetorische Strategie im fortwährenden Kampf um literarische Absatzmärkte verstehen: Die Konstruktion einer erdrückenden Dominanz des

1 KAG, Erwin Guido Kolbenheyer an Hermann Ullmann, 29. März 1927 (Durchschlag).

2 Lokatis, Intelligenz, S. 248.

3 Vgl. Die Literatur. Monatsschrift für Literaturfreunde 31 (1928/29), S. 681. 
Gegenübers und der geradezu gebetsmühlenartig wiederholte Appell, dass jene Dominanz unter allen Umständen durchbrochen werden müsse, sollte für zusätzliche Kaufanreize innerhalb der eigenen Zielgruppen sorgen. In der Logik dieses Denkens lag es für Publizisten der Weimarer Rechten denn auch, große Erfolge „ihrer“ Autoren wie etwa jene Grimms und auch Kolbenheyers gleichsam zu Mirakeln zu stilisieren, die widrigsten äußeren Umständen abgetrotzt worden seien. Komplementär dazu wurden die Erfolge politisch linksstehender Autoren, etwa jene Alfred Döblins, Erich Maria Remarques, Lion Feuchtwangers oder Jakob Wassermanns, zu rein „gemachten“, sprich: künstlich herbeigeführten und dem deutschen Lesepublikum durch desinformierende Literatur-Propaganda gleichsam aufgezwungenen Scheinerfolgen herabgewürdigt.

Das Image des zum „Schaden“4 des deutschen Volks um seine Chancengleichheit auf dem Literaturmarkt geprellten Autors, wie es auch von rechtsgerichteten Verlagen der Weimarer Republik gepflegt wurde, war jedoch mehr als eine lediglich aufgesetzte, wider besseres Wissen ausgesprochene Vermarktungsstrategie. Zumindest im Fall Grimms und Kolbenheyers kann kein Zweifel bestehen, dass beide Autoren die Vorstellung, ungerecht benachteiligte, ja „totgeschwiegene“ Autoren $\mathrm{zu}$ sein, tief verinnerlicht hatten und persönlich für völlig plausibel hielten. Entsprechend reproduzierten sie diese Vorstellung auch jenseits der Öffentlichkeit beständig in ihren privaten Korrespondenzen mit persönlichen Vertrauten. Auch der Austausch mit ideologisch verwandten Autoren stand im Zeichen einer wechselseitigen Bestärkung dieser Selbstbilder, sodass das Klischee des „totgeschwiegenen“ Autors nach 1918 zu einem identitäts- und gemeinschaftsstiftenden Element innerhalb der völkisch-nationalistischen Literaturszene wurde. Die jeweils nur schwer zugängliche „Teilöffentlichkeit“ der Gegenseite wurde dabei notorisch an Gewicht und Größe überschätzt, die eigene, wohlwollende „Teilöffentlichkeit“ hingegen kleingeredet. ${ }^{5}$

Wie tief Grimm und Kolbenheyer diese Vorstellung internalisierten, zeigt sich auch daran, dass sie noch in ihren nach dem Zweiten Weltkrieg verfassten Lebenserinnerungen zum Ausdruck kommt - nach langen und erfolgreichen, mit der Zäsur des Jahres 1945 freilich jäh unterbrochenen Karrieren. Von Anbeginn

4 Von dem Schriftsteller Werner Bergengruen (1892-1964), seit 1936 Nachbar Kolbenheyers in Solln bei München, ist folgende, ironisch gebrochene Anekdote überliefert: „Das theatralische Pathos, mit dem er [Kolbenheyer] sich umgab, trat gelegentlich sehr drollig zu Tage. [...] Einem Bekannten sprach er von der durch den Krieg hervorgerufenen Knappheit an Papier, Druckerschwärze und Buchbindereibedarf, auf Grund derer sich die Neuauflage eines seiner Bücher verzögerte. Der Schilderung dieser Schwierigkeiten fügte er schlicht und mit ehrlichem Mitgefühl die Bemerkung hinzu: ,Und den Schaden hat das deutsche Volk!"“ (Bergengruen, Schriftstellerexistenz, S. 127). Ob Kolbenheyer diesen einfältigen Satz genau in der von Bergengruen überlieferten Form gesprochen hat, mag dahingestellt bleiben. Da Kolbenheyer sein Euvre jedoch dezidiert als „Dienst am Volk“ verstand, ist es sehr wohl denkbar, dass dieser Satz sinngemäß so gefallen ist.

5 Darauf, dass das Gefühl des „Totgeschwiegenwerdens“ unter politisch rechts stehenden Autoren eine weit über den hier untersuchten Personenkreis hinausgreifende Virulenz besaß, weist beispielsweise im Hinblick auf die Vertreter der norddeutschen „Heimatdichtung“ hin: Dohnke, Weg, S. 23. 
seiner Laufbahn, so Kolbenheyer, habe das „Judentum“ eine erdrückende Dominanz über die deutschsprachige Literaturkritik ausgeübt. Jeder Autor, der auch nur „das Bekenntnis zum Liberalismus versäumte, er brauchte durchaus kein Antisemit zu sein“, sei unter den „Bann publizistischer Vernachlässigung und des Verschweigens“ geraten, mochte er auch noch so „Meisterliches leisten“. Dasselbe Schicksal sei all jenen Autoren widerfahren, die in „artgerechte[r] Form“ Stoffe behandelt hätten, die „einem jüdischen Autor“ - in Ermangelung „arteigene[r] Intuition“ - „ähnlich zu erfassen unmöglich gewesen“6 sei. Es war in den Augen Kolbenheyers demnach die Schuld des „unleugbar rassepolitisch“ eingestellten „literarische[n] Judentum[s]“, dass auch er als Autor erst dann Beachtung gefunden habe, als sein Name „nicht mehr zu umgehen“7 gewesen sei. ${ }^{8}$ Etwas nüchterner und weniger larmoyant, inhaltlich aber identisch fiel Grimms Bilanz der Lage völkisch-nationaler Autoren auf dem Weimarer Buchmarkt aus: Dieser Markt sei gänzlich „von einer Art Literatur beherrscht“ worden, die den Lesern und Buchhändlern „von den ausgesprochenen Großstadtblättern, von Berliner Tageblatt, von Ullsteins Vossischer Zeitung und auch [...] von der Frankfurter Zeitung [...] als so gut wie allein gültig empfohlen" ${ }^{\text {"9 }}$ worden sei.

Vor dem Hintergrund dieser Erklärungsmuster nehmen sich die literarischen und publizistischen Arbeiten Grimms und Kolbenheyers während der Weimarer Republik indes merkwürdig lebendig aus. Der Sachverhalt, dass sie spätestens seit Mitte der 1920er Jahre in einem Umfang um Mitarbeit in Zeitungen und Zeitschriften aufgefordert wurden, der das ihnen mögliche Arbeitspensum bei Weitem überstieg, konnte ihre Gewissheit des „totgeschwiegen-Seins“ aber ebenso wenig erschüttern wie der Umstand, dass die überwältigende Mehrzahl der Rezensionen zu ihren Werken positiv, ja häufig genug huldigend ausfielen, wie das nachfolgende Kapitel zeigen wird. Selbst die „lawinenartige Kraft“, die der DHVfinanzierte Buchhandel seit Mitte der 1920er Jahre entfaltete und durch den „das literarische Klima auch außerhalb der eigenen Teilöffentlichkeit"10 zugunsten

${ }^{6}$ Kolbenheyer, Sebastian Karst, Bd. 2, S. 390 (Herv. i. Orig.).

7 Ebd., S. 391. Der um die Vollendung seiner Einzelgängerlegende bemühte, alternde Kolbenheyer resümierte überdies: „Wenn ich meine Erfahrungen mit Verlagen und mit der deutschen Publizistik überblicke, so kann ich nicht von glücklichen Zuständen sprechen. Dabei war es mir von Anbeginne auferlegt, wider den Strom zu schwimmen. Ich wundere mich, daß mein Werk so weit durchgedrungen ist. Die literarische Propaganda, das Glück der meisten Autoren, ging über mich hinweg“" (Kolbenheyer, Sebastian Karst, Bd. 3, S. $461 \mathrm{f}$.).

${ }^{8}$ Schon während der Weimarer Republik war Kolbenheyer in der Verbreitung dieser Legende von Stapel sekundiert worden. Vgl. etwa den Artikel Kolbenheyer. Zu seinem 50. Geburtstag am 30. Dezember, in: München-Augsburger Abendzeitung vom 30. Dezember 1928, Nr. 354, S. 7: „Es gibt heute einen Kreis von Menschen, die wissen, daß Kolbenheyer der heimliche König der Dichter unserer Zeit ist, dessen Stern immer glänzender strahlen wird, je mehr die anderen Sterne erblassen. Kolbenheyer hat kein Publikum, aber eine Gemeinde. Für ihn arbeitet nicht der Reklameapparat der Weltpresse, der [...] einen Literaterich wie Lion Feuchtwanger zu einem repräsentativen Dichter Deutschlands aufgeblasen hat, für ihn arbeitet nur die Empfehlung von Mund zu Mund“.

${ }^{9}$ Grimm, Suchen [1960], S. 136.

${ }^{10}$ Lokatis, Intelligenz, S. $248 \mathrm{f}$. 
DHV-geförderter Autoren wie insbesondere Grimm und Kolbenheyer zu kippen begann, kratzte bestenfalls oberflächlich an dem Selbstbild und Gefühl des „Zukurz-gekommen-Seins". ${ }^{11}$ Bei Grimm ist noch im April 1932, lange also nachdem sein Verlag vom DHV aufgekauft und etwa sein im Ersten Weltkrieg verfasster Propagandaroman Der Ölsucher von Duala ${ }^{12}$ in der verbandseigenen, auflagestarken Buchgemeinschaft Deutsche Hausbücherei wiederaufgelegt worden war ${ }^{13}$, die fixe Idee nachweisbar, „mit dem D.H.V. nichts, aber absolut nichts zu tun“ ${ }^{4} \mathrm{zu}$ haben.

Dass die Bedeutung des eigenen Verlags, aber auch anderer völkisch-nationalistisch ausgerichteter Verlage auf dem Literaturmarkt der späten Weimarer Republik spürbar wuchs, wurde von Grimm und Kolbenheyer zwar durchaus registriert; sie relativierten die Tragweite dieser Entwicklung jedoch, indem sie sie als gerechtfertigte, ja überfällige Eindämmung der mutmaßlich nach wie vor vorhandenen Dominanz der politischen Linken interpretierten. In dieser verzerrten wie selbstgerechten Perzeption unterstützte Stapel die beiden Dichter: In einer Replik auf einen Artikel des Berliner Tageblatts, der vor einer „literarischen Diktatur“ des DHV infolge der Langen-Müller-Verlagsfusion ${ }^{15}$ gewarnt hatte, bemühte sich Stapel, sämtliche Kritikpunkte des Berliner Tageblatts auf den von der Zeitung angeblich repräsentierten „jüdisch-liberalistischen“ Literaturbetrieb zurückzuprojizieren: Von einer „Diktatur“ des LMV könne keine Rede sein; in Wirklichkeit habe das Berliner Tageblatt in der Vergangenheit eine „infame“, einseitig parteipolitische Diktatur errichtet, gegen die sich die Verlagsfusion richte und zur Wehr setze. Nicht jedoch, so Stapel, um eine eigene Diktatur zu errichten, sondern lediglich um „die deutsche Literatur“ adäquat zu fördern, die vom Berliner Tageblatt „zum Teil totgeschwiegen, zum Teil gehässig heruntergerissen, zum Teil wi-

${ }^{11}$ Von der ungeachtet aller gegenteiligen Rahmenbedingungen immerzu aufrechterhaltenen Vorstellung, auf dem deutschen Literaturmarkt auf sich allein gestellt zu sein, zeigte sich mitunter schon das Umfeld von Hans Grimm irritiert: Der mit Grimm seit 1928 befreundete, spätere Vorsitzende der Literarischen Gesellschaft Gräfelfing Theo Engelmann bestritt jedenfalls entschieden die ihm gegenüber erhobene Behauptung Grimms, er würde in Deutschland „ganz allein stehen“. Diese Aussage sei unverständlich, „zumal in Hinblick auf den Beifall“, den Grimms Berliner Vorträge unlängst gefunden hätten, „und den erfreulichen Erfolg der neuen Ausgabe von Volk ohne Raum". Gemeint war hier die Volksausgabe von Volk ohne Raum, die zu einem großen Verkaufserfolg werden sollte (vgl. Kap. 2.3.2, Anm. 420). Grimm, so Engelmann weiter, unterschätze den „Einfluss“ seines „Namens bei Redaktionen, Verlegern etc.“ erheblich, wenn er von lediglich „schwachen Verbindungen“ spreche. Dies habe er "gerade heute" an dem Chefredakteur der Münchner Neuesten Nachrichten, Fritz Büchner, beobachten können, der Grimm „außerordentlich“ schätze (DLA, A:Grimm, Theo Engelmann an Hans Grimm, 15. Dezember 1931).

12 Vgl. Kap. 2.1.

13 Zur Deutschen Hausbücherei, die bis 1930 knapp 40000 Mitglieder gewinnen konnte, vgl. Hamel, Verband, S. 135-145. Die Buchgemeinschaft wurde bei „Langen-Müller-Dichtern so beliebt, daß ein strenges Proporzverfahren den umkämpften Zugang zur Jahresreihe zwischen ihnen regeln mußte" (Lokatis, Verlagsanstalt, S. 102).

14 DLA, A:Grimm, Hans Grimm an Mündensche Nachrichten, 5. April 1932.

${ }^{15} \mathrm{Zu}$ den Hintergründen des Kaufs der Münchner Verlage Georg Müller und Albert Langen durch den DHV vgl. Meyer, Verlagsfusion, S. 21-75. 
derwillig und mit Anwendung der Entwertungstechnik anerkannt" worden sei. Nun aber, „da wir die Diktatur der Unbefugten brechen und der deutschen Dichtung ihre Freiheit zurückgeben, schreit man hinter uns her: Diktatur! Diktatur!“ Dass ausgerechnet das Berliner Tageblatt vor der Entstehung eines „allmächtigen und seelenlosen Konzern[s]“ gewarnt und sich dazu aufgerufen gefühlt hatte, „die deutsche ,Seele“ gegen uns [zu] schützen“, empfand Stapel als derart geschmacklos, dass er sich „an einen „alten Roués“ erinnert fühle, „der mit zweckbewußter Sentimentalität von ,Liebe““ rede. Die Verlagsfusion ziele in Wahrheit darauf, „die großen deutschen und nordischen Dichter [...] zu einer geistigen Gesamtwirkung“ zu vereinigen - eine Gesamtwirkung, „an der alle Taktiken derer, welche die deutsche Kultur aus selbstsüchtigen Motiven beherrschen“ wollten, „alle Taktiken des Totschweigens und Verlästerns, des Hohnes und der Ironie und der Brutalität zuschanden" würden. ${ }^{16}$

SACHLICHE HINTERGRÜNDE - Die Annahme, die deutschsprachige Literatur- und Kunstkritik sei, gemeinsam mit den wichtigsten Verlagen, infolge der Judenemanzipation des 19. Jahrhunderts sukzessive unter jüdische Kontrolle geraten, bildete schon im wilhelminischen Kaiserreich einen Grundpfeiler völkischer Kulturkritik. Nach dem Ersten Weltkrieg steigerte sich diese Vorstellung in völkischen Kreisen mitunter gar zu der panischen Warnung, nicht weniger als 95\% der deutschen Presse stehe unter direktem jüdischem Einfluss. ${ }^{17}$ Zum Verständnis solch geradezu hysterischer Übertreibungen ist es wichtig, sich die tatsächliche Bedeutung jüdischer Redakteure, Journalisten und Publizisten im Weimarer Kulturleben vor Augen zu führen.

In der Tat wurden „wichtige überregionale Tageszeitungen“ der Weimarer Republik von Juden „herausgegeben oder von jüdischen Chefredakteuren geleitet“18. Auch konnten einige Verlagshäuser, die seitens völkischer Autoren und Verleger mit einer explosiven Mischung aus Argwohn und Neid beäugt wurden, enorme Verkaufserfolge verbuchen. Zu nennen ist hier insbesondere der Ullstein-Verlag, dessen „höchst effizient funktionierende[s], werbestrategisch ausgefeilte[s] Verlagskonzept“ primär auf das „Bestsellergeschäft“, den „Geschmack eines Massenpublikums, aktuelle Zeitströmungen und die Unterhaltungskultur in Berlin"19 ausgerichtet war. Die merkliche, angesichts des winzigen Bevölkerungsanteils von

16 Sämtliche Zitate aus diesem Absatz in: Stapel, Diktatur [1931], S. 217-219 (Herv. i. Orig.).

${ }^{17}$ So 1924 Georg Ahlemann, der amtierende Berliner Landesleiter des Tannenberg-Bunds und spätere Landtags- und Reichstagsabgeordnete der NSDAP: „Heute kann die Vormachtstellung Alljudas auf dem Gebiet der Weltpresse nicht mehr bestritten werden. In Deutschland allein kann man getrost von 95 v[on] H[undert] Übergewicht der jüdisch beeinflußten Presse sprechen" (Ahlemann, Einführung, S. 57). Diese Perzeption stand in einer langen Tradition völkischer Polemik, als deren vulgärste Ausformung das von Theodor Fritsch verbreitete Bild des jüdischen „Zeitungs-Polyp“ (vgl. Bibliografie) gelten darf.

18 Büttner, Weimar, S. 292.

${ }^{19}$ Schneider, Romanabteilung, S. 93. 
weniger als einem Prozent ${ }^{20}$ freilich schnell erreichte Überproportionalität von Juden in der Journalistik stand - ebenso wie bei Rechtsanwälten und Medizinern - in der Tradition der bevorzugten Wahl freier Berufe, die sich auf faktische Berufsbeschränkungen in anderen Karrierezweigen und Segmenten des Arbeitsmarkts während des deutschen Kaiserreichs zurückführen lässt. ${ }^{21}$ Von einer dominierenden Rolle von Juden konnte gleichwohl auch in den freien Berufen keine Rede sein, was antisemitische Autoren freilich nicht daran hinderte, jegliche Artikel vor allem des Berliner Tageblatts, der Frankfurter Zeitung und der Vossischen Zeitung, die ihren politischen und gesellschaftlichen Ordnungsvorstellungen zuwiderliefen, als angebliche Beweise ihrer „paranoiden Vorstellungen“22 von „Überfremdung“, „Zersetzung“ und der Existenz einer „antigermanischen“ Kollektividentität der Juden zu verwenden.

Dass hierbei die breit ausdifferenzierte und entsprechend heterogene großstädtische Presse, insbesondere jene der "Zeitungsstadt Berlin“23, unzulässig auf (links-)liberale Blätter reduziert wurde, ist evident. Ebenso typisch und bezeichnend für die zeitgenössische völkische Publizistik war es, die Linkspresse in ihrer Repräsentativität einseitig zu „verallgemeiner[n]“ und damit in ihrer Wirkung deutlich zu überzeichnen - insbesondere im Hinblick auf die "große Mehrheit der ländlichen Bevölkerung “24, die wesentlich stärker von der Vielzahl „lokaler Blätter" beeinflusst wurde. Augenfällig ist darüber hinaus, dass die Problematisierung der „Überrepräsentation von Juden [...] in der liberalen demokratischen Presse“ überhaupt erst „unter der Voraussetzung einer durch Feindseligkeit geprägten Haltung der nichtjüdischen Mehrheit gegenüber der Minderheit“ ${ }^{“ 25}$ möglich war. Wie wirkmächtig die „antisemitische Stigmatisierung der demokratischen Presse" war, ist nicht zuletzt auch daran ablesbar, dass entsprechend attackierte Zeitungen immer wieder personalpolitisch auf sie reagierten, etwa indem für die Berichterstattungen über „jüdische“ Themen gezielt „nichtjüdische Mitarbeiter"26 engagiert wurden. Unbelehrbare, verrannte Agitatoren deuteten dies jedoch lediglich als hinterlistige Ablenkungsmanöver und denunzieren die engagierten nichtjüdischen Autoren als willfährige Agenten des Judentums.

Trotz der eminenten Verkaufserfolge völkisch-nationalistischer Autoren und einer Vielzahl aufnahmewilliger Zeitschriften und Zeitungen regionaler und

201933 war der jüdische Bevölkerungsanteil innerhalb der deutschen Reichsgrenzen im Vergleich zu 1910 von 1,0\% auf 0,77\% gefallen. Die deutschen Staatsangehörigen jüdischen Glaubens lebten mehrheitlich (66,8\%) in Großstädten (ab 100000 Einwohner), 31\% (ca. 160 000) davon in Berlin. Diese Konzentration war historisch unter anderem dadurch bedingt, dass den Juden „in Brandenburg-Preußen [...] die Ansiedlung auf dem Land lange untersagt gewesen" war. Vgl. Büttner, Weimar, S. 284.

${ }^{21}$ Vgl. zu diesem Zusammenhang die kurze Zusammenfassung und weiterführende Literatur in: Armbrecht, Liebe, S. 33-37.

22 Büttner, Weimar, S. 292

${ }^{23}$ Mendelssohn, Zeitungsstadt.

24 Sösemann, Journalismus, S. 242.

${ }^{25}$ Suchy, Presse, S. 170.

${ }^{26}$ Ebd., S. 171. 
überregionaler Provenienz unterliegt es dennoch keinem Zweifel, dass während der Weimarer Republik eine „enorme Kluft“ bestand zwischen den „städtischen Minderheiten mit ihren avancierten Kultur- und Lebensstilen, auf die ein großer Teil der modernen Medien der Zeit ausgerichtet war", auf der einen Seite und der „schweigenden Mehrheit, für die das alles nur die Unsicherheit und Bodenlosigkeit ihres Lebensgefühls verstärkte" 27 auf der anderen Seite. Dem Phänomen, dass erst die liberalen Rahmenbedingungen von Politik und Öffentlichkeit nach 1918 „Außenseitern - Demokraten, Kosmopoliten, Juden - die Möglichkeit“ gaben, „Stellungen in Gesellschaft, Geschäftsleben, Universität und Politik einzunehmen“, die ihnen zuvor „versagt worden waren“, hat Peter Gay 1970 eine ganze Studie gewidmet. ${ }^{28}$

Praktiken Des „Totschweigens“ In LMV und HVA - Doch wie sahen die Praktiken des „Totschweigens“ innerhalb von LMV und HVA aus? Im Jahr 1930 wurde der damals erst 26-jährige Gunther Haupt von Gustav Pezold, dem kurz zuvor auf Initiative Kolbenheyers neu berufenen Direktor des GMV ${ }^{29}$, als leitender Verlagsangestellter engagiert. ${ }^{30}$ Diesen Posten behielt Haupt auch nach der Gründung des LMV im Jahr 1931. Sein zunächst sehr enges Verhältnis zu Pezold als Verlagsdirektor sollte sich in der Folgezeit jedoch nach und nach verschlechtern. ${ }^{31}$ In seinen nach dem Zweiten Weltkrieg verfassten Erinnerungen Einer in der Zeit schildert Haupt plastisch die Pressearbeit des Verlags, deren Belebung und Mitgestaltung zu seinem eigentlichen Aufgabenbereich wurden.

In seiner Funktion als leitender Verlagsangestellter versandte Haupt nicht nur zahlreiche „Besprechungsexemplare, zum Vorabdruck oder Nachdruck geeignete Buchauszüge sowie hausgemachte empfehlende Besprechungen" an verschiedenste Zeitungen und reiste durch „ganz Deutschland“, um gezielt „Feuilletonredaktionen aufzusuchen und persönliche Beziehungen herzustellen“ - Bemühungen, die nicht immer von Erfolg gekrönt worden, im Wesentlichen aber „gut an[gekommen]“32 seien. Neben diesen Netzwerktätigkeiten umfasste Haupts Arbeitsalltag auch eine Praxis, die verdächtig an jene Methode des „Totschweigens“ und prinzipiellen Herabwürdigens politisch-weltanschaulich differierender Autoren erinnert, welche die deutsche Rechte dem ,jüdisch-liberalistischen“ Literaturkritik immer wieder vorwarf. Ein besonders beschwerlicher Zwang seiner damali-

27 Koenen, Vesper, Ensslin, Baader, S. 44.

28 Vgl. Gay, Republik, S. 10.

${ }^{29} \mathrm{Zu}$ den Hintergründen der Berufung Pezolds (1891-1961) zum Leiter des GMV und den maßgeblichen Einfluss, den Kolbenheyer in diesem Zusammenhang ausgeübt hat, vgl. Meyer, Verlagsfusion, S. 63-68.

${ }^{30}$ Pezold übertrug Haupt die Leitung der Presseabteilung. Vgl. Meyer, Verlagsfusion, S. $72,77$.

31 Ebd., S. 141.

32 Haupt, Zeit, S. 92. Auf diese Weise ergaben sich nach der Darstellung Haupts beispielsweise zu Wilhelm Westecker (1899-1974), dem für die Literaturbeilage zuständigen Redakteur der Berliner Börsen Zeitung, sowie zu Hans Franke (1893-1964) dem Leiter des Feuilletons der in Heilbronn erscheinenden Neckar-Zeitung, „freundschaftliche Beziehungen, die lange angehalten haben“. 
gen Verlagsarbeit, so Haupt, sei es gewesen, dass er auf die ausdrückliche Weisung Pezolds hin „gezwungen“ gewesen sei, „beständig Mittelmäßiges“ aus den eigenen Verlagsreihen „als weltbewegend zu preisen“, wohingegen er auf der

„gegenüberliegenden Seite des literarischen Frontenkrieges [...] nichts, aber auch rein garnichts anerkennen durfte. [...] Alles, was nicht in den durch und durch ,deutschen' Verlagen erschien, was - und das war ja auch eine der verrückten Maximen der Zeit - nicht in Fraktur, sondern in der als undeutsch geltenden Antiqua gedruckt war, durfte nur mit verächtlichem Lächeln abgetan, wenn nicht gar verdammt werden." ${ }^{33}$

Diese Praxis habe „nicht etwa nur für jüdische und politisch links stehende Autoren“ gegolten, sondern beispielsweise auch „für Thomas Mann [und] Hermann Stehr, der aufgrund seiner Freundschaft mit Walther Rathenau als Judenfreund“ gegolten habe. Zur kritischen Berichterstattung seien die Verlagsangestellten auch im Fall von Hermann Hesse verpflichtet worden, da dieser „als Landesverräter angesehen wurde, weil er sich der aktiven und literarischen Teilnahme am Kriege entzogen hatte und zudem 1921 Schweizer Bürger geworden war“. Besonders betroffen habe diese „höchst einseitige und bornierte Entweder-Oder“-Politik Pezolds den Prokuristen Karl Krause ${ }^{34}$, in dessen Verantwortungsbereich die wenig beneidenswerte Aufgabe gelegen habe, „die ältere Romanproduktion des Verlages, darunter also auch ziemlich viel Minderwertiges, so lukrativ wie möglich auf den Unterhaltungsseiten der Presse unterzubringen“. Krause habe diese Aufgabe indes „mit viel Geschick und Einfallsreichtum“ und einem „sehr sicheren Instinkt für Machbarkeit und Erfolg“ bewältigt. Indes erwuchs aus dieser Tätigkeit rasch ein „peinliche[r] Widerspruch“, da Pezolds Vorgaben, auch „schundige Fortsetzungsromane zweifelhafter Autoren an die Presse [zu] verhökern“, eklatant mit dem Selbstanspruch des Verlags kollidiert sei, „betont für die völkische ,Reinheit' der deutschen Literatur ein[zu]treten“"35.

Doch nicht nur in der Retrospektive, sondern auch schon zeitgenössisch wurde in DHV-Kreisen über die massiven und als unsachgemäß empfundenen Eingriffe Pezolds in die Literaturkritik geklagt - wenn auch hinter vorgehaltener Hand. So beschwerte sich Will Vesper, Herausgeber der 1928 vom DHV aufgekauften Zeitschrift Die neue Literatur ${ }^{36}$, im Juli 1932 bei Wilhelm Stapel über Pezolds Einmischungen in die Redaktionsarbeit und monierte, er versuche schließlich auch nicht, auf Pezolds Verlagsangelegenheiten Einfluss zu nehmen, obgleich er „sehr viel Einwendungen zu machen hätte “37. Wie stark Vespers Zeitschrift bereits zu diesem Zeitpunkt zu einem Marketingwerkzeug des DHV - und also der von dem Verband protektierten Autoren, allen voran Grimm und Kolbenheyer - he-

\footnotetext{
${ }^{33}$ Haupt, Zeit, S. 95.

${ }^{34}$ Krause war schon im GMV „für Romanvertrieb und Propaganda, und damit für die Verbindung zur Presse zuständig" gewesen (Meyer, Verlagsfusion, S. 36). Krause wurde im Juni 1931 entlassen und beging daraufhin im Verlagsgebäude Selbstmord. Zu den Hintergründen vgl. ebd., S. 75-82.

${ }^{35}$ Haupt, Zeit, S. $95 \mathrm{f}$.

361928 trug die Zeitschrift noch den Namen Die schöne Literatur, die Umbenennung erfolgte 1931.

37 DLA, A:Stapel, Will Vesper an Wilhelm Stapel, 28. Juli 1932.
} 
rabgesunken war, zeigt sich an dem Eingeständnis Vespers, die Autarkie über die Inhalte seiner Zeitschrift mittlerweile verloren zu haben: „Ich muß in der ,Neuen Literatur" schon allzuoft beide Augen zudrücken“ 38 .

Dass auch in der HVA „die Abneigung gegen sogenannte ,Jüdische Literaten““ nicht nur „zum guten Ton“ gehörte, sondern der Antisemitismus schlechterdings zu ihrem „Geschäftsprinzip“ wurde, das es ihr ermöglichte, „jede beliebige Konkurrenz [...] als ,verjudet" zu denunzieren“"39, hat Siegfried Lokatis herausgearbeitet. Die nicht zuletzt antisemitischen Motive des DHV bei seiner Entscheidung zum Aufkauf von ALV und GMV bestätigte 1931 auch der Verbandshistoriograf des DHV, Albert Zimmermann. Demnach war die Entscheidung zum Erwerb der Verlage auch von der Überlegung motiviert, dass beide Verlagshäuser andernfalls Gefahr gelaufen wären, „in jüdische Hände zu fallen“. Hier habe es der Verband als seine Pflicht und Aufgabe empfunden, die Verlage „vor diesem Schicksal zu bewahren: Denn wir wollen nicht, dass der geistige Besitz unseres Volkes von Volksfremden, ob sie nun Mosse oder Ullstein heißen, verwaltet wird“40.

Verworrene Fronten - Die von Grimm, Kolbenheyer und Stapel - und mit ihnen von zahlreichen anderen DHV-geförderten Autoren - gepflegte, verführerisch bequeme Vorstellung einer fein säuberlich in „Freund“ und „Feind“ gliederbaren Öffentlichkeit erweist sich rasch als ein Erklärungsmodell, das dem Weimarer Literaturmarkt nur bedingt gerecht wird. Dass sich zwischen politisch rechts- und linksorientierten Blättern und Publizisten generell eine tiefe, in einigen Fällen schier unüberbrückbar scheinende Kluft auftat, bleibt zwar unbestritten. Wirft man jedoch einen näheren Blick auf einige der Vorstellungen und Überzeugungen Grimms, Kolbenheyers und Stapels, so zeigt sich bald, dass die zwischen Freund und Feind gezogenen Grenzlinien erhebliche Unschärfen besaßen.

Vor allem ist in diesem Zusammenhang auf das klischeelastige, simplifizierte Bild großer Tageszeitungen und ihrer Feuilletons zu verweisen, besonders jenem der Frankfurter Zeitung. Schon der Sachverhalt, dass etwa der Literaturhistoriker Werner Mahrholz nach 1918 mehrfach mit ausführlichen, lobenden Kritiken für Kolbenheyer hervortrat ${ }^{41}$, zugleich aber in der „ersten Hälfte der 20er Jahre“ ein

$38 \mathrm{Ebd}$

${ }^{39}$ Lokatis, Stapel, S. 32.

40 Zimmermann, Mosse, S. 188. Dass zunächst einmal finanzielle Gewinnerwartungen für die Entscheidung des DHV ausschlaggebend waren, versteht sich von selbst. Doch ohne Berücksichtigung ideologischer Motive bliebe eine Erklärung unvollständig. Zu den Verlagsunternehmen Mosse und Ullstein vgl.: Mendelssohn, Zeitungsstadt, S. 80-101; Eksteins, Limits, S. 104-137.

41 Vgl. v. a. Mahrholz, Dichtung, S. 234-246, sowie: Ders., Bemerkungen. In letzterem Aufsatz zog Mahrholz folgendes Fazit: Wenn Kolbenheyer „den Weg zum Herzen aller deutschen Volksgenossen“ fände, „so wäre dies uns allen zum Heil, denn schließlich sind die Dichter zu allen Zeiten Führer und Gewissensstärker gewesen und keine Zeit hat führende Menschen nötiger gehabt als die unsere. Sie aber sind Führer in eine Zukunft der deutschen Seele, welche alle erhoffen, denen das Deutschtum nicht ein Geschäft oder ein Wort, sondern eine lebendige Wirklichkeit und eine Hoffnung der Zukunft ist“ (S. 188). 
„häufig[er] Beiträger des Feuilletons der ,FZ' in Sachen Philologie “42 war, muss hier stutzig machen. Dass Mahrholz im November 1921 Kolbenheyer in der Vossischen Zeitung, die in der völkischen Polemik seit jeher zum Kern der ,jüdischliberalistischen" Totschweigeverschwörung gerechnet wurde, zudem in einer sehr positiven Besprechung als Erzieher ,zur Deutschheit und zur Volksgemeinschaft“43 zelebrierte, macht es nicht leichter, wollte man die Vorstellung eines unzweideutig feindlichen Verhältnisses zwischen dem liberalen Weimarer Blätterwald und einem Autor wie Kolbenheyer aufrechterhalten. In Wirklichkeit war die Situation sehr viel offener. Zwischen den literarischen Teilöffentlichkeiten der Weimarer Republik agierten mit Autoren wie Werner Mahrholz Grenzgänger, die in beiden Welten Anschluss fanden.

Insgesamt, so haben die Forschungen von Almut Todorow gezeigt, setzte sich im Feuilleton der Frankfurter Zeitung erst ,in den späteren Weimarer Jahren“, unter der Federführung von Siegfried Kracauer und Benno Reifenberg, die von Grimm, Kolbenheyer und Stapel mit so großer Skepsis und Verunsicherung betrachtete „Moderne“ durch „und mit ihr auch das Bewußtsein [...] von Massengesellschaft und Massenkultur, industrieller Ästhetik und Medienkonkurrenz" 44 . Hinsichtlich der „sogenannte[n] Judenfrage“ zog sich die Frankfurter Zeitung die sich trotz ihrer jüdischen „Eignerfamilie Simon-Sonnemann“ ausdrücklich „weder programmatisch noch wirtschaftlich als jüdische Zeitung" verstand - auf eine rein defensive Stellung zurück, indem sie jede „bösartig ausgrenzende und diabolisierende Aggressivität“ zur Angelegenheit „rechtskonservativ-völkischer und antisemitischer Kreise und ihrer Presse" erklärte, die sie nichts angehe. Darin kam die fatale „Wunschvorstellung liberaler und linker Kreise“ 45 zum Ausdruck, nach der sich die „Judenfrage“ in einem vorurteilsfreieren und vernunftbestimmteren Diskurs der Zukunft gleichsam von selbst lösen werde.

Ein besonders sprechendes Beispiel für die Projektion eigener Vorurteile und Ressentiments auf den Literaturmarkt und die Medienlandschaft der Weimarer Republik lieferte Stapel im November 1931. Er warnte Kolbenheyer damals eindringlich vor dem Herausgeber der konservativen Zeitschrift Die Tat ${ }^{46}$ und späteren Vertrauten Axel Springers, Hans Zehrer. ${ }^{47}$ Den „gewaltigen Aufstieg“, welchen

42 Todorow, Philologie, S. 35.

${ }^{43}$ Vgl. Mahrholz, Paracelsusroman: „Hier ist ein Werk, das mehr zur Erziehung zur Deutschheit und zur Volksgemeinschaft wirken kann als viele Geschichtswerke mit noch so starkem nationalen Pathos, weil hier durch das geschichtliche Kostüm hindurch ein Mensch und eine Zeit sprechen, die unserer Menschlichkeit und unserer Not aufs tiefste verbunden und verwandt sind“.

44 Todorow, Philologie, S. 35. Für eine ausführliche Darstellung vgl. Dies., Feuilleton.

${ }^{45}$ Dies., Philologie, S. 36.

46 Vgl. Hübinger, Tat.

47 Zur Biografie Hans Zehrers (1899-1966) vgl. Demant, Schleicher. Spezifisch zur „zweiten Karriere“ Zehrers nach 1945 siehe: Sothen, Zehrer. Hatte Die Tat zunächst noch einen „offenen Charakter, wenn auch unter zunehmend republikkritischen Vorzeichen" besessen, so gab Zehrer der Zeitschrift zu Beginn der 1930er Jahre „eine stärker politische Ausrichtung und brachte sie auf einen grundsätzlich rechtsrevolutionären Kurs" (Graf, Zukunft, S. 44). Damit ging auch eine erhebliche Auflagensteigerung (bis zu 10000 Exemplare) einher, womit in die- 
die neue Zeitschrift unter dem „Halbjude[n]“ Zehrer in den Jahren zuvor erlebt hatte, führte Stapel „besonders“ auf die „Aufsätze von [Ferdinand] Fried“ zurück - ein Pseudonym, hinter dem sich ein Jude verberge. Zu seinem großen Unglück sah Stapel ausgerechnet „die jüngeren Nationalsozialisten in Scharen“ Zehrers Zeitschrift zulaufen, woran ihm einmal mehr „das deutsche Verhängnis“ offenkundig zu werden schien, dass „die national gutwilligen Deutschen sich unter die Führung oberflächlicher, gewandter jüdischer Journalisten begeben " 48 und somit vom rechten Weg abgebracht würden. In der Realität nahm sich die Situation freilich anders aus: Zwar war „Ferdinand Fried“ in der Tat ein Pseudonym, hinter dem sich jedoch kein jüdischer Autor verbarg, sondern Ferdinand Friedrich Zimmermann ${ }^{49}$, später Hauptschriftleiter der Münchner Neuesten Nachrichten, SSObersturmbannführer, Mitarbeiter im Rasse- und Siedlungshauptamt der SS und Autor der 1937 im Goslarer Blut-und-Boden-Verlag erschienenen antisemitischen Hetzschrift Der Aufstieg der Juden.

\title{
3.1.2 Das Verhältnis Kolbenheyers zur Weimarer Presse
}

\begin{abstract}
Das Tiefste, Verborgene und immer Lebendige deutschen Geistes, die unverlierbare, ratlos suchende Kraft unseres Volkes hat - seit Wilhelm Raabe gestorben ist - keinen würdigeren, keinen größeren Meister und Former gefunden als Kolbenheyer. [...] Im Bekenntnis zu ihm begegnen und erkennen sich die Gläubigen, die Jungen, die Geläuterten und die Gereiften, die Sehnsüchtigen und die Brünstigen, in deren Herzen tief innen heimlich und trächtig wahrhaft deutsches Wesen glüht und schafft. ${ }^{50}$
\end{abstract}

Von den moralischen Pflichten der „Nationalen Mittler“ - Wie bei den Universitätsprofessoren ${ }^{51}$ zeigte Kolbenheyer auch gegenüber den Vertretern der „Rechtspresse“ keine Scheu, sie vorwurfsvoll an ihre große, angeblich nur unzureichend eingelöste Pflicht gegenüber der zeitgenössischen, „artgerechten“ deutschen Dichtung - und nicht zuletzt gegenüber seinem eigenen Cuvre - zu erinnern. Eine solche Gelegenheit bot Kolbenheyer ein an ihn gerichteter Brief des Schriftleiters der Politischen Wochenschrift Hermann Ullmann ${ }^{52}$ vom Oktober 1927, in dem Ullmann in einem polemischen Rundumschlag dem Gros der Autoren der deutschen Rechten jedes literarische Talent absprach und ihren Lesern

ser Hinsicht Stapels Deutsches Volkstum deutlich überflügelt wurde. Auch daraus mögen sich Stapels Warnungen gespeist haben.

48 KAG, Wilhelm Stapel an Erwin Guido Kolbenheyer, 31. Oktober und 1. November 1931.

49 Zum Werdegang Zimmermanns (1898-1967) siehe: Klee (Hg.), Kulturlexikon, S. 685.

50 Rauch, Kolbenheyer, S. 332.

51 Vgl. Kap. 3.5.

52 Zum freundschaftlichen Verhältnis zwischen Kolbenheyer und Ullmann vgl. Kap. 2.3.1. 
völlige Anspruchslosigkeit attestierte. ${ }^{53}$ Kolbenheyer wies diese Ansicht scharf zurück; die „unbedingte Schuld“ an den geringen Erfolgen der „aufbauenden deutschen Dichtung“ sah er nicht auf Seiten der Leser, sondern allein auf Seiten der „nationalen Presse“ und dem „nationalen Zeitschriften- und Verlagswesen“54. Verheerend wirke insbesondere deren Streben, „lediglich die Menge zu befriedigen [...], die auf minderwertige Literatur eingestellt" sei. Allzu rar, so Kolbenheyer, seien Schriftsteller von dem Format und "Schneid eines [Wilhelm] Stapel“, die „frei für sich bestehen“ könnten und auch ein Gespür dafür entwickelt hätten, wie sehr die „durch den Zivilisationsterror der Juden und der Politiker [...] urteilslos“ gemachten Deutschen „darauf warten“ würden, „geführt zu werden“. Der eklatante Mangel solcher Persönlichkeiten sei „schauderhaft“, die Gesamtlage schlicht „zum Dreinschlagen!“ Der fehlende Weitblick der „Rechtspresse“, ihr geringer Mut zu „kämpfen“ und ihre Bereitschaft für „Kitsch [...] einzustehen“ durften laut Kolbenheyer nicht auf die Leser abgewälzt werden. Während die „liberale Presse [...] ihr geschäftliches und ihr spezifisch kulturelles Rückgrat" habe, besitze die „nationale Presse“ lediglich „ein geschäftliches“, jedoch „kein kulturelles Rückgrat" ${ }^{\prime 55}$.

Was aber erwartete Kolbenheyer konkret von der „Rechtspresse“? Worin sah er ihre Aufgaben und Pflichten? Einen Einblick gewährt ein Vortrag, den Kolbenheyer im Juni 1931 bei einem Dichtertreffen auf Schloss Osterstein im thüringischen Gera hielt. Das Treffen wurde von dem Erbprinzen des Fürstenhauses Reuß, Heinrich XLV., organisiert. ${ }^{56}$ In seinem Vortrag Über die biologische Funktion der Dichtkunst konfrontierte Kolbenheyer das „deutsche Mittlertum in der Literatur“57 mit dem Vorwurf, „in einer großen und bedeutsamen Kampfeszeit bisher

53 Vgl. KAG, Hermann Ullmann an Erwin Guido Kolbenheyer, 23. Oktober 1927: „Das Publikum u[nd] die Rechtskreise vertragen nun einmal künstlerische Qualität nicht. Der richtige ,Konservative von heute [...] ist ja überhaupt zumeist nur scheinbar konservativ, in Wahrheit reaktionär, aus irgend einem unsachlichen Privat- und Nebenmotiv heraus. Ich weiß jetzt, was dazu gehört, ,Erfolg' zu haben und dieser Einblick kann einem allen Mut nehmen [...]. Es ist greulich, was verlangt wird und ,geht'. Kein Wunder, daß die sog[enannten] Geistigen zum [Berliner] Tageblatt fliehn. Wo bekommt man auf unserer Seite 200000 Intellektuelle auf diesem Niveau zusammen [...]?“

${ }^{54}$ KAG, Erwin Guido Kolbenheyer an Hermann Ullmann, 27. Oktober 1927 (Durchschlag).

55 Ebd.

56 Zur Entstehungsgeschichte der Dichtertagung vgl. Mittenzwei, Untergang, S. 167-169. Die Affinität Heinrichs XLV. für die NSDAP ist durch Tagebuchaufzeichnungen Joseph Goebbels belegt: „Hofprediger Döring habe ich nun ganz gewonnen. Ebenso einen Prinz Reuß, der uns sofort kapierte“. Und in einem späteren Eintrag: „Unterredung mit Erbprinz Reuß über unsere n[ational]s[ozialistische] Bühne. Er soll sie im nächsten Spielplan übernehmen. Macht einen guten, klugen Eindruck, aber ob er’s schafft?" (Die Tagebücher von Joseph Goebbels, Teil I, Bd. 2/I, S. 159, 333).

${ }^{57}$ Kolbenheyer, Funktion [1931], S. 237. Als Anwesende in Gera sind belegt: Harald Braun, Paul Joseph Cremers, Karlfried Graf Dürckheim, Albrecht Erich Günther, Hanns Johst, Felix Krueger, Karl Benno von Mechow, Börries von Münchhausen, Wilhelm Schäfer, Eugen Schmahl, Wilhelm Stapel, Hermann Stehr, Josef Magnus Wehner, Wilhelm Westecker und Erich Wiechert. Hans Grimm sagte sein Kommen ab, nachdem Wilhelm Frick entgegen der ursprünglichen Konzeption nicht mehr zu den Veranstaltern zählte: „[Die Tagung] sollte ursprünglich ausgehen von dem Minister Frick und dem Erbprinzen, wäre also eine politische 
versagt“ zu haben. Kolbenheyer sprach von einer „Mittlerkrisis“: Der „am Aufbau schaffende Dichter“ habe "heute keine geschlossen reagierende Mittlergruppe hinter sich“, die sich mit jener der „devastierenden Literatur" der „Gegenseite“ messen könnte. Vor allem fehle es den Schriftleitern und Journalisten des rechten Lagers an der Bereitschaft, sich uneigennützig als „Pionier und Wegbereiter“ in den „Dienst der Kunst zu stellen“. Stattdessen gefalle sich jeder darin, Kunstkritik und Literaturvermittlung je „auf seine eigene Weise ${ }^{\text {“ } 58} \mathrm{zu}$ betreiben. Der Euphemismus „pionierhafter Dienst“ verweist hier auf das Wesentliche: Kolbenheyer verlangte die bewusste (nicht zuletzt intellektuelle) Unterordnung der Publizistik gegenüber der Dichtung - auch unter Preisgabe eigener Überzeugungen. Unter „Dienst“ verstand er „nicht etwa“ nur „da und dort eine wohlwollende Geste zuzulassen oder selbst zu äußern, sondern innerlich und ununterbrochen sich einzusetzen“ und dabei „die eigene, in dieser oder jener Teilansicht vielleicht abweichende, Meinung nicht als das Um und Auf der Kunst eines Schaffenden entgegen zu werfen.“ Kolbenheyer bekämpfte ausdrücklich den in seinen Augen „gefährlichen und häufigen Hang der deutschen Mittler, eine besserwisserische Meinung auch einem Meister der Kunst gegenüber wie einen Felsbau der Überzeugung aufzutürmen, nach dem er sich zu orientieren habe ${ }^{\text {"59 }}$.

Die meisten der nach Gera angereisten Literaturkritiker reagierten auf die Vorwürfe und Forderungen Kolbenheyers verständlicherweise abwehrend. Schon Hermann Ullmann hatte in diesem Zusammenhang vorsichtig den fehlenden Weitblick Kolbenheyers angesprochen ${ }^{60}$, wich ansonsten aber - merklich darum bemüht, den befreundeten Dichter nicht vor den Kopf zu stoßen - aus angebli-

Tagung bestimmt gewesen. In diesem Falle, wenn also Frick, eine Person des Staates und der Repräsentant derjenigen Partei, bei der unsere Zukunft wahrscheinlich liegt, eingeladen hätten, wäre ich trotz manchen Bedenken hingefahren“ (DLA, A:Stapel, Hans Grimm an Wilhelm Stapel, 30. Mai 1931).

${ }^{58}$ Kolbenheyer, Funktion [1931], S. $236 f$.

59 Ebd., S. 237f. Dass Kolbenheyer diesen „Geist von Gera“ auch privat weiterzutragen versuchte, zeigt ein Briefwechsel mit Josef Hofmiller (1872-1933) aus dem Herbst 1931. Kolbenheyer versuchte Hofmiller zu überreden, seine Tätigkeit als Gymnasiallehrer, die nur seine „sekundäre Bestimmung" sei, aufzugeben, um sich ganz der Literaturgeschichte zuzuwenden. Hofmiller müsse „den, sei’s auch für Sie schmerzlichen, Willen“ entwickeln, seine „Belesenheit, die Witterung hat [...], in den Dienst" der Dichtung zu stellen. Hofmiller habe die moralische Verpflichtung, seinen Teil dazu beizutragen, „das internationalistische, jüdisch-terrorisierte Literatengeschmeiß zurechtzurütteln", was er am besten dadurch erreichen könne, schriebe er „dem deutschen Volk eine Literaturgeschichte unsrer Zeit“. Würden nationale Schreiber ,jetzt nicht zupacken“, so werde "unser Volk“ dereinst "mit Fingern auf uns weisen“ (DLA, A:Hofmiller, Erwin Guido Kolbenheyer an Josef Hofmiller, 30. September 1931). Hofmillers klare Absage - niemals werde er den notwendigen Leseaufwand auf sich nehmen und auf seine alten Tage am Ende gar noch Bücher Feuchtwangers lesen (KAG, Josef Hofmiller an Erwin Guido Kolbenheyer, 5. Oktober 1931) - enttäuschte Kolbenheyer, der seinem feurigen Plädoyer gute Erfolgschancen ausgerechnet hatte. Hofmillers Entscheidung sei „ein Verlust für diese kämpfende Zeit“ (DLA, A:Hofmiller, Erwin Guido Kolbenheyer an Josef Hofmiller, 7. Oktober 1931).

60 „Du hast recht und auch nicht. Du siehst die Dinge zu sehr in Richtung: Organisation, zu sehr von außen. Das klingt sonderbar und ist doch so" (KAG, Hermann Ullmann an Erwin Guido Kolbenheyer, 1. Dezember 1927). 
chen Zeitmangel einer weiteren Diskussion aus. Angesichts dessen, dass Ullmann auf ein bis auf das Jahr 1909 zurückreichendes, persönliches Engagement für Kolbenheyer verweisen konnte, ist seine irritierte Haltung zu dessen verallgemeinernden Vorwürfen sehr verständlich und nachvollziehbar. ${ }^{61}$

In Gera reagierte besonders der Feuilletonleiter der Deutschen Allgemeinen Zeitung, Paul Fechter ${ }^{62}$, der dem Erbprinzen zuvor bei der Auswahl der einzuladenden Personen behilflich gewesen war $^{63}$, mit amüsierter Ironie auf Kolbenheyers Auslassungen. Noch in Fechters Erinnerungen findet sich über das Dichtertreffen die Anekdote, dass er, kaum in Gera angekommen, direkt von Kolbenheyer in Beschlag genommen und mit einem länglichen „Vortrag über die Verpflichtungen der Kritik gegenüber den deutschen Dichtern als den eigentlichen Trägern des Geistes“ beglückt worden sei. Fechter bedankte sich laut eigener Darstellung bestens für die erhellenden Erläuterungen des Dichters, „noch nie“ habe er „die Prinzipien der kritischen Arbeit so klar entwickelt vor mir gesehen" wie in Kolbenheyers Referat, aus dem er „die wertvollsten Anregungen mitnähme“64. Dass die ironische Distanz dieser rückblickenden Zeilen die damalige Reaktion Fechters durchaus authentisch wiedergibt, ist einem unmittelbar nach dem Dichtertreffen verfassten Brief an Hans Grimm zu entnehmen. Fechter, der nicht an mangelndem Selbstbewusstsein litt, betonte darin: „Ich habe ein paar Mal dort beim Erbprinzen fürchterlich lachen müssen; Kolbenheyer ist, wie Sie ihn schilderten - als Opfer nahm er mich. Aber ich habe mich nach Kräften gewehrt" ${ }^{\text {65 }}$.

Kolbenheyer entging es nicht, dass er mit seinem Plädoyer bei Fechter auf Granit gebissen hatte: „Herr Fechter“, so schrieb er in seiner Autobiografie, „fühlte sich angegriffen und hat mir mein Thema und seine Behandlung kaum mehr verziehen"66. In einer raren Anwandlung von Selbstkritik betonte Kolbenheyer allerdings, bei seinem Appell auf Schloss Osterstein womöglich „etwas eindringlich“ vorgegangen zu sei. Wirkung gezeigt hätten sein Worte gleichwohl: „[E]s

${ }^{61} 1909$ besprach Ullmann in Die schöne Literatur. Beilage zum Literarischen Zentralblatt für Deutschland den Roman Amor Dei, 1912 folgte ein Artikel im Wiener Deutschen Tageblatt (Nr. 29 des Jahrgangs), 1913 schließlich ein Artikel in der Literaturzeitschrift Eckart. Die zum Entstehungszeitpunkt des Briefs jüngste Rezension war am 24. Dezember 1925 in der Politischen Wochenschrift erschienen. In ihr wurde Kolbenheyer von Ullmann als der seinerzeit „innerlichste und aus seiner Innerlichkeit heraus stärkste Künder des deutschen Wesens" beschrieben, der insbesondere durch seine historischen Romane in einzigartiger Weise "Seelen- und Geistesbewegung“ der Vergangenheit ins Licht gehoben habe, „die damals das deutsche Volk neu schuf“ und die bis heute „noch nicht ausgelebt“ seien. Kolbenheyers Werk gehöre „zu den tröstlichen Erscheinungen dieses heutigen Deutschlands“ - einer in den Augen Ullmanns „,von Journalismus und Literatentum durchseuchten Zeit“. „Die Frage: Was ist deutsch? Um welche Werte kämpfen wir? - hier werden wir dichterisch von ihr erlöst“" (Ullmann, Ingenium, S. 688).

62 Vgl. Kap. 3.1.3.

${ }^{63}$ Vgl. Fechter, Menschen, S. $180 \mathrm{f}$.

${ }^{64}$ Ebd., S. 184f. Am Tag darauf, so Fechter, habe er dann aber „die Genugtuung“ gehabt, dass sich bei einem Gespräch mit Kolbenheyer und Stapel „ein langes biologisch-philosophisches Gespräch“ entwickelt habe, das angenehmerweise „ohne berufliche Abschweifungen“ ausgekommen sei.

65 DLA, A:Grimm, Deutsche Allgemeine Zeitung an Hans Grimm, 6. Juni 1931.

${ }^{66}$ Kolbenheyer, Sebastian Karst, Bd. 3, S. 96. 
kam zu lüftenden Streitgesprächen, die ich mit den Publizisten weiter fortsetzte “67. Diese retrospektive Einschätzung der Ereignisse ist gewiss nicht völlig falsch, jedoch relativierungsbedürftig. Dies zeigt nicht nur die Reaktion Fechters, der in jene „lüftenden Streitgespräche“ involviert gewesen war. Auch Eugen Schmahl, damals verantwortlich für die kulturpolitische Kreuzzeitungs-Beilage „Zeitenspiegel“, brachte von der Tagung „den Eindruck mit nach Hause“, dass „mit Menschen, wie Kolbenheyer etwa, im Sinne einer Gemeinschaftsbildung, die über den hintergründigen Interessenskreis des Einzelnen hinausgeht und sich in den Dienst einer außerpersönlichen Sache stellen will [...] nichts anzufangen“ sei. Die nach Gera gekommenen „Jüngeren“ hätten vor Ort im Wesentlichen geschwiegen und seien sich „,in dieser Welt selbstgefälliger Größen“ „reichlich verlassen und verloren“68 vorgekommen. Nicht alle „nationalen Mittler“ aber blieben von Kolbenheyers Ermahnungen unbeeindruckt, wie am Beispiel des Literaturhistorikers und Kunstkritikers Conrad Wandrey näher illustriert werden wird. ${ }^{69}$

Das ÖFfentliche Echo auf die Vollendung der Paracelsus-Trilogie (1925) - In seiner Autobiografie bilanzierte Kolbenheyer lapidar, dass der Inhalt und die sprachlich-stilistische Form seiner Paracelsus-Trilogie ${ }^{70}$ „nur deutsches Blut“ habe „ansprechen können“; „fremdes“ Blut sei gleichsam naturnotwendig „kaum oder überhaupt nicht bewegt" worden. Kolbenheyer glaubte hier nicht etwa an eine autonome Entscheidung oder an ehrliches Missfallen kritisch-distanzierter Leser. Als ausschlaggebend galten ihm allein die überindividuellen Mächte des Blutes und der Abstammung: „Jüdische Literaten und Rezensenten und deren Assimilaten“ seien „innerlich genötigt“ gewesen, die „Darstellungsweise abzulehnen“. Entsprechend seien sie an sein Werk „nicht heran“ gekommen, hätten sich aber in der „versteckte[n] Gehässigkeit des emotional Ausgeschiedenen "71 gleichwohl gegen ihn verschworen. Kolbenheyer glaubte, die Rezensenten präzise in einen angeblich aufgrund innerer Artverwandtschaft einsichtig-lobendenden und einen mutmaßlich aus „undeutscher“ Art heraus verständnislos-ablehnenden Flügel trennen zu können. Kritische Distanz zu seinen Werken reichte dabei als Beweis „undeutscher“ Art und Gesinnung, welche Kolbenheyer zugleich als ausreichende Erklärung für geäußerte Kritik oder vorhandenes Desinteresse behandelte. Aus diesem bezeichnenden Zirkelschluss darf indessen nicht geschlossen werden, dass es bei der zeitgenössischen Rezeption der Paracelsus-Trilogie tatsächlich zu einer hitzigen, kontroversen Debatte gekommen wäre, in der sich eine Front von Kolbenheyer-Befürwortern und eine Front seiner Gegner gegenübergestanden seien. In Wirklichkeit fielen die zahlreichen Besprechungen, die nach der Publikation des letzten Bands der Trilogie im Jahr 1925 erschienen, in ihrer überwältigenden Mehrheit wohlwollend bis hymnisch aus. Der sogenannte Gegner glänzte mit Abwesenheit und gab sich in erster

67 Ebd., S. 95 f.

68 DLA, A:Grimm, Eugen Schmahl an Hans Grimm, 5. Juli 1931.

${ }^{69}$ Vgl. Kap. 3.1.5.

70 Vgl. die Hinweise in Kap. 2.3.2.

${ }^{71}$ Kolbenheyer, Sebastian Karst, Bd. 2, S. 225 (Herv. i. Orig.). 
Linie durch die Verweigerung zu erkennen, in den Lobgesang mit einzustimmen. Die Haltlosigkeit der Behauptung Kolbenheyers, während der Weimarer Republik ein "totgeschwiegener" Autor gewesen zu sein, soll exemplarisch das Presse-Echo auf die Vollendung der Paracelsus-Trilogie illustrieren.

Mit den abschließenden Worten des dritten Bands seiner Trilogie - „Ecce ingenium teutonicum" - gab Kolbenheyer selbst das Stichwort zu einem zentralen Topos der Rezeption seinen literarischen Hauptwerks. Kolbenheyer habe es, so wollten es zahlreiche Rezensenten, durch das Porträt seines Romanprotagonisten vollbracht, grundlegende Züge deutsch-germanischer Wesens- und Geistesart freizulegen. Sein Streben, „das Wesen des deutschen Menschen in Gestaltung zum Ausdruck zu bringen", so der österreichische Literaturhistoriker Ernst Alker in der Monatsschrift Das deutsche Buch, habe in der Paracelsus-Trilogie „beglückende Erfüllung "72 gefunden. Worin aber bestanden jene Wesenszüge? Kolbenheyer stilisierte Paracelsus zum „Befreier von lateinischem Zwang und mediterraner Überfremdung", mit besonderem Fokus auf den angeblich unauflöslichen „Gegensatz zwischen germanischem und mittelmeerischem" beziehungsweise zwischen dem „deutschen und christlichen Denken und Leben "73. Grundlage dieses Gedankens war Kolbenheyers Perzeption des Reformationszeitalters als "Schwellenzeit" ${ }^{\text {"74 }}$. Nach seinem Geschichtsverständnis hatte sich „der deutsche Geist“ während der Reformation nach einer jahrhundertelangen Gängelung durch eine ihm „fremde mediterrane (mittelländische) Geisteshaltung“ erstmals im „Bewußtsein eigener Mündigkeit“" zu lösen und zu emanzipieren begonnen und dabei seine ,eigene Art und Sprache" behauptet. Spätestens seit dem Ende des Dreißigjährigen Kriegs sah Kolbenheyer dieses frühe Aufscheinen deutscher Wesensart jedoch wieder durch eine „Welle des englischen und französischen Rationalismus"75 unterdrückt, dessen Höhepunkt die spätere Aufklärung gebildet habe.

Doch zurück zur Paracelsus-Rezeption: „Unwillkürlich“, so der durch zahlreiche Artikel über Kolbenheyer hervorgetretene Karl Fuß in der Zeitschrift Hellweg, übertrage der Leser die Worte „ecce ingenium teutonicum“ nach dem Ende der Lektüre „auf den Dichter selbst“, denn in ihm vereinigten sich „Deutschheit und Mannheit und ein hoher Geist" ${ }^{\text {"76 }}$. Den Topos, Kolbenheyer habe in seiner Trilogie den innersten Wesenskern des deutschen Menschen freigelegt, griff auch der mit dem Dichter seit den frühen 1920er Jahren bekannte Hermann Werner auf, ein

72 Alker, Kolbenheyer, S. 385.

73 Keller, Nationalismus, S. $117 \mathrm{f}$.

$74 \mathrm{Zu}$ dem Konzept der „Schwellenzeit“ vgl. Kap. 3.3.1.

75 Kolbenheyer, Geist [1930], S. 230f. Für seine Gegenwart postulierte Kolbenheyer die unbedingte Notwendigkeit, der anhaltenden geistigen Übertölpelung des deutschen Volks endgültig einen Riegel vorzuschieben: „Auf Generationen hin geknechtet und bedrückt, haben wir kaum mehr etwas zu verschwenden, am wenigsten unsere Geisteskräfte, und müssen uns von einem Bildungsideal befreien, dessen Hang nach fremder Geistigkeit nicht mehr der längst erreichten Vollmacht unseres Geistes und unserer Sprache entspricht. Jedes spielerische Übermaß der Bildungsarbeit, das wir ohne Not an fremde Geistigkeit verschwenden, muß den inneren Kräften unserer Selbstbefreiung Abbruch tun" (ebd., S. 232).

${ }^{76}$ Fuß, Kolbenheyer, S. 763. 
langjähriger Mitarbeiter des Schwäbischen Merkur, der schon im Herbst 1923 als Mitglied der Stuttgarter Ortsgruppe des Deutschen Sprachvereins einen Kolbenheyer-Abend organisiert hatte. ${ }^{77}$ Kolbenheyer, so Werner, habe im Paracelsus „mit kühnem Griff“ den „letzten Gründen“ der deutschen Seele nachgespürt und in seiner Romanfigur „einen Menschen von typisch deutscher Geistesanlage“ freigelegt. ${ }^{78}$ Sehr ähnlich urteilte auch der seit 1919 am Germanischen Seminar der Universität Hamburg lehrende Literaturwissenschaftler Robert Petsch ${ }^{79}$, der bereits Ende 1921 mit einer Rezension Kolbenheyers Aufmerksamkeit erregt hatte. ${ }^{80}$ Petsch machte die Werke Kolbenheyers in seinen Vorlesungen und Seminaren „wieder und wieder" 81 zum Gegenstand und würdigte im Januar 1926 in der Zeitung Hamburgischer Correspondent insbesondere den abschließenden Band der Paracelsus-Trilogie als eine nach Inhalt und „innerliche[r] Haltung“ „durch und durch deutsch[e]“ Schöpfung, die ,in höchstem Sinne zeitgemäß“ sei, ohne sich jedoch ,in Zeitmoden“ zu erschöpfen. ${ }^{82}$

Wilhelm Matthießen schließlich, ein sehr erfolgreicher, der Ludendorff-Bewegung nahestehender Jugend- und Kinderbuchautor der Zwischenkriegszeit, der im „Dritten Reich“ durch krude antisemitische Verschwörungstheorien ${ }^{83}$ hervortreten sollte, zelebrierte zum Jahreswechsel 1925/26 in den Münchner Neuesten Nachrichten ${ }^{84}$ sowie in der Zeitschrift Orplid die außerordentliche dichterische

77 Vgl. KAG, Hermann Werner an Erwin Guido Kolbenheyer, 8. September und 18. Oktober 1923.

78 Vgl. Schwäbischer Merkur vom 10. September 1925.

${ }^{79}$ Zum Wirken von Robert Petsch in Hamburg vgl. Müller, Petsch, sowie die Hinweise in: Hempel-Küter, Germanistik.

80 Vgl. KAG, Erwin Guido Kolbenheyer an Robert Petsch, 12. Dezember 1921 (Durchschlag).

${ }^{81}$ KAG, Robert Petsch an Erwin Guido Kolbenheyer, 17. Dezember 1921. Noch 17 Jahre später, im November 1938, bemerkte Petsch anlässlich der Zusendung des Kolbenheyer-Romans Das gottgelobte Herz, dass er sich mit seinen Studenten "hier in unserm Seminar noch viel mit Ihrem Werke beschäftigen“ werde. „Ein paar meiner Studenten vertiefen sich jetzt schon darein [sic!]" (KAG, Robert Petsch an Erwin Guido Kolbenheyer, 10. November 1938).

82 Petsch, Reich. „Ernst [sic!] Guido Kolbenheyer“, so Petsch weiter, passe zwar „so recht in keine ,Richtung der gegenwärtigen ,Literatur', aber sein Lebenswerk“ werde „voraussichtlich selbst einst richtunggebend wirken".

${ }^{83}$ Vgl. Matthießen, Geheimplan; ders., Ritualmord.

${ }^{84}$ Kolbenheyer genoss primär aufgrund seiner freundschaftlichen Beziehung zu dem Feuilletonredakteur Walter Behrend einen hervorragenden Stand in den Münchner Neuesten Nachrichten. Dies ist nicht nur an einigen Veröffentlichungen Kolbenheyers in der Zeitung ablesbar. Beispielsweise engagierte Behrend auf Weisung des Dichters Wilhelm Stapel als Rezensent des Kolbenheyer-Theaterstückes Die Brücke (vgl. KAG, Inv. Nr. 73: München: Erwin Guido Kolbenheyer an Walter Behrend, 20. Oktober 1929 [Durchschlag], ferner: KAG, Walter Behrend an Erwin Guido Kolbenheyer, 22. Oktober 1929). Weitere Besprechungen von Werken Kolbenheyers durch Stapel in den Münchner Neuesten Nachrichten folgten. Behrend wurde natürlich auch ohne Fingerzeige für Kolbenheyer aktiv. Im Herbst 1929 gewann er Friedrich Muckermann für eine Besprechung des Theaterstücks Heroische Leidenschaften (Vgl. KAG, Walter Behrend an Erwin Guido Kolbenheyer, 23. Oktober 1929), im Folgejahr drängte er mehrfach „öffentlich darauf, [...] daß eine Münchner Bühne endlich“ eines der Stücke Kolbenheyers aufführen möge, und veranlasste schließlich die „gebührend[e]“ Würdigung einer entsprechenden Aufführung (vgl. KAG, Walter Behrend an Erwin Guido Kolbenheyer, 8. November 1930 und 13. Februar 1931). 
und philosophische Begabung Kolbenheyers. Das Werk Kolbenheyers, der zugleich ein „neuer Weiser“ und „Philosoph von reinstem, aber auch schwerstem deutschen Geblüt“ sei, zeichnete sich demnach nicht nur durch sprachliche und stilistische Brillanz aus, sondern darüber hinaus durch die „ungeheure Durchschlags- und Überzeugungskraft“ einer „lebenerhellende[n] Philosophie“85. Die Bedeutung des Dichters gehe weit über das bloß Schriftstellerische hinaus; in den Augen Matthießens hatte Kolbenheyer gar das Erbe Goethes angetreten:

„So dürfen wir Kolbenheyers Werk keinen Roman mehr nennen. Dichtung? Gewiß! Aber noch mehr: wir haben das neue deutsche Epos. Heldenlied der deutschen Seele. Doch es gibt noch eine andere, jedermann verständliche Wertbezeichnung; sei es gesagt nach langer, verantwortungsschwerer Prüfung: wir haben den neuen deutschen Faust. Ecce ingenium teutonicum! - so schließt das ,Dritte Reich [des Paracelsus]'. Und so schließen auch wir: Siehe, Deutschlands Seele!"86

Bei solchen Lobgesängen überrascht es nicht, dass Matthießen 1929 von Kolbenheyer zu seinen verdienstvollsten Helfern gerechnet wurde. ${ }^{87}$ Die Erhebung Kolbenheyers zum Nachfolger Goethes findet sich indes nicht nur bei Matthießen. So hieß es auch in einem Beitrag der Zeitschrift Eckart. Blätter für evangelische Geisteskultur: "Wie etwa der ,Faust' als vollendetes Abbild des deutschen Menschen Gemeingut aller Völker geworden ist, so wird Kolbenheyers ,Paracelsus' über die Grenzen unserer Zeit und unseres Volkstums hinaus sich Geltung verschaffen“" Wertungen wie diese stehen stellvertretend für einen zweiten zentralen Topos der Paracelsus-Rezeption: Die Stilisierung der Trilogie zum „größten Roman unserer

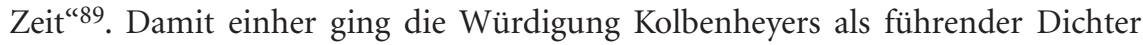
der Gegenwart, dem bis dato jedoch nicht annähernd die ihm zustehende Wertschätzung und Hochachtung zugekommen sei. Es entbehrt angesichts der eingangs geschilderten strikten Zweiteilung seiner Rezensenten in Kolbenheyers Autobiografie nicht einer gewissen Komik, dass selbst im Berliner Tageblatt eine lobende Paracelsus-Rezension erschien - in jener Zeitung also, die in der damaligen Rechten neben der Frankfurter Zeitung als die schädlichste und verdammungswürdigste Ausgeburt der angeblich jüdisch-liberalistischen Überfremdung des deutschen Kulturlebens galt. ${ }^{90}$ Autor der Rezension war der später emigrierte Berliner Theaterkritiker und Feuilletonist Felix Langer. Bruchlos schloss sich Langer dem von der Kolbenheyer-Entourage intonierten Klagelied an, wonach Kolbenheyer - gemessen an seiner überragenden literaturhistorischen Bedeutung -

${ }^{85}$ Matthießen, Paracelsus-Werk, S. 82. Matthießens Artikel war am 29. Dezember 1925 bereits in den Münchner Neuesten Nachrichten erschienen.

86 Ebd., S. 84.

87 Vgl. DLA, A:Stapel, Erwin Guido Kolbenheyer an Wilhelm Stapel, 24. Januar 1929.

88 Wegner, Paracelsus, S. 205. Bisweilen wurde die Darstellung Kolbenheyers als dem Autor, der in die Fußstapfen der größten Dichter der deutschen Literaturgeschichte getreten sei, auch variiert. So wurde der Paracelsus mitunter zum neuen Parzival und neuen Abenteuerlichen Simplicissimus erklärt, vgl. Rauch, Kolbenheyer, S. $332 \mathrm{f}$.

${ }^{89}$ Bernt, Kolbenheyer, S. 189.

${ }^{90} \mathrm{Vgl}$. auch die Auslassungen in: Hitler, Kampf, Bd. 1, S. $258 \mathrm{f}$. 
viel zu wenig öffentliche Aufmerksamkeit zuteil geworden sei. Vor allem mit seiner Paracelsus-Trilogie habe Kolbenheyer „ein Werk geschaffen“, das

„ebenbürtig neben den klassischen Prosawerken aller Literaturen steht, deren Wert und Dauer über Generationen hinüberlebt, deren Tiefe vielleicht der Zeit ihrer Entstehung sich nicht ganz erschliessen konnte, weil die Menschennähe ihrer Schöpfer ein Respekt und ehrfürchtiges Verstehen hinderndes Medium vorstellte, deren Wucht und Anschaulichkeit aber, deren Ethos und künstlerische Läuterung erst mit der wachsenden Entfernung in der Zeit voll begriffen wurde. [...] Nur ein grosser Dichter kann Philologie und Historie so weit hinter sich lassen, dass seine Schöpfung reines Kunstwerk wird. Wie der ,Ulenspiegel' des [Charles] de Coster seines Volkes Sinn und Sendung erfasste, so zeigt Kolbenheyer den deutschen Geist in der erschauten Gestalt. ,Ecce ingenium teutonicum', so schliesst sein Werk. Es ist nicht der Teutonengeist Hitlers und Ludendorffs, um den es sich handelt, es ist jener ewige Menschengeist, der auch Goethe und Sebastian Bach durchflutet hat." 91

In dieselbe Kerbe schlug auch der Berliner Schriftsteller und Journalist Hans Fischer, der zeitweise ebenfalls Mitarbeiter des Berliner Tageblatts gewesen war. ${ }^{92}$ Unter seinem Pseudonym „Kurt Aram“ notierte er in der DVP-nahen Täglichen Rundschau, dass mit Veröffentlichung des dritten Paracelsus-Bands erst „das Ganze der ungewöhnlichen Leistung“ Kolbenheyers ermessen werden könne. In „der zeitgenössischen deutschen Romanliteratur“ wusste Fischer „der Trilogie Kolbenheyers überhaupt nichts an die Seite zu stellen. [...] Ecce ingenium teutonicum! Mit diesem Wort schließt Kolbenheyer sein Werk. Ich möchte es auch ihm zurufen. "93

Auch der Münchner Schriftsteller und Mitbegründer des Simplicissimus, Hans Erich Blaich, würdigte Kolbenheyers Trilogie in der Stuttgarter Sonntags-Zeitung unter seinem Pseudonym „Dr. Owlglaß“ als eine unter den zeitgenössischen Dichtern beispiellos „tiefgründig[e]“ und „männlich[e]“ Schöpfung von „elementarer künstlerischer Kraft“94. Synonym dazu hob die zeitgenössisch vielgelesene, im völkisch-nationalistischen Fahrwasser schwimmende Bertelsmann-Autorin Auguste Supper in der Süddeutschen Zeitung hervor, dass mit Wertmaßstäben jenseits von „Zeitgeschrei und Marktlage“ bei der Einordnung des Paracelsus bekannt werden müsse, dass Kolbenheyer ein weit über allem „kurzlebige[n] Lobgehudel“ stehendes Werk geschaffen habe. In Kolbenheyers Hauptfigur komme gar „eine wahrere, klarere Wirklichkeit“ zum Ausdruck als in dem „historischen Paracelsus“, namentlich ein „Typus höherer Art“, mit dem der Dichter den in pluralistischer Beliebigkeit zerfließenden Weimarer Zeitgeist weit unter sich gelassen habe:

„Vom Psychologischen ist heute viel die Rede. Hier ist mehr. Nichts Zerlegtes und Zerteiltes, nichts, was durch suchende, zersetzende Analyse gewonnen wird. Ganz - wie das Lebendige und wie große Kunst - ist dieser Paracelsus, eine unzerteilte Einheit. - Ecce ingenium teutonicum, ist das letzte Wort des Buches. [...] Flattert es als Inschrift auf unsichtbar stolzer Standarte hoch über den Köpfen eines gehetzten Volkes? Nimmermehr, nimmermehr kann und darf das Wort verblassen!" 95

${ }^{91}$ Langer, Paracelsus (Herv. i. Orig.).

92 Vgl. den Hinweis in: Kirova, Redaktion, S. 218.

${ }^{93}$ Aram, Paracelsus.

94 Die Sonntags-Zeitung vom 13. Dezember 1925.

95 Süddeutsche Zeitung vom 29. Oktober 1925. 
Dieses Panorama der Paracelsus-Rezeption, das keineswegs die Gesamtheit der positiven Besprechungen dokumentiert, zeigt exemplarisch, wie unhaltbar, ja schlechterdings bizarr Kolbenheyers nimmermüde wiederholte und nie revidierte Behauptung war, sich als Autor stets ohne erwähnenswerte Presseunterstützung durchgeschlagen zu haben. Wie die Rezensionen Felix Langers und Hans Fischers zeigen, könnte nicht einmal dann von einem „totgeschwiegenen“ Werk die Rede sein, ließe sich die Weimarer Presselandschaft auf linksstehende Organe wie das Berliner Tageblatt, die Frankfurter Zeitung und die Vossische Zeitung reduzieren, deren Einfluss auf das gesamte Reichsgebiet (zumal jenseits der großen urbanen Zentren) innerhalb der Weimarer Rechten überdies notorisch überschätzt wurde. ${ }^{96}$

DAS Verhältnis ZWISCHEN Kolbenheyer Und ERWIn ACKERKNeCHT - Ein Aspekt, der bei Kolbenheyers Darstellung seiner Beziehungen zur Presse ebenfalls nicht aus den Augen verloren werden sollte, besteht darin, dass sich der Dichter mitunter durch sein brüskes und anmaßendes Auftreten seiner beflissenen Förderer selbst beraubte. Dies soll abschließend am Beispiel des Bibliothekars und Publizisten Erwin Ackerknecht illustriert werden, der lange Jahre nicht nur zu den engsten Freunden Kolbenheyers zählte, sondern zugleich sein fleißigster und im Nordosten Deutschlands einflussreichster Förderer war, ehe es 1923 zu einem endgültigen Bruch mit Kolbenheyer kommen sollte.

Erwin Ackerknecht, am 15. Dezember 1880 im baden-württembergischen Baiersbronn geboren, arbeitete nach Abschluss seines Studiums der Philosophie, Geschichte und Theologie an der Universität Tübingen von 1907 bis 1945 als Direktor der Stadtbibliothek Stettin. ${ }^{97}$ Parallel dazu entfaltete er eine breite volksbildnerische Aktivität. So gehörte er ab 1913 zur Leitung der „staatliche[n] Beratungsstelle“ und ab 1923 der „Landeswanderbücherei für das ländliche Büchereiwesen der Provinz Pommern". Ab 1919 leitete er die Stettiner Volkshochschule, in den Jahren 1932/33 die dortige Staatliche Büchereischule. Hinzu kam eine Dozentur am Berliner Zentralinstitut für Erziehung und Unterricht (1916-1923), ein Engagement als Mitglied des künstlerischen Beirats der Stettiner Theatergemeinde ${ }^{98}$ sowie Aktivitäten im pommerschen Vereins- und Verbandsleben, unter anderem „im Vorstand des Wandervogel“99. Ackerknecht gelang es darüber hinaus, sich mit seiner von 1921 bis 1933 herausgegebenen Zeitschrift Bücherei und Bildungspflege ein „überregional anerkanntes Sprachrohr“100 zu schaffen. Ackerknecht, der vor allem nach 1918 eine äußerst rege Publizistik entfaltete ${ }^{101}$, stand dem natio-

\footnotetext{
96 Sösemann, Journalismus, S. 242.

97 Vodosek, Annäherung, S. 17-19.

98 Ebd., S. 21-24.

99 KAG, Erwin Ackerknecht an Erwin Guido Kolbenheyer, 31. Januar 1914.

100 Vodosek, Annäherung, S. 24.

101 Eine nicht weniger als 508 Titel erfassende Bibliografie zu Erwin Ackerknecht bietet: Messin/Hoffmann, Ackerknecht, S. 21-91.
} 
nalrevolutionären „Tat-Kreis“102 nahe und erachtete es - der Auffassung Karla Poewes zufolge - als „sacred duty to promote the ideas of völkisch and Nationalist writers by organizing countless reading and talks throughout Germany" ${ }^{103}$.

Auch Peter Vodosek hat im Hinblick auf einige Briefwechsel und Publikationen Ackerknechts „von einem bedenklichen Antisemitismus“ und „anti-rationalistischen und anti-aufklärerischen" 104 Anschauungen gesprochen. Nach dem Ersten Weltkrieg zeigte Ackerknecht zudem eine Affinität zu dem biologistischen Denken, wie es ihm etwa in Kolbenheyers Flugschrift Wem bleibt der Sieg? (1919) begegnete. ${ }^{105}$ Dessen ungeachtet bedeutete die „Machtergreifung“ der Nationalsozialisten ein jähes Ende der „umfassenden und weitausgreifenden Tätigkeiten“ Ackerknechts; während des „Dritten Reichs“ blieben seine Aktivitäten weitestgehend „auf die wissenschaftliche Abteilung der Stadtbücherei Stettin“106 begrenzt. So vermochte Ackerknecht nach dem Zweiten Weltkrieg dann auch rasch wieder Anschluss zu finden: Bereits 1947 übernahm er den Direktorposten des SchillerNationalmuseums in Marbach am Neckar, den er bis 1954 innehatte. Am 24. August 1960 starb Ackerknecht in Ludwigsburg bei Stuttgart.

Kolbenheyer schilderte Ackerknecht in seiner Autobiografie als den „erste[n] eigentliche[n] Freund“, den er sich durch seine „Dichtung erworben habe“107. Die Freundschaft entsprang aus einem Aufenthalts Ackerknechts in Wien im Frühling 1912. ${ }^{108}$ Die erste Begegnung, so Kolbenheyer im Rückblick, habe auf Acker-

102 Zum „Tat-Kreis“ vgl. Sontheimer, Tatkreis; Hübinger, „Die Tat“.

103 Poewe, Religions, S. 24.

104 Vodosek verweist auf eine 1938 publizierte Monografie Ackerknechts über Franz Nabl, die Passagen beinhalte, „die auch Adolf Bartels hätte schreiben können“ (Vodosek, Annäherung, S. 28f.). In den Briefen an Kolbenheyer finden sich schon früh Äußerungen Ackerknechts, die auf antisemitische Ressentiments schließen lassen: Im Mai 1914 bezeichnete er die nicht weiter aufgeschlüsselte Zeitung/Zeitschrift „N.M.“ in abschätziger Weise als „ein Judenblatt“. Und im Dezember 1919 machte es Ackerknecht dem Schriftsteller Wilhelm Schäfer (1868-1952) insgeheim zum Vorwurf, die „Judenpartei [...] hinter sich“ zu haben. Vgl. KAG, Erwin Ackerknecht an Erwin Guido Kolbenheyer, 2. Mai 1914 und 15. Dezember 1919.

105 Vgl. Kap. 2.2.1. Voller Freude über die signalisierte Bereitschaft Kolbenheyers, bei Gelegenheit einen Beitrag für Ackerknechts Zeitschrift zu verfassen, stellte Ackerknecht die als Aufforderung zu verstehende Überlegung an, dass Kolbenheyer gegebenenfalls die Erfahrung seiner „eigenen literarischen $u[n d]$ weltanschaulichen Wirkung Gelegenheit zu einem Impromptu“ geben könne, in dem er beispielsweise schildern könne, dass es den „Gebildeten [an] biologischen $u[n d]$ physiologischen Hilfen bei der Erfassung kultureller Vorgänge“ fehle, eine Beobachtung, die Ackerknecht „selbst auch auf Schritt u[nd] Tritt“ machen zu können glaubte (KAG, Erwin Ackerknecht an Erwin Guido Kolbenheyer, 25. August 1919).

106 Vodosek, Annäherung, S. 25.

107 Kolbenheyer, Sebastian Karst, Bd. 2, S. 167.

108 „Unsere Begegnung in Wien hat das Gefühl freundschaftlicher Verwandtseins wie eine Welle in mir emporgetrieben" (KAG, Erwin Ackerknecht an Erwin Guido Kolbenheyer, 30. Mai 1913). Das kurz darauf angebotene $D u$ kommentierte Ackerknecht mit den Worten: „Wir wollen das bespöttelte Wort von der Nibelungentreue, die Österreich und Deutschland verbinden soll, an unserm bescheidenen Teil zu Ehren bringen, gelt?" (KAG, Erwin Ackerknecht an Erwin Guido Kolbenheyer, 8. Juli 1913). Wenig später übernahm Kolbenheyer die Patenschaft für eine Tochter Ackerknechts. Vgl. KAG, Erwin Ackerknecht an Erwin Guido Kolbenheyer, 2. Oktober 1913). 
knecht einen „nachhaltigen Eindruck“ ausgeübt, sei für ihn selbst jedoch noch „ungleich wirkungsmächtiger" gewesen. Habe er sich zu jenem Zeitpunkt doch als „Vereinsamter“ und von der „von Juden beherrscht[en]“ Wiener Literaturszene Abgestoßener „,nach einer Freundschaft“ gesehnt, von der er ein „unmittelbares Verständnis“ für sein literarisches „Schaffen erwarten konnte“109. Genau damit konnte Ackerknecht damals dienen. Entscheidend für die sich rasch festigende Freundschaft war nicht zuletzt Ackerknechts affirmative Haltung zu den bis dahin entstandenen Werken Kolbenheyers, die bis dahin nur wenig Aufmerksamkeit gefunden hatten: „Er sagte mir gleich, es könne nur eine Frage der Zeit sein, daß mein Werk von selbst in die Weite des Volkes gelange"110.

„Von selbst" geht auf dem Literaturmarkt jedoch selten etwas und so machte sich Ackerknecht alsbald selbst ans Werk, die Werbetrommel für Kolbenheyers Werke zu rühren. Schon im Juni 1912 veröffentlichte er eine Besprechung des Romans Montsalvasch (1911) ${ }^{111}$, im Frühjahr 1913 steuerte er die Einleitung einer „Kolbenheyernummer" der Zeitschrift Die Lese bei ${ }^{112}$, kurze Zeit später folgte eine ,ausführliche Besprechung "113 der Novellensammlung Ahalibama (1913) für die Zeitschrift Eckart. Nach dem Ersten Weltkrieg knüpfte Ackerknecht nahtlos an seine Rezensionstätigkeiten an und besprach Kolbenheyers erste Nachkriegspublikation, die Flugschrift Wem bleibt der Sieg?114 Für sie warb er auch gegenüber Josef Hofmiller von den Süddeutschen Monatsheften. Mit Erfolg, wie Ackerknecht glaubte: Er habe Hofmiller, der „viel dazutun“ könne, damit die Ideen der Flugschrift „,verbreitet werden“, „schon stark mit Verständnis für deine Sache infiziert"115. Im Sommer 1920 veröffentlichte Ackerknecht zudem einen Artikel in Wilhelm Schäfers einflussreicher Kulturzeitschrift Die Rheinlande116, wobei er sein Manuskript Kolbenheyer vorab zum Korrekturlesen gab. ${ }^{117} 1921$ folgte

109 Kolbenheyer, Sebastian Karst, Bd. 2, S. 168f.

110 Ebd., S. 170.

111 Der Beitrag Ackerknechts ist erwähnt in: KAG, Erwin Ackerknecht an Erwin Guido Kolbenheyer, 1. und 6. Juli 1912.

112 Vgl. KAG, Erwin Ackerknecht an Erwin Guido Kolbenheyer, 13. April 1913.

113 KAG, Erwin Ackerknecht an Erwin Guido Kolbenheyer, 31. Oktober 1913.

114 Vgl. Bildungspflege. Monatsschrift für die gesamten außerschulmäßigen Bildungsmittel 1 (1919/20), H. 1, S. 46: Da Kolbenheyer bereits „zur Genüge bewiesen“ habe, „wie reich und urständig in ihm deutsches Leben quillt", bestehe bei ihm „besondere[r] Anlaß, vertrauensvoll hinzuhören, wenn er von der Zukunft unseres Volkes“ spreche: „Hier ist kein leichtmütiges Hinwegreden über die Not des nächsten Menschenalters. Aber hier ist seelische Kraft, die sich mit prophetenhafter Unerbittlichkeit geistig auswirkt“. Kolbenheyers „gewaltige Rede an die deutsche Nation“ gereiche den Volksbildnern, „denen ein unmittelbares Verhältnis, ja das unmittelbarste Verhältnis zur deutschen Volksseele Lebensbedürfnis ist, [...] zu besonderer Herzensstärkung“.

115 KAG, Erwin Ackerknecht an Erwin Guido Kolbenheyer, 17. August 1919.

116 Vgl. Ackerknecht, Kolbenheyer [1920]. Zur Geschichte und Ausrichtung dieser Zeitschrift vgl. Brenner, „Das Rheinland aus dem Dornröschenschlaf wecken!“.

117 Kolbenheyer solle den Text prüfen, ob er etwas "gestrichen od[er] geändert" wünsche. „Selbstverständlich“ werde er Schäfer nicht wissen lassen, „daß du das Man[uskript] gesehen hast!“ (KAG, Erwin Ackerknecht an Erwin Guido Kolbenheyer, 10. Juni 1920). 
schließlich eine Besprechung des zweiten Bands der Paracelsus-Trilogie in der traditionsreichen Zeitschrift Das literarische Echo. ${ }^{118}$

Ackerknecht verteidigte Kolbenheyer darüber hinaus gegen eine als unangemessen und gönnerhaft empfundene Äußerung in Adolf Bartels' Zusammenstellung Die besten deutschen Romane, die 1921 bereits in siebter Auflage erschienen war. ${ }^{119}$ Auch durch Vorträge bemühte sich Ackerknecht, Kolbenheyers Werke zu popularisieren. ${ }^{120}$ Kurzum: Es steht außer Zweifel, dass Ackerknecht seit der ersten Begegnung mit Kolbenheyer nach Kräften und unter Mobilisierung erheblicher Zeit- und Arbeitsressourcen darum bemüht war, den zu Beginn der Weimarer Republik noch weithin unbekannten Autoren zu fördern und breiteren Leserschichten bekannt zu machen. Dennoch kam es 1923 zu einem jähen und irreversiblen Bruch zwischen beiden Männern.

Was waren die Hintergründe? Schon im Sommer 1921 waren erste Spannungen aufgetreten, als Kolbenheyer ein Schreiben scharf zurückwies, in das Ackerknecht die Bemerkung eingestreut hatte, „unabhängig“ von Kolbenheyer „auf ähnliche Perspektiven in Einzelfragen herausgekommen“ zu sein wie dieser, namentlich „durch berufliche Erfahrungen“121. Sein ausuferndes Geltungsbedürfnis erlaubte es Kolbenheyer nicht, diese harmlose Bemerkung unkommentiert zu lassen. Stattdessen hielt er es für angebracht, Ackerknecht darauf hinzuweisen, dass sich dessen Denken in Wahrheit auf das (dürftige) Niveau „vieler anderer Volksbildner“ beschränke. Seine eigenen Ansichten hingegen, so Kolbenheyer, würden $\mathrm{zu}$ „weiteren u[nd] gründlicheren Gesichtspunkten führen“122.

118 Vgl. Das literarische Echo. Halbmonatsschrift für Literaturfreunde 24 (1921/22), H.4, Sp. $235 \mathrm{f}$.

119 Vgl. Ackerknecht, Bartels, S. 88: „Sehr dankbar aber sind wir, daß Sie ,gegen biographische Romane wie die genannten von Bartsch, Kolbenheyer, usw. durchaus nichts einzuwenden haben. Welcher Stein wird Kolbenheyer vom Herzen fallen, wenn er erfährt, daß Sie nichts, aber auch gar nichts dagegen haben, wenn er an seinem 3. Band des ,Parazelsus' [sic!] weiterschafft". Die Aussage von Bartels, über die sich Ackerknecht hier echauffierte, lautete: „Jedenfalls ist es zu begrüßen, daß das deutsche Volk jetzt wieder stärker in seine Geschichte hineingetrieben wird, ich habe auch gegen biographische Romane wie die genannten von Bartsch, Kolbenheyer, usw. [...] durchaus nichts einzuwenden“ (Bartels, Romane, S. 52). Ackerknecht ließ an Bartels' Schrift generell kein gutes Haar. Über die von Bartels „mit der Objektivität eines Schlächtermeisters, der seine Opfer mustert" vorgenommene Buchauswahl urteilte Ackerknecht: „Selbst ein Volksbibliothekar braucht - Gott sei Dank! - nicht den zehnten Teil der Romane gelesen zu haben [...]; ja er braucht nicht einmal alle die deutschen ,Dichter' mit Namen zu kennen, die hier in der bekannten Bartelschen Manier im Ramsch ,charakterisiert' werden. Hier feiert eine Belesenheit wahre Orgien, der jedes Augenmaß für das Wesentliche abgeht und die in ihrer Sammelwut blind ist für bedeutende Neuerscheinungen (z. B. Hans Grimm), sofern diese von ,der Kritik` noch nicht beachtet sind“. „Alles in allem hoffen wir, daß aus der Praxis der deutschen Büchereien bald ein in jeder Hinsicht besseres Hilfsmittel hervorgehe!“ (Ackerknecht, Bartels, S. 88, 90).

120 „Die beiden nächsten Mittwoch Abende als die letzten Stunden meiner Vortragsreihe gehören dir. Meine Hörer sind bis jetzt prächtig mitgegangen, da hoffe ich, daß diesmal ganz besonders das Wort gilt: ,Ende gut, alles gut!"“ (KAG, Erwin Ackerknecht an Erwin Guido Kolbenheyer, 26. Februar 1920).

121 KAG, Erwin Ackerknecht an Erwin Guido Kolbenheyer, 7. August 1921.

122 Ebd. 
Die aus diesen Zeilen sprechende Arroganz ist umso frappierender, als Kolbenheyer zum damaligen Zeitpunkt noch kaum mit philosophischen Arbeiten hervorgetreten war; bis zur Veröffentlichung der Bauhütte ${ }^{123}$ sollten noch einige Jahre vergehen.

Der spürbar in seinem Selbstwertgefühl verletzte Ackerknecht zeigte wenig Verständnis für Kolbenheyers Bedürfnis, ihn in solcher Weise seine „Schranken zurückzuweisen“. Ob Kolbenheyer, dessen „Priorität“ Ackerknecht nicht „anzutasten“ gedachte, nicht gespürt habe, welch „bodenlose Dummheit u[nd] Eitelkeit" er ihm mit seiner Aussage bescheinigt habe? Nehme Kolbenheyer ernsthaft an, er, Ackerknecht, habe mit seiner Bemerkung das „hohe Lebensgut“ der Freundschaft „dem erbärmlichsten Ehrgeiz, mich mit dir zu messen“, opfern wollen? Wie schwer sich Ackerknecht beleidigt fühlte, geht aus seiner anschließenden Bemerkung hervor, niemals habe er sich vorstellen können, dass ihre Freundschaft, seinerseits erwachsen „aus reiner Liebe zu deinem Gemüt“, „ein so klägliches Ende nehmen könnte" 124 .

Der Bruch blieb jedoch zunächst noch aus; in den kommenden Monaten normalisierte sich vielmehr das Verhältnis. Als Kolbenheyer jedoch im September 1923 in einem Brief abermals despektierliche Töne gegenüber Ackerknecht anschlug, war das Tischtuch endgültig zerrissen. Hintergrund war eine kritische Rezension Ackerknechts über eine neuerschienene Nietzsche-Monografie des Wiener Philosophieprofessors Robert Reininger ${ }^{125}$, mit dem Kolbenheyer persönlich bekannt und befreundet war. Kolbenheyer hatte Ackerknecht zuvor lobend auf die Studie Reiningers hingewiesen. Nun störte er sich nicht nur an der negativen Rezension, sondern auch daran, dass Ackerknecht diese nicht sogleich an ihn weitergeleitet hatte. Kolbenheyer war der Überzeugung, dass Ackerknecht über das Buch hätte „schweigen sollen“, wenn er schon glaubte, „mit seinem Inhalte nicht einverstanden sein zu müssen“. Da sich Ackerknecht nicht zu den „berufenen Vertretern der heutigen philosophischen Literatur" rechnen dürfe, habe es keine Veranlassung gegeben, sich zu Reiningers Studie anders als zurückhaltend positiv zu Wort zu melden. ${ }^{126}$ Damit nicht genug: Kolbenheyer bezichtigte Ackerknecht einer „geradezu unphilosophische[n] Denkweise“. Die deutsche Philosophie, so Kolbenheyer vielsagender Fingerzeig, habe jedoch „ihre Kinderschuhe ausgetreten“. Infolgedessen berühre „der überhebliche, fast arrogante Schulmeisterton“ Ackerknechts und das in ihm angeblich angelegte „Ressentiment gegen das Akademische“ peinlich; Kolbenheyer fühlte sich an das „Temperamente eines Jüngers“ erinnert, der „in philosophicis kaum mehr aufzuweisen“ habe „als eben seine Ambition“. Überhaupt schien Kolbenheyer immer deutlicher zu werden, dass sich Ackerknechts „Weg von dem meinen, als dem Deines Freundes, immer

123 Vgl. Kap. 3.3.

124 KAG, Erwin Ackerknecht an Erwin Guido Kolbenheyer, 7. August 1921.

125 Vgl. Reininger, Kampf.

126 KAG, Erwin Guido Kolbenheyer an Erwin Ackerknecht, 20. September 1923 (Durchschlag). 
weiter“ entferne. Trocken bezeichnete er dies als „eine natürliche Entwicklung [...], gegen die kaum etwas bewerkstelligt werden"127 könne.

Ackerknecht zeigte sich im Gegenzug „entsetzt“ von dem „Misstrauen“, mit dem Kolbenheyer seine Arbeit „seit etwa drei Jahren“ begleite. Bemüht um die Vermeidung einer Eskalation, entschuldigte sich Ackerknecht trotzdem dafür, wenn seine Besprechung ungewollt „überheblich“ gewirkt habe. Zugleich signalisierte er seinen Willen, an der Freundschaft festzuhalten: Die „Abkanzelung“ durch Kolbenheyer, die er „von keinem anderen ertragen hätte“, wollte Ackerknecht „überwinden“, die „dämonische Entfremdung“ Kolbenheyers „durch unbeirrbare Treue bannen “128. Kolbenheyer wies diese Geste des Entgegenkommens jedoch brüsk zurück und warf Ackerknecht vor, in seinem Brief „durch allerlei Nebensächliches“ um den „Kern meiner Vorhaltungen“ herumgeredet zu haben. Jovial notierte er, lediglich um Ackerknechts Entschuldigung willen, in der „noch der alte Erwin Ackerknecht“ zum Vorschein komme, auf „zwei pathetische Übertreibungen" 129 hinweisen zu wollen: Keineswegs habe er - erstens - Ackerknechts Tätigkeiten mit Misstrauen verfolgt, vielmehr sei er dessen „bibliothekarischen Leistungen“ seit jeher „mit aufrichtiger Wertschätzung“ begegnet. Im Gegensatz dazu trügen Ackerknechts „Versuche volkstümlich Philosophie zu lehren und anderweitig schriftstellerisch hervorzutreten“ jedoch „alle Zeichen eines [...] Dilettierens“. Zweitens wies Kolbenheyer Ackerknechts Verweis auf die „dämonische Entfremdung“, die ihn, Kolbenheyer, ergriffen habe, als lächerlich zurück. Ob Ackerknecht wirklich glaube, „daß ein Freund, der dir in klarer u[nd] ruhiger Weise einen Verstoß gegen seine Freundschaft nachweist, von Dämonen befallen sein“ müsse, die es zu bannen gelte? In dieser Auffassung sah Kolbenheyer große „Überheblichkeit [...] mir gegenüber“ angelegt. Ackerknecht sollte daher „jeden Dämon“ „ruhig [...] aus dem Spiele“ lassen und selbst „nicht die Rolle des Exorzisten"130 in Anspruch nehmen.

Spätestens nach diesem höhnischen Abschluss des Briefs hatte auch Ackerknechts Bedürfnis, mit Kolbenheyer in freundschaftlicher Beziehung zu bleiben, ein Ende. Er verzichtete auf eine weitere Replik und auch in der Folgezeit kam es zu keinen Korrespondenzen mehr. Öffentlich trat Ackerknecht nach 1923 zwar noch vereinzelt mit positiven Rezensionen über Arbeiten Kolbenheyers hervor ${ }^{131}$, sein Engagement beschränkte sich nun jedoch, gemessen an den frühen 1920er

127 Ebd.

128 KAG, Erwin Ackerknecht an Erwin Guido Kolbenheyer, 29. September 1923.

129 KAG, Erwin Guido Kolbenheyer an Erwin Ackerknecht, 3. Oktober 1923 (Handschriftliche Abschrift).

$130 \mathrm{Ebd}$.

131 Im Generalanzeiger Stettin bewarb Ackerknecht am 3. Oktober 1925 den dritten ParacelsusBand als „eines der gewaltigsten Denkmäler deutscher Erzählkunst“. Die Trilogie sei „die bedeutungsvollste epische Verkörperung eines deutschen Genies und seiner Umwelt“. An dem Roman Das Lächeln der Penaten lobte er, dass ein an mehr als nur „spannende[n] Belanglosigkeiten“ interessierter Leser „künstlerisch erbaut“ und „weltanschaulich bereichert und gekräftigt" aus der Lektüre hervorgehe. Vgl. Die Literatur. Monatsschrift für Literaturfreunde 29 (1926/27), S. 296. 
Jahren, auf ein Minimum. Den hauptsächlichen Anteil an dieser Entwicklung wird man Kolbenheyer attestieren müssen, der durch sein herablassendes und kränkendes Auftreten ohne jede Notwendigkeit einen langjährigen Förderer verspielte, dessen Freundschaft durch ein empathischeres und psychologisch klügeres Verhalten unschwer hätte bewahrt werden können.

\subsubsection{Grimms Beziehung zur Deutschen Allgemeinen Zeitung}

Sie können mit der ,DAZ' sogar immer rechnen, wenn sich auch natürlich gelegentlich vor dem Druck kleine Unterhaltungen mit Ihnen ergeben können. ${ }^{132}$

Betrachtet man die Entwicklung der Beziehungen Grimms zur deutschen Presse während der Weimarer Republik, wandert der Blick unweigerlich auf die Veröffentlichung von Volk ohne Raum im Jahr 1926. Infolge der Publikation des Romans verdichtete und intensivierte sich die Vernetzung Grimms in der deutschen Zeitungs- und Zeitschriftenlandschaft in geradezu explosionsartiger Weise. Überraschend ist dieser Mechanismus freilich nicht - welcher aus der Taufe gehobene Bestsellerautor wäre je nicht sogleich von der Presse begierig umgarnt worden? Einen bemerkenswertes Spezifikum stellt Volk ohne Raum indes aufgrund seiner auffällig "lange[n] und folgenreiche[n] Rezeptionsgeschichte" dar, wie sie von Annette Gümbel bis über den Tod des Autors hinaus nachverfolgt worden ist. ${ }^{133}$ Dabei fällt ins Auge, dass die Rezensionen des Romans trotz seiner kontroversen Thematik in ihrer überwältigenden Mehrheit wohlwollend bis euphorisch ausgefallen sind ${ }^{134}$ - eine deutliche Parallele zu dem Presse-Echo nach Vollendung der Paracelsus-Trilogie durch Kolbenheyer. ${ }^{135}$ Die im Nachlass Grimms überlieferten Korrespondenzen mit Zeitungen und Zeitschriften bieten sogar Beispiele, in denen der Dichter von Seiten einzelner Redaktionen zum eigenhändigen Verfassen einer Besprechung von Volk ohne Raum aufgefordert wurde: Verweisend darauf, wie schwierig es sei, ein derart gewichtiges Buch angemessen zu würdigen, trat im Januar 1927 etwa die Berliner Zeitschrift Volk und Reich mit der Bitte um eine solche "Selbstbesprechung" an Grimm heran. ${ }^{136}$ Diese Bitte blieb nicht unerhört; zwei Monate später bedankte sich die Redaktion für den Eingang der Besprechung. 137

132 DLA, A:Grimm, Deutsche Allgemeine Zeitung an Hans Grimm, 6. Juni 1931.

133 Gümbel, Volk, S. 345.

134 Vgl. ebd., S. 128-132. Kritik wurde nur von einigen wenigen „ausgewiesen linke[n] Journalisten wie Kurt Tucholsky" geäußert, welche freilich den horrenden Erfolg des Romans "nicht aufhalten konnte[n]“ (ebd., S. 131f.).

135 Vgl. Kap. 3.1.2.

136 DLA, A:Grimm, Volk und Reich an Hans Grimm, 24. Januar 1927.

137 Vgl. DLA, A:Grimm, Volk und Reich an Hans Grimm, 22. März 1927: „Es scheint mir das Geeignetste zu sein, wenn diese in die große Bayernfestschrift, die wir anlässlich der Tagung des Deutschen Schutzbundes zu Pfingsten in Regensburg herausgeben, aufgenommen wird.“ Das Heft werde im ganzen „Grenzdeutschtum Verbreitung finden“. 
Die Korrespondenzen Grimms zu Redaktionen deutschsprachiger Zeitungen und Zeitschriften seit 1926 lassen ein sich stetig wiederholendes Muster von Kontaktaufnahme seitens der Publikationsorgane, schmeichelnder Umwerbung und kontinuierlicher Beziehungspflege erkennen. Eine summarische Zusammenschau all jener Kontakte wäre aufgrund des schieren Quellenumfangs nur in einer eigenen, separaten Studie zu leisten - einer Studie indes, die Gefahr liefe, sich in Redundanzen zu verlieren. Im Folgenden wird daher unter mehreren intensiven Pressebeziehungen Grimms stellvertretend das Verhältnis zur Deutschen Allgemeinen Zeitung (DAZ) herausgearbeitet, das sich aus den Quellen besonders anschaulich rekonstruieren lässt.

Bedingt und getragen war die Beziehung zwischen DAZ und Grimm auf persönlicher Ebene zunächst von dessen enger persönlicher Freundschaft mit Paul Fechter ${ }^{138}$, dem Leiter des Feuilletons der Zeitung und einem der einflussreichsten Literaturkritiker der Weimarer Rechten. ${ }^{139}$ Neben der Arbeit in der DAZ war Fechter Mitarbeiter zahlreicher weiterer Zeitungen und Zeitschriften. Regelmäßig schrieb er etwa in Will Vespers Die schöne Literatur (ab 1931: Die neue Literatur), für die er unter der Rubrik Peinlichkeiten „Attacken auf die moderne bzw. linksorientierte Literatur" 140 führte. Forschungen Andreas Zeisings haben gezeigt, dass Fechters Publizistik insbesondere gegen „Ende der zwanziger Jahre [...] eine verschärfte, zuweilen ins Völkische tendierende Betonung des ,Deutschen“ als geschichtlicher Wesenheit“ aufweisen. Insbesondere dem Thema des „deutschen Ostens“ begegnete Fechter demnach mit einer „geradezu obsessive[n], zuweilen überaus prekären Leidenschaft"141. In diese Entwicklung ist die Beziehung zwischen Grimm und Fechter nicht nur einzuordnen - Grimm gelang es vielmehr, das Denken Fechters auf diesem Feld aktiv und nachhaltig zu beeinflussen.

Die Freundschaft zwischen Fechter und Grimm nahm Mitte der 1920er Jahre ihren Ausgang und dauerte bis zum Ende der 1950er Jahre ungebrochen an. Wie nahe sich die beiden Männer während dieser Zeit kamen und welch starken Eindruck Grimms Persönlichkeit und Werk auf Fechter ausübten, geht schon daraus hervor, dass Fechter in seinen 1949 erschienenen Erinnerungen An der Wende der Zeit. Menschen und Begegnungen Grimm ein eigenes, fast 30 Seiten langes Kapitel

138 Paul Fechter (1880-1958) studierte Architektur in Dresden und Charlottenburg, später Mathematik, Physik und Geisteswissenschaften in Berlin. Nach seiner Promotion (1905) etablierte sich Fechter durch seine Mitarbeit in verschiedenen Tageszeitungen als einer der bedeutsamsten Feuilletonisten seiner Zeit. Nach 1933 trat Fechter als Mitherausgeber der Deutschen Zukunft (bis 1940) und der Deutschen Rundschau (bis 1942) hervor. Nach dem Zweiten Weltkrieg gab er von 1954 bis 1956 die Neuen Deutschen Hefte heraus.

139 Über den Stellenwert Fechters innerhalb der Berliner Literaturkritik der Weimarer Republik bemerkt Hans Friedrich Blunck: „In Berlin wohnten einige der großen Herren des kritischen Griffels. Da waren Paul Fechter, der in der ,Deutschen Allgemeinen Zeitung' thronte und mit seinem erbarmungslos ehrlichen Urteil der ernste Gegenspieler der ,Voss[ischen Zeitung]' war" (Blunck, Zeiten, Bd. 2, S. 155).

140 Schuhmann, Leipzig-Transit, S. 343.

141 Zeising, Revision, S. 173-175. 
widmete. ${ }^{142}$ Die enge, langanhaltende Freundschaft erfüllte Fechter mit Stolz. Rückblickend hob er unmissverständlich hervor, dass sein Verhältnis zu Grimm während der Weimarer Republik keine Beziehung auf Augenhöhe war, sondern eher der Beziehung eines Schülers zu seinem Meister glich. ${ }^{143}$ Erstmals einander vorgestellt wurden Grimm und Fechter bereits kurz nach dem Ersten Weltkrieg durch Arthur Moeller van den Bruck im Berliner Juni-Klub. ${ }^{144}$ Ein engerer Austausch stellte sich jedoch erst ab 1925 ein. Strippenzieher war auch hier ihr gemeinsamer Freund Moeller van den Bruck, der kurze Zeit später aus dem Leben scheiden sollte. ${ }^{145}$ Fechter war in jenem Jahr für die Vergabe des Kleist-Preises verantwortlich. Moeller van den Bruck, aus erster Hand über den Arbeitsfortschritt Grimms informiert, wies Fechter deshalb mit Nachdruck auf Grimms Volk ohne Raum hin, das damals unmittelbar vor der Vollendung stand. Ein würdigeres Werk für den Preis, so versicherte Moeller van den Bruck, werde sich nicht finden lassen. Da der ALV Fechter bis zum Vergabetermin des Preises jedoch nur einen kleinen Teil des Texts vorgelegt hatte, konnte Fechter den Preis zu seinem Bedauern letztlich nicht an Grimm verleihen. ${ }^{146}$ Umso stärker waren nach der erfolgten Veröffentlichung des Romans dann aber Fechters Wille und Bedürfnis, Grimm für die im Jahr zuvor ungewollt verwehrte Ehre der Preisverleihung zu kompensieren.

Dies geschah zuvorderst durch Rezensionen. Noch in seinen Memoiren rechnete es sich Fechter als eines seiner größten Verdienste als Literaturkritiker an, durch seine Besprechung von Volk ohne Raum in der DAZ „wie eine Fanfare und zugleich wie eine Richtschnur auf viele der anderen Blätter" 147 gewirkt zu haben. In der entsprechenden Rezension zelebrierte Fechter Grimms Werk als jenen Roman, der es als erstes vollbracht habe, „das Schicksal eines Volkes zu gestalten“ und dabei „den Sinn und Widersinn des letzten Jahrhunderts deutscher Geschichte $[\ldots]$ erkennbar zu machen"148. Originell war diese Deutung indes schon zum damaligen Zeitpunkt nicht, folgte Fechter mit ihr doch schlicht dem selbsterklärten Anspruch Grimms, in der Lebensgeschichte seines Hauptprotagonisten

142 Vgl. Fechter, Wende, S. 390-419.

143 Vgl. Ebd., S. 397f.: „Zwischen ihm, dem Älteren und Weltberühmten, und mir hatte sich eine Beziehung entwickelt, auf die ich aufrichtig stolz war und bin. Ich fühlte, dass er Dinge besaß und zu geben hatte, zu denen ich von mir aus keinen direkten Zugang hatte, ich empfand dankbar die Stellung, die er, der viel Gefeierte, mir einräumte, und noch dankbarer die Freundschaft, die er offen bekannte, wohl weil er fühlte, wie ich innerlich zu ihm stand“.

144 Vgl. Fechter, Menschen, S. 333.

$145 \mathrm{Zu}$ den Hintergründen des Selbstmords Moeller van den Brucks am 30. Mai 1925 vgl. die Hinweise in: Schlüter, Moeller van den Bruck.

146 Vgl. Fechter, Wende, S. 390 f. Es entbehrt nicht der Komik, dass der Preis letztendlich anstelle an Grimms Volk ohne Raum an Carl Zuckmayer und dessen Lustspiel Der fröhliche Weinberg ging. So unglücklich Fechter rückblickend mit dieser Wahl war, so ist an ihr doch deutlich abzulesen, dass Fechter während der Weimarer Republik keineswegs auf Autoren des rechten Politikspektrums fixiert blieb.

147 Fechter, Wende, S. 393.

148 Zitiert nach Gümbel, Volk, S. 132, Anm. 290. 
Cornelius Friebott das allgemeine Schicksal des gesamten deutschen Volks seit dem ausgehenden 19. Jahrhundert zu spiegeln. ${ }^{149}$ Volk ohne Raum, so Fechter, sei „aus erlebtem Wissen um die deutsche Welt und die deutschen Menschen“ geboren, „vor allem“ jedoch auch aus Wissen „um die deutschen Notwendigkeiten“. In „natürlichem, aufrechtem und allgemeinem Gefühl“ habe Grimm „das Gelebte klar, stark und eindringlich in lebendiger Wirklichkeit“ hingestellt. Überhaupt stelle Volk ohne Raum „den ersten großen politischen Roman des deutschen Volkes“ dar, wodurch Grimm himmelhoch über der „kümmerlichen Literatur von heute" stehe. 150

In seiner 1929 veröffentlichten Schrift Deutsche Dichtung der Gegenwart bediente Fechter in mustergültiger Form einen weiteren Topos der Volk-ohneRaum-Rezeption: Das gezielte Einebnen der Grenzen zwischen Fiktionalität und empirisch nachprüfbaren Fakten. Fechter behandelte den Roman - abermals ganz im Sinne Grimms - schlechterdings als Ausdruck faktentreuer Kolonialgeschichte: „Jenseits aller großen menschlichen und künstlerischen Qualitäten“ habe der Roman „den ungeheuren Vorzug, ein Stück der wirklichsten, der schwersten deutschen Wirklichkeit, unsere politische Wirklichkeit"151 geschildert zu haben. Durch den Verzicht auf die Unterscheidung zwischen authentischer Kolonialgeschichte und deren fiktionaler Bearbeitung sollte der Roman die Aura eines glaubhaften, historisch-politischen Zeugnisses erhalten. Diese prekäre Vermengung erwies sich auf dem hochgradig politisierten Literaturmarkt der Weimarer Republik als überaus aussichtsreich.

Gleichsam im Gegenzug für Fechters Engagement für Volk ohne Raum zeigte sich Grimm trotz erheblicher Arbeitsbelastung zu mehreren Auftragsarbeiten für die DAZ bereit. Für die Weihnachtsnummer der Zeitung verfasste er 1928 etwa einen Beitrag zu der Umfrage „Wie lange soll das Versailler Diktat noch gelten?“ Grimm, dem die inhaltliche Ausrichtung seines Beitrags völlig freigestellt wurde, wiederholte in ihm jene Deutung des Vertragswerks, die den Lesern von Volk ohne Raum bereits bekannt sein musste: Der Versailler Vertrag sei ein welthistorisch beispielloses Unrecht, dessen „ungeheuerliche Folgen“ das deutsche Volk „körperlich, geistig und seelisch verzwingen [sic!] “ müsse; würden die Vertragsbedingungen nicht zügig revidiert, werde Deutschland zu einem „verwesenden Körper“ inmitten Europas, der schließlich die gesamte „Welt verpeste[n]“152 müsse. Nach dem Abdruck seines Artikels erhielt Grimm von Seiten der Redaktion für seinen „leider sehr zutreffend[en] “ Beitrag besonderen Applaus. Im Ganzen fiel das Fazit der DAZ hinsichtlich der Zahl und vor allem Qualität der eingegangenen Beiträge hingegen ausgesprochen ernüchtert aus: „Sowohl der Prozentsatz der Teilnehmer [...] als auch manche der Antworten“ hätten „von neuem die bedauerliche Tat-

149 Vgl. den Exkurs zu Volk ohne Raum im Anschluss an Kap. 2.2.1.

150 Zitiert nach Gümbel, Volk, S. 132, Anm. 290.

151 Fechter, Dichtung, S. 35f.

152 Grimm, Diktat [1928], S. 76. 
sache“ offenbart, „wie gering politischer Sinn und politisches Verständnis“153 unter Deutschlands Intellektuellen sei.

Von Grimms enger Freundschaft mit Fechter darf indes nicht pauschal auf Grimms Verhältnis zur DAZ insgesamt geschlossen werden. An dem Feuilleton der Zeitung hatte der Dichter zwar - soweit bekannt - nichts auszusetzen, deren Haltung zur Tages- und Parteipolitik stand jedoch auf einem anderen Blatt. Als die Zeitung 1930 eine Haltung zu den ersten fulminanten Wahlerfolgen der NSDAP einnahm, die Grimm als zu reserviert und nicht hinreichend affirmativ empfand, setzte eine Entfremdung zur DAZ ein. Im Dezember 1930 kündigte Grimm sogar sein Abonnement der Zeitung, mit dem expliziten Hinweis, dass er „mit der politischen Haltung der DAZ nicht mehr überein[stimme]“. Fortan wollte Grimm „eine mehr rechts stehende Zeitung von den großen Zeitungen lesen“; seine Wahl fiel letztendlich auf das Scherl-Blatt Der Tag. ${ }^{154}$

Innerhalb der DAZ registrierte nicht nur Fechter die Entscheidung Grimms mit großem Bedauern. Den seit 1925 amtierenden Chefredakteur der DAZ Fritz Klein, unter dem die Zeitung einen „entschiedenen Rechtskurs"155 verfolgte, stimmte es einer Darstellung Fechters vom März 1931 zufolge „sehr traurig“, als er einen im Konkurrenzblatt Der Tag publizierten Artikel Grimms zu Gesicht bekam. Als Fechter seinem Chef die Gründe des Dichters auseinanderzusetzen versuchte, sei Klein nur „noch trauriger“156 geworden. Das Mischungsverhältnis von Dichtung und Wahrheit in dieser tränenreichen Anekdote mag dahingestellt bleiben; außer Zweifel steht jedoch, dass sich Fechter und Klein in der Folgezeit intensiv darum bemühten, den berühmten Romancier zurück in die Arme der DAZ $\mathrm{zu}$ lotsen. In diesen Kontext ist auch die eingangs dieses Kapitels zitierte Aussage Fechters zu stellen, Grimm könne, wenn er sich zu einem beliebigen, ihm freistehenden Thema äußern wolle, „immer“ mit der Zeitung „rechnen“. Die Bemerkung, dass sich „gelegentlich vor dem Druck kleine Unterhaltungen mit Ihnen ergeben könn[t]en"157, relativiert nicht den unbedingten Willen der Redaktion, Grimm erneut als Mitarbeiter zu gewinnen.

Solche Rahmenbedingungen brachten für Grimm attraktive Vorzüge mit sich: Fechter und Klein verfuhren etwa betont vorsichtig, wenn es um die Kürzung oder Überarbeitung eingereichter Manuskripte ging - ein zwischen Autoren und Redaktionen stets heikles, konfliktträchtiges Thema. Fechter bot sich darüber hinaus als Lektor auch jener Manuskripte Grimms an, die nicht in der DAZ veröffentlicht wurden, so etwa bei der Veröffentlichung der Broschüre Von der bürger-

153 DLA, A:Grimm, Deutsche Allgemeine Zeitung an Hans Grimm, 10. Dezember 1928 und 5. Januar 1929. Im Juli 1929 veröffentlichte die DAZ einen Aufsatz Grimms zur Lage in Südwest-Afrika, wobei der etwas verspätete Abdruck damit begründet und entschuldigt wurde, dass der Aufsatz „als Leitartikel unserer in erhöhter Auflage erscheinenden Sonntagsnummer eine besonders große Wirkung ausüben“ könne. Vgl. DLA, A:Grimm, Deutsche Allgemeine Zeitung an Hans Grimm, 27. Juli 1929.

154 Vgl. DLA, A:Grimm, Hans Grimm an Deutsche Allgemeine Zeitung, 14. Dezember 1930.

155 Fischer, Zeitung, S. 278.

156 DLA, A:Grimm, Deutsche Allgemeine Zeitung an Hans Grimm, 31. März 1931.

157 DLA, A:Grimm, Deutsche Allgemeine Zeitung an Hans Grimm, 6. Juni 1931. 
lichen Ehre und bürgerlichen Notwendigkeit (1932). ${ }^{158}$ Hierbei riet Fechter Grimm unter anderem dazu, die Bezeichnung des russischen Volks als „Sklavenvolk“ zu überdenken. Fechter widersprach dem Dichter zwar nicht in der Sache, dem slawophoben Verdikt stimmte er persönlich vielmehr zu, sorgte sich aber um die dem Text zu wünschende „stärkste mögliche Wirkungskraft“159. Der Begriff „Sklavenvolk“, so befürchtete Fechter, könne in Teilen des Publikums kontraproduktiv wirken. Grimm entsprach schließlich dem Vorschlag Fechters und strich den Begriff aus dem Manuskript.

Die großen Freiheiten, die sich Grimm gegenüber der DAZ erlauben konnte, zeigten sich bereits unmittelbar nach der Kündigung seines Abonnements, als er dem Feuilleton anbot, eine neue Kurzgeschichte zu einem Honorar von einer Mark pro Zeile in der DAZ zu veröffentlichen ${ }^{160}$ - ein Angebot, das die Zeitung unverzüglich annahm. In sein nächstes Schreiben streute Grimm dann en passant die Information ein, dass die Kurzgeschichte deutlich länger ausfallen werde als ursprünglich angekündigt: Statt 180-200 waren es nun 300-350 Zeilen. Die erhebliche Steigerung des Umfang und damit auch des Honorars im Bereich von 50 bis 90 Prozent ergänzte Grimm lapidar mit der Information, eine nachträgliche Kürzung des Texts sei ausgeschlossen. ${ }^{161}$ Nachdem eine Korrektur und Anpassung des Zeilenhonorars ebenfalls nicht zur Debatte stand, blieben für die Zeitung nur zwei Optionen: Entweder die von Grimm beiläufig kommunizierte Änderung klaglos zu akzeptieren oder aber auf der ursprünglichen Abmachung zu beharren, damit aber Gefahr zu laufen, Grimm abermals und womöglich endgültig vor den Kopf zu stoßen. Die Redaktion bevorzugte letztlich die erste Option. Grimm dankte es der DAZ in der Folgezeit mit weiteren Beiträgen: Im April 1931 verfasste er eine Auftragsarbeit mit dem Titel Wann wird es endlich besser? ${ }^{\text {162 }}$, im Juli desselben Jahres gab er den neu verfassten Artikel Afrika und England am Schreibtisch als Erstveröffentlichung an die DAZ.

Von besonderem Interesse für das Verhältnis zwischen Grimm und der DAZ ist ein im Herbst 1931 erschienener Artikel, in dem Grimm Ernst Krieck ${ }^{163}$ vertei-

158 Vgl. zu dieser Broschüre Kap. 5.2.2.

159 DLA, A:Grimm, Deutsche Allgemeine Zeitung an Hans Grimm, 21. Januar 1932.

160 Vgl. DLA, A:Grimm, Hans Grimm an Deutsche Allgemeine Zeitung, 16. Dezember 1930. Bei der Kurzgeschichte handelte es sich um Der Hottentott und der Schakal.

161 Vgl. DLA, A:Grimm, Hans Grimm an Deutsche Allgemeine Zeitung, 18. Dezember 1930.

162 Vgl. Grimm, Wann [1931], S. 80f. Die Frage, was besser werden solle, beantwortete Grimm wie folgt: „Besser werden soll, daß unsere Osterjugend nicht von Jahr zu Jahr zunehmend die Wege ihrer Begabung verrammelt findet, besser werden soll, daß die Tüchtigsten und Kräftigsten eines adeligen Volkes nicht länger verquält, mißbraucht und verbogen werden, sondern in der Welt zu ihren Gottesreich kommen, besser werden soll, daß Leistung vor Anmaßung gilt unter Menschen und Völkern“ (ebd., S. 80).

163 Ernst Krieck (1882-1947) war nach seiner Ausbildung am Lehrerseminar Karlsruhe bis 1924 im Volksschuldienst tätig, ehe er sich mit seiner Studie Philosophie der Erziehung (1924) als Schriftsteller etablierte. 1928 wurde Krieck zum Professor der Pädagogik an der Pädagogischen Akademie in Frankfurt am Main ernannt. 1932 trat er der NSDAP bei, 1934 der SS. Von 1934 bis 1945 lehrte Krieck als Ordinarius Philosophie und Pädagogik an der Universität Heidelberg. Krieck begründete 1933 die Zeitschrift Volk im Werden und gab seit 
digte, der am 1.Oktober 1931 von der Pädagogischen Akademie Frankfurt am Main an die Pädagogische Akademie Dortmund strafversetzt worden war. Die Hintergründe dieser Maßnahme sind bekannt: Krieck hatte Ende Juni 1931 vor Frankfurter Studenten seine sogenannte Rede am Feuer gehalten, die mit dem Ruf schloss: „Heil der deutschen Jugend, Heil dem deutschen Volk, Heil dem dritten Reich!“"164 Informiert über diesen Vorfall, reichte die „sozialdemokratische und jüdische Frankfurter Landtagsabgeordnete Jourdan " 165 offiziell Beschwerde gegen Krieck ein. Infolgedessen sah sich der damalige preußische Minister für Wissenschaft, Kunst und Volksbildung, Adolf Grimme, zu einer Strafversetzung Kriecks veranlasst, die er am 7. August 1931 verfügte. ${ }^{166} \mathrm{Zu}$ seinem Protest gegen die Behandlung Kriecks fühlte sich Grimm nicht nur aufgrund seiner bis 1927 zurückreichenden, freundschaftlichen Beziehung mit Krieck veranlasst. ${ }^{167}$ In seine Entscheidung dürfte auch hineingespielt haben, dass er in der „Rede am Feuer" als jener Dichter der Gegenwart namentlich erwähnt worden war, der am eindringlichsten „deutsches Schicksal, deutsche Not, deutschen Drang in die Ferne ins Schaubild erhoben " 168 habe. Diese Deutung entsprach ganz einem im September 1931 im Deutschen Volkstum veröffentlichten Aufsatz, in dem der Frankfurter Pädagoge Grimm sogar zur Referenz für die Beantwortung der Frage erkoren hatte, was der Wesenskern völkischer Weltanschauung sei. ${ }^{169}$

In seinem mit „Politische Dolmetscher" betitelten Kommentar zur Strafversetzung Kriecks nahm Grimm primär die jüdische Landtagsabgeordnete Jourdan ins Visier, die gegen die „Rede am Feuer“ protestiert hatte. Immer häufiger, so Grimm, müsse man in Deutschland die Beobachtung machen, wie „die staatlich erlaubte Deutschheit eines Deutschen“ und die „Art seines Volksgefühls [...] von Leuten beurteilt" werde, die an sich „wohl [...] fleißige Arbeit leisten“ und ihre

1936 die Schriftenreihe Weltanschauung und Wissenschaft heraus. Nach öffentlichen Angriffen trat er 1938 aus der SS aus. Nach Kriegsende wurde Krieck im Internierungslager Moosburg inhaftiert, wo er am 19. März 1947 starb.

164 Krieck, Rede, S. 678f. Zuvor war die Rede bereits in der Zeitschrift Bündische Welt. Blätter deutscher Sammlung publiziert worden. Laut Gerhard Müller erschien Kriecks Rede zudem in einigen anderen „bündischen und nationalrevolutionären Blättern“ (Müller, Krieck, S. 481).

165 Müller, Krieck, S. 89.

166 Für eine apologetisch angehauchte, an Sachinformationen aber erschöpfende Zusammenfassung der Hintergründe und Folgewirkungen der Strafversetzung Kriecks siehe: Ebd., S. 8694.

167 Der Erstkontakt war von Krieck ausgegangen und basierte, wie bei so vielen anderen, auf einer restlosen Begeisterung des aufstrebenden Pädagogen für Volk ohne Raum. Vgl. DLA, A:Grimm, Ernst Krieck an Hans Grimm, 14. und 25. Januar 1927.

168 Krieck, Rede, S. 678.

169 Vgl. ders., Nationalerziehung, S. 616: „Was ist das, die völkische Weltanschauung? Als Hans Grimm in seinem Buch vom deutschen Schicksal, in ,Volk ohne Raum, dem neuen, dem sozialen Nationalbewußtsein die Geburtsgeschichte deutete, hat er zugleich die Grundlinien der deutschen Weltanschauung gezeichnet. [...] Das heißt deutsche Weltanschauung, daß wir durchdrungen und ausgerichtet werden von dem Erkennen: Jeder Einzelne von uns kommt her aus dem Schoße des Volkes, jeder ist in seinem Werben bestimmt vom völkischen Gehalt und Charakter, jeder zehrt von der Substanz des Volkes“. 
„Staatsbürgerpflicht erfüllen“ würden, die jedoch eine „deutsche Seele garnicht haben“170 könnten. Eine solche „Seele“ aber sei notwendig zu einer angemessenen Einschätzung einer Rede wie jener Kricks. Künftig müsse daher die zwischen deutschen Volksgenossen zur Gewohnheit gewordene „politische Dolmetschertätigkeit" durch fremde (gemeint: jüdische) „Mittelsleute“ mit ihrem „ausgesprochene[n] ,Antigermanismus“" unterbunden werden. Allzu leicht und unbedacht schenke der Deutsche aufgrund seiner „empfindlichen und gefährlich mißverstehenden Seele“ jenen Mittelsleuten Glauben. Zwar zeigte Grimm Verständnis für die „Abwehr gegenüber einem vermuteten Antisemitismus der Dummheit und Brutalität“ von Seiten der jüdischen „Mittelsleute“. Zugleich verdächtigte er diese jedoch, einen „blinden Haß“ gegenüber der „erwachsenen Seele“ der Deutschen zu empfinden, welche naturgemäß „anders “ sei als ihre eigene. ${ }^{171}$

Gegenüber der DAZ kündigte Grimm seinen Artikel selbstbewusst mit den Worten an, alles, was er „zu sagen habe“, könne „unbedingt“, also bedenkenlos veröffentlicht werden. Die Affäre um Krieck kommentiere er bewusst vom Standpunkt eines unparteilichen „nationalen Mannes“172 aus. Paul Fechter hatte sich zuvor in Abstimmung mit Fritz Klein auf Grimms Nachfrage stark interessiert am Abdruck des Artikels gezeigt und auch gegen eine gleichzeitige Veröffentlichung in der Zeitschrift Der Ring keine Bedenken erhoben. ${ }^{173}$ Nach der Lektüre des Manuskripts kamen jedoch Bedenken auf: Etwas kleinlaut teilte Fechter nach einem Gespräch mit Klein mit, dass man den Aufsatz zwar „furchtbar gern bringen“ wolle, dass Grimms "harte[r] Satz von den Leuten , die nur eben eine deutsche Seele gar nicht haben können“"174 aber für Bedenken sorge. Abermals störte sich Fechter jedoch nicht an der ideologischen Implikation der Aussage Grimms, vielmehr hielt er sie „natürlich“ für sachlich „richtig“. Fechters Bedenken zielten stattdessen erneut auf jene Leser der DAZ, „die versuchen, bei uns mit einer anständigen nationalen Haltung mitzumachen“. Der fragliche Satz würde sie aber voraussichtlich „generell zurück[stoßen]“ und damit „etwas anrichten [...], das wir aus mancherlei Gründen lieber vermeiden möchten “175. Fechter stimmte der antisemitischen Auffassung Grimms also zu, scheute sich aber, dies durch einen ungekürzten Abdruck des Aufsatzes auch öffentlich zu vertreten.

Auf die Bitte nach einer Umformulierung des fraglichen Satzes gab sich Grimm verwundert: „Wenn ein Jude von mir schriebe, daß ich eine jüdische Seele gar nicht haben könne, so fände ich das richtig und jeder andere Mensch fände es richtig"176. Dennoch zeigte er sich kooperativ und brachte Vorschläge zur Um-

170 Grimm, Dolmetscher [1931], S. 12.

171 Ebd., S. 13.

172 DLA, A:Grimm, Hans Grimm an Deutsche Allgemeine Zeitung, 20. August 1931.

173 Vgl. DLA, A:Grimm, Deutsche Allgemeine Zeitung an Hans Grimm, 6. August 1931.

174 DLA, A:Grimm, Deutsche Allgemeine Zeitung an Hans Grimm, 29. August 1931.

175 Ebd.

176 DLA, A:Grimm, Hans Grimm an Deutsche Allgemeine Zeitung, 31. August 1931. 
formulierung. ${ }^{177}$ Als er nach diesem Schreiben für sechs Wochen ohne Antwort blieb, reagierte Grimm jedoch verärgert. Würde nicht sein Freund Fechter bei der Zeitung arbeiten, so seine Mitteilung vom 13. Oktober 1931, hätte er seinen Artikel längst andernorts veröffentlicht, unter dem Titel: „Was die DAZ nicht zu bringen wagt "178. Auf dieses Schreiben reagierte Fritz Klein unverzüglich, entschuldigte sich für die Verzögerung und versicherte, den Beitrag nach Grimms „liebenswürdigem Abänderungsvorschlag" ${ }^{179}$ sogleich zu veröffentlichen. Die Publikation erfolgte im Sonntagsblatt vom 18. Oktober. Im Ring erschien der Artikel hingegen im Originalwortlaut.

Krieck selbst dürfte es indes kaum gestört haben, dass Grimms Artikel in der DAZ erst verspätet und mit abgestumpfter antisemitischer Spitze erschien. Mit dem Schicksal der Strafversetzung konnte der Pädagoge jedenfalls gut leben. Aufgrund der disziplinarischen Maßnahme war die Aufmerksamkeit, die er und seine „Rede am Feuer" gefunden hatten, auf ein Vielfaches dessen angewachsen, was andernfalls an Resonanz zu erwarten gewesen wäre. Zugleich gefiel sich Krieck in der gut vermarktbaren Rolle des völkischen Märtyrers. Dass ihm die Affäre zu einem nur umso größeren Erfolg als Autor verhelfen würde, hatte er bereits im Herbst 1931 klar erkannt: „Die ganze Geschichte hat meinen Arbeiten zu einem vielleicht durchschlagenden Erfolg verholfen. Und ich habe zuletzt allen Grund dafür, dankbar zu sein" ${ }^{180}$. Wie seine spätere Karriere als NS-Hofpädagoge erweist ${ }^{181}$, lag Krieck mit dieser Diagnose nicht falsch.

\subsubsection{Hans Grimm als „Auslandsexperte"}

Die große Mehrzahl der nicht enden wollenden Anfragen, die Grimm seit Mitte der 1920er Jahre von Seiten deutscher Zeitungs- und Zeitschriftenredaktionen erreichten, zielten auf literarische Beiträge. Immer wieder wurde jedoch auch der Wunsch geäußert, Grimm möge sich zu den Themenfeldern „Kolonialwesen“ und „Auslandsdeutschtum“182 äußern. Das Spektrum der Zeitungen und Zeitschriften reichte hier von gewichtigen, auflagestarken und einflussreichen Organen wie den Süddeutschen Monatsheften ${ }^{183}$, die im September 1929 wegen eines Beitrags über „die koloniale Schuldlüge“184 bei Grimm vorstellig wurden, über

177 Vgl. ebd.: Grimms Gegenvorschlag zur beanstandeten Formulierung lauteten: Entweder „... die nur eben - Gott weiß warum - meinen, sich zur deutschen Seele feindlich stellen zu müssen“ oder „... die nur eben - Gott weiß warum - tun, als ob sie sich zur deutschen Seele feindlich stellen müssten“.

178 Vgl. DLA, A:Grimm, Hans Grimm an Deutsche Allgemeine Zeitung, 13. Oktober 1931.

179 DLA, A:Grimm, Deutsche Allgemeine Zeitung an Hans Grimm, 17. Oktober 1931.

180 DLA, A:Grimm, Ernst Krieck an Hans Grimm, 18. Oktober 1931.

181 Vgl. hierzu: Hojer, Nationalsozialismus.

182 Zur Virulenz dieses Themas nach 1918 vgl. Oberkrome, Geschichte.

183 Zum Profil dieser Zeitschrift, die während der Weimarer Republik besonders durch die Verbreitung der Dolchstoßlegende bekannt wurde, vgl. Flemming, „Gegen die intellektualistische Zersetzung der alten moralischen Werte“; Kraus, Kulturkonservatismus.

184 DLA, A:Grimm, Süddeutsche Monatshefte an Hans Grimm, 2. September 1929. 
regional einschlägige Zeitungen wie den Hannoverschen Kurier ${ }^{185}$ bis hin zu randständigen Journalen wie der Zeitschrift Völkische Kultur ${ }^{186}$, die im Winter 1932/33 gegründet wurde, jedoch schon 1936 wieder eingehen sollte.

Grimm kam hierbei entscheidend zugute, dass er vor dem Ersten Weltkrieg selbst für zehn Jahre in Südafrika gelebt hatte, zunächst als Handelsangestellter, schließlich als selbstständiger Kaufmann und Landwirt in der britischen Kapkolonie. ${ }^{187}$ Durch diesen biografischen Erfahrungshintergrund schien er bereits in der „Person des Sprechers [...] für die Authentizität des Gesagten“188 bürgen zu können. Insofern steckte durchaus Methode hinter Grimms notorischer Neigung, seine Artikel zum Kolonialismus und „Auslandsdeutschtum“ mit detaillierten Informationen zu seinem eigenen Werdegang zu spicken ${ }^{189}$; Primärerfahrung sollte hier Expertentum suggerieren und belegen. Die Erfolgswahrscheinlichkeit dieses rhetorischen Manövers war umso größer, als kaum ein Leser (und kaum ein Redakteur) mit eigenen, vergleichbaren Auslandserfahrungen aufwarten konnte, die als Korrektiv und Vergleichsmaßstab zu Grimms Ausführungen hätten dienen können. Hinzu kam, dass Grimms Anspruch, insbesondere mit Volk ohne Raum weniger ein fiktionales literarisches Produkt als ein historisch authentisches Dokument verfasst zu haben, von bedeutenden und vielgelesenen Kritikern akzeptiert und weitergetragen wurde - wie bereits am Beispiel Paul Fechters gezeigt. ${ }^{190}$ Die Grenzen zwischen Realität und Fiktionalität wurden so zunehmend unkenntlich.

Schon der gemeinhin der „Inneren Emigration“ zugerechnete Schriftsteller Werner Bergengruen ${ }^{191}$ hat in seinen privaten Aufzeichnungen darauf hingewiesen, dass Grimm aufgrund seiner Biografie und der thematischen Ausrichtung seiner Werke gerade unter „Sudetendeutschen als Autorität“ und „authentischer Eingeweihter" gegolten habe, an den „man sich mit der Bitte um allerhand Aufschlüsse wenden konnte“192. Welche Ausschnitte des vielfältigen Koloniallebens und „Auslandsdeutschtums“ hatte Grimm aber tatsächlich aus erster Hand erlebt und erfahren? Welche Veränderung hatten die Kolonien seit seiner Umsiedlung

185 Anlässlich einer bevorstehenden Tagung des Vereins für das Deutschtum im Ausland in Münden plante der Hannoversche Kurier die Veröffentlichung einer „Sondernummer“, für die Grimms Mitarbeit gewünscht wurde. Ende Mai 1924 skizzierte der Feuilletonleiter der Zeitung, Eberhard Sarter, seine Vorstellungen folgendermaßen: „Ich denke etwa an einen Aufsatz über den Typus des Kolonialdeutschen oder an einen Aufsatz über den deutschen Siedler im Auslande oder etwa speziell über den Deutschen, der im Auslande reist" (DLA, A:Grimm, Hannoverscher Kurier an Hans Grimm, 31. Mai 1924, Herv. i. Orig.).

186 Vgl. DLA, A:Grimm, Völkische Kultur an Hans Grimm, 27. Januar 1933.

187 Vgl. Kap. 2.1.

188 Jäger, Schriftsteller, S. 9.

189 Vgl. exemplarisch: Grimm, Übervölkerung, S. 329-333.

190 Vgl. Kap. 3.1.3.

191 Zur literaturhistorischen Ordnungskategorie „Innere Emigration“ vgl. Zimmermann, „Innere Emigration“; die Zugehörigkeit Bergengruens (1892-1964) zur „Inneren Emigration“, für die unter anderem Hackelsberger, Wort, argumentiert, ist unlängst in Zweifel gezogen worden, vgl. Bergmann, Bergengruen.

192 Bergengruen, Schriftstellerexistenz, S. 158. 
von der Kapkolonie nach Deutschland im Jahr 1910 durchlebt - vor allem infolge des Ersten Weltkriegs? Und nicht zuletzt: Welche politisch-ideologische Agenda verfolgte Grimm in seinen Texten? Diese naheliegenden Fragen wurden nicht thematisiert.

Am Beispiel des Berliner Lokal-Anzeigers, des auflagenstärksten Blatts des deutschnationalen Scherl-Verlags ${ }^{193}$, soll im Folgenden zunächst geschildert werden, zu welch attraktiven Möglichkeiten politischer Publizistik Grimm das ihm zugesprochene Expertentum verhalf. Anschließend wird illustriert, wie die fiktionalen literarischen Texte Grimms über das Kolonialwesen mitunter als empirisch belastbares Quellenmaterial betrachtet und behandelt wurden. Bewusst wird dabei mit dem Stuttgarter Mathematikdozenten Hasso Härlen ein Beispiel außerhalb des engeren Kreises der Freunde und Vertrauten Grimms herausgegriffen. ${ }^{194}$

Hans Grimm und der Berliner Lokal-Anzeiger - Anlass dazu, Artikel Grimms über koloniale Fragen und über das „Auslandsdeutschtum“ einzuwerben, bot für zahlreiche Zeitungs- und Zeitschriftenredaktionen also nicht nur der klangvolle Name des Autors, sondern zugleich ein ihm unkritisch zugeschriebenes, generelles Expertenwissen. Schon aus arbeitsökonomischen Gründen erteilte der Dichter freilich einer Vielzahl der an ihn heranflutenden Anfragen eine Absage. Immer wieder verstanden es Redakteure jedoch, Grimms Aufmerksamkeit und Interesse zu wecken. So auch der Berliner Lokal-Anzeiger, dem es im September 1928 gelang, Grimm zum Verfassen eines Leitartikels zu bewegen. ${ }^{195}$ Anlass der Anfrage war der damals unmittelbar bevorstehende Deutschlandbesuch des amtierenden Administrators des britisch verwalteten Mandatsgebiets Südwestafrika, der ehemaligen Kolonie Deutsch-Südwestafrika, Albertus Johannes Werth. Die Anfrage an Grimm stellte der damalige Chefredakteur des Berliner Lokal-Anzeigers Samuel Breslauer, der später von den Nationalsozialisten in das Konzentrationslager Theresienstadt deportiert werden und dort zu Tode kommen sollte. ${ }^{196}$ Die gewünschte Ausrichtung des für die „Vorderseite unseres Hauptblattes“197 vorgesehenen Artikels wurde von Breslauer schon dadurch unterstrichen, dass der Anfrage ein Aufsatz des bekannten Weimarer Kolonialpropagandisten Oskar Karstedt ${ }^{198}$ bei-

193 Zum Berliner Lokal-Anzeiger vgl. Schilling, Erbe, S. 178-189. Die Geschichte des Scherl-Verlages ist ein bedauerliches Desiderat der Forschung. Die bislang beste Annäherung an die Thematik bietet: Holzbach, System.

194 Schließlich entsprach es Selbstanspruch und -verständnis Grimms, in seinen literarischen Arbeiten ein authentisches Spiegelbild historischer Sachverhalte zu bieten, vgl. den Exkurs zu Volk ohne Raum im Anschluss an Kap. 2.2. Bestätigten Freunde diese Qualität der Werke Grimms, konnte es sich auch lediglich um rücksichtsvolle Lippenbekenntnisse handeln.

195 Der Kontakt zwischen Grimm und dem Berliner Lokal-Anzeiger geht bis auf den Mai 1924 zurück, als die Redaktion erstmals mit Bitten um literarische Beiträge an Grimm herantrat. Vgl. DLA, A:Grimm, Berliner Lokal-Anzeiger an Hans Grimm, 15. Mai 1924.

196 Zum Leben Samuel Breslauers (1870-1942) vgl. die zahlreichen Hinweis in: Hambrock, Etablierung.

197 DLA, A:Grimm, Berliner Lokal-Anzeiger an Hans Grimm, 19. September 1928.

198 Oskar Karstedt (1884-1945) war von 1906 bis 1913 in der Kolonie Deutsch-Ostafrika tätig gewesen. Während der Weimarer Republik und im „Dritten Reich“ arbeitete er hauptberuf- 
lag, begleitet von der „ergebenste[n] Bitte“, Grimm möge „einen Aufsatz ähnlichen Inhalts zur Verfügung"199 stellen.

In seinem Antwortschreiben an Breslauer dankte Grimm zunächst für die Übersendung des Karstedt-Artikels „über das erdrosselte Deutschtum in Südwest-Afrika“. Zugleich bestätigte Grimm, der nach Eigenaussage seit Wochen in „größte[r] Angst vor dem Besuche Werths in Berlin“200 war, sein Interesse, den gewünschten Leitartikel zu verfassen. Wie seiner Ansicht nach schon beim Londoner Abkommen im Jahr 1923201, schien sich dem Dichter in Berlin ein „scheußlicher Unsinn“202 zusammenzubrauen. Als Grimm seinen Artikel schließlich fristgerecht einreichte, bat er jedoch plötzlich um eine anonyme Veröffentlichung. Als Grund gab er an, dass Werth, der eine „ganz minderwertige“ und „sehr eitle Nummer“ sei, in ihm als Verfasser „einen Gegner von Südwest her“ sehen würde, so wie er es bei „jedem Deutschen“ mache, „der den ungeheuren Burenschwindel durchschaut“203 habe. Grimm sah die erhoffte Wirkung des Artikels nun also durch die Erwähnung seines Namens gefährdet.

Für den Berliner Lokal-Anzeiger kam ein Verzicht auf die Nennung Grimms indes nicht infrage - „aus naheliegenden Gründen“204, wie die Redaktion in ihrem Dankesschreiben für die Ablieferung des Aufsatzes lapidar vermerkte. Eine Anonymisierung des Artikels musste den Interessen der Zeitung zuwiderlaufen, die sich nicht zu Unrecht von der Namensnennung Grimms einen erhöhten Absatz der entsprechenden Ausgabe versprach. Ob Grimm die Zurückweisung seiner Bitte verärgerte oder ob er sie mit Verständnis zu Kenntnis nahm, lässt sich aus den Quellen nicht beantworten. Der Kontakt mit der Zeitung brach jedenfalls nicht ab. Bis 1937 trat der Berliner Lokal-Anzeiger noch insgesamt sieben Mal mit Bitten um Beiträge an Grimm heran, wobei er mit zwei Zusagen und fünf arbeits-

lich als Ministerialrat im Reichsarbeitsministerium, wobei er unter anderem für die „Internationale Bekämpfung der Arbeitslosigkeit durch Erschließung überseeischer Gebiete“ (so der Titel einer 1931 veröffentlichten Broschüre) argumentierte. Vielfach trat er nach 1918 publizistisch zu Kolonialfragen hervor. Biografische Informationen zu Karstedt in: Schwoch, Standespolitik, S. 365.

199 DLA, A:Grimm, Berliner Lokal-Anzeiger an Hans Grimm, 19. September 1928.

200 DLA, A:Grimm, Hans Grimm an Berliner Lokal-Anzeiger, 23. September 1928.

201 Während sich Deutschland in dem am 23. Oktober 1923 mit der Südafrikanischen Union abgeschlossenen Abkommen bereiterklärte, den Deutschen in Südwestafrika zu einer Kollektiveinbürgerung zu raten, räumte die Union den in Südwestafrika verbliebenen deutschen Siedlern unter anderem das Bleiberecht und die Ausstattung mit den vollen Bürgerrechten ein. Für Hintergründe und Details des Abkommens vgl. Eberhardt, Nationalsozialismus, S. 99-116.

202 DLA, A:Grimm, Hans Grimm an Berliner Lokal-Anzeiger, 23. September 1928.

203 DLA, A:Grimm, Hans Grimm an Berliner Lokal-Anzeiger, [?] September 1928. In seinem Artikel warf Grimm den Buren - „die wir als Freunde ansahen, und um deretwillen wir einst [gemeint ist hier der Zweite Burenkrieg] den Vernichtungswillen des englischen Volkes mit auf uns lenkten“ - vor, im Mandatsgebiets Südwestafrika „ohne jegliche innere Notwendigkeit“ zum schlimmsten „Bedrücker unserer Stammesbrüder“ geworden zu sein. Vgl. Grimm, Mandatsland [1928], S. 146.

204 DLA, A:Grimm, Berliner Lokal-Anzeiger an Hans Grimm, 3. Oktober 1928. 
bedingten Absagen Grimms zwar eine mäßige Quote erntete ${ }^{205}$, die jedoch nicht auffällig unter jener anderer Zeitungen lag.

EXPERTISE KRAFT FIKTION - In den Korrespondenzen Grimms finden sich auch Beispiele, in denen sich Privatpersonen in der sicheren Annahme, einen Mann mit hohem, unvoreingenommenen Fachwissen vor sich zu haben, mit Fragen zu Auslands- und Kolonialthemen an den Dichter wandten. Dabei zeigt sich, welch hohe Suggestionskraft gerade die literarischen Arbeiten Grimms besaßen, die immer wieder als authentisches Abbild der jeweils bearbeiteten Gegenstände angesehen und akzeptiert wurden. Dass sich - wie Wolfram Pyta hellsichtig hervorgehoben hat - literarische Texte infolge ihres „Vermögen[s], das ,kulturelle Imaginäre' zu konstituieren und damit auch politisch relevante Ordnungsvorstellungen zu formen und zu vermitteln“ durch eine „besondere Fähigkeit zur Welterzeugung"206 auszeichnen können, lässt sich am Beispiel Grimms anschaulich bestätigen. Das Phänomen des Verdrängens „der Wahrheit (im Sinne wissenschaftlich überprüfbarer Richtigkeit)“ durch „die Form der ,moralischen Beglaubigung“"207 eines Schriftstellers kommt bei Grimm in eklatanter Weise zur Geltung. Dass dabei jedoch nicht immer Volk ohne Raum die Basis einer entsprechenden Vermengung von Realität und Fiktionalität bildete, zeigt das Beispiel des an der Technischen Hochschule Stuttgart arbeitenden, jungen Mathematikdozenten Hasso Härlen. ${ }^{208}$

Laut Eigenaussage vom Juni 1928 griff Härlen auf das während des Ersten Weltkriegs im Auftrag der Obersten Heeresleitung verfasste Werk Der Ölsucher von Duala ${ }^{209}$ zurück, um „verschiedentlich in Diskussionen“, insbesondere mit „Paneuropäern“, seinen „Standpunkt zu dokumentieren, dass die deutsche und die französische Wesensart [...] unvereinbar" 210 seien. Zwar versicherte Härlen, keiner „einfache[n] Antipathie“ das Wort sprechen zu wollen - als Mathematiker

205 Im August 1931 gab Grimm die Zusage, sich an einer Umfrage an mehrere Autoren zu beteiligen, welches „Zeiterlebnis“ für ihr jeweiliges „künstlerisches Schaffen entscheidend gewesen" sei (vgl. DLA, A:Grimm, Berliner Lokal-Anzeiger an Hans Grimm, 22. August 1931). Dass Grimm gegenüber der Redaktion des Berliner Lokal-Anzeigers dabei nicht viele Rücksichten nahm zeigt sich daran, dass er zunächst selbstbewusst sein Honorar selbst bestimmte (1 Mark pro Zeile, vgl. DLA, A:Grimm, Hans Grimm an Berliner Lokal-Anzeiger, 23. August 1931) und anschließend seine Geschäftstüchtigkeit dadurch unter Beweis stellte, dass er einen erheblich längeren Artikel abgab als von der Redaktion gewünscht worden war. Wie in fast allen Fällen wies er auch hier die Bitte um Kürzung zurück (vgl. DLA, A:Grimm, Hans Grimm an Berliner Lokal-Anzeiger, 26. September 1931) - sehr zum Ärger der Redaktion, die sich beklagte, bei Grimm „so wenig Verständnis für die doch wohl selbstverständlichen Ansprüche einer Redaktion gefunden zu haben". Auf diese Weise sah sie sich gezwungen, Grimms Beitrag „bei späterer Gelegenheit als selbstständigen Artikel zu bringen“ (DLA, A:Grimm, Berliner Lokal-Anzeiger an Hans Grimm, 3. Oktober 1931). Wann Grimms Beitrag letztendlich publiziert worden ist wurde nicht recherchiert.

206 Pyta, Weltkrieg, S. $14 \mathrm{f}$.

207 Jäger, Schriftsteller, S. 9.

208 Knappe biografische Informationen zu Härlen (1903-1989) in: Pierzchała, Fängen, S. 317.

209 Vgl. Kap. 2.1.

210 DLA, A:Grimm, Hasso Härlen an Hans Grimm, 17. Juni 1928. 
hatte er vielmehr „Hochachtung vor dem französischen Geiste“. Dies durfte in den Augen Härlens jedoch „nicht darüber hinwegtäuschen“, dass „zwischen deutsche $[\mathrm{m}]$ und französische[m] Geiste“ eine „ausgesprochene Feindschaft“ bestand. Um diese Deutung zu untermauern, hatte Härlen in seinen Diskussionen auf jene „Tatsachen“ verwiesen, wie er sie in Grimms Der Ölsucher von Duala vorgefunden hatte. Vor allem meinte Härlen die in dem Roman „geschilderten Greuel“ gegen Deutsche durch den „schwarzen Bruder““ der Franzosen. Ihnen warf Härlen vor, jedes natürliche „Abstandsgefühl“ gegen die koloniale Bevölkerung ,verloren“211 zu haben.

Nach der Kalkulation des jungen Mathematikers konnte demnach ein inmitten des Weltkriegs verfasster Propagandaroman, der gezielt die Misshandlung deutscher Kolonisten durch Truppen einer erbittert bekämpften feindlichen Militärmacht schilderte und schildern sollte, als verlässliches Quellenmaterial und solide Basis einer politischen Anschauung gelten. Von Ferne scheint Härlen indes die hierin zum Ausdruck kommende, geradezu abenteuerliche Kritiklosigkeit gedämmert zu haben. Seine „paneuropäisch“ gesinnten Diskussionsgegner wies er jedenfalls vorsichtshalber nicht darauf hin, dass er seine Argumente einem Roman entliehen hatte. Härlen führte hierfür zwei Gründe an. Der erste unterstreicht zunächst lediglich nochmals die eigene starke emotionale Aufwühlung des Mathematikers durch die Schilderungen Grimms: Das Buch, so Härlen, habe er niemandem empfehlen wollen, von dem er nicht wusste, „ob er es auch vertragen“ 212 könne. Der zweite, stichhaltigere Grund bezeugt hingegen das Bewusstsein, sich durch die Stützung auf Der Ölsucher von Duala in den Augen seiner „Diskussionsgegner" leicht angreifbar zu machen. Ihnen wollte Härlen jedoch keine einfachen Ausflüchte aus der Debatte bieten:

„Ich fürchtete, daß mein jeweiliger Diskussionsgegner sich an die Greuelschilderungen Ihres Buches klammern würde. Ich wollte ihm aber seinen Stand nicht so leicht machen wie den Gegnern des Antisemitismus, die, beflissentlich das Wesentliche übersehend, sich auf den Greuelantisemitismus stützen." 213

Dass sein Name in den Diskussionen Härlens nicht fiel, wird Grimm verschmerzt haben. Entscheidend an dem Briefwechsel ist auch etwas anderes: Sein hoher Aussagewert für die große Suggestionskraft Grimms als Privatperson und Autor. Dabei war Härlen keineswegs ein vollends verrannter Parteigänger der Weimarer Rechten. Im Juni 1931 kam es vielmehr zu deutlichen Meinungsverschiedenheiten mit Grimm, als Härlen die Sozialdemokratie gegen eine in seinen Augen zu scharfe Kritik des Dichters in Schutz nahm. ${ }^{214}$ Umso bemerkenswerter ist die Wirkung der Texte Grimms auf den Mathematikdozenten.

211 Ebd.

212 Ebd.

213 Ebd.

214 Vgl. DLA, A:Grimm, Hasso Härlen an Hans Grimm, 7. und 13. Juni 1931; DLA, A:Grimm, Hans Grimm an Hasso Härlen, 9. Juni 1931. 


\subsubsection{Beflissene Dauerrezensenten: Conrad Wandrey und Helmut Wocke}

CONRAD WANDREY Und ERWIN GUido KolbenheYer - Wie gezeigt, wiederholten Grimm und Kolbenheyer während der Weimarer Republik nimmermüde ihre Überzeugung, Opfer einer sie "totschweigenden“ oder offen anfeindenden Linkspresse einerseits und einer angeblich nicht ausreichend aktiven und dienstbeflissenen Rechtspresse andererseits geworden zu sein. ${ }^{215}$ Bei aller genuinen Empörung, mit der dies geschah, lässt sich diese Praxis auch als Strategie verstehen, wohlwollende Journalisten zu einer umso emphatischeren und unkritischen Werbeaktivität zu animieren. Erfolg hatte Kolbenheyer mit dieser Strategie in den frühen 1920er Jahren insbesondere bei den Publizisten Eugen Kalkschmidt ${ }^{216}$, Hermann Missenharter ${ }^{217}$ und Erwin Ackerknecht ${ }^{218}$. Auch Stapels Verhalten nach Veröffentlichung eines Verrisses gegen Kolbenheyers Roman Das Lächeln der Penaten (1927) in dem „Literaturblatt“ der Frankfurter Zeitung hat gezeigt, wie

215 Vgl. Kap. 3.1.1.

216 Nachdem Kolbenheyer gegenüber Kalkschmidt (1874-1962) in einem Brief vom 9. Januar 1922 en passant erwähnt hatte, dass er sich nur „langsam u[nd] hinter dem Rücken der Presse von Mund zu Mund durchgesetzt" habe, da „die jüdische Presse meine Bücher totschweigt" und er „ohne Pressehilfen" sei (vgl. Literaturarchiv der Monacensia, NL Eugen Kalkschmidt, B 54), schritt Kalkschmidt prompt in Form einer Rezension zur Tat: In der Zeitschrift Oberdeutschland schlug er „Alarm [...] für einen deutschen Poeten, wie wir ihn so wurzelhaft und geistig umfassend unter den Lebenden schwerlich zum zweitenmal besitzen. Wem das zuviel des Guten dünkt, der lasse sich gesagt sein, daß wir in diesen kläglichen Zeiten des Guten gar nicht genug kriegen können, zumal wenn es uns als Geschenk von oben in den Schoß fällt wie hier" (Kalkschmidt, Paracelsus-Roman, S. 311). Die Vorlage zu Kolbenheyers Äußerungen hatte Kalkschmidt durch ein kulturantisemitisches Klagelied über die Lage der deutschen Presse geliefert: „Die jüdische Literatenzunft sitzt jetzt dermaßen auf dem hohen Roß, daß es einfach Pflicht der wenigen noch nicht verjudeten Blätter ist, sich ab und zu mal einen Hauptschreiber herauszuholen und übers Kreuz zu legen. Ich bin kein Hakenkreuzler und habe gescheite Juden gern, wenn sie in ihren Grenzen bleiben und sich nicht anmaßen, Sprecher der deutschen Volksseele zu sein. Jetzt wollen sie nicht nur das, sie wollen uns auch politisch regieren und das wenige, was an nationalem Stolz und nationaler Würde in dem Zusammenbruch noch aufrecht steht, dem Götzen ihrer verwaschenen ,Liberalität" opfern" (KAG, Eugen Kalkschmidt an Erwin Guido Kolbenheyer, 30. Dezember 1921).

217 Missenharter (1886-1962), seit 1919 Mitherausgeber von Der Schwäbische Bund (ab 1921 Oberdeutschland) und wichtiger Förderer Kolbenheyers in Südwestdeutschland (vgl. auch Kolbenheyer, Sebastian Karst, Bd.2, S. 434), zeigte sich sichtlich beeindruckt von den Dienstpflichten als Journalist, wie sie ihm zuvor von Kolbenheyer angezeigt worden waren. Kolbenheyers Brief, so Missenharter, werde ihm „für immer wertvoll bleiben [...]. Ich kann Ihnen nur versprechen, daß ich die Pflichten, die er für mich enthält, wichtig nehmen werde" (KAG, Hermann Missenharter an Erwin Guido Kolbenheyer, 30. Dezember 1921). Für ein Exempel der Unterstützung Missenharters für Kolbenheyer vgl. Missenharter, Dichter: Kolbenheyer repräsentierte und bewahrte demnach „die Würde [...] unserer deutschen Kunst, die unser Heiligstes ist“. Hierzu bedürfe es „eines [...] männlichen Geistes, der das Gemeine des Tages bändigt und unseres Wesens unsterbliches Teil in der Glut seiner Kunst läutert. Das Erscheinen eines solchen Führers ist immer Gnade für ein Volk [...] Wir müssen zu ihm hinan nicht er zu uns herab" (S. 113f.).

218 Zum Verhältnis zwischen Kolbenheyer und Ackerknecht (1880-1960) vgl. Kap. 3.1.2. 
Bewunderer des Dichters durch vereinzelte negative Presse dazu angestachelt werden konnten, zur Ehrenrettung ihres Heroen vermeintlich richtigstellende Lobeshymnen in den Feuilletons zu platzieren. ${ }^{219} \mathrm{Zu}$ den Publizisten, die während der Zwischenkriegszeit eine besonders intensive Werbetätigkeit für Kolbenheyer entfalteten, gehörte auch der Münchner Literaturhistoriker Conrad Wandrey. 220 Dessen Verhältnis zu Kolbenheyer sei exemplarisch herausgestellt.

Der Erstkontakt zwischen Wandrey und Kolbenheyer wurde im Herbst 1926 durch den GMV hergestellt. Wandrey hatte sich zuvor an Kolbenheyers Verlag gewandt und seine Absicht bekundet, Vorträge über die Werke des Dichters halten zu wollen. Die Bewunderung für Kolbenheyer ging der Kontaktaufnahme mit dem GMV weit voraus, sodass es irrig wäre, in dem Münchner Literaturkritiker lediglich einen kühl kalkulierenden Rezensions-Söldner auf dem umkämpften Weimarer Buchmarkt erblicken zu wollen. Kolbenheyer wurde durch den GMV auf das Ansinnen Wandreys aufmerksam gemacht, woraufhin er diesen zu sich nach Tübingen einlud. ${ }^{221}$ Dass der Journalist und Literaturkritiker Wandrey als sehr ernst zu nehmender Multiplikator gelten durfte, ging schon aus seiner Mitteilung vom November 1926 hervor, über einen kurz zuvor von der Literarischen Gesellschaft in Marburg veranstalteten Kolbenheyer-Abend in den Münchner Neuesten Nachrichten, in der Literarischen Welt sowie in der Schweizer Rundschau berichten zu wollen. ${ }^{22}$ Als darüber hinaus auch noch in der Essener Allgemeinen Zeitung ein Artikel Wandreys über Kolbenheyer erschien, zeigte sich dieser hocherfreut über Wandreys Engagement und vertiefte Kenntnisse der Bauhütten-Philosophie. ${ }^{223}$ Überhaupt war Kolbenheyer zufrieden, in Wandrey einen neuen, schlagkräftigen „Mitkämpfer“224 gefunden zu haben.

Die Titulierung als „Mitkämpfer“ sollte sich Wandrey in den Jahren bis zum Beginn des Zweiten Weltkriegs redlich verdienen: Im Zeitraum von 1926 bis 1939 weist die Bibliografie Wandreys nicht weniger als 20 Veröffentlichungen über Kolbenheyer auf. Die Artikel reichten von Rezensionen einzelner Werke 225 über Versuche einer Popularisierung der Bauhütten-Philosophie ${ }^{226}$ bis hin zu einem mehrfach wiederabgedruckten „Bekenntnis zu Kolbenheyer“, das anlässlich des 50. Geburtstags des Dichters erschien. In ihm unternahm Wandrey eine Gesamt-

219 Vgl. Kap. 2.3.1.

220 Zur Biografie Wandreys (1887-1947) vgl. die zahlreichen Hinweise in: Heißerer, Literaturpolitik.

221 Vgl. KAG, Erwin Guido Kolbenheyer an Conrad Wandrey, 21. September 1926 (Durchschlag).

222 KAG, Conrad Wandrey an Erwin Guido Kolbenheyer, 12. November 1926.

223 Vgl. Kap. 3.3.

224 KAG, Erwin Guido Kolbenheyer an Conrad Wandrey, 19. November 1926 (Durchschlag).

225 Vgl. exemplarisch Wandreys Besprechung von Das Lächeln der Penaten in: Deutsche Rundschau 210 (1927), S. $102 \mathrm{f}$.

226 Vgl. Wandrey, Kolbenheyer [1927]. In dem Artikel schloss Wandrey mit dem Fazit, dass Kolbenheyer in beispielhafter Weise für die „Fruchtbarmachung naturwissenschaftlicher Erkenntnis auf der kulturwissenschaftlichen Ebene“ und den „Einbruch biologisch-intuitiven Denkens ins Reich der dichterischen Gestaltung" stehe. Siehe auch: Wandrey, Kulturbesinnung. 
würdigung des literarischen und philosophischen Schaffens seines Dichterheroen. ${ }^{227}$ Den unumstrittenen Höhepunkt des Engagements Wandreys stellt indes die in den Jahren 1930-1933 verfasste, 1934 erschienene Monografie Kolbenheyer. Der Dichter und der Philosoph dar.

Darüber hinaus trat Wandrey mit Vorträgen über Kolbenheyer hervor: Schon im Dezember 1927 bestritt er eine halbstündige Sendung über Kolbenheyer in der Berliner Funkstunde, die aus einem zehnminütigem Vortrag und einer zwanzigminütigen Lesung aus Werken des Dichters bestand. Kolbenheyer ließ Wandrey dabei freie Hand in der Textauswahl, was das große Vertrauen anschaulich unterstreicht, das Wandrey damals bei dem gegenüber Journalisten ansonsten notorisch argwöhnischen Kolbenheyer genoss: „Seien Sie bestens ersucht, die Rundfunkvorlesung nach Ihrer eigenen Meinung auszuwählen - die Berliner Radiopsyche ist mir gänzlich fremd." 228 Im Nachhinein zeigte sich Wandrey mit dem Verlauf der Sendung zufrieden. Unter den „620000 Abonnenten“ des „Berliner Funk $[s]$ “ werde gewiss „da und dort jemand" für die Inhalte empfänglich gewesen sein, „sodass das Ganze nicht umsonst war“. Wandrey versicherte Kolbenheyer: „Es macht mir immer Freude, etwas für Ihre Bücher tun zu können, da es wirklich aus innerer Ueberzeugung geschieht, wie Sie glauben dürfen.“229

Im Februar 1930 informierte Wandrey den Dichter zudem über einen von ihm dozierten „vierstündigen Vortragszyklus“230 zu Kolbenheyers Werken, der in der Münchner Buchhandlung Lehmkuhl stattfand. Hocherfreut über diese „freundliche Nachricht", lobte Kolbenheyer Wandrey als einen der „wenigen Menschen [...], die aus innerstem Interesse mittlerisch und aufklärend für mein Werk tätig“231 seien. Wandrey hielt Kolbenheyer anschließend über den Erfolg des Vortragszyklus auf dem Laufenden, wobei er auch auf die zu erwartenden Verständnisschwierigkeiten des Publikums zu sprechen kam, soweit die biologischphilosophischen Anschauungen des Dichters betroffen waren. ${ }^{232}$ Er ging jedoch scherzhaft mit ihnen um:

„Der hiesige Zyklus lässt sich gut an. Er findet aber in geschlossenem Rahmen statt, sodass es mit Pressenotizen nichts ist. Vier Abende. [...] Zwei Zuhörer zogen mit allen drei Bänden [des Paracelsus] aus der Lehmkuhlschen Buchhandlung ab. Das nächste Mal habe ich den Leuten versprochen, spanisch zu kommen. Es ist nämlich die Bauhütte dran. “233

Trotz dieses energischen Einsatzes schwankte Kolbenheyer in seinem Verhältnis zu Wandrey. Hatte er gegenüber Stapel im Winter 1928/29 noch „etliche innere Vorbehalte“ angemeldet, durch die es ihm unangenehm war, Wandrey „Dank [zu]

227 Vgl. Conrad Wandrey, Bekenntnis zu Kolbenheyer, in: Münchner Neueste Nachrichten, 29. Dezember 1928. Wiederabgedruckt in Tübinger Chronik und Steinlachbote, 29. Dezember 1928, und Deutsche Arbeit. Sudetendeutsche Monatsschrift 28 (1929), S. 129-132.

228 KAG, Erwin Guido Kolbenheyer an Conrad Wandrey, 8. November 1927 (Durchschlag).

229 KAG, Conrad Wandrey an Erwin Guido Kolbenheyer, 1. Februar 1928.

230 KAG, Conrad Wandrey an Erwin Guido Kolbenheyer, 16. Februar 1930.

${ }^{231}$ KAG, Erwin Guido Kolbenheyer an Conrad Wandrey, [?] Februar 1930 (Durchschlag).

232 Vgl. hierzu Kap. 3.3.1.

233 KAG, Conrad Wandrey an Erwin Guido Kolbenheyer, 6. März 1930. 
schulde[n] "234, fiel das Urteil vor dem Hintergrund des Münchner Vortragszyklus ein Jahr später sehr viel wohlwollender aus: „Wandrey ist ein feiner Mensch, hat schon etliche ziemlich eingehende Aufsätze über mich geschrieben. Ich kenne ihn auch persönlich. [...] Viel Hörer hat er nun auch in München mit Kolbenheyer locken können." 235 Auch Wandreys Monografie von 1934 bot für Kolbenheyer Anlass für Lob und Kritik zugleich. Nicht einverstanden war Kolbenheyer besonders mit Wandreys Beschreibung und Wertung seines lyrischen und dramatischen Schaffens. ${ }^{236}$ Bis zum Ende des Zweiten Weltkriegs sollte sich Kolbenheyers Urteil über die Studie Wandreys dann gar zu offener Antipathie wandeln. Peter Dimt, der 1946 im Haus Kolbenheyers lebte und seine Erlebnisse im sogenannten Schlederloher Tagebuch festhielt, bemerkt in einem Eintrag vom 13. März 1946, Kolbenheyer sei Wandreys Arbeit „derart verhasst“, dass der Dichter eine von ihm erbetene Signierung des Buchs abgelehnt habe. ${ }^{237}$ Diese schroffe Ablehnung verwundert umso mehr, als Kolbenheyer während des langwierigen Schreibprozesses von Wandrey mehrfach miteinbezogen worden war und Teile des Manuskripts korrekturgelesen hatte. ${ }^{238}$ Weitere Hintergründe $\mathrm{zu}$ der Entfremdung zwischen Kolbenheyer und Wandrey ließen sich jedoch nicht erheben; nach 1934 kam es lediglich noch im Oktober/November 1938 zu einem Briefwechsel zwischen Kolbenheyer und Wandrey, der aber noch von einer intakten Beziehung zeugt.

Helmut Wocke und Hans Grimm - Ebenso wie Kolbenheyer verfügte auch Grimm über Dauerrezensenten, deren Tätigkeit ursprünglich auf eine Vermittlung seines Verlags zurückging. Angeheuert vom ALV wurde etwa der im niederschlesischen Liegnitz hauptberuflich als Deutsch- und Geschichtslehrer arbeitende Helmut Wocke, der als Musterbeispiel eines bienenfleißigen und ausnahmslos positiv urteilenden Dauerrezensenten gelten darf. Laut Eigenaussage war Wocke kurz nach der Veröffentlichung von Volk ohne Raum erstmals von Reinhold Geheeb, einem Mitglied des vierköpfigen Kuratoriums des ALV ${ }^{239}$, kontaktiert und „auf das Werk hingewiesen“ worden. Wocke verfasste daraufhin „eine kleine Anzeige“, die „mehrmals nachgedruckt“ wurde, und setzte sich auch anschließend „immer wieder für den großen Roman“240 ein, wie er Grimm im September 1928

234 DLA, A:Stapel, Erwin Guido Kolbenheyer an Wilhelm Stapel, 24. Januar 1929.

235 Vgl. DLA, A:Stapel, Erwin Guido Kolbenheyer an Wilhelm Stapel, 8. März 1930.

236 „Ich habe nun Ihr Buch zu Ende gelesen und hoffe, daß Sie den dritten Teil noch einmal einer Revision unterziehen werden. Ich glaube nicht, daß Sie meinen Dramen, und auch nicht, daß Sie meinen Gedichten völlig gerecht werden konnten. Ich glaube aber fest, daß das Buch viel zur Orientierung über mein Werk beitragen wird, und vielleicht ist es für manche Leser, besonders der intelektuellen [sic!] Kreise ganz gut, wenn sie irgend etwas finden, wo sie eine kritische Stellung zu meinem Werk nehmen können“ (KAG, Erwin Guido Kolbenheyer an Conrad Wandrey, 19. Dezember 1933, Durchschlag).

237 Dimt, Tagebuch, S. 30.

238 Vgl. KAG, Conrad Wandrey an Erwin Guido Kolbenheyer, 30. Juni 1931, 26. September 1932 und 1. Juli 1933.

239 Vgl. Meyer, Verlagsfusion, S. 56-59. Zuvor hatte Geheeb seit 1901 für über zwei Jahrzehnte als Hauptredakteur des Simplicissimus gearbeitet.

240 Vgl. DLA, A:Grimm, Helmut Wocke an Hans Grimm, 1. September 1928. 
wissen ließ. 1930 veröffentlichte der ALV außerdem einen Essayband Wockes unter dem Titel Neue Jugend und neue Dichtung, der unter anderem einen ausführlichen Aufsatz über Grimm enthielt. Diesen Aufsatz schloss Wocke nach einer detaillierten Zusammenfassung von Grimms Gesamtwerk mit einem emphatischen Bekenntnis zur Lebensraum-Ideologie des Dichters. „Unbestechlich“ und voller „Wahrhaftigkeit“ habe Grimm in seinen Werken „die Lage“ dargestellt:

„Wir brauchen Freiheit und Sonne und Weite, wollen wir nicht Sieche und Krüppel werden. Wir leben wohl, doch wir versklaven ohnmächtig, wenn uns unser Recht versagt bleibt. Täuschen wir uns nicht hinweg über den Ernst unseres Schicksals: [...] Die Erde ist groß. Das deutsche Volk aber, das zahlreichste, friedliebendste, tüchtigste weiße Volk, soll gezwungen sein, auf einem Raume zu leben, der ihm nicht hinreicht zur Arbeit und zum Broterwerb, geschweige denn zur freien Entfaltung seines Wesens! "241

Wocke führte seine Rezensionstätigkeit bis zum Ende der Weimarer Republik ungebrochen fort: Zu Grimms 1928 wiederaufgelegten Südafrikanischen Novellen verfasste er „eine Besprechung [...] für ein pädagogisches Blatt“242; für die Novellensammlung Der Richter in der Karu und andere Geschichten (1930) wurde Wocke von „zwei Blätter[n]“, darunter die Schlesische Zeitung, „zu einer Besprechung aufgefordert“ - eine Einladung, der Wocke „mit Vergnügen“243 Folge leistete. Im Mai 1931 gingen Wocke durch den ALV „die Aushängebogen“ eines „neuen Buches“244 von Grimm zu, wobei unklar bleibt, ob es sich um die Kurzgeschichtensammlung Der Gang durch den Sand und andere Geschichten aus Südafrika gehandelt hat oder um die Aufsatzsammlung Der Schriftsteller und die Zeit, beide Bücher erschienen 1931. Wocke sandte daraufhin „auf Einladung der Redaktion" eine "Würdigung an die Münchner Neuesten Nachrichten“. Parallel dazu entsprach er der Bitte „um eine Besprechung“ seitens der Ostdeutschen Monatshefte. Damit nicht genug, versicherte Wocke zudem, sich zu bemühen, in einem (namentlich nicht weiter genannten) „pädagogischen Blatte“, an dem er „seit Jahren mitarbeite, für Ihr Buch eintreten zu können“245. Die 1932 publizierte Broschüre Von der bürgerlichen Ehre und bürgerlichen Notwendigkeit besprach Wocke schließlich in der Schlesischen Zeitung. ${ }^{246}$ Grimm konnte sich bei alledem sogar den Luxus herausnehmen, ein ihm vom Verlag zugegangenes Manuskript Wockes ohne vorhergehende Rücksprache mit dem Autor „einer Korrektur" ${ }^{\text {" } 47} \mathrm{zu}$ unterziehen. Wocke erhob ob dieser Bevormundung und Eigenmächtigkeit keine Einwände.

In Wockes Einsatz für Grimm lediglich den Opportunismus eines um publizistische Nebeneinkünfte bemühten Auftragsschreibers erkennen zu wollen, hieße

241 Wocke, Jugend, S. 196.

242 DLA, A:Grimm, Helmut Wocke an Hans Grimm, 5. Dezember 1928.

243 DLA, A:Grimm, Helmut Wocke an Hans Grimm, 14. Mai 1930.

244 DLA, A:Grimm, Helmut Wocke an Hans Grimm, 21. Mai 1931.

245 Ebd.

246 Vgl. DLA, A:Grimm, Helmut Wocke an Hans Grimm, 15. August 1932. Zu den Inhalten der Broschüre vgl. Kap. 5.2.2.

247 Vgl. DLA, A:Grimm, Hans Grimm an Helmut Wocke, 8. März 1929. 
die innere Verbundenheit und tiefe persönliche Bewunderung zu unterschätzen, die der niederschlesische Lehrer dem Schöpfer von Volk ohne Raum entgegenbrachte. Seine Wertschätzung teilte er dem Dichter im Dezember 1928 auch privat mit: Grimms Werke waren Wocke demnach nicht nur als Kunstwerke, sondern „nicht minder als Ausdruck eines Menschentums, das in deutscher Art wurzelt" ${ }^{248}$ von hohem Wert.

Auch an der Herzog-Heinrich-Schule in Liegnitz nutzte Wocke alle ihm zur Verfügung stehenden Mittel, um für eine möglichst weitere Verbreitung Grimms unter den Schülern zu wirken. In seiner Funktion als „Leiter der Schülerbücherei“ war es ihm möglich, „die Schüler in der Auswahl der Lektüre ja bis zu einem bedeutenden Grade [zu] beeinflussen"249. Infolgedessen waren Grimms Werke „ständig unterwegs“, vor allem freilich Volk ohne Raum. Auch als Unterrichtsmaterial verwende Wocke die Werke des Dichters. Im Mai 1931 informierte er Grimm darüber, im „vergangenen Jahr [...] im Geschichtsunterricht auf der Oberstufe Ihre Briefe aus Deutsch-Südwest[-Afrika] behandelt“ zu haben. Die Teilnahme sei „außerordentlich rege“ gewesen, mit der Folge, dass „die meisten [Schüler] auch Ihre anderen Bücher nunmehr kennen lernen wollten“. Auch im Deutschunterricht las Wocke „nicht selten kleinere Abschnitte“ aus Grimms Werken, um auf diese Weise zu dessen „Schaffen selbst hinzuleiten“250.

Dass er sich „seit Jahren“ in seiner Funktion als Leiter der Schulbücherei ebenso für die Werke Kolbenheyers einsetzte, teilte Wocke im November 1929 mit. ${ }^{251}$ Wocke und Wandrey waren insgesamt betrachtet zwar außergewöhnlich aktive Rezensenten, sie bildeten jedoch keinesfalls singuläre Ausnahmen. Wie geschildert war etwa schon Erwin Ackerknecht in ähnlicher Intensität für Kolbenheyer tätig gewesen, ehe ihm der Dichter aufgrund einer Lappalie die langjährige Freundschaft aufkündigte. ${ }^{252}$ Die Beispiele Wocke und Wandrey illustrieren indes nochmals besonders eindrücklich die Absurdität der geschilderten Überzeugung Grimms und Kolbenheyers, in der deutschen Öffentlichkeit und Presse stets verlassen und auf sich allein gestellt gewesen zu sein.

248 DLA, A:Grimm, Helmut Wocke an Hans Grimm, 10. Dezember 1928.

249 DLA, A:Grimm, Helmut Wocke an Hans Grimm, 21. Mai 1931.

$250 \mathrm{Ebd}$.

251 Vgl. KAG, Helmut Wocke an Erwin Guido Kolbenheyer, 20. November 1929. Wocke gab Kolbenheyer zudem sein volles Einverständnis für den Aufruf an die Universitäten (vgl. Kap. 3.5) zu verstehen: „Ich stimme Ihnen in allem bei u[nd] freue mich Ihrer Worte. Ihre Vorwürfe sind leider allzu berechtigt $\mathrm{u}[\mathrm{nd}]$ erwachsen aus ernster Sorge um das Schicksal der deutschen Kunst u[nd] aus Verantwortungsbewußtsein. Das fühlt man, u[nd] Ihr Werk selber gibt Ihnen zudem recht: in dem Sinne, daß jedes Werk wurzelt in eigenbetontem Wesen u[nd] Leben spendet, schöpferisches Leben. Ich glaube nur: die Vorwürfe, die Sie erheben, treffen z. T. schon die höheren Schulen. Auf den Oberklassen nimmt in erschreckendem Maße die Teilnahme an Kunst u[nd] Kunstfragen ab; dafür herrscht Sensationslüsternheit vor, Freude am Äußerlichen. Mangel an Wille zur Konzentration. Oberflächlichkeit. Und vor allem: Mangel an Ehrfurcht, das Verstummen vor Ehrfurcht“ (ebd., Herv. i. Orig.).

252 Vgl. Kap. 3.1.2. 


\title{
3.2 Wilhelm Stapel als Referenz eines „sachlichen“ Antisemitismus
}

\subsubsection{Kernelemente der von Stapel vertretenen Haltung zur "Judenfrage"}

\begin{abstract}
In einem solchen Augenblick sollte ich nicht mit aller Kraft mich auflehnen gegen die Überjudung des deutschen Seelenlebens? Aus Rücksicht auf die inneren Nöte geistig vornehmer Juden? Wer wagt das zu fordern? Wer wagt es, meine Liebe und Sorge um das deutsche Volk, mein Verlangen nach Ehrlichkeit in die Nähe jener moralischen Minderwertigkeiten $z u$ rücken, von denen jüdische Apologeten geflissentlich glauben machen wollen, dass sie zum Wesen des Antisemitismus gehörten? Ich werde mich durch solche Urteile nicht bewegen lassen. ${ }^{253}$
\end{abstract}

Der Versuch einer - nach seinem eigenen Verständnis - kritischen und konstruktiven Auseinandersetzung mit dem Antisemitismus als historisch-gesellschaftlichem Phänomen war während der gesamten Weimarer Republik eine Grundkonstante von Stapels Publizistik. Auch in seiner Zeitschrift waren Antisemitismus und „Judenfrage“ zwei prominente, immer wieder aufgegriffene Themen. Die Gretchenfrage, wie stark antisemitisch das Deutsche Volkstum ausgerichtet gewesen ist, verschließt sich indes einer eindeutigen Antwort. Die Beiträge einzelner Mitarbeiter der Zeitschrift weisen deutliche inhaltliche Unterschiede auf - ein Hinweis auf den hohen Wert, den Stapel darauf legte, seine Zeitschrift nicht in den Ruf undifferenzierter und vorhersehbarer Einseitigkeit geraten zu lassen. $\mathrm{Zu}$ diesem Zweck stellte Stapel oftmals in einzelnen Ausgaben des Deutschen Volkstums Aufsätze zu ein und derselben Thematik nebeneinander, die in ihrer Deutung und Aussage stark voneinander abwichen. Exemplarisch ist dies an zwei Leitartikeln eines Themenhefts zum Antisemitismus ablesbar, das im Februar 1921 erschien: In ihm steht einem zwar von großstadtfeindlichen Ressentiments durchzogenen, ansonsten aber betont maßvollen Artikel des Hamburger Theologen Walther Classen, der trotz einiger Vorbehalte für eine deutsch-jüdische Verständigung plädierte ${ }^{254}$, ein Beitrag des österreichischen Schriftstellers Richard von Schaukal gegenüber, der verbissen die Möglichkeit oder auch nur Wünschbarkeit einer solchen Verständigung bestritt. Schaukal sprach stattdessen von einem „natürlichen Widerstreben“ der Deutschen gegen die Juden, das zu Unrecht „als ,Antisemitismus' verschrien“ sei. ${ }^{255}$

Ausschlaggebend für das große Interesse, das Stapel dem Antisemitismus entgegenbrachte, war laut einer selbstrechtfertigenden Eigenaussage aus dem Jahr 1921 die Beobachtung, dass „gerade bei bedeutenden und schöpferischen Per-

253 Stapel, Antisemitismus [1920], S. 53 (Herv. i. Orig.).

254 Vgl. Classen, Antisemitismus.

255 Vgl. Schaukal, Bemerkungen, Zitat S. 43. 
sönlichkeiten“ der deutschen Geschichte - Stapel erwähnt Fichte, Goethe, Luther, Schopenhauer, Treitschke und Wagner - der Antisemitismus „ausgeprägt“ gewesen sei. Stapel nahm dies als Beweis, dass im Antisemitismus „irgend eine Wahrheit und irgend ein Recht stecken“ müsse; es könne sich „nicht bloß [um] eine zu irgendwelchen politischen oder wirtschaftlichen Zwecken betriebene Hetze“256 handeln. Damit griff er ein Argumentationsmuster auf, das in antisemitischen Schriften seit der Jahrhundertwende überaus geläufig war, wobei die jeweiligen eklektischen Namensreihungen freilich immer wieder leicht variierten. Alle von Stapel aufgeführten Namen finden sich beispielsweise auch in Theodor Fritschs Handbuch der Judenfrage, in dem „Luther, Goethe, Fichte, Schopenhauer, Moltke, Rich. Wagner, Lagarde, Treitschke, Düring, Wahrmund u. a." die angebliche Legitimität antisemitischen Denkens bezeugen sollen. ${ }^{257}$

Die „redliche Prüfung“258 des Antisemitismus, die Stapel laut eigenem Anspruch anstrebte, gründete auf drei fixen Grundannahmen. Erstens galt ihm die Existenz natürlicher, historisch konstanter „Volksverschiedenheiten“ als unleugbare Tatsache des Völkerlebens. Zweitens lehnte er interkulturellen Austausch bzw. die wechselseitige Beeinflussung verschiedener Völker als Verstoß gegen jene natürliche Ordnung ab. Diese Abwehrhaltung verstand Stapel als eine Angelegenheit der Selbstverteidigung und „Selbstachtung“ eines Volks. Drittens postulierte es Stapel als die „selbstverständliche Pflicht“ eines jeden Volksbürgers, dem eigenen Volk - verstanden als mental-geistige und rassisch-biologische Singularität unter allen Umständen die „Treue zu wahren“. Letzteres galt ihm auch deshalb als evident, da die Volkszugehörigkeit des Individuums in seinen Augen qua Geburt „in Blut und Seele“ festgelegt war und nicht durch autonome Willensentscheidung verändert werden konnte. ${ }^{259}$

Obgleich Stapel diese Annahmen als unveränderliche Tatsachen erachtete, bemühte er sich in seiner Zeitschrift dennoch um eine durchaus facettenreiche Behandlung des Antisemitismus. In dem vorgeblich sachlichen und emotionsfreien Umgang mit diesem Themenkomplex kam Stapels Absicht und Anspruch zum Ausdruck, sich vor den Augen der Öffentlichkeit von vulgären, aggressiven und undifferenzierten, kurz: radikalen Antisemiten abzugrenzen und intellektuell abzuheben. Aus privaten Briefen Stapels geht indes hervor, dass diese „objektivitätsheischende [...] Form geistiger Distinktion“ “260, so die treffende Formulierung Matthias Hambrocks, lediglich das nicht rationale, sondern emotionale Funda-

256 Stapel, Recht [1921], S. 46.

257 Fritsch (Hg.), Handbuch, S. 12 (Herv. i. Orig.). Für weitere Beispiele vgl. Deutsch-Soziale Blätter 14 (1899), S. 275; Weininger, Geschlecht, S. 413, Anm. 1; Bartels, Rasse, S. 274; Politischanthropologische Monatsschrift für praktische Politik 18 (1920), S. 329 sowie Alfred Rosenbergs Aufsatz Herr Endres und die Judenfrage in: Völkischer Beobachter, 22. August 1919.

258 Stapel, Recht [1921], S. 46.

259 Ebd., S. 46f. Die These der Irreversibilität der Volkstumszugehörigkeit jedes Menschen hatte Stapel bereits 1917 in der Erstauflage seiner Volksbürgerlichen Erziehung vertreten: „Kein Mensch kann das Blut in seinen Adern willkürlich verändern, und wenn er sich noch so grimmig dagegen wehrt, es anzuerkennen“. Stapel, Erziehung [1917], S. 9.

260 Hambrock, Etablierung, S. 462. 
ment der Judenfeindschaft kaschieren sollte. Auch zeigt sich im privaten Umfeld, dass die öffentlich eingeübten und standardisierten Distanzierungsgesten gegenüber radikalen Antisemiten kein immerwährendes Grundbedürfnis Stapels darstellten, sondern zugleich diskursstrategischen Erwägungen unterlagen. So betonte Stapel im April 1931 gegenüber Kolbenheyer, seine öffentlichen Abgrenzungen von dem „sog[enannten] Radau-Antisemitismus“ nicht zu weit treiben zu wollen. Ebenso „wie die Juden nach außen hin“ nicht „ihre Tucholskys“ preisgäben, wolle und dürfe er „nach außen hin“ nicht die „Nationalsozialisten“261 preisgeben. Kritik solle daher nur innerhalb der eigenen Reihen und also „fern vom Beifall der Ausländer“ geäußert werden. Indes könne mit einer „Preisgabe der ,wilden“ Antisemiten“ durch öffentliche Kritik bei den Juden ohnehin kaum etwas „erreich[t]" werden, würden ihre Zeitschriften doch nicht müde zu betonen, dass „die ,EdelAntisemiten' viel schlimmer seien als die ,Radau-Antisemiten “"262. Dass diese Auffassung relativierungsbedürftig ist, wird im Abschnitt zur öffentlichen Rezeption der Schriften Stapels zum Antisemitismus gezeigt werden. ${ }^{263}$ Zunächst gilt es jedoch, die Kernelemente der Ansichten Stapels zur „Judenfrage“ offenzulegen. Ein Blick auf die einzelnen Publikationen und Argumentationsmuster zeigt dabei rasch, dass der Anspruch auf einen rationalen und rein „sachlichen“ Umgang mit dem Antisemitismus auf Sand gebaut war.

ZUR FRAGE DER JÜDISCHEN „ASSIMILATION“ - Wie erwähnt, basierte Stapels Glaube an einen naturbedingten „Gegensatz“ zwischen Juden und Deutschen auf der Grundannahme, dass „Volkstümer“ notwendig spezifisch und „unteilbar“264 seien und daher streng voneinander geschieden werden müssten. Jeder Einzelmensch, so Stapel 1920, sei durch seine Abstammung untrennbar an seine spezifische „völkische Art“ gebunden. „Die Menschheit“ sei „nicht die Summe der Menschen, sondern der Völker.“ Ein Volk aber könne nicht als ein „Werk menschlichen Willens“ verstanden werden, sondern nur als „eine naturhafte, gewachsene Einheit wie der Baum, das Korallenriff, der Bienenschwarm“ - als „ein Stück Wirklichkeit, genau so wirklich wie der einzelne Mensch“. Alles „wirkliche Leben“ sei jedoch „Individuation“ und ein allgemeines, gleichförmiges „Menschentum“ daher eine Chimäre: Menschen ohne spezifisches und einzigartiges Volkstum seien „in Wirklichkeit nicht möglich“ und könnten lediglich „gedacht werden“265. Stapels Perzeption der „Judenfrage“ war somit maßgeblich von den weltanschaulichen Gewissheiten seiner Volksnomoslehre durchdrungen, welche im Kern auf folgendes Credo hinauslief:

„Jedes Volk wird zusammengehalten durch ein Gesetz des Lebens, das, entsprechend seiner Natur, seine innere und äußere Form, seinen Kult, seinen Ethos, seine Verfassung und sein Recht

${ }^{261}$ KAG, Wilhelm Stapel an Erwin Guido Kolbenheyer, 11. April 1931.

262 Ebd.

263 Vgl. Kap. 3.2.2.

264 Stapel, Antisemitismus [1920], S. 5 (Herv. i. Orig.).

265 Ebd., S. 7f. (Herv. i. Orig.). 
bestimmt: durch den Nomos. Der Nomos macht das Volk, das ursprünglich Kultgemeinde ist, zum Volke [...]. Jedes Volk hat seinen besonderen Nomos" ${ }^{\text {" } 66 . ~}$

Dieser Überzeugung entsprechend spielte in Stapels Überlegungen zur „Judenfrage" die Taufe keinerlei Rolle - ungeachtet seiner ausgeprägten persönlichen Religiosität. Einen bloß religiös argumentierenden Antijudaismus lehnte Stapel als unzeitgemäß ab, da dieser dem naturwissenschaftlichen Kenntnisstand seiner Zeit nicht mehr zu entsprechen schien.

Hinsichtlich der Frage jüdischer „Assimilation“ lief Stapels Argumentation im Kern darauf hinaus, sowohl ihre praktische Durchführbarkeit als auch Wünschbarkeit zu verneinen. Mehrfach schlussfolgerte er lapidar, dass es Juden grundsätzlich „unmöglich“ sei, „wesenhaft zum Deutschen“ zu werden. ${ }^{267}$ Doch auch in den Texten, in denen er das Modell der „Assimilation“ etwas differenzierter behandelte und ihre Möglichkeit in grauer Theorie nicht völlig ausschloss, stellte Stapel klar, dass eine „Lösung der Judenfrage durch ,Assimilation“", das heißt durch eine „Vermischung der Völker“, abzulehnen sei - ein Reflex auf die allen völkischen Autoren gemeine, manische Sorge vor einer kulturellen und rassischen „Überfremdung“ des deutschen Volks. Nach Auffassung Stapels war es gleichgültig, dass es „wohl einzelne Juden“ gäbe, die, als seltene Ausnahmen der Regel, theoretisch „im deutschen Volke aufgehen“ könnten. Für ihn war ausschlaggebend, dass „ein im Ganzen unserer Art so fremdes Volk wie das jüdische“, welches „von Osten her einen schier unerschöpflichen Zustrom“ aufweise, nicht „in das deutsche Blut und die deutsche Seele einfließ[en]“268 dürfe.

Von Stapels vereinzelten Überlegungen zu potenziell „assimilierbaren“ Juden sollte man sich daher nicht blenden lassen. Wie unausgegoren und auch kurzlebig Stapels Vorstellungen waren, wenn es darum ging, das theoretische Modell eines quasi geordneten Assimilationsprozederes zu beschreiben, belegt sein 1932 publizierter Text Versuch einer praktischen Lösung der Judenfrage ${ }^{269}$. Frühestens, so Stapel, sollte der „Übertritt vom Judentum zum Deutschtum“ nach einer bis in die „dritte Generation“ andauernden Bewährungsfrist „möglich“ gemacht werden. ${ }^{270}$ Zur naheliegenden und entscheidenden Frage, nach welchen Kriterien der Erfolg oder Misserfolg einer solchen „Bewährung“ entschieden werden sollte und vor allem von wem, schwieg sich Stapel bezeichnenderweise aus. Auch in der Folgezeit griff Stapel sein dürftiges Gedankenmodell nicht mehr auf. Große Bedeutung für seine Publizistik, ganz zu schweigen von deren Außenwirkung, besaßen

266 Stapel, Staatsmann, S. 174. Für eine ausführliche Erläuterung der Volksnomoslehre vgl. Schmalz, Kirchenpolitik, S. 62-69.

267 Stapel, Antisemitismus [1920], S. $10 \mathrm{f}$.

268 Ders., Recht [1921], S.50f. Gerade in den ersten Jahren der Weimarer Republik war die Hetze gegen die sogenannten Ostjuden zentraler Bestandteil völkischer Agitation. Hervorzuheben ist hier insbesondere die Propaganda des Deutschvölkischen Schutz- und Trutzbunds. Vgl. Lohalm, Radikalismus, S. 147-152. Generell zum Phänomen der „Ostjuden“ und ihrer durch antisemitische Pogrome in Osteuropa bedingten Flucht nach Westen vgl. Maurer, Ostjuden; Haumann, Ostjuden.

269 Weitere Informationen zum Entstehungshintergrund des Textes in Kap. 5.2.1.

270 Stapel, Versuch [1932], S. 190. 
die 1932 skizzierten Überlegungen also nicht. Überblickt man alle Texte Stapels zur „Judenfrage“, so lässt sich bilanzieren, dass Stapel die Eingliederung der Juden in die deutsche Gesellschaft durch „Assimilation“ prinzipiell ablehnte.

Zum deutschen und JÜdischen „Volkscharakter“ - Eine Paradoxie, die in Stapels Texten zum Antisemitismus häufig aufscheint, besteht darin, dass in ihnen einerseits die diametrale Gegensätzlichkeit des deutschen und jüdischen „Volkscharakters" als feststehende Tatsache behauptet wird, Stapel andererseits jedoch die Möglichkeit einer definitiven Bestimmbarkeit von Volkscharakteren bestritt. Was „jüdische Art und deutsche Art“ sei, lasse sich „niemals rational mit festen Begriffen umzirkeln"271. Durch dieses Unschärfetheorem ließ sich Stapel indes nicht davon abhalten, deutsche und jüdische „Volksart“ als a priori unvereinbar zu definieren. Diesen Widerspruch versuchte Stapel aufzulösen, indem er den Antisemitismus letztendlich zu einer Gefühlsangelegenheit erklärte; die Unterschiedlichkeit einer Volksart, so behauptete er, müsse „instinktiv“ erkannt werden: „Wer die Fremdheit oder Gleichartigkeit nicht erfühlt, wird sie mit Begriffen nie erjagen“272. Die „Weckung“ eines solchen „gesunden Instinktes für eigenes und fremdes Volkstum“ definierte Stapel auch als Notwendigkeit und „Vorbedingung zur Lösung der Judenfrage“. Nur wer sich seines „Volkstums instinktiv sicher" sei, lasse sich „nicht durch fremdes Volkstum blenden“ und „nicht bewundernd von Fremden bei Seite drängen“273.

Eine solche Instinktsicherheit erschien Stapel insbesondere vor dem Hintergrund des verlorenen Weltkriegs und der zunehmenden Öffnung der Weimarer Kultur gegenüber fremden äußeren Einflüssen als essenziell wichtig. Nur durch eine konsequente und bedingungslose Abgrenzung gerade von der jüdischen Kultur und ihren Trägern war für Stapel an die „Möglichkeit“ eines funktionalen und tolerierbaren Nebeneinanders des deutschen und des jüdischen Volks zu denken - „als einander Fremde, aber doch als vom Schicksal zum Zusammenleben Gezwungene“. Nur so würden das deutsche Volk und seine Geschichte nicht „überfremdet“ und „verfälscht“ ${ }^{\text {“ }} 74$ werden. Hierbei grenzte sich Stapel insofern von dem „dogmatische[n] Antisemitismus“ ab, als er vor „Niedrigkeiten gegen jüdische Menschen“ und einer „Aufstachelung des Hasses“ warnte. Menschen, „denen es mit dem deutschen Volkstum ernst ist“, sollten sich stets „in der Gewalt behalten“275. Die Grenzen und Erfolge dieses Selbstanspruchs wurden bereits thematisiert. ${ }^{276}$

„Kulturantisemitismus“ - Nach der Auffassung von Louis Dupeux bildete die Auseinandersetzung mit liberal und pazifistisch orientierten, jüdischen Kunst-

271 Ders., Recht [1921], S. 50.

272 Ebd. (Herv. i. Orig.).

273 Ebd.

274 Stapel, Recht [1921], S. $51 \mathrm{f}$.

275 Ebd., S. 50f. (Herv. i. Orig.).

276 Vgl. Kap. 2.2.2. 
und Kulturschaffenden den Kern des Stapel'schen Antisemitismus. Dieser Antisemitismus, so Dupeux, sei „nicht biologisch begründet“277 gewesen. Obgleich sich Stapel in der Tat am häufigsten im Kontext von Kunst- und Literaturfragen antisemitisch äußerte, wohingegen die Politik bei ihm eine vergleichsweise untergeordnete Rolle spielte ${ }^{278}$, greift die Deutung Dupeux’ zu kurz. Schon Stapels Auffassung der „Assimilations“-Thematik hat gezeigt, dass Kunst und Kultur für ihn nur einen äußerlichen Rahmen darstellen, hinter dem der feste Glaube an einen viel fundamentaleren, sowohl seelisch als auch biologisch kodierten Volksgegensatz zum Vorschein kommt. Auch das noch zu schildernde Verhältnis Stapels zu Kolbenheyers Bauhütten-Philosophie wird die große Affinität Stapels zu biologistischem Denken erweisen. ${ }^{279}$ Dennoch verdient Stapels Perzeption der Weimarer Kunstlandschaft und Kulturpolitik aufgrund ihrer prominenten Stellung in dessen Publizistik nähere Aufmerksamkeit.

Bedingt durch seine eigene Berufstätigkeit, seine Aufgabenbereiche innerhalb der $\mathrm{HVA}^{280}$ sowie seiner eigenen schöngeistigen Interessen lud sich Stapels Kritik

277 Vgl. Dupeux, Kulturantisemitismus, S. 167.

278 Am deutlichsten tritt Stapels Haltung zur politischen Rolle der Juden in der Innen- und Außenpolitik in dem im April 1931 in Nyon bei Genf gehaltenen Vortrag Die Rolle der Juden im politischen Leben der Gegenwart zutage. Darin skizzierte Stapel insgesamt vier Problemkomplexe, ohne jedoch „Lösungen“ zu bieten, da diese nicht „Zweck“ des Vortrags sein könnten. Als die zwei spezifischen Probleme der Innenpolitik behauptete Stapel, dass erstens das „jüdische Volk den Liberalismus und den liberalen Sozialismus zu konservieren“ suche und damit unweigerlich ,innenpolitisch zu einer Entwicklungshemmung für die anderen Völker" werde. Zweitens führe der Zionismus und die Tendenz der Juden, sich „auf sich selbst" zurückzuziehen, dazu, dass den Juden „die Eigenart sowie die politische Größe des andern Volkes immer gleichgültiger" werde. Infolgedessen trete an die Stelle des zuvor gefochtenen „Kampfes für allgemeine Ideen (Liberalismus, Sozialismus) ein Kampf für die Durchsetzung des spezifisch Jüdischen“ innerhalb der fremden Völker: „Es kommt in reziprokem Verhältnis zur Abnahme des praktischen jüdischen Einflusses eine Zeit der Präpotenz jüdischer Geistigkeit“. - Als die zwei spezifischen Probleme der Außenpolitik beschrieb Stapel folgende Komplexe: Erstens seien die Juden „infolge ihrer politischen Lage zwischen den Völkern“ als Kollektiv unweigerlich „Vertreter des Pazifismus“. Hierdurch würden sie gerade auf das deutsche Volk nach 1918 verheerend wirken, denn: „Wer den Pazifismus vertritt, vertritt, mag er es wollen oder nicht, die realen politischen und wirtschaftlichen Interessen der Weltkriegsgewinner". Zweitens verfüge das jüdische Volk durch seine Zerstreuung „durch alle Nationen“ über eine hohe Zahl außenpolitisch hochbedeutsamer „Querverbindungen“. Diese nutze es für die Interessen des jüdischen Volks, nicht aber für die Interessen jenes Volks, „unter dem sie ihren Aufenthalt gewählt haben“. Dies sei zumal deshalb der Fall, da „ihm [dem Juden] scheint, daß sein Interesse das moralisch ,höhere` sei. Das behauptet er. Den andern Nationen ist das nicht moralisch evident" (Stapel, Rolle [1931], S. 406-408, Herv. i. Orig.).

279 Vgl. Kap. 3.3.2.

280 Seit 1926 hatte Stapel die Leitung der innerhalb der HVA neugegründeten „Volkstumsabteilung" inne. Damit erlangte er großen Einfluss auf das gesamte kulturpolitische Schriftgut der Verlagsanstalt und mithin „an enormous influence over the house's publishing program“ (Stark, Entrepreneurs, S. 27). Stapel setzte seine Leser sogleich stolz über das neue Amt in Kenntnis und gab seiner Zufriedenheit und Freude darüber Ausdruck, dass das Deutsche Volkstum in Form einer „Personalunion zwischen einem Teil des Buchverlags und der Zeitschrift“ künftig „nicht mehr als einzelne, zufällige Unternehmung im Verlag" stehen, sondern „in den Mittelpunkt“ einer der HVA-Abteilungen rücken werde (Stapel, Verlag [1926], S. 909). 
an den Juden häufig daran auf, dass sie es „durch äußere Betriebsamkeit, durch Flinkheit der Intelligenz, durch Anpassungsfähigkeit, durch Schreib- und Redegewandtheit“ und „durch Mangel an Zurückhaltung“ vermocht hätten, die einflussreichsten Ämter im Theaterleben, in der Presse, im Kunsthandel, vor allem aber in der Literatur- und Kunstkritik zu besetzen. ${ }^{281}$ Ähnlich wie viele völkische Autoren vor ihm sah Stapel in diesen Arbeitsfeldern seitens der Juden eine zielgerichtete, sittliche wie moralische Zerstörungsarbeit am Werk. Jüdischen Literaturkritikern warf Stapel vor, „das beste Gut“ des ihnen innerlich fremden und in letzter Konsequenz unverständlichen deutschen Volks gezielt „,in den Winkel“ zu „spotte[n]“, „artfremde“ Werke hingegen, mit denen der deutsche Leser „in Wirklichkeit nichts anfangen“ könne, „als tiefste Offenbarung“282 zu verklären und so dem Publikum gleichsam aufzunötigen. Diese Projektion eigener literarischer Vorlieben auf das deutsche Volk als mutmaßlich homogenen Gesamtorganismus und der in ihr angelegte Anspruch, den wahren Geschmack der deutschen Leser gleichsam ferndiagnostizieren zu können, erlaubte es Stapel, etwa die Erfolge eines Erich Maria Remarque als rein „gemachtes“, also künstlich herbeigeführtes Ergebnis manipulativer jüdischer Desinformation auf dem Feld der Literaturkritik darzustellen. Für die Überlegung, ob Teile der deutschen Gesellschaft nach dem verlorenen Weltkrieg, der allein auf deutscher Seite knapp zwei Millionen Soldatenleben gekostet hatte ${ }^{283}$, aus sich selbst heraus eine genuine Affinität für Antikriegsliteratur entwickelt hatten, war in diesem Erklärungsmodell kein Raum.

Das eigenhändig platzierte Damoklesschwert einer immerzu drohenden, endgültigen feindlichen Übernahme des deutschen kulturellen Lebens durch jüdische Intellektuelle erlaubte es Stapel zudem, die Unterstützung vermeintlich „artgemäßer" Werke durch deutsche Kunstkritiker zu einem Akt völkischer Notwehr zu stilisieren. Auch postulierte Stapel das moralische Recht des deutschen Volks, sich im Sinne völkischer Selbstverteidigung gegen die behaupteten Urheber der kulturellen Überfremdung aktiv zur Wehr zu setzen:

„Sobald ein Volk die Eigenart eines anderen Volkes angreift, hemmt oder verändert, sei es durch den Versuch, die Führung an sich zu bringen, sei es durch absichtliches Sich-vermischen, hat dieses andre Volk ein Recht, die Führung oder Vermischung zu bekämpfen. In Bezug auf das Völkische hat also der Antisemitismus recht, wenn er sich gegen eine Führung der Deutschen durch Juden oder gegen eine Vermischung beider Völker wehrt." 284

Den „deutsch-jüdische[n] Kulturkampf", verstanden als langfristige Folge der Judenemanzipation, sah Stapel durch die Weltkriegsniederlage um ein Vielfaches zugespitzt und gesteigert. Stapel argumentierte, dass der (kultur-)politische Einfluss der Juden als „geborene Pazifist[en]“ für das seiner Freiheit beraubte deutsche Volk die existenzielle Bedrohung „ewige[r] Knechtschaft und Lebens-

281 Stapel, Antisemitismus [1920], S. 18.

282 Ebd.

283 Damit stellte der „relative Anteil getöteter Soldaten im deutschen Militär [...] den höchsten Wert im Vergleich aller kriegführenden Gesellschaften“ dar. Vgl. Leonhard, Büchse, S. 767. 284 Stapel, Recht [1921], S. 47f. 
hemmung "285 in sich berge. Stapel warnte zugleich davor, sich von patriotisch und deutschnational gebärdenden Juden nicht hinters Licht führen zu lassen; der „innere Zwang“, fälschlicherweise „die Interessen des deutschen Volkes“ mit ihren eigenen zu identifizieren, sei den Juden in die Wiege gelegt. Aus der Verstreuung der Juden über viele verschiedene Staaten und ihrem mutmaßlichen länderübergreifenden Zusammengehörigkeitsgefühl folgerte Stapel, jüdische Interessen müssten unweigerlich „mit denen des Internationalismus zusammengehn [sic!]“. Für sämtliche „deutsch-jüdische Zeitungen und Zeitschriften“ sei „das deutsche Interesse“ stets identisch mit dem „des Internationalismus“. Aus diesem sauber gezogenen Zirkelschluss leitete Stapel für die Zeit seit 1918 eine existenzielle Bedrohung des deutschen Volks ab: Infolge des angeblich angeborenen internationalistischen Denkens jüdischer Intellektueller drohe „die deutsche Geschichte schließlich mit der jüdischen Geschichte über eins [zu] kommen“. Aufgrund dieser Gefahr der Selbstentfremdung sah Stapel in den Juden nach dem Ersten Weltkrieg „eine geschichtlich größere Gefahr für uns"286 als für die Siegermächte des Kriegs.

Zur Frage der Gleichberechtigung - In dem 1932 veröffentlichten Sammelband Der Jud ist schuld...? Diskussionsbuch über die Judenfrage stellte Stapel die These auf, „der Liberalismus“ habe „die Möglichkeit der Symbiose“ zwischen Juden und Deutschen „zerstört“. Durch ihn sei der „widernatürliche Begriff“ der „Gleichberechtigung“ in die Welt gesetzt worden, welcher „gegen allen natürlichen Rang und gegen jede natürliche Verantwortlichkeit zersetzend und vergiftend“ gewirkt habe. Für Stapel widersprach die Vorstellung natürlicher Gleichheit allem gesunden Ordnungsempfinden; „Gleichberechtigung“ existiere nur „im Himmel der Vernunft, d.h. in der pathetischen Phrase“. In Wirklichkeit habe

„jeder Stand [...] sein Recht, das Kind sei nicht gleichberechtigt mit den Eltern und umgekehrt, die Frau ist nicht gleichberechtigt mit dem Manne und umgekehrt, der Führer ist nicht gleichberechtigt mit dem geführten und umgekehrt; der Jude ist nicht gleichberechtigt mit dem Deutschen und umgekehrt." 287

Stapel vertrat zudem die Ansicht, dass die Juden nicht aus aufrichtigem Idealismus für die Gleichberechtigung einträten, sondern lediglich aus Kalkül. In Wahrheit gehe es ihnen darum, „unter dem Schein der, Gleichberechtigung“ eine geistige Vorherrschaft [zu] etablieren" 288 .

285 Ebd., S. 49f. (Herv. i. Orig.). 1920 begründete Stapel seine Haltung, sich „gerade jetzt“ gegen den Anspruch der Juden zu wenden, Teil des deutschen Volks sein zu wollen, damit, dass das deutsche Volk „eben jetzt [...] in seinem Volkstum“ besonders „bedroht“ sei. Erstens, da der Staat „durch gewaltsame Grenzen zerteilt worden“ sei und seine „Souveränität" verloren habe, zweitens, weil die „deutsche Volkswirtschaft [...] vernichtet" darniederliege, drittens, weil „Millionen von Deutschen“ nunmehr „über die ganze Welt zerstreut" worden seien. Unter diesen Umständen sei „die Gefahr der inneren Auflösung unseres Volkstums erhöht“, zumal „wenn in diesem Augenblick fremdes Volkstum verwirrend“ eindringe, wie es den Juden mit ihrer „bewegliche[n] Geistigkeit“ tagtäglich gelinge. Vgl. Stapel, Antisemitismus [1920], S. 52 (Herv. i. Orig.).

286 Stapel, Recht [1921], S. 50.

287 Ders., Aphoristisches [1932], S. 173 (Herv. i. Orig.).

288 Ebd. 
Es war aus dieser Perspektive daher nur konsequent, dass Stapel auch konkrete Forderungen nach Rechtsbeschränkungen für deutsch-jüdische Staatsbürger erhob. Von besonderer Bedeutung war aus seiner Perspektive der Ausschluss der Juden aus den „hierarchischen Funktionen des Richtens und Erziehens“289. Die Überzeugung, dass den Juden besonders pädagogische Tätigkeiten verschlossen bleiben müssten, basierte auf dem Glauben, dass jüdische Lehrer deutsche Schüler „notwendig“ in ihren „innerlichen Instinkten und tiefsten Werturteilen verbiegen " 290 würden. Im Hinblick auf die Universitäten forderte Stapel zudem das Verbot für Juden, auf den Gebieten der „Theologie und der deutschen Geschichte“291 zu lehren. Als unentbehrlich galt Stapel zudem die „Schaffung eines jüdischen Standes“ mit eigener „Standesvertretung“, die Erschwerung der „Ehegemeinschaft zwischen Juden und Deutschen“ 292 sowie die Nichtzulassung der Juden zum Militärdienst - um sie „nicht in die Lage [zu] zwingen“, im Härtefall gegen „Juden anderer Länder zu kämpfen“293, so Stapels perfide Begründung. Gerade bei diesem Gedankengang offenbart sich die für Stapel typische selbstreferenzielle Eigenlogik: Die Gleichsetzung von Judentum mit „Antigermanismus“ und „Internationalismus“ schloss die Möglichkeit eines genuin (deutsch-)national empfindenden Judentums a priori aus - ungeachtet der vielen gegenteiligen Befunde, die gerade der Erste Weltkrieg bereithielt. ${ }^{294}$

Stapels Resümee, das Verhältnis zwischen Deutschen und Juden solle letzten Endes von „achtungsvolle $[r]$ Distanz“295 getragen sein, nimmt sich vor dem Hintergrund seiner offenen Forderungen nach partieller Entrechtung beinahe sarkastisch aus. Dennoch unterscheidet es ihn, was nicht verkannt werden sollte, deutlich von den gewaltorientierten antisemitischen Hetzern und Agitatoren seiner Zeit. Stapels 1932 geäußerte Gedanken zur Frage jüdischer Gleichberechtigung sind freilich stets auch vor dem Hintergrund des Aufstiegs der NSDAP zu verstehen: Sowohl als Versuch Stapels, radikalen Maximalforderungen entgegenzutreten, wie auch als Ausdruck seines Bemühens, sich vor den Augen der Nationalsozialisten, deren Machtergreifung Stapel begrüßte und auch erwartete, nicht durch eine allzu starke Mäßigung unmöglich zu machen.

VOM MANGELNDEN „TAKTGEFÜHL“ DER JUdEN - Der politischen Betätigung von Juden suchte Stapel dadurch einen moralischen Riegel vorzuschieben, dass er jeden Versuch jüdischer Staatsbürger, eine politische Karriere in Deutschland einzuschlagen, als Ausdruck fehlenden "Taktgefühls“ geißelte. Auch hier waren es die

289 Stapel, Versuch [1932], S. 189.

290 Ders., Antisemitismus [1928], S. 96.

291 Ders., Versuch [1932], S. 189.

292 Schmalz, Kirchenpolitik, S. 80.

293 Stapel, Versuch [1932], S. 189.

294 Anders als es die zeitgenössische völkische Polemik wollte, die gebetsmühlenartig das Stereotyp des jüdischen „Drückebergers“ reproduzierte, entsprach der Anteil jüdischer Kriegsfreiwilliger, Frontkämpfer und Gefallener im Ersten Weltkrieg dem jüdischen Bevölkerungsanteil der deutschen Gesellschaft. Vgl. Kap. 2.2, Anm. 201.

295 Stapel, Versuch [1932], S. 191 (Herv. i. Orig.). 
Folgewirkungen der Weltkriegsniederlage, die Stapel eine besonders harte Haltung einnehmen ließen. Basierend auf seiner Überzeugung, dass das Denken jüdischer Politiker letztlich auf eine internationalistische und pazifistische Haltung zurückfallen müsse, behauptete Stapel, jeder jüdische Einfluss auf die Reichspolitik müsse den existenziellen Lebensinteressen des deutschen Volks zuwider laufen. ${ }^{296}$

Die These jüdischer „Taktlosigkeit“ nutzte Stapel zudem als sittliche Rechtfertigung von „Abwehrreaktionen“ deutscher „Volksbürger“ gegen Juden. Als geradezu hochnotpeinlich empfand er es, „jüdische Politiker“ bei ihren Bestrebungen zu beobachten, „mit geilem Eifer in den Akten unseres Reiches“ nach Beweismaterial „für unsere Mitschuld am Kriege“297 ${ }^{\text {zu suchen }}{ }^{298}$; eine solche Tätigkeit hätten sie aus Anstandsgründen ,anderen überlassen sollen“. Für Stapel stand hinter dieser Forderung „keine ,Entrechtung“", vielmehr markierte sie in seinen Augen eine „Grenze“, die den Juden „vom moralischen Takt gezogen“ würde: Es sei kein Angriff gegen die „Gleichberechtigung“, wenn „rund und klar“ ausgesprochen werde, dass es für einen Deutschen „unerträglich“ sei, die „Geschicke“ seines Volks „von Juden geleitet zu sehen“. Zwar handle es sich um „keine staatliche, wohl aber [um] eine völkische Fremdherrschaft “299, gegen die Widerstand zu leisten nicht nur legitim, sondern eine Angelegenheit des Nationalstolzes sei. ${ }^{300}$

296 Vgl. Deutsches Volkstum. Monatsschrift für das deutsche Geistesleben 5 (1923), S. 293: „Pazifismus heißt heute deutsche Volksversklavung. Pazifismus ist die Sittlichkeit eines siegreichen Volkes, Sichwehren ist die Sittlichkeit eines getretenen und geknechteten Volkes. Wer heute die Deutschen für den Pazifismus wirbt, geht sittlich irre und führt sittlich irre“.

297 Stapel, Antisemitismus [1920], S. $20 \mathrm{f}$.

298 Stapel dürfte hiermit auf Kurt Eisner anspielen, der am 23. November 1918 als bayerischer Ministerpräsident Aktenfunde aus dem bayerischen Außenministerium vom Juli 1914 publizieren ließ, die eine deutsche Schuld am Ausbruch des Ersten Weltkriegs beweisen sollten. Mit dieser Maßnahme, die in allen politischen Lagern auf heftigen Protest stieß, hoffte Eisner vergeblich, den Siegermächten das Bild von einem - im Vergleich zur Zeit vor 1914 - grundlegend gewandelten Deutschland zu vermitteln und auf diese Weise günstigere Friedensbedingungen zu erreichen. Darüber hinaus sollten vor dem Augen der Öffentlichkeit die nach Ansicht Eisners verheerenden Fehler der deutschen Außenpolitik während der „Julikrise“ offengelegt werden, um einer möglichen Verklärung der deutschen Vorkriegspolitik entgegenzuwirken. Dass Stapel die Motive Eisners bekannt waren, darf angenommen werden. Er verwarf sie jedoch - in selbstreferenzieller Eigenlogik - als weiteres Indiz "undeutschen“ Wesens. So schrieb er 1920: „Jüdische Politiker mögen mit den besten Absichten den Feinden die deutsche ,Schuld' ,bekennen, um dadurch bessere Bedingungen für das äußere Dasein des deutschen Volkes zu erwirken - es gibt Grenzen, wo man lieber auf ein besseres Leben verzichtet, als daß man sich moralisch vor anderen auszieht. Diesen Takt hatten jüdische Politiker nicht, weil sie eben nicht Deutsche waren“ (Stapel, Antisemitismus [1920], S. 20).

299 Stapel, Antisemitismus [1920], S. 21.

300 Die Vorstellung einer „immer verhängnisvoller hervortretende[n] Vorherrschaft des Judentums in Regierung und Öffentlichkeit", so schon der Wortlaut der 1920 verabschiedeten, programmatischen Grundsätze der DNVP (vgl. Mommsen (Hg.), Parteiprogramme, S. 538), war vor allem seit der Novemberrevolution fester Bestandteil rechtsradikaler Ideologie. Exponenten dieses Denkens verwiesen meist auf die jüdischen Vertreter im Rat der Volksbeauftragten, Otto Landsberg (SPD) und Hugo Haase (USPD), wie auch auf einzelne jüdische oder jüdischstämmige Minister der Republik, von denen der von Januar bis Juni 1922 amtierende Außenminister Walther Rathenau der prominenteste war. Der Umstand, dass während der Republik insgesamt nur sehr wenige jüdische Politiker Ministerposten bekleideten und auch keiner der deutschen Reichskanzler jüdisch war, blieb hingegen außen vor. 
Auch seine scharfe Ablehnung der Weimarer Verfassung begründete Stapel nicht nur mit konkreten Mängeln - in seinem Jargon: „Fiktionen“301 - dieser Verfassung, sondern zugleich damit, dass sie mit Hugo Preuß maßgeblich (freilich nicht ausschließlich) von einem jüdischen Staatsrechtslehrer konzipiert worden war. „Gerade“ hier glaubte Stapel mangelndes Taktgefühl erkennen zu können. Als ähnlich dreist erschien es ihm, wenn jüdische Akademiker juristische Karrieren einschlugen. Müsse es sein, so seine rhetorische Frage, dass „deutsche Staatsmänner und Heerführer, die vor den Staatsgerichtshof treten sollen, von Juden verhört“ würden? Eine solche Konstellation sei „peinlich für jene und sollte peinlich sein für diese“302. Mit dieser Feststellung glaubte Stapel, den „Wert des Judentums“ nicht „in Zweifel“ zu ziehen, wünschte jedoch, dass in Zukunft „über alle juristischen Rechte und moralischen Berechtigungen hinweg nicht nur der persönliche Takt [...], sondern auch der völkische Takt gewahrt werde“303. Die Gleichzeitigkeit, mit der Stapel einerseits den Juden die Verfolgung politischer und juristischer Karrieren als Beleg mangelnder Sittlichkeit anlastete und die Konditionen künftiger Berufsverbote diskutierte, andererseits jedoch wähnte, über allen Angriffen gegen jüdische Gleichberechtigung zu stehen, offenbart die ganze Inkonsistenz seiner gedanklichen Konstruktionen.

In der Forschung wurde bereits vereinzelt aus den hohen Stellenwert hingewiesen, den Stapels Publikationen in der Antisemitismus-Debatte der Weimarer Republik eingenommen haben. Demnach erlangte Stapel durch seine Artikel die Reputation einer „Galionsfigur des Antisemitismus“304 und habe als „Virtuose einer vornehmen und deshalb auch für Intellektuelle verführerischen Version des ,Salonantisemitismus“"305 gegolten. Der Diskursrahmen, in dem während der 1920er Jahre in Deutschland über die „Judenfrage“ diskutiert wurde, sei maßgeblich von Stapel mitbestimmt worden. ${ }^{306}$ Detailliert empirisch fundiert wurden diese Deutungen bis dato jedoch nicht. Gegenstand des folgenden Kapitels ist es, dieses Desiderat anhand der Rezeption der Stapel'schen Texte im Lager der deutschen Rechten wie auch unter jüdischen Intellektuellen aufzuhellen.

\subsubsection{Rezeption der Texte Stapels im Lager der Gleichgesinnten und der politischen Gegner}

Stapel als Antisemitismus-Referenz InNerhalb Der Weimarer Rechten - Die in vielen Texten Stapels seit 1919 bekräftigte Haltung, dass es einem Juden letztend-

301 Vgl. hierzu: Jelich, Verfassung.

302 Stapel, Antisemitismus [1920], S. 43. Stapel zielte hier auf den jüdischen USPD-Politiker Oskar Cohn. Zu dessen Rolle im „Untersuchungsausschuss über Ursachen und Folgen des Ersten Weltkriegs" vgl. Heid, Cohn, S. 276-308.

303 Stapel, Antisemitismus [1920], S. 43.

304 Dupeux, Kulturantisemitismus, S. 167.

305 Lokatis, Stapel, S. 32.

306 Angedeutet auch in: Stark, Entrepreneurs, S. 209. 
lich „unmöglich“ sei, „wesenhaft zum Deutschen“307 zu werden, wurde bereits 1920 in einem Aufsatz der Preußischen Jahrbücher zum Thema „Jüdischer und arischer Geist" aufgegriffen und zu einem definitiven Beweis der Unvereinbarkeit von „Deutschtum“ und Judentum stilisiert. Der offenbar hinter einem Pseudonym (Alexander Waldmann) verborgene Verfasser erklärte Stapel in seinem Aufsatz kurzerhand zur repräsentativen Stimme des „deutsche[n] Arier[s]“308. Ausdrücklich lobte „Waldmann“ die etwa im Vergleich zu Adolf Bartels „viel unparteiischere“ Argumentation und Sprache Stapels, mit der es gelungen sei, die wissenschaftliche Grundlage dafür zu schaffen, dass „die Assimilation für aktive jüdische Elemente“ eben „ganz unmöglich“ sei. Der Autor hatte es schon lange geahnt, nun erfreute er sich an Stapels angeblichen Beweis: Sowohl „neurasthenisch-dekadente jüdische Sensationssucher“ als auch „temperamentvoll-ungeduldige Willensmenschen“ seien dem „Arier“ schlicht „unverdaulich“309.

Mehrfach berief sich auch der Schriftsteller und Philosoph Hans Blüher auf Stapel, der schon im wilhelminischen Kaiserreich durch mehrere kontroverse Studien zur Wandervogelbewegung Berühmtheit erlangt hatte. ${ }^{310}$ In seiner vielbeachteten Studie Die Erhebung Israels gegen die christlichen Güter (1931) erklärte Blüher Stapel zu einem der „wenigen echten Antisemiten, die es in Deutschland“311 gebe. Angesichts der regen Umtriebe radikalantisemitischer Agitatoren seit der Jahrhundertwende mag diese Aussage zunächst zwar kurios anmuten, ihr Sinn erschließt sich aber, sobald man den Begriff „echt“ im Sinne Blühers als Synonym für „ernstzunehmend“ und „diskussionswürdig“ versteht. Ähnlich wie bei Stapel konzentrierten sich die antisemitischen Ausfälle Blühers primär auf die Beseitigung von jedem „geistigen Einfluss“ der Juden auf das deutsche Volk - ohne dabei auf einen primitiven „Rassenwahn“312 zu verfallen. Blüher hatte es besonders Stapels „ausgezeichnete“ 313 Broschüre Antisemitismus und Antigermanismus. Über das seelische Problem der Symbiose des deutschen und des jüdischen Volkes (1928) angetan. ${ }^{314}$

307 Vgl., Stapel, Antisemitismus [1920], S. 10.

308 Waldmann, Geist, S. 432.

309 Ebd.

310 Besonders hervorzuheben ist die skandalumwitterte Schrift Wandervogelbewegung als erotisches Phänomen (1912). Zu Blüher und der Rezeption seiner Schriften vgl. Bruns, Subjekt, sowie die zahlreichen Hinweise in: Bruns, Politik.

311 Blüher, Erhebung [1931], S. 128.

312 Weiling, Bewegung, S. 70.

313 Ebd, S. 201.

314 In dem 1932 erschienenen Sammelband Klärung. 12 Autoren, Politiker über die Judenfrage war es indessen Stapels in sieben Auflagen erschienene Broschüre Sechs Kapitel über Christentum und Nationalsozialismus (1931), auf die Blüher mit besonderem Nachdruck verwies. Vgl. Blüher, Erhebung [1932], S. 176f. Mit „Antigermanismus“ griff Stapel auf einen Begriff zurück, der sich schon während des Ersten Weltkriegs als „fester Bestandteil völkischen Vokabulars" etabliert hatte und der als „Synonym für die den Juden angelastete ,Überfremdung der akademischen Berufe' oder für den heimlichen ,Vernichtungskampf ' gegen die ,völkische Bewegung' und ihr Ziel einer ,deutsch-innerlichen und art-echten Kultur ' diente" (Hambrock, Etablierung, S. 317). 
Sehr ähnlich ging es Edgar Julius Jung ${ }^{315}$, der sich 1930 in der erweiterten Neuauflage seiner für die Ideengeschichte der Weimarer Rechten bedeutsamen Studie Die Herrschaft der Minderwertigen ebenfalls auf Stapels Broschüre berief. In ihr glaubte er den definitiven Beweis für seine Auffassung gefunden zu haben, dass das Volk für den Einzelmenschen die „stärkste metaphysische Gebundenheit“ darstelle. ${ }^{316}$ Auch Stapels Herleitung des deutschen Antisemitismus als Abwehrreaktion gegen den mutmaßlichen „Antigermanismus“ jüdischer Intellektueller leuchtete Jung ein:

„Stapel hat [...] dem Antisemitismus mit Recht einmal den Antigermanismus der Juden gegenübergestellt. In der Tat! Die Behauptung der jüdischen Sonderart ist das gute Recht dieses langlebigen und zähen Volkes [...]. Es ist nur die Frage, ob auf Dauer ein Minderheitenvolk seine geistige Zuständlichkeit dem zahlenmäßig viel stärkeren Wirtsvolke aufzwingen darf und kann. Heute haben die Juden diese geistige Machtstellung inne und verteidigen sie mit einer Kraft, die Gegenwirkung erzeugen muß ${ }^{\text {3317. }}$.

Doch nicht nur einflussreiche Intellektuelle wie Blüher und Jung zählten zu den Bewunderern von Stapels Broschüre Antisemitismus und Antigermanismus. Dies zeigt exemplarisch ein 1931 veröffentlichter Leitartikel der Burschenschaftlichen Blätter. Dieser Artikel, verfasst von H. Rüdel, war in erster Linie als Verteidigung eines zuvor in der Zeitschrift erschienenen Artikels des völkischen Burschenschaftlers Karl Hoppmann konzipiert ${ }^{318}$, der eine scharfe Replik des Breslauer Professors für Pharmakologie Otto Riesser provoziert hatte. Um Hoppmanns antisemitische Auslassungen zu verteidigen, führte Rüdel Stapels Broschüre ins Feld. Rüdel argumentierte, dass all denjenigen, die gleichsam in humaner Verblendung den Antisemitismus „als vollkommen menschenunwürdig“ betrachteten, „die Tatsache zu denken geben“ müsse, dass „alle geistig und schöpferisch bedeutenden deutschen Männer“ der Vergangenheit „dem Judentum im Bewußtsein der Artfremdheit ablehnend gegenüber[ge]standen“ seien. Schon dieser Sachverhalt beweise die Existenz einer „tiefere[n] Ursache“ und „innere[n] Begründung“ des Antisemitismus - ein Gedanke, den „Wilhelm Stapel in seinem leider viel zu wenig bekannten Buch ,Antisemitismus und Antigermanismus “"319 überzeugend entwickelt habe.

$315 \mathrm{Zu}$ Leben und Werk Jungs vgl. Jahnke, Jung; ferner die zahlreichen Bemerkungen in: Breuer, Anatomie.

316 Vgl. Jung, Herrschaft, S. 118.

317 Ebd., S. 123.

318 Vgl. Hoppmann, Antisemitismus. Für biografische Informationen zu Karl Hoppmann, dem Organisator der bis dato leider nicht erforschten Arbeitsgemeinschaft der völkischen Akademikerverbände des deutschen Sprachgebiets, vgl. auch Kap. 4.1.

319 Rüdel, Antisemitismus, S. 278 (Herv. i. Orig.). Insgesamt kam Rüdel in seiner Verteidigung Hoppmanns zu dem Ergebnis, dass der Antisemitismus „keine Ausdrucksform persönlicher Feindschaften, sondern naturnotwendige Reaktion aller Völker" sei, „die durch das Schicksal zu einem Zusammenleben mit dem [...] Judentum gezwungen“ seien. Eine noch „tiefere Begründung" finde der Antisemitismus „in der Artfremdheit, die das jüdische Volk von einem großen Teil der übrigen Völker trennt, verbunden mit jener merkwürdigen Eigenschaft, diese seine fremde Art überall in den Vordergrund zu stellen und so volkstümliches Geschehen zu unterdrücken“. Auf dies hinzuweisen und dies zu bekämpfen sei „kein gedankenloser Radauantisemitismus [...], sondern allein bewußte, unerbittliche, immerwährende Ablehnung des jüdischen Geistes in allen seinen Erscheinungsformen“ (S. 279, Herv. i. Orig.). 
Zur Etablierung Stapels als Antisemitismus-Referenz versuchte natürlich auch die Deutsche Handelswacht, das Organ des DHV, der auch Stapels Zeitschrift finanziell trug ${ }^{320}$, beizutragen. Nicht zufällig wurde Albrecht E. Günther, der Mitherausgeber des Deutschen Volkstums, als Rezensent von Stapels Broschüre Antisemitismus und Antigermanismus engagiert. Günther stellte es als den größten Vorzug der Broschüre heraus, gerade auf die "großstädtischen Intellektuellen“ eingewirkt zu haben, unter denen der angemessene und „natürliche Rassenwiderstand“ gegen die Juden bis dahin „oft versagt“321 habe; in der Großstadt sei der auf dem Land noch unversehrte "gesunde Rasseninstinkt" unglückseligerweise verloren gegangen. Anders konnte es sich Günther nicht erklären, dass „die populäre antisemitische Literatur" in den Städten einem „ungünstige[n] Vorurteil gegen die antisemitische Bewegung überhaupt" gewichen sei. Stapels Schrift galt nach dieser Lesart als „wertvolle[r] Beitrag“, um ,in sachlicher Form die Diskussion über die Judenfrage" auch in jene Kreise hineinzutragen, „die sich bisher dagegen gesträubt" hätten, sich mit ihr auseinanderzusetzen, und infolgedessen glaubten, sich "mit dem Schlagwort, Radau-Antisemitismus“" um eine Auseinandersetzung mit dem ,jüdischen Problem [...] herumdrücken zu können“322.

Weiterhin, so Günther, habe Stapel anschaulich „die Unvermeidlichkeit des Konflikts“ zwischen Deutschen und Juden als „zwei einander seelenfremde Völker" herausgearbeitet - eine „unüberbrückbare Seelenfremdheit", an der auch „alles Einfühlungsvermögen und Nachempfinden fremder Kulturwerte“, um das besonders "geistige Juden“ oft bemüht seien, „nichts zu ändern“ vermöge. Zielsicher der kulturpolitischen Meistererzählung des DHV folgend, betonte Günther schließlich die verheerende Wirkung der postulierten Dominanz der Juden Günther sprach von ,artfremden Gäste[n] “ - über „den größten Teil des deutschen Schrifttums“. Auch diese habe Stapel anschaulich aufgezeigt. Mehr noch: "Überzeugend“ weise dessen Schrift nach, wie der in der Anmaßung, die Deutschen „darüber aufzuklären“ zu wollen, welche Literatur von Wert sei und welche nicht, angelegte "angreifende Antigermanismus" der Juden in Deutschland erst den „abwehrende[n]“, „aus dem gesunden Rasseninstinkt unseres Volkes“ entspringenden Antisemitismus evoziert und provoziert habe. Da Stapel dieses hochsensible Thema überaus „zart und taktvoll“ behandle, sein Text „keine Spur von Judenhaß“ enthalte und sich durch eine völlig „,objektive Behandlung" seines Gegenstands auszeichne, sei die Broschüre auch ideal dazu geeignet, ,in Gegenwart von Juden erörtert [zu] werden“"323.

Stapels Antisemitismus im Urteil jüdischer InTellektueller - Wie aber fielen die Reaktionen jüdischer Intellektueller auf Stapels Schriften tatsächlich aus? Dass Stapels selbsterhobener Anspruch auf eine sachlichere Auseinandersetzung mit

320 Vgl. Kap. 2.1.

321 Günther, Antisemitismus, S. 155.

322 Ebd.

323 Ebd. (Herv. i. Orig.). 
dem Antisemitismus nicht nur eine selbstbeweihräuchernde Marketingstrategie war, sondern zeitgenössisch sehr ernst genommen wurde, unterstreicht anschaulich der Sachverhalt, dass Stapel auch von politischen Gegnern das Bemühen um eine reflektiertere Diskussion zuerkannt wurde. Die intensive Beschäftigung jüdischer Intellektueller mit Stapels Schriften belegt den Erfolg von dessen Absicht, auch in den Augen eines gebildeten, den Antisemitismus ablehnenden Publikums - oder, um eine Formulierung Stapels zu bemühen: in den Augen der „Gebildeten unter seinen Verächtern“324 - als Maßstab einer diskussionswürdigen Form des Antisemitismus wahr- und ernst genommen zu werden. Die Anerkennung höherer Sachlichkeit war dabei sowohl Grundlage für Respektsbekundungen gegenüber Stapel als auch Anlass für umso intensivere Kritik an seinen AntisemitismusSchriften. Mehrere jüdische Kritiker sahen von ihnen eine noch größere Gefahr ausgehen als von den hasserfüllten und törichten Traktaten, wie sie in der Frühphase der Weimarer Republik vor allem der Deutschvölkische Schutz- und Trutzbund massenhaft verbreitet hatte. ${ }^{325}$

Beifall erhielt Stapel zunächst von Seiten der Zionisten. Den bereits mehrfach zitierten, 1919 im Deutschen Volkstum veröffentlichten Antisemitismus-Aufsatz übernahm die Zeitschrift Die Arbeit, eines der Hauptorgane des deutschen Zionismus ${ }^{326}$, sogar als Wiederabdruck. ${ }^{327}$ Die Redaktion fügte dem Aufsatz Stapels lediglich die Vorbemerkung zu, bislang „zum Problem des Antisemitismus“ geschwiegen zu haben, da die „Kleinlichkeit“, mit der das Thema von Seiten der jüdischen und deutschen Presse bis dato behandelt worden sei, keine Reaktion notwendig gemacht habe. Anknüpfend an Stapels Ablehnung der jüdischen „Assimilation" hatten sich die Herausgeber auch deshalb zum Wiederabdruck des Aufsatzes entschieden, um sich von der in ihren Augen „verächtliche[n]“ und „empörende[n] Argumentation der jüdischen Assimilaten“ abzugrenzen. Stapels Erörterungen deutete die Redaktion demgegenüber als die eines „aufrechten und ehrlichen Deutschen“. Stapel hatte zugleich die Haltung der Arbeit „ein für allemal“" geklärt; seiner Darstellung hatte die Redaktion „nichts hinzuzufügen“328.

Als Kronzeuge eines gemäßigten Antisemitismus erschien Stapel dem an der Humboldt-Hochschule Berlin lehrenden Nationalökonomen Arthur Prinz. ${ }^{329}$ In

324 Stapel, Jahre [1938], S. 801.

325 Lohalm, Radikalismus, bes. S. 122-132, 139-152; Breuer, Völkischen, S. 150-160.

326 Die selbsterklärten Aufgaben der Arbeit waren die folgenden: „Der Zionismus als Ganzes hat sich noch nicht zu einer Gesinnung der Kultur, der Wirtschaft, der Politik entschieden. Und er muß jetzt im größten Stile nationale Politik treiben, muß nationale Wirtschaft begründen, muß Bedingungen nationaler Kultur schaffen. [...] Palästina kann unser werden und es kann unser Zion sein oder ein neuer Ort unseres Galuth. Der Hapoel Hazair will, daß es Zion werde, er will in diesem Augenblick der tausend Möglichkeiten die eine Möglichkeit, die ihm die reinste und einzig segenvolle erscheint, verkünden, für sie werben, für sie kämpfen. Das ist die Aufgabe dieses Blattes“ (Die Arbeit. Organ der Zionistischen Volkssozialistischen Partei Hapoel Hazair 1 (1919), S. 1, Herv. i. Orig.).

327 Vgl. ebd., S. 252-255.

328 Ebd., S. 252.

329 Arthur Prinz (1898-1981) besuchte das Bismarck-Gymnasium Berlin und studierte anschließend Nationalökonomie, Philosophie und Geschichte an den Universitäten Berlin und 
einer Replik auf Paul Fechters vieldiskutierten Aufsatz Kunstbetrieb und Judenfra$g e^{330}$ warnte Prinz zwar mit Nachdruck vor den gesellschaftlichen Auswirkungen der in Deutschland grassierenden Judenfeindschaft, hob jedoch zugleich das Bemühen einzelner Intellektueller der politischen Rechten hervor, sich „von den Schandmethoden eines antisemitischen Pöbels“ abzugrenzen. Ihnen dürfe „auch von jüdischer Seite der gute Wille und die geistige Klarheit nicht wohl abgesprochen werden“. Konkret dachte Prinz hierbei „an Willy Hellpach, Fritz Klein, [Paul] Rohrbach, [Walter] Bloem, und ,last not least', trotz mancher Entgleisungen, an Wilhelm Stapel“331.

Ein namentlich nicht erwähnter Mitarbeiter der von Martin Buber herausgegebenen Monatsschrift Der Jude begründete 1920 die Bedeutung der Antisemitismus-Schriften Stapels damit, dass in ihnen „von einem denkenden Deutschen zum ersten Mal ausgesprochen“ werde, was „zweifellos viele Deutsche unklar fühlen“332 würden. Der Autor setzte sich jedoch deutlich kritischer mit Stapel auseinander, als es die Herausgeber der Arbeit getan hatten. Zwar hielt er Stapel die Absicht zugute, „ehrlich und offen die völkischen Verschiedenheiten“ zwischen den Juden und Deutschen darzustellen; dem Anspruch, sich von einem „fälschenden und hetzenden Antisemitismus“ gänzlich „freizuhalten“, sei Stapel jedoch nicht gerecht geworden. Zu Recht verwies der Autor hier insbesondere auf das kollektivistische Denken Stapels, welches zwischen individuellen Juden und dem Judentum als heterogenem, vielfältigem Ganzen nicht zu differenzieren vermöge. Stapel habe sich „von dieser verlogenen Grundeinstellung des Antisemitismus“ nicht emanzipiert und damit bewiesen, „wie nahe er diesem“333 in Wirklichkeit stehe. Auch seine Neigung, bisweilen „dem Gassen-Antisemitismus einige mauschelnde Wendungen“ zu entleihen, demaskiere Stapel, zeige sich in ihr doch, „wie feindlich trotz allen Strebens nach Gerechtigkeit die gefühlsmäßige Einstellung Stapels zum Judentum“ sei. Wolle Stapel, „wie man nach seinen Aufsätzen gerne annehmen“ möge, ernsthaft auf ein „vernünftiges und auf gegenseitiger Achtung begründetes Zusammenleben“ der Juden und Deutschen wirken, so müsse er künftig „zunächst versuchen“, jenes kollektivistische Denken und jegliche Rückfälle in den „Gassen-Antisemitismus“ zu

Würzburg. 1923 promovierte er zum Thema „Das Marxsche System in psychologischer Betrachtung" - eine Arbeit, die jedoch ungedruckt blieb. Von 1926 bis zu seiner Entlassung im Juli 1933 lehrte Prinz an der Berliner Freien Volkshochschule (Humboldt-Hochschule) Nationalökonomie. Anschließend fand er Beschäftigung als Vorstandsmitglied des Hilfsvereins der Juden in Deutschland. Nach kurzer Inhaftierung (1938) wanderte Prinz im März 1939 nach Palästina aus, wo er bis 1947 als Journalist und freier Schriftsteller wirkte. Nach seiner Emigration in die USA 1948 lehrte er bis zu seiner Emeritierung 1966 am Dickinson College in Carlisle (Pennsylvania).

$330 \mathrm{Zu}$ dem Aufsatz und der von ihm hervorgerufenen Diskussion vgl. Hambrock, Etablierung, S. 316-318.

331 Prinz, Entgiftung, S. 70.

332 Vgl. Der Jude. Eine Monatsschrift 5 (1920/21), H. 1, S. 62 f.

333 Ebd. 
„überwinden“, durch die „seine sachlichen Ausführungen“ noch „entwertet“ würden. ${ }^{334}$

Besonders anschaulich wird die Bedeutung, die jüdische Intellektuelle Stapels Antisemitismus-Schriften zusprachen, schließlich dadurch illustriert, dass sich Julius Goldstein, Extraordinarius für Philosophie an der Technischen Universität Darmstadt und Herausgeber der Zweimonatsschrift Der Morgen ${ }^{335}$, in einer Aufsatzserie, die er dort 1926/27 veröffentlichte ${ }^{336}$, ausschließlich mit Stapel auseinandersetzte. Diesen Schritt begründete Goldstein damit, dass der enorme Umfang und die große Heterogenität der „Literatur des völkischen Antisemitismus“ die Beschränkung auf einzelne maßgebliche Texte für den Forscher notwendig mache. Als sinnlos galt es Goldstein, sich mit „den völkischen Erzeugnissen aus der Gasse" abzugeben, für deren minimales Reflexionsniveau er in selbstbewusstdespektierlicher Manier nur höhnische Goethe-Verse übrig hatte. ${ }^{337}$ Anstatt sich mit dem „Gassenantisemiten“ zu beschäftigen, verwendete Goldstein als Grundlage seiner Untersuchung ausschließlich Stapels 1920 veröffentlichte Broschüre Antisemitismus. Diese Schrift, so Goldstein, habe „viele Leser gefunden“ und werde „gerade in jenen Kreisen“, die sich ansonsten von der „Ungezogenheit und Unerzogenheit der antisemitischen Tagesliteratur" fernhielten, „als das Beste und Unangreifbarste“ wertgeschätzt, „was sich über diesen Gegenstand sagen“ lasse. Damit sei die Schrift zugleich „am besten geeignet“, um „die Argumente des völkischen Antisemitismus zu erfassen und zu prüfen"338.

Der Suggestionskraft der Argumentation Stapels, die im Ausdruck „vornehm und zurückhaltend“ sei und pauschale „abwertende Urteile über Juden“ vermeide, konnte sich auch Goldstein nicht gänzlich entziehen: Bisweilen geschehe es, dass man bei der Lektüre vergesse, „einen antisemitischen Schriftsteller“ vor sich zu haben, dessen Erfolgsgeheimnis eben genau darin liege, „kein Polterer“ zu sei und „nicht mit der Tür ins Haus" ${ }^{\text {“39 }}$ zu fallen. Doch machte es sich Goldstein zur Aufgabe, genau dieses hohe Ansehen, in dem Stapel mit seinen Publikationen zum Antisemitismus stand, zu demontieren und die ihnen inhärenten komplexi-

334 Ebd.

$335 \mathrm{Zu}$ Leben und Werk Julius Goldsteins (1873-1929) vgl. die Einleitung in: Zuber (Hg.), Goldstein.

336 Die Serie trug den Titel Völkischer Antisemitismus. 1927 sammelte Goldstein seine Aufsätze in der Schrift Deutsche Volksidee und deutsch-völkische Idee. Nach ihr wird im Folgenden zitiert.

337 Vgl. Goldstein, Volks-Idee, S. 8. Konkret zitierte Goldstein das dem West-östlichen Divan entnommene Gedicht „Wanderers Gemütsruhe“: „Übers Niederträchtige / Niemand sich beklage; / Denn es ist das Mächtige, / Was man dir auch sage. / In dem Schlechten waltet es / sich zu Hochgewinne, / Und mit Rechtem schaltet es / Ganz nach seinem Sinne. / Wandrer! - Gegen solche Not / Wolltest du dich sträuben? / Wirbelwind und trocken Kot, / Laß sie drehn und stäuben" (Goethe, Berliner Ausgabe, Bd. 3, S. 63 f.).

338 Goldstein, Volks-Idee, S. 8.

339 Ebd. Max Naumann, die bedeutendste Figur im 1921 gegründeten Verband nationaldeutscher Juden, stieß sich hingegen am „abstoßenden Ungeschmack“ in Stapels Literatenwäsche (1930). Zitiert nach: Hambrock, Etablierung, S. 296. 
tätsreduzierenden Ressentiments freizulegen. ${ }^{340}$ So lohnend es auch heute noch ist, Goldsteins Darstellung zu lesen, interessieren an dieser Stelle nicht die detaillierten Inhalte seiner Studie, sondern der Sachverhalt, dass Stapel auch von Goldstein zur Referenzgröße einer gerade unter gebildeten, anspruchsvollen Lesern wirkmächtigen Ausformung des Antisemitismus gewertet wurde. In dieser Rolle hielt er Stapel für ausreichend gefährlich, um sich zwei Jahre lang der Widerlegung seiner Thesen zu widmen - trotz allem Überdruss, der ihn während dieser Auseinandersetzung mitunter überkam. ${ }^{341}$

Stapel erhielt auch Gelegenheit, seine Haltung zur „Judenfrage“ im Weimarer Rundfunk zu verbreiten und zu verteidigen. Am 24. Mai 1932 nahm Stapel an einer „halbstündige[n] Rundfunkdiskussion über Antisemitismus“ mit Ludwig Holländer teil, dem Direktor des Central-Vereins deutscher Staatsbürger jüdischen Glaubens. Nach eigener Aussage war Stapel von Seiten des (namentlich nicht genannten) Senders zur Teilnahme an der Diskussion „arg gedrängt“ worden, „durch Eilbrief und Telefon“ sowie „durch persönliche Einwirkung“342 des DHV-Funktionärs Walther Lambach und des Reichstagsabgeordneten der Konservativen Volkspartei Hans-Erdmann von Lindeiner-Wildau. Über die Inhalte dieses „in den Grundzügen vorher festgelegte[n]“343 Gesprächs finden sich allerdings weder im Nachlass Stapels noch in den Briefen an Kolbenheyer nähere Informationen. Dass Stapel aber im Wesentlichen keine grundlegend neuen Gedanken präsentierte, sondern lediglich die in seinen früheren Schriften ausgearbeiteten Positionen wiederholte, geht aus einem knappen Kommentar hervor, den Max Dienemann, Rabbiner der Israelitischen Gemeinde Offenbach am Main, in der Zeitschrift Der Morgen veröffentlichte. Demnach griff Stapel in der Diskus-

340 Dies konnte der Leser seiner Broschüre bereits unschwer aus dem weiteren Wortlaut der Einleitung erschließen. Besonders stieß sich Goldstein an der Widersprüchlichkeit der Aussagen Stapels, wonach er einerseits „die staatsbürgerlichen Rechte der Juden durchaus nicht angetastet" sehen wolle, er es andererseits aber als „unerträglich“ bezeichnete, „die Geschicke meines Volkes von Juden geleitet zu sehen“. Schließlich bedeuteten volle staatsbürgerliche Rechte für jeden Juden, dass dieser „selbstverständlich nach Maßgabe seiner Befähigung, auch jene Stellungen inne haben [dürfe], von denen aus die Geschicke des Volkes mitbestimmt werden“. Von Stapels Aussage über die Unerträglichkeit, so Goldstein, müssten „alle philosophischen Erörterungen über Volk, Individuum, Fichte gewertet werden: von diesem Satz aus muss die ganze Schrift aufgerollt werden" (Goldstein, Volks-Idee, S. 9).

341 Von diesem Überdruss legt Goldsteins Tagebuch beredt Zeugnis ab. Ihm vertraute er schon am 27. Mai 1925 seine grundlegende Skepsis an, ob sich die Auseinandersetzung mit dem völkischen Antisemitismus überhaupt lohnen würde: „Ich bin dabei, mich mit Stapel: Antisemitismus auseinanderzusetzen und nehme die Gelegenheit wahr, über Volk, völkisch mich und die andern aufzuklären. Lohnt's sich eigentlich?". Ein am 27. Februar 1927 verfasster Eintrag erlaubt einen Einblick in die Gemütsverfassung Goldsteins nach knapp zweijähriger Arbeit an dieser Thematik: „Hin und wieder bin ich noch empört über tückischen Antisemitismus und bin voll Ekel über ihn und die Abwehr. Ewig Feuerspitze sein, wo ein Weltfeuer doch nicht gelöscht werden kann und wo die Zionisten immer wieder Öl in's Feuer gießen. Heute Nacht vor Zorn kein Auge geschlossen. [...] Ich kann kaum noch die Morgen-Aufsätze gegen Stapel fertig machen. Ekel! Und Überdruß! Ich will von all den Dingen nichts mehr wissen." Vgl. Zuber (Hg.), Goldstein, S. 198, 207.

342 KAG, Wilhelm Stapel an Erwin Guido Kolbenheyer, 22. Mai 1933.

${ }^{343}$ Keßler, Stapel, S. 284. 
sion mit Holländer auf „Gedankengänge“ zurück, die er „schon früher in seinem Buch ,Antisemitismus' angebahnt" hatte. Primär, so Dienemann, sei es Stapel darum gegangen, einen prinzipiellen „Gegensatz“ zwischen der deutschen und jüdischen „Auffassung vom Wesen der Gemeinschaft" ${ }^{\text {“44 }}$ zu begründen. Auch die im Anhang des noch in der zweiten Jahreshälfte 1933 vom Verlag der Jüdischen Rundschau publizierten Buchs Ja-Sagen zum Judentum aufgeführten Informationen zu dem nach Ansicht des Verfassers „unbefriedigend“ verlaufenen RundfunkGespräch bieten keinen Anlass zur Annahme, dass Stapel in der Diskussion mit Holländer neue Argumente präsentiert hätte. ${ }^{345}$

STAPEL ALS AUSHÄNGESCHILD EINES GEMÄSSIGTEN ANTISEMITISMUS IM JAHR 1933 Zwar sollte Stapel in den Jahren 1935-1937 für seine „sachliche“ Einstellung zur „Judenfrage“ in massive öffentliche Kritik geraten ${ }^{346}$, dieser Sachverhalt spiegelt jedoch noch nicht die Situation des Jahres der nationalsozialistischen „Machtergreifung“ wider. Für das Jahr 1933 ist vielmehr ein Briefwechsel mit dem Reichsministerium für Volksaufklärung und Propaganda überliefert, der hinsichtlich des Rufs von Stapel, Referenz eines gemäßigten, intellektuell anspruchsvollen Antisemitismus zu sein, von einigem Interesse ist. Stapel war zunächst, beginnend mit dem 1. Juni 1933, durch das Ministerium „auf die Dauer von drei Jahren zum Beisitzer der Oberprüfstelle für Schund- und Schmutzschriften "347 bestimmt worden - eine Auszeichnung, die für eine hohe Wertschätzung der im Deutschen Volkstum eingeübten Literaturkritik spricht. Dass das Goebbels-Ministerium zunächst jedoch auch Stapels Perzeption der „Judenfrage“ als wertvoll erachtete, jedenfalls für die Außendarstellung des NS-Staats, geht daraus hervor, dass Stapel im Oktober 1933 von dem damaligen Leiter der Ausland-Abteilung im Propagandaministerium, Hermann Demann, zur Mitarbeit an dem geplanten Sammelband Germany speaks aufgefordert wurde. Dieser sollte „die Leistungen des Neuen Deutschlands auf allen Gebieten beleuchten“, war also „gewissermaßen als ,Weiß-

344 Dienemann, Wesen, S. 181. Dienemann zitierte Stapel in seinem Beitrag mit den Worten: „Das, was uns trennt, ist, daß wir vom Wesen der Gemeinschaft entgegengesetzte Anschauungen haben. Sie sehen alles aufgelöst in einzelne Gruppen und Individuen und messen dem Willen einen Bereich zu, den ich dem Willen nicht zuerkennen kann. Meine Volksauffassung ist die, daß Volk eine überindividuelle Gemeinschaft ist, unabhängig von dem Wollen des Einzelnen" (ebd., Herv. i. Orig.).

345 Die Unzufriedenheit des Verfassers gründete sich darauf, dass die Debatte „oft auf Nebengleise“ geraten sei, der „Kern des Problems“ also „nicht herausgearbeitet" wurde. Darauf, dass Stapel (jedenfalls aus der Perspektive des Verfassers) das Gespräch mit Holländer dominierte, deutet die Bemerkung hin, dass der „Antisemitismus [...] nur von der deutschen, nicht von der jüdischen Seite beleuchtet“ worden sei. Über das „Primäre der jüdischen Position“ und die „Einzigartigkeit des jüdischen Schicksals" hätten „die Rundfunkhörer nichts erfahren“. Vgl. Weltsch (Hg), Ja-Sagen, S. 147-153, hier S. 147. Dass das Buch erst in der zweiten Jahreshälfte erschien, ist dadurch belegt, dass das Vorwort des Herausgebers auf den 1. August 1933 datiert.

346 Vgl. Kapitel 5.2.2.

347 DLA, A:Stapel, Reichsministerium für Volksaufklärung und Propaganda an Wilhelm Stapel, 10. Juni 1933. 
buch deutscher Arbeit und deutscher Kultur' gedacht". Mit anderen Worten: In dem Sammelband sollte der "negativen Kritik“ des Auslands „das positive Schaffen des Neuen Deutschlands entgegengesetzt werden“348.

Zwar verzögerte sich das Buchprojekt so lange, dass Stapels Mitarbeit letztendlich unter den Tisch fiel ${ }^{349}$, im vorliegenden Argumentationszusammenhang ist jedoch entscheidend, dass Stapel zunächst als Mitarbeiter dieses prestigeträchtigen Buchprojekts angedacht war. Wie hoch Stapels Name im Propagandaministerium gehandelt wurde, geht aus der dem Schreiben Demanns beigelegten Auflistung der geplanten Mitarbeiter des Sammelbands hervor, die sich wie ein politisches „Who is Who" des „Dritten Reichs“ liest: Zugesagt hatten ihre Mitarbeit Joseph Goebbels, Konstantin von Neurath, Hjalmar Schacht und Kurt Schmitt. Ferner waren, neben Stapel, als weitere Mitarbeiter vorgesehen: Werner von Blomberg, Walther Darré, Otto Dietrich, Gottfried Feder, Walter Frank, Wilhelm Frick, Wilhelm Furtwängler, Hermann Göring, Hans F. K. Günther, Konstantin Hierl, Hanns Johst, Ernst Krieck, Robert Ley, Franz von Papen, Max Planck, Ernst Röhm, Bernhard Rust und Baldur von Schirach. 350

Der Ruf, den sich Stapel nach 1918 als Vertreter eines vorgeblich „sachlichen“ Antisemitismus erworben hatte, kam hier zum Tragen. Eine ausgewogene und argumentationsstarke, nicht aber polemische Behandlung der „Judenfrage“ entsprach exakt der vom Propagandaministerium gewünschten Außenwahrnehmung vor allem im englischsprachigen Ausland, an das sich der geplante Sammelband in erster Linie richten sollte. Mit diesem Hintergedanken trug Demann Stapel die Aufgabe an, einen Artikel „etwa unter dem Titel: ,Deutschland und die Juden' in deutscher oder englischer Sprache" 351 zu verfassen. Schließlich sollte - so das ausführliche, dem Brief beiliegende, vertrauliche Memorandum an alle vorgesehenen Mitarbeiter - ,jedes Kapitel“ in Germany speaks auch „von einem Mann geschrieben sein, der auf dem betreffenden Gebiet die größte Autorität genießt ${ }^{\text {“352 }}$.

Stapel zeigte sich an der Aufgabe interessiert; auf seine Nachfrage hin teilte Demann mit, dass der gewünschte Beitrag eine Länge von fünf bis zehn Schreib-

348 DLA, A:Stapel, Reichsministerium für Volksaufklärung und Propaganda an Wilhelm Stapel, 28. Oktober 1933.

349 Der Sammelband erschien erst im Jahr 1938. Zu diesem Zeitpunkt stand Stapels Mitarbeit nicht mehr zur Debatte, einerseits aufgrund seiner scharfen Konflikte mit dem Amt Rosenberg und dem SS-Organ Das schwarze Korps, andererseits aufgrund seines generellen Bedeutungsverlusts seit 1933. Vgl. Kap. 5.2.2.

350 DLA, A:Stapel, Reichsministerium für Volksaufklärung und Propaganda an Wilhelm Stapel, 28. Oktober 1933.

351 Ebd.

352 Ebd., beiliegendes vertrauliches Memorandum über das Buchprojekt Germany speaks, S. 2. Darin auch die weiterführende Information $\mathrm{zu}$ dem von Stapel erbetenen Artikel: In Deutschland und die Juden solle es darum gehen, der im Ausland geübten „recht starke[n] Kritik der Judenbehandlung in Deutschland“ entgegenzuwirken, wobei die Darstellung aber keinesfalls den Eindruck erwecken dürfe, als ob Deutschland „unter Anklage stände“. Es solle keine „Verteidigung“, sondern eine nüchterne Darstellung werden. Zudem solle Stapels Artikel klarmachen, dass „das Judenproblem nur ein Teilproblem und zwar ein verhältnismäßig kleines Teilproblem des breiten deutschen Programms" darstelle (ebd., S. 7f.). 
maschinenseiten haben dürfe. ${ }^{353}$ Die Gründe, warum der geplante Sammelband verschoben wurde und schließlich erst 1938 erschien (ohne Beteiligung Stapels), sind nicht bekannt, hier allerdings auch ohne Belang. Dass man sich innerhalb des Ministeriums ursprünglich auf Stapel als Wunschautor eines Beitrags über Deutschland und die Juden verständigt hatte, zeugt nicht nur von der Absicht, Stapel für eigene Propagandazwecke einzuspannen, sondern unterstreicht zugleich dessen Ruf als Referenzautor eines - vergleichsweise - reflektierten, argumentativ kohärenten und somit gleichsam vorzeigbaren Antisemitismus, der 1933 auch in das Lager der Nationalsozialisten vorgedrungen war.

\title{
3.3 Kolbenheyers biologistisches Weltbild und seine Rezeption 1925-1945
}

\subsubsection{Grundzüge der Philosophie der „Bauhütte“}

\author{
Nur der biologische Standpunkt ist unangreif- \\ bar, alles andere verfällt dem Rationalismus. Es \\ wird auch der biologische Standpunkt allein \\ fruchtbar bleiben. 354
}

Für jede wissenschaftliche Beschäftigung mit Kolbenheyer, sei es biografischer, mentalitätsgeschichtlicher oder literaturhistorischer Art, ist es unabdingbar, sich mit Kolbenheyers philosophischem Hauptwerk, Die Bauhütte. Elemente einer Metaphysik der Gegenwart (1925) ${ }^{355}$, auseinanderzusetzen. Als wichtigste Quelle seiner Weltanschauung durchziehen die Inhalte dieses Werks fast sämtliche Texte des Dichters. Doch hat die Bauhütte seit Ende des Zweiten Weltkriegs kaum (philosophie-)geschichtliche Spuren hinterlassen; heute, 90 Jahre nach ihrer Veröffentlichung, darf sie als ein weitestgehend vergessenes wie auch gesellschaftlich bedeutungsloses Werk gelten. Die Hauptursachen hierfür sind leicht auszumachen. Sie liegen erstens in der Kontaminierung des Namens Kolbenheyer, dessen enge und langfristige Verbindung mit dem Nationalsozialismus ${ }^{356}$ eine Anerken-

353 DLA, A:Stapel, Reichsministerium für Volksaufklärung und Propaganda an Wilhelm Stapel, 3. November 1933.

354 DLA, A:Stapel, Erwin Guido Kolbenheyer an Wilhelm Stapel, 11. Mai 1931 (Herv. i. Orig.).

355 Mit dem Titel Bauhütte wollte Kolbenheyer andeuten, seine Lehre „nicht in systematischer Geschlossenheit“, sondern nur nach ihren grundsätzlichen „Denkeinstellungen“ nach präsentieren zu können (Koch, Kolbenheyer [1953], S. 84). Kolbenheyer wollte also kein vollständiges „metaphysisches System“ aufbauen, sondern „nur Materialien [...] für ein solches beibringen, so wie es die Dombaumeister in ihren Bauhütten taten“ (Alker, Metaphysik, S. 882). Eine vollständige Darstellung seiner Philosophie, so betonte Kolbenheyer stets, hätte eine Vielzahl von Büchern erfordert: Er habe in seiner Bauhütte aus Platzgründen „nur Grundzüge entworfen“ und seine „Vorschläge dogmatisiert“. Andernfalls hätte „die ,Bauhütte $[$ [...] ein Sammelwerk von zehn Bänden werden müssen“ (zitiert nach: Koch, Kolbenheyer [1953], S. 86).

356 Vgl. die Kap. 5.1, 5.2.1, 5.3.2 und 6.2. 
nung als geistige Autorität in der Bundesrepublik von vornherein unwahrscheinlich machte. ${ }^{357}$ Zweitens ist auf die Delegitimierung monokausal biologistischen Denkens und entsprechender Welterklärungsmodelle zu verweisen, die vor dem Erfahrungshintergrund der verbrecherischen Rassenpolitik des „Dritten Reichs“ ebenfalls leicht einsichtig ist. Unabhängig von den historisch-gesellschaftlichen Rahmenbedingungen basiert Kolbenheyers Philosophie - drittens - jedoch auch auf einem überaus wackeligen Fundament spekulativer Grundannahmen, um deren Beweis sich Kolbenheyer gar nicht erst bemühte, sondern die er als vermeintlich evidente und angeblich wissenschaftlich abgesicherte Tatsachen darstellte und verstanden wissen wollte. Kritiker, die sich hiervon nicht überzeugen ließen, pflegte Kolbenheyer der Befangenheit in überlebten und unzeitgemäßen Denkmustern zu bezichtigen, die ihnen ein Verständnis der Bauhütte von vornherein unmöglich mache. Viertens schließlich hat Kolbenheyers philosophisches Hauptwerk nach 1945 auch deshalb kaum mehr Aufmerksamkeit gefunden, da die biologischen Kenntnisse des Autors, auf denen seine gesamte Argumentation beruhte, im Wesentlichen auf dem Kenntnisstand der Jahrhundertwende verharrten jener Zeit also, in der Kolbenheyer an der Universität Wien unter anderem Zoologie studiert hatte. ${ }^{358}$ Die grundstürzend neuen Erkenntnisse der Klassischen Genetik seit 1910, die mit den weitreichenden Spekulationen der evolutions- und entwicklungsbiologischen Debatten des 19. Jahrhunderts schrittweise aufräumten, nahm Kolbenheyer ebensowenig zur Kenntnis wie die Errungenschaften der modernen Molekularbiologie ${ }^{359}$ seit den 1930er Jahren. So lebte Kolbenheyer bis zu seinem Tod in der Illusion, sich auf Augenhöhe mit der wissenschaftlichen Entwicklung der Biologie zu bewegen - ja, ihr sogar einen Schritt voraus zu sein. 360

357 Dass es immerhin nicht ausgeschlossen war, trotz NS-Vergangenheit zu einem Klassiker der modernen Philosophie aufzusteigen, zeigt das Beispiel Martin Heideggers. Für eine einführende Literatur in die umstrittene Frage zum Verhältnis Heideggers zum Nationalsozialismus vgl. Zaborowski, „Der verwüstenden Sandstürme nicht vergessen...“.

358 Vgl. Kap. 2.1.

359 Vgl. hierzu: Rheinberger, Geschichte, sowie Ders./Müller-Wille, Vererbung, S. 209-240. Hinsichtlich der Klassischen Genetik ist etwa an den 1915 erbrachten Nachweis spontaner Mutationen durch die Taufliegen-Experimente des amerikanischen Biologen Thomas H. Morgan (1866-1945) zu erinnern, die eine „Erklärung für einen Mechanismus der Anpassung von Merkmalen ohne die Übertragung erlernter Charakteristika" (Blom, Kontinent, S. 390 f.) lieferte. Freilich muss der Gerechtigkeit halber betont werden, dass Kolbenheyer bereits 80 Jahre alt war, als Francis Crick 1958 das von der biologischen Forschung mittlerweile zwar ergänzte, bis heute aber in seinem Kern als gültig anerkannte „Zentrale Dogma“ der Molekularbiologie formulierte, demzufolge „der molekulare Informationsfluss [...] von der DNA über die RNA zu den Proteinen“ verläuft, „der umgekehrte Weg einer Informationsübertragung von den Proteinen zum Erbmaterial“ hingegen "ausgeschlossen“ ist. Vgl. Rheinberger/Müller-Wille, Vererbung, S. 236.

360 Noch in seinen Memoiren wies er alle von seinem eigenen Vererbungsmodell abweichenden Vorstellungen selbstgefällig als „sehr bequeme“ und „in ihrer Einfalt" „beneidenswert[e]“ „Denk- und Vorstellungsart[en], die der theoretische Idealismus gezeitigt" habe, ab. Die Erbbiologen, so Kolbenheyer, schreckten „,or den Gedanken an eine Vererbung jener Anpassungen zurück, die der Organismus unter der Einwirkung seiner Umwelt während des 
Kolbenheyers fehlende Bereitschaft, seine biologischen Kenntnisse in selbstkritischer Weise aufzufrischen und neu zu prüfen, macht es Kritikern seit jeher leicht, die Bauhütte auch unabhängig von ihrer ideologischen Aufladung zu kritisieren. Selbst ein politisch alles andere als unvorbelasteter Akademiker wie der Würzburger Philosophieprofessor Hans Meyer ${ }^{361}$ kommentierte in seiner Geschichte der abendländischen Weltanschauung (1949) süffisant, Kolbenheyer habe so viel „überhaupt nicht gesehen oder falsch gesehen“, dass man bei der Kritik nicht wisse, „wo man anfangen und, hat man angefangen, wo man aufhören“362 solle.

In den ersten zwei Jahrzehnten nach der erstmaligen Publikation der Bauhütte im Jahr 1925 nahm sich diese Situation jedoch noch anders aus. Wohl wurde die Bauhütte nie zu einem populären Werk und selbst ein jahrelanger, phasenweise euphorischer Anhänger der Philosophie Kolbenheyers wie Wilhelm Stapel ${ }^{363}$ stellte schon 1927 insgeheim die durchaus einleuchtende Vermutung an, Kolbenheyers Verlag habe die Bauhütte letztlich nur deshalb in sein Programm aufgenommen, um sich „dadurch die moralische Anwartschaft auf spätere Romane“364 zu sichern. Wer der langsamen aber steten Rezeption der Bauhütte im Zeitraum von 1925 bis 1945 nachspürt, vermag dennoch einige interessante Funde zu machen. Ehe dies erläutert wird, sollen jedoch zunächst die zentralen Grundannahmen und Inhalte der Bauhütten-Philosophie dargestellt werden. Dabei kann es nicht darum gehen, das Buch in seiner Gesamtheit zusammenzufassen. Der Umfang eines Kapitels würde dabei gesprengt, vor allem aber wäre eine solch umfassende Rekapitulation kaum zielführend. Denn die Bauhütte wurde während des genannten Untersuchungszeitraums in aller Regel nur selektiv, nach einzelnen zentralen Ideologemen, Gedankengängen und Argumentationssträngen rezipiert. Diese stehen im Folgenden im Vordergrund.

VOM „PLASMA“, VON „ALTEN“ UND VON „JUNGEN“ VÖLKERN - Im Zentrum der Weltanschauung Kolbenheyers stand das „Plasma“ - verstanden als die „materielle Grundlage des Erbguts“ und „organische Basis allen Lebens“ 365 , respektive als der

Lebens erreichen muß, um weiter bestehen zu können“. Der Grund für das Zurückschrecken liege darin begründet, dass „bisher kein Experiment die Erbfähigkeit des intra vitam Erworbenen beweisen konnte“. Es sei indes „irrig“, „als wissenschaftlichen Beweis nur das anzusehen, was einem Forscherauge sichtbar werden kann". Selbst die durch modernste technische Gerätschaften und Beobachtungsmethoden gewonnenen Einblicke seien „längst nicht erforderlich tief, das Vererbungsproblem zu lösen" (Kolbenheyer, Sebastian Karst, Bd. 1, S. 53f.). Den Grund, warum sich angesichts der von ihm angenommenen Unvermeidlichkeit des Unbeweisbaren sein intuitives, anti-empirisches biologisches Weltbild als zwingend wahr aufdrängen müsse, ließ Kolbenheyer im Dunkeln.

361 Vgl. Tilitzki, Universitätsphilosophie, S. 357f., 1043. Zur Biografie Meyers (1884-1966) vgl. ebd. S. $143 \mathrm{f}$.

362 Meyer, Geschichte, S. 492.

363 Stapels Eintreten für und Verhältnis zur Bauhütten-Philosophie ist in den Kap. 2.3.1 und 6.1 beschrieben.

364 DLA, A:Grimm. Deutsches Volkstum an Hans Grimm, 19. März 1927.

365 Friedrich, Lebensbilder, S. 93. 
„natürliche Träger aller Lebenserscheinung“366, um Kolbenheyers Wortwahl zu bemühen. Nach seiner Auffassung bedingte das „Plasma“ die Fertigkeit aller natürlichen Organismen - beginnend von der Pflanzenwelt über das Tierreich bis hin zum Menschen und schließlich den einzelnen Völkern -, sich den beständig verändernden äußeren Lebensbedingungen anzupassen und auf diese Weise den eigenen Fortbestand zu sichern. Kolbenheyers Plasmabegriff stand in der Tradition der erbbiologischen Vorstellungen des 19. Jahrhunderts. Er erinnert insbesondere an den Botaniker Carl Wilhelm von Nägeli (1817-1891), der als konstante "Vererbungssubstanz" aller Organismen die Existenz eines Idioplasma postulierte $^{367}$, sowie an den Biologen und Evolutionstheoretiker August Weismann (1834-1914), der Ende des 19. Jahrhunderts die Theorie eines „die Kontinuität der Vererbung durch die Generationen“ garantierenden Keimplasmas entwickelt hatte ${ }^{368}$; die Thesen beider Wissenschaftler wurden von Kolbenheyer aufgegriffen, jedoch auch individuell abgewandelt. ${ }^{369}$

366 Kolbenheyer, Bauhütte [1940], S. 38.

367 Nägeli nahm das Idioplasma insofern als „historisches Produkt" wahr, als er durchgehende Kontinuitätslinien in dessen struktureller Zusammensetzung behauptete. Dem Idioplasma stellte er das Trophoplasma gegenüber, eine „Körpersubstanz“, welche als „mehr oder weniger vergängliche Hülle [...] das evolvierende idioplasmatische System durch die Generationen" trage (Rheinberger/Müller-Wille, Vererbung, S. 115ff.). Mit dieser Vorstellung blieb Nägeli hinter den lange vorher angestellten Vermutungen Darwins zurück: Dieser hatte zwar auch "die Möglichkeit einer Vererbung erworbener Eigenschaften“ konzediert, zugleich aber „unmissverständlich klar" gemacht, dass „die wahren Träger der zu vererbenden Eigenschaften nicht etwa die Eltern und ihre jeweiligen Nachkommen“ seien, sondern „submikroskopische Entitäten, die in jeder Generation neu verteilt“ würden. In einer „bemerkenswerte[n] Umkehrung“ der "frühneuzeitlichen Konzeptionen [...] geradliniger Abstammung“ zeichnete Darwin ein Bild, „in dem horizontale Beziehungen vorherrschten: Anlagen, die von der Gesamtheit der Vorfahren herstammen, rekombinieren und verteilen sich jeweils neu auf die Individuen einer jeweiligen Generation und konkurrieren in diesem Rahmen um ihre jeweils aktuelle Realisierung“. Darwins Vorstellungen markieren damit einen „ersten Übergang zum modernen Vererbungsdenken“ (ebd., S. 62f.).

368 Diese Kontinuität war nach der Auffassung Weismanns (Das Keimplasma. Eine Theorie der Vererbung, Jena 1892) durch die räumliche Abscheidung der „komplette[n] historische[n] Architektur" des Keimplasmas „vom sich differenzierenden Körpergeschehen“ garantiert, weshalb es „von dessen Modifikationen unberührt“ blieb. Das ,in der Keimbahn weitergegebene Kernplasma“ zog sich nach dieser Vorstellung „kontinuierlich und in Gänze durch die Generationen“, wodurch sich „sein Potential erhielt, sich in einem vollständigen, neuen Individuum zu entfalten“. Bei aller Statik dieses Erklärungsmodells war Weismann gleichwohl nicht der Überzeugung, „das in der Keimbahn weitergegebene Kernplasma könne keine neuen Eigenschaften erwerben“. Weismann war von der Möglichkeit „einer spontanen Variabilität des Keimplasmas“ ebenso überzeugt, wie davon, dass das Keimplasma „durch äußere Faktoren direkt beeinflusst werden konnte" (Rheinberger/Müller-Wille, Vererbung, S. 120-123).

369 Kolbenheyer fasste seine Vorstellung von Vererbung nach 1945 folgendermaßen zusammen: „Wir müssen mit dem Gedanken vertrauter werden, daß Fertigkeiten und Eigenschaften, Gewohnheiten und Übungen, die wir erwerben, weil wir genötigt sind, uns im Bereiche unserer Lebensnotdurft anzupassen, unsere plasmatischen Vererbungsbestände zu beeinflußen vermögen“. Das „durch zahllose Generationen angepaßte Erbgut [...] ist ein Entwicklungsboden, auf dem sich nur Entsprechendes ein- und ausbilden kann. Aber es ist eine Überfolgerung, wenn angenommen wird, daß die Entwicklungs- und Vererbungsfähigkeit der lebendigen Substanz nur in einer Kombination urbeständiger, fixer Anlageelemente bestünde" (Kolbenheyer, Sebastian Karst, Bd. 1, S. 54f.). 
Anpassungsleistungen des Plasmas an die sich verändernden Umweltbedingungen bezeichnete Kolbenheyer als „Ausdifferenzierung“. Dazu sah er das Plasma jedoch nur in einem endlichen Umfang fähig. Das Verhältnis zwischen bereits ausdifferenziertem (das heißt: irreversibel verbrauchtem) und noch ausdifferenzierungsfähigem Plasma galt Kolbenheyer als die „Plasmatische Kapazität" eines Organismus. Als Organismen nahm Kolbenheyer dabei auch ganze Völker wahr und glaubte, hinsichtlich ihrer jeweiligen „plasmatischen Kapazität" eklatante Unterschiede feststellen zu können. Dies galt insbesondere mit Blick auf die europäischen Nationen. Konzeptionell an Arthur Moeller van den Brucks Theorem der „Jungen Völker“ erinnernd ${ }^{370}$, bemaß Kolbenheyer den Grad biologischer "Jugendlichkeit" und Leistungsfähigkeit eines Volks anhand des ihm noch verfügbaren Schatzes von noch nicht ,ausdifferenziertem“ Plasma, der allein die Befähigung und Kraft zu künftigen Anpassungsleistungen im immerwährenden Kampf ums Dasein zu gewährleisten schien. ${ }^{371} \mathrm{Da}$ Kolbenheyer zur Bemessung der „plasmatischen Kapazität" der verschiedenen Völker keine belastbaren empirischen Korrektive bieten konnte, blieben seine Einschätzungen und Hierarchisierungen freilich willkürlich.

Wenig überraschend war es denn auch das deutsche Volk, das der Dichter als das ,jüngste“, zu den größten Anpassungsleistungen fähige und somit mit der höchsten „volksbiologische[n] Mächtigkeit“" ${ }^{372}$ ausgestattete, um nicht zu sagen: auserwählte Volk der "weißen Rasse“ ausrief. Kolbenheyer trat damit in eine Phalanx völkischer Autoren, die nach dem verlorenen Ersten Weltkrieg mit einer besonderen Akzentuierung der „unverbrüchliche[n] biologische[n] Kraft des Erbgutes [und] des germanischen Blutes" hervortraten, welches als ein vor dem „Reparationszugriff der Sieger“ unberührtes Gut galt und zugleich zur „Kompensation für den gebrochenen Nationalstolz“373 diente. Gegenüber einer „studentischen Studienkommission" der Universität Tübingen, die damals vor einer Reise in die Tschechoslowakei stand, um die Lage des dortigen „Auslandsdeutschtums“ zu erkunden, hatte Kolbenheyer bereits 1922 die Auffassung vertreten, das deutsche Volk habe „nichts [...] verloren“, wenn es nur „aus dem Schutte der Welthandelspolitik zu einem tieferen völkischen Lichte“ erwachse. „Und wir haben

370 Vgl. Moeller van den Bruck, Recht. Die Thesen von Arthur Moeller van den Brucks Schrift Das Recht der jungen Völker (1919) sind zusammengefasst in: Schlüter, Moeller van den Bruck, S. 279-286. Ob Kolbenheyer die Arbeit Moeller van den Brucks aus erster Hand kannte, ist unklar.

371 Kolbenheyer, Sebastian Karst, Bd.1, S. $180 \mathrm{f.:}$ „Völker und Volksgruppen haben sich im Anpassungsleben an die verschiedenen Daseinsbedingungen der umgebenden Natur verschieden ausgegeben. [...] Diese, Alters'-Stufen ergeben sich aus den verschiedenen Mächtigkeitsverhältnissen der plasmatischen Kapazität des Einzelorganismus, aber auch einer Familie, eines Volkes, einer Rasse ist ein charakteristischer Zustand des plasmatischen Lebensgutes. [...] Je weiter das Lebensgut einer Familie, eines Stammes, eines Volkes, einer Volksgruppe ausdifferenziert ist, desto ,älter' kann dieser überindividuelle Lebenskomplex genannt werden, seine plasmatische Kapazität hat sich dann zugunsten des angepaßten und weiterhin nicht mehr anpassungsfähigen Erbgutes seines Plasmas verändert“.

372 Kolbenheyer, Bauhütte [1940], S. 82.

373 Lösch, Biologisierung, S. 343. 
den Krieg volksbiologisch gewonnen, das heißt wir haben unsere Weltzukunft neu begründet, wenn wir alle unsere Kräfte erkennen und einen - diesseits und jenseits der [Grenz-]Pfähle. " ${ }^{374}$

Den naheliegenden Vorwurf, er habe mit seiner Diagnose der biologischen „Mächtigkeit“ eine natürliche, zu erstrebende Hegemonie des deutschen Volks über die Siegermächte des Ersten Weltkriegs impliziert, hat Kolbenheyer in dem 1929 erschienenen Aufsatz Naturalistischer Konservatismus zurückgewiesen. Kolbenheyer versicherte, dass ein „naturgemäße[r] Ausgleich“ zwischen den Völkern „nicht durch Verzicht [...] auf wesentliche Lebensbestände“ erreicht werden könne; „Sicherheit“ sei „im heutigen Entwicklungszustande des Lebens“ nur möglich, „wenn jedem Volke die freieste Betätigung seiner Lebenskräfte gemäß seiner biologischen Leistungsfähigkeit (Mächtigkeit) im Sinne eines menschheitlichen Ausgleiches gewahrt“375 bleibe. Schon diese Beschwichtigung aber beinhaltete eine folgenschwere Krux: Die unbestimmte Variable der Gleichung nämlich, die spezifische „biologische Leistungsfähigkeit“ der einzelnen Völker, von der Kolbenheyer die ihnen zustehende „freie Betätigung“ abhängig machte, führte im und noch nach dem Zweiten Weltkrieg dazu, dass Kolbenheyer alle kriegerischen Aggressionen des NS-Regimes einschließlich des Überfalls auf die Sowjetunion als angeblich der biologischen Leistungsfähigkeit des deutschen Volks entsprechende Maßnahmen verteidigte. ${ }^{376}$

DAS KONZEPT DER „SCHWELLENZEIT“ - Die Durchsetzung einer neuen „Bestandsform“ der Menschheit schien Kolbenheyer also speziell von „dem deutschen Volk als dem jüngsten und damit noch im Plasma am wenigsten [...] verhärteten zu bewerkstelligen "377 zu sein. Woraus aber leitete Kolbenheyer die Notwendigkeit einer solchen neuen „Bestandsform“ ab? Von entscheidender Bedeutung war hier seine Überzeugung, die „weiße Menschheit“ befinde sich in einem „Schwellenzustand“378. Diese „biologisch bestimmte geschichtsphilosophische Kategorie“379 bezeichnete jene Phasen „starke[r] innere[r] Bewegungen“ in der Menschheitsund Völkergeschichte, welche „durch das Anschwellen einer hochgesteigerten biologischen Entwicklung eingeleitet " 380 würden. In einer für die Ideengeschichte der deutschen Rechten typischen Weise ${ }^{381}$ identifizierte Kolbenheyer die fundamentalen gesellschaftlichen Wandlungsprozesse des langen 19. Jahrhunderts primär als krisenhafte Erscheinungen. Als das augenfälligste Indiz dafür, dass sich die „weiße Menschheit“ in einer „Schwellenzeit“ befand, galt Kolbenheyer die europäische Populationssteigerung seit etwa 1800. Die extrem dynamische Be-

374 Kolbenheyer, Äußerung [1922], S. 411.

375 Ders., Konservativismus [1929], S. 25, 30 (Herv. i. Orig.).

376 Vgl. Kap. 5.3.2 und 6.2.

377 Ketelsen, Kapitel, S. 176.

378 Kolbenheyer, Bauhütte [1925], S. 47.

379 Friedrich, Lebensbilder, S. 84.

380 Kolbenheyer, Bauhütte [1940], S. 38.

381 Vgl. Schulz, Industrialisierung, sowie die dortige weiterführende Literatur. 
völkerungsentwicklung des 19. Jahrhunderts, mit deren konkreten politik-, wirtschafts-, technik- und medizingeschichtlichen Ursachen er sich nicht aufhielt ${ }^{382}$, musste laut der Bauhütte mit einer gesteigerten Ausdifferenzierung des Plasmas einhergehen, mit einem „Anpassungssturm der weißen Menschheit“383.

Kolbenheyer war der Überzeugung, alle „schweren Erschütterungen des europäischen Gleichgewichts“384 seit 1800 auf jene krisenhafte biologische „Schwellenzeit“ zurückführen und mit ihr hinreichend erklären zu können. Dies galt insbesondere für den Ersten Weltkrieg. Der intensiv geführten Weimarer Kriegsschulddebatte fügte er eine exkulpierend-biologistische Nuance hinzu, indem er 1923 im Deutschen Volkstum erklärte:

„Was den jungvölkischen Deutschen das natürliche und unbezwingliche Streben nach selbsteigener Entwicklung war, das wurde und mußte so aus Mangel an Begriffsvermögen von den anderen Völkern als Macht- und Weltherrschaftsgelüste aufgefasst werden. [...] Das deutsche Volk wollte und will den Teil an den Wirkungsmöglichkeiten auf der Erde, der ihm seine biologische Entwicklung sichert. Will ihn mit dem Blutrechte, das in allen Völkern lebt. Nichts mehr." ${ }^{385}$

Kolbenheyer sah die internationale Politik vor die Hauptaufgabe gestellt, ihren Teil zur Bewältigung des „Schwellenzustands“ zu leisten. Als zwingende Voraussetzung hierfür galt ihm die vollständige Revision der aus dem Ersten Weltkrieg erwachsenen europäischen Staatenwelt, die Kolbenheyer als ein unerträgliches und widernatürliches, den wahren biologischen Kräfteverhältnissen der Völker spottendes Konstrukt der Siegermächte von 1918 wahrnahm. Nach dieser Lesart waren die Alliierten nach Kriegsende „nicht zur Einschätzung ihrer eigenen biologischen Volkskräfte" gelangt und hätten sich daher hoffnungslos überhoben. Die - aus volksbiologischer Perspektive - „fast kindliche Reaktion“ der Alliierten wertete Kolbenheyer als Kennzeichen „rationale[r] Befangenheit“ und „geistige[r] Blendung“. Europa müsse so lange an der „Künstlichkeit“ der in den Pariser Friedensverträgen geschaffenen Staatsgebilde „kranken“"386, als diese existierten.

Eine weitere Forderung Kolbenheyers zur Überwindung der „Schwellenzeit“ war die Preisgabe der aus dem Zeitalter der Aufklärung hervorgegangenen „idealistischen“ Denktraditionen zugunsten einer biologisch-„,naturalistischen“ Betrachtungsweise der Welt. Die Notwendigkeit eines solchen Paradigmenwechsels begründete Kolbenheyer mit der Behauptung, Idealismus und Rationalismus seien nicht mehr in der Lage, den „metaphysischen Trieb“387 der Menschheit zu befriedigen. Was war damit gemeint? Kolbenheyer schrieb jedem Menschen ein „Verlangen nach Orientierung letzter Wesenheiten“ zu, das sogenannte „metaphysische Verlangen“. Den Ursprung dieses Verlangens, das ihm als „triebhaft gebunden“ galt, führte Kolbenheyer auf zwei spezifische „Spannungen“ zurück:

382 Für eine Zusammenfassung der wichtigsten Ursachen des Bevölkerungswachstums seit ca. 1800 siehe: Ehmer, Bevölkerungsgeschichte, bes. S. 19-56.

383 Kolbenheyer, Bauhütte [1940], S. 30.

384 Koch, Kolbenheyer [1953], S. 99.

385 Kolbenheyer, Nationalismus [1923], S. 213.

386 Ders., Nationalismus [1925], S. 456.

387 Ders., Diskussion [1955], S. 57. 
Erstens jene „zwischen dem Ich und dem Außerindividuellen der belebten und unbelebten Umwelt“, zweitens jene „zwischen dem Ich und dem Überindividuellen der unüberblickbar gewordenen Mitmenschenwelt “388.

Ideengeschichtlich betrachtet stand Kolbenheyer mit seiner Ablehnung von Rationalismus und Idealismus zugunsten biologistisch-naturalistischer Ordnungsvorstellungen in einer Tradition zu der „die Jahrzehnte zwischen 1880 und 1930“ prägenden „Lebensphilosophie“389. „Leben“ fand hier als „kultureller Kampfbegriff“ Verwendung, der unter Abgrenzung von den Traditionen der Aufklärung „den Aufbruch zu neuen Ufern signalisieren“ sollte. Auch die Vertreter der „Lebensphilosophie“ stellten sich in einen bewussten „Gegensatz zu Rationalität, Vernunft, Begriff oder Idee“ 390 . Sie wandten sich gegen das vermeintlich „Tote und Erstarrte, gegen eine intellektualistische, lebensfeindlich gewordene Zivilisation, gegen in Konvention gefesselte, lebensfremde Bildung“, und traten für ein „neues Lebensgefühl“, für „das ,Echte““, für „Dynamik, Kreativität, Unmittelbarkeit, Jugend“ ein. Die „Differenz zwischen dem Toten und dem Lebendigen“ wurde zum „Kriterium der Kulturkritik“ und als vermeintlich „Überkommene“ darauf befragt, „ob es echtes Leben repräsentiert, ,dem Leben dient', oder lebenshemmend, lebensfeindlich ist“391. Von August Julius Langbehn ${ }^{392}$, dem prominentesten völkischen „Lebensphilosophen“ des deutschen Kaiserreichs, unterschied sich Kolbenheyer indes insofern, als er dessen Auffassung nicht teilte, „Wissenschaft und Kunst“ stünden sich „polar entgegen"393. Kolbenheyer grenzte sich gerade nicht ostentativ von der Wissenschaft ab, sondern lebte in der illusorischen Gewissheit, sich mit seiner Metaphysik auf Höhe der Biologie als Wissenschaft zu bewegen.

Kolbenheyers Kritik an Idealismus und Rationalismus fußte darüber hinaus auf einer Neuinterpretation des menschlichen Bewusstseins und seiner Entstehung. ${ }^{394}$ Auch hier sah der Dichter eine biologische Anpassungsreaktion („Ausdifferenzierung“) des Plasmas am Werk. Nach seiner Auffassung war ein Bewusstsein genau zu jenem (retrospektiv nicht mehr bestimmbaren) Zeitpunkt der menschlichen Entwicklungsgeschichte entstanden, als es überlebens- und „seinsnotwendig“ geworden sei. Mit anderen Worten: Das menschliche Bewusstsein galt Kolbenheyer als „ein Mittel [...] des erbgearteten menschlichen Plasmas, sei-

388 Ebd.

389 Schnädelbach, Philosophie, S. 172.

390 Ebd., S. $172 \mathrm{f}$.

391 Ebd., S. 172.

$392 \mathrm{Zu}$ Julius Langbehn (1851-1907) und seinem Bestseller Rembrandt als Erzieher vgl. Behrendt, Langbehn; Breuer, Konservatismus; Heinßen, Kulturkritik.

393 Langbehn, Rembrandt, S. 18.

394 Die evolutionsgeschichtlichen Hintergründe der Entstehung des menschlichen Bewusstseins wurden bis heute nicht abschließend wissenschaftlich geklärt. Für die aktuellste Erörterung des Themas aus neurowissenschaftlicher Perspektive vgl.: Damasio, Mensch. Über die Diskussionen aus dem Fachbereich der Philosophie informiert der mehrfach neu aufgelegte Sammelband: Metzinger (Hg.), Bewußtsein. Eine Darstellung aus evolutionsbiologischer Perspektive bietet die betont auch auf ein fachfremdes Publikum zielende Studie: Heschl, Darwins Traum. 
nen Bestand auch noch auf jener Stufe seiner Entwicklung [...] durchzusetzen, wo es ohne Bewußtsein nicht mehr möglich wäre“395. Das Wesen des menschlichen Bewusstseins war somit „nicht elementar“ oder absolut, sondern lediglich biologisch „funktionell“ und „dienend“ im „Kampfe des Lebens um seinen Bestand“396. Mit diesem antikartesischen Gedankengang glaubte Kolbenheyer das Bewusstsein des Menschen als eine reine „Ordnungsfunktion“ des Lebens erkannt und das idealistische Dogma der Polarität von Geist und Materie widerlegt zu haben. In einem nächsten Schritt postulierte er, dass sämtliche Erscheinungen des menschlichen Bewusstseins zwingend von einem volksspezifisch gearteten „biologischen Wachstumsboden“ abhängig seien. Alles menschliche Denken, Fühlen und Werten konnte demnach keine die „natürlichen“ Grenzen von „Rasse“ und „Volk“ transzendierenden Charakter haben, sondern waren als „jeweils rassisch, völkisch und individuell“ geartete „wachstumsbedingte und wachstumsveranlagte Lebenserscheinung “397 anzusehen.

ERLebnisgrenze Volk und AHnenerbe - Ein Axiom der Bauhütten-Philosophie war es demnach, dass jedes „einzelne Wesen“ als Repräsentant des sich „durch die Geschlechter hindurch" 398 auslebenden Plasmas anzusehen sei, dessen Beschaffenheit Kolbenheyer als „volksspezifisch“ definierte. Auf den Menschen bezogen leitete er hieraus ein konkretes „Erbverhängnis“ ab, das jedes Individuum zwangsweise $\mathrm{zu}$ einem biologischen „Funktionsexponent[en]“399 jenes Volks werden ließ, in das er hineingeboren war. Originell hieran war indes allenfalls die eigenwillige Nomenklatur Kolbenheyers, nicht jedoch die Idee an sich. Dass es sich hier vielmehr im Wesentlichen um einen Basiskonsens völkischen Denkens handelte, zeigt schon ein Blick in die seit 1922 in vielen Auflagen zirkulierende Schrift Rassenkunde des Deutschen Volkes, das Hauptwerk des seinerzeit sehr populären Rassenideologen und Laienanthropologen Hans F. K. Günther. In ihr monierte Günther, dass dem „neuzeitlichen Menschen [...] jedes Gefühl genommen worden [sei] für das schicksalhafte Hineingeborensein in einen weiten Zusammenhang der werdenden und vergehenden Geschlechter, des ihm eigenen Volkstums und der dieses Volkstum bedingenden Rassenteile“400.

Von dem skizzierten „Erbverhängnis“ sah Kolbenheyer auch den Sachverhalt bedingt, dass nicht etwa die Menschheit als Ganzes, sondern das eigene Volk die größte biologische Einheit darstelle, der für den einzelnen Menschen noch bewusst erlebbar sei und somit sinn- und orientierungsstiftend wirken könne. Un-

395 Koch, Kolbenheyer [1953], S. 83.

396 Ebd., S. 81. - „Auch das Bewußtsein ist [...] nichts anderes als ein Mittel der lebendigen Substanz, des erbgearteten menschlichen Plasmas, seinen Bestand auch noch auf jener Stufe seiner Entwicklung, seiner Ausdifferenzierung durchzusetzen, wo es ohne Bewußtsein nicht mehr möglich wäre" (ebd., S. 83).

397 Kolbenheyer, Bauhütte [1940], S. 19, 21.

398 Ders., Sebastian Karst, Bd. 1, S. 28.

399 Ebd., Bd. 2, S. 122.

400 Günther, Rassenkunde, S. 400. 
ter Abgrenzung von der „Ideologie eines Weltbürgertums“ definierte Kolbenheyer „das Volk“ als den „lebendige[n] Wirkungskörper weitesten Ausmaßes“, der „dem Individuum eben noch gefühlsmäßig erlebbar" sei. Die „autochthonen Stämme und Völker“, so seine Begründung, hätten während ihrer biologischen Entwicklungsgeschichte unter „den begrenzten Bedingungen des Lebensraumes [...] in weitausgefächerten und einander durchkreuzenden Ahnenfolgen“ einen „überindividuelle $[n]$ plasmatische[ $n]$ Bestand“ ausgeprägt, der „in seiner Geartetheit [sic!] aus jedem Individuum“ wirke. Über „die eigene Volkheit“ hinaus könne das dem Menschen „intuitiv“ Erlebbare nicht hinausgehen: „Das Erlebnis ,Menschheit' gibt es nicht, es sei denn in der Phraseologie einer gewissen Propaganda“ “401. Sinn und Orientierung fand das Individuum in den Augen Kolbenheyers dann auch erst in der Erkenntnis, „funktionelle[r] Teilbestand einer umfassend überindividuellen Wesenheit" $402 \mathrm{zu}$ sein.

Das in der Kontinuität des „Lebenskampfe[s] zahlreicher Generationen“403 stehende Individuum schien Kolbenheyer darüber hinaus an eine „erbbedingte“ moralisch-ethische „Funktionsverpflichtung "404 gebunden. Nicht in der Freiheit sah er die Würde des Menschen begründet, sondern in dem Umstand, Endprodukt und „Zeugnis“ eines „um den Bestand des Lebens selbst“ ausgefochtenen „Daseinskampfes unabsehbar weiter Ahnenwelten“ zu sein. „Welch eine Wucht des Ausscheidens- und des Beharrungskampfes über Jahrmillionen hin!“405 „Unsterblich“ sei der Mensch nur darin, was er in seiner Rolle als „Funktionsexponent der plasmatischen Anpassung seiner Art“406 leiste - ein Gedanke, in dem Kolbenheyer ein „über alles Religiöse“ hinausgreifendes „Ethos“ wie auch „die äußerste“ und „innerlichste Verpflichtung“407 des Menschen angelegt sah. Diese Ethikvorstellung kulminierte letztendlich in einer gleichsam vom idealistischen Kopf auf den biologischen Boden gestellten Neuformulierung von Immanuel Kants „Kategorischem Imperativ“:

„Handle so, daß du überzeugt sein kannst, mit deinem Handeln auch dein Bestes und Äußerstes dazu getan zu haben, die Menschenart aus der du hervorgegangen bist, bestands- und entwicklungsfähig zu erhalten" 408 .

Im Übrigen trat Kolbenheyer - bewusst oder unbewusst - auch hiermit in die Fußstapfen Hans F. K. Günthers, der schon 1920 in seinem Erstlingswerk Ritter, Tod und Teufel. Der heldische Gedanke inhaltlich identisch, wenngleich etwa weniger arriviert formuliert hatte: „Handle so, daß du die Richtung deines Willens jederzeit als Grundrichtung einer nordrassischen Gesetzgebung denken könnest“409.

\footnotetext{
401 Kolbenheyer, Dreigespräch, S. 598, 601 (Herv. i. Orig.).

402 Ders., Sebastian Karst, Bd. 1, S. 312.

403 Ebd., S. 68.

404 Kolbenheyer, Dreigespräch, S. 639

405 Ders., Sebastian Karst. Bd. 1, S. 49.

406 Ders., Bauhütte [1940], S. 504.

407 Ders., Sebastian Karst, Bd. 1, S. 49.

408 Ders., Dreigespräch, S. 565.

409 Günter, Ritter, S. 159.
} 


\title{
3.3.2 Öffentliche und private Rezeption der „Bauhütte”
}

\author{
Was Kolbenheyer [...] sehen lehrt, ist uns \\ durch die starken Bewegungen der letzten Jahre \\ deutlicher und schärfer ins Blickfeld gerückt \\ worden; wir haben es als wesenhaft, bedeutsam \\ und lebenswirksam erfahren. Kolbenheyer ist \\ heute weniger Prophet als Wegweiser [...] In \\ solcher Situation hat die weite Umsicht und die \\ Zielsicherheit seiner Führung etwas Erlösen- \\ des. ${ }^{410}$
}

LOB UND KRITIK (1925-1934) - Durchaus zufrieden und optimistisch schrieb Kolbenheyer im August 1929 an Stapel, er erhalte nun - nach einem zunächst nur sehr schwachen Echo - „von allen Seiten“ Signale, dass die Kerngedanken seiner Bauhütte immer häufiger aufgegriffen würden und Verbreitung fänden. $\mathrm{Zu}$ seinem Leidwesen machte Kolbenheyer jedoch zugleich die Beobachtung, dass sein Name in jener beginnenden Rezeption meist unerwähnt geblieben sei. Trost fand der „Dichterphilosoph“ jedoch in dem Gedanken, dass man „in 30 Jahren [...] vielleicht wissen“ werde, dass er es gewesen sei, der als erstes den „naturalistischen Standpunkt im prinzipiellen Gegensatze zum ,idealistischen “411 definiert habe. An alledem ist zutreffend, dass die Rezeption der Bauhütte zunächst in der Tat nur schleppend voranschritt; unzutreffend ist jedoch, dass es nur zu einer gleichsam verdeckten Rezeption der Bauhütte gekommen sei, bei der Kolbenheyers Name keine Erwähnung gefunden hätte.

Verwunderlich wäre es indes nicht gewesen, hätte sich rasch kaum mehr jemand der Bauhütte erinnert. Das rezeptionsstrategische Ungeschick Kolbenheyers, seine Studie mit einer Unzahl nicht oder nur unzureichend definierter Neologismen zu überfrachten, rief jedenfalls auch unter dezidiert lern- und wissbegierigen Lesern immer wieder massive Verständnisprobleme hervor. So warf etwa der Wiener Professor für politische Ökonomie Eugen Schwiedland, den mit Kolbenheyer eine langjährige Freundschaft verband ${ }^{412}$, im Januar 1926 nicht ohne Ironie die Frage auf, wie es Kolbenheyer anstellen wolle, mit seiner Philosophie in breiteren Kreisen bekannt zu werden, wenn selbst jemand, „der Deine Klugheit so hoch schätzt, wie ich, dich nicht kapieren kann?"413 Damit nicht genug: Selbst auf Nachfragen interessierter Leser, was es mit diesem oder jenem Terminus auf sich habe, bot Kolbenheyer keine klärende Hilfestellung. Stattdessen verwies er auf den Gemeinplatz, dass mehrfaches Lesen zu einem tieferen Verständnis seiner Begrifflichkeiten führen würde. So erging es etwa seinem ergebe-

410 Lehmann, Art, S. 129.

411 DLA, A:Stapel, Erwin Guido Kolbenheyer an Wilhelm Stapel, 17. August 1929.

412 Wann diese Freundschaft genau begann, lässt sich anhand des Nachlasses Kolbenheyers nicht ermitteln. Der erste überlieferte Brief Schwiedlands aus dem Jahr 1919 beginnt mit der Anrede „Lieber Freund“, markiert also sicherlich nicht den Beginn der Bekanntschaft.

413 KAG, Eugen Schwiedland an Erwin Guido Kolbenheyer, 15. Januar 1926 (Herv. i. Orig.). 
nen Dauerrezensenten Conrad Wandrey ${ }^{414}$, der im November 1926 Auskunft darüber erbat, an welcher Stelle er sich über die genaue Bedeutung der von Kolbenheyer verwendeten Fachbegriffe informieren könne. Auf diese - gänzlich nachvollziehbare - „Anfrage wegen des Lexikons der Fachausdrücke“ wusste Kolbenheyer jedoch nichts angeben, „was Ihnen dienlich sein könnte“. Stattdessen empfahl er Wandrey, „ruhig weiter[zu]lesen“; dies werde mehr und mehr „von tieferem Eindringen begleitet sein“415.

Bei den frühesten Besprechungen der Bauhütte kam Kolbenheyer sein exzellentes Verhältnis zur Universität Tübingen zugute. ${ }^{416}$ Schon kurze Zeit nach der Erstveröffentlichung besprach der Tübinger Professor für Botanik und Direktor des Botanischen Instituts Ernst Lehmann das Buch ausführlich im renommierten Biologischen Zentralblatt, wo er zu dem Ergebnis kam, dass der Bauhütte „die weitestgehende Aufmerksamkeit“ zu wünschen sei. Angesprochen fühlte sich Lehmann insbesondere von Kolbenheyers Kombination „biologische[r] Erkenntnisse“ und ihrer „metaphysisch-weltanschaulich[en]“417 Auswertung. Nach einer Abgrenzung der Plasma-Lehre der Bauhütte von Darwins Selektionstheorie - die Kolbenheyer, der stets besorgt war, in den Ruf eines Epigonen Darwins zu geraten, besonders gefreut haben wird - zeigte sich Lehmann von Kolbenheyers Herleitung der Entstehung des menschlichen Bewusstseins besonders angetan. Als ein „Meisterstück“ galt dem Botaniker auch die Interpretation des Individuums als moralisch verpflichteten Funktionsexponenten seines „volksspezifisch“ gearteten Plasmas. ${ }^{418}$

Ebenfalls wohlwollend, wenngleich mit einiger Detailkritik, äußerte sich der Extraordinarius (ab 1928 Ordinarius) für Philosophie an der Universität Tübingen Theodor Haering. In der Deutschen Literaturzeitung für Kritik der internationalen Wissenschaft lobte er gleichermaßen Kolbenheyers „berechtigten Kampf gegen die überschätzende Verselbstständigung von Bewußtsein und Individualität des Menschen“ sowie den „fast ansteckende[n] heroische[n] Optimismus seine[r] Darlegungen " 419 . Bedenken erhob Haering allerdings - hellsichtig auf das monokausale Denken der Bauhütte verweisend - angesichts einer „allzu gewaltsame[n] Erweiterung des Geltungsbereichs“ eines „rein biologischen Gesichtspunkt[s]“. $\mathrm{Ob}$ die Zurückführung sämtlicher Lebenserscheinungen auf „die Anpassung ein und desselben ,Plasmas“" nicht lediglich bedeute, „einen Namen für das unbekannte $\mathrm{X}^{\text {“ } 420} \mathrm{zu}$ setzen? Ob einige der von Kolbenheyer beschriebenen Erscheinungen möglicherweise „nur dann in der Weise des Verf[asser]s gedeutet“ werden könnten, wenn „die Theorie nicht nach den Tatsachen, sondern die Tatsachen

\footnotetext{
414 Vgl. Kap. 3.1.5.

415 KAG, Erwin Guido Kolbenheyer an Conrad Wandrey, 29. November 1926 (Durchschlag).

416 Vgl. Kapitel 3.4.

417 Lehmann, Bauhütte, S. 314.

418 Ebd., S. 320.

419 Haering, Kolbenheyer, Sp. $1751 \mathrm{f}$.

420 Ebd., Sp. 1753 f.
} 
nach einer vorgefassten Theorie“ 421 geformt und gerichtet würden? Im gleichen Atemzug betonte Haering jedoch, Kolbenheyers Betrachtungsweise der Welt „in vielen Fällen“ für „berechtigt“ ${ }^{2} 2 \mathrm{zu}$ halten. Insgesamt resümierte Haering, dass Kolbenheyers „biologische[r] Naturalismus [...] eine außerordentlich konsequente und in vielem in der Tat der gegenwärtigen äußeren und inneren Lage der Menschheit außerordentlich adäquate Denkweise“ darstelle, in ihrer Eindimensionalität jedoch „der spezifischen Bedeutung des menschlichen Geisteslebens nicht gerecht“ werde - ebenso wenig wie früher die „rein anorganische (atomistische) Denkweise den biologischen (organischen) Phänomenen gerecht“ geworden sei. Mit anderen Worten: Kolbenheyer habe zwar „vollkommen recht“, den „Idealismus der Vergangenheit“ abzulehnen und zu bekämpfen, dem Idealismus dürfe jedoch nicht jeder Eigenwert abgesprochen werden. Der „extreme biologistische Naturalismus" 423 Kolbenheyers beleuchtete in den Augen Haerings nur eine Seite der Medaille, diese jedoch in überzeugender Weise.

Sehr viel weniger kritisch äußerte sich im Juni 1926 der hauptberuflich für die Vossische Zeitung arbeitende Feuilletonredakteur Otto Ernst Hesse in einer Besprechung der Münchner Neuesten Nachrichten, zu der Kolbenheyer in den 1920er Jahren ein exzellentes Verhältnis unterhielt. Die Rezension kam zustande, nachdem Kolbenheyer bereits ein Jahr zuvor bei Hesse - dessen Beschäftigung mit der Bauhütte er schon zu diesem Zeitpunkt schätzte - wegen einer möglichen Besprechung in den Münchner Neuesten Nachrichten angeklopft hatte. Hesse gab daraufhin gerne seine Zusage: „Wenn ich Ihnen bei den Münch. N. N. dienlich sein könnte, so nennen Sie bitte meinen Namen“424. Daraufhin machte Kolbenheyer die Redaktion sogleich darauf aufmerksam, dass Hesse wohl „am geeignetsten“ wäre, um von der Redaktion „zu einer Besprechung meiner ,Bauhütte ‘ [...] eingeladen zu werden“. Hesse hatte sich nach der Ansicht Kolbenheyers nicht nur „sehr eingehend mit dem Buche befasst“, sondern vor allem erkannt, „worauf es mir nach manchen Richtungen hin ankommt" 425 . In der Rezension hielt sich Hesse mit eigenen Wertungen auffallend zurück und begnügte sich ganz mit einer $\mathrm{Zu}$ sammenfassung der wichtigsten Grundgedanken der Bauhütte. ${ }^{426}$ Nach manchen Besprechungen, bei denen er sich an missverständlichen Interpretationen gestört hatte, war Kolbenheyer diese Zurückhaltung Hesses sehr recht. Entsprechend drückte er Hesse bereits einen Tag nach der Veröffentlichung seine große Dankbarkeit für die „ausgezeichnete Besprechung“ aus. Laut Eigenaussage hatte Kolbenheyer zuvor die Befürchtung geplagt, sein Werk würde „mit dem üblichen

421 Ebd., Sp. 1752.

422 Ebd.

423 Ebd., Sp. 1755f. - Schieße nicht, so fragte Haering, Kolbenheyers rein biologisch-naturalistische Erklärungsweise ebenso sehr über ihre Grenzen hinaus wie der von K[olbenheyer] bekämpfte übertriebene Idealismus?"“ (ebd., Sp. 1752).

${ }^{424}$ KAG, Otto Ernst Hesse an Erwin Guido Kolbenheyer, 24. Oktober 1925.

425 KAG, Erwin Guido Kolbenheyer an die Münchner Neuesten Nachrichten, 29.Oktober 1925 (Durchschlag).

426 Otto Ernst Hesse, „Die Bauhütte“. Zu E. G. Kolbenheyers neuer Metaphysik, in: Münchner Neueste Nachrichten, 1. Juni 1926, Nr. 150. 
Stillschweigen matt“ gesetzt. Durch Hesses Besprechung sei der Bauhütte nun jedoch „einen Schritt weiter geholfen“, zumal in ihr der "Kernpunkt der ,Bauhütte“ [...] klar und verständlich ins Licht gerückt" ${ }^{\text {“427 }}$ worden sei.

Ablehnende Rezensionen der Bauhütte blieben selten. Dies verwundert schon insofern nicht, als es die sprachliche Unzugänglichkeit des Werks wohl manch potenziellen Kritikern verleidete, sich überhaupt dem unweigerlich hohen Zeitaufwand einer Rezension auszusetzen. Die $1927 \mathrm{im}$ Archiv für die gesamte Psychologie veröffentlichte, kritische Besprechung des studierten Theologen und geweihten Priester Aloys Müller, der seit 1926 einem „Lehrauftrag für Philosophie der Mathematik und der exakten Naturwissenschaften " 428 nachging, blieb daher eine Ausnahme. In seinem knapp gehaltenen Text, der noch spürbar von nicht ganz überwundenen Verständnisproblemen gekennzeichnet war, resümierte Müller, dass ihn „Einzelheiten“ der Bauhütte zwar „sympathisch“ berührt hätten - so vor allem der „Kampf gegen den Individualismus und den Egoismus des Zeitgeistes“; Kolbenheyers Versuch, „eine Weltanschauung biologisch zu begründen“, erschien ihm hingegen ganz „unmöglich“. Falls es „überindividuelles organisches Leben“ gebe, so glaubte Müller, sei dieses „eine rein naturwissenschaftliche Angelegenheit“, die „mit der Sinnfrage der Weltanschauung nichts zu tun“429 habe.

Ebenfalls mit Skepsis auf Kolbenheyers Verdikt gegen den Idealismus reagierte ein namentlich nicht genannter Rezensent der Zeitschrift für Bücherfreunde: Wohl wirke „Kolbenheyers Eifer, aus der Naturwissenschaft alle rationalen Elemente auszumerzen, die radikale Absage an alles Rationalistische und Individualistische [...] zweifellos klärend“; Kolbenheyers Behauptung einer „unvermeidliche[n] Verstrickung“ des Idealismus ,mit individualistischen, rationalistischen, pessimistischen Denkformen“ wirke hingegen „weniger überzeugend“. Insgesamt stelle die Bauhütte die „schroffste, männlichste Übersteigerung eines relativistischen Naturalismus" dar, welche „allenthalben“ von der "Notwendigkeit einer Ergänzung durch idealistisch-absolute, ja religiöse Werte“ gekennzeichnet sei. „Sehr anregend" bleibe die "gedankenvolle Arbeit" ${ }^{\text {" }} 330$ Kolbenheyers nichtsdestotrotz.

Eine sehr respektvolle Kritik der Bauhütte formulierte 1927 der österreichische Literaturhistoriker und spätere Germanistikprofessor im schweizerischen Freiburg, Ernst Alker, in der Monatsschrift Das deutsche Buch. Die Kritik richtete sich hier gegen die Irreligiosität der Bauhütte. Alker überraschte es, dem ihn vertrauten Dichter als „Lehrer eines - wenn auch beträchtlich vertieften - Monismus“ zu begegnen. Die „Doktrin von der Ewigkeit des Plasma und dessen fortwährender, sich steigernden Anpassung“ hielt der Germanist zwar für „eine hochwertige geistige Leistung“, einen Beitrag zur Schaffung eines „,neue[n] Gemeinschaftsgefühl[s]“ der Deutschen und zur Überwindung des angeblich „zügellose[n] Individualismus der Gegenwart“ traute er der Bauhütte hingegen nicht zu: Eine „neue Sinn-

427 KAG, Erwin Guido Kolbenheyer an Otto Ernst Hesse, 2. Juni 1926 (Durchschlag).

428 Tilitzki, Universitätsphilosophie, S. 159.

429 Müller, Kolbenheyer, S. 248f.

430 Zeitschrift für Bücherfreunde. Organ der Gesellschaft der Bibliophilen. Neue Folge 19 (1927), Sp. 263f. 
gebung des Lebens" ${ }^{431}$ sei aus dem Werk nicht zu gewinnen. Ein solcher Anspruch war freilich hoch gegriffen. Auch war der Vorwurf gegen die Bauhütte, einer nicht ausreichend kollektivistischen Weltanschauung das Wort zu reden, alles andere als naheliegend. Später scheint sich Alkers Urteil denn auch zugunsten Kolbenheyers geändert zu haben, vornehmlich in Bezug auf die sinn- und orientierungsstiftende Qualität der Bauhütte: 1934 lobte er das Werk in der Schweizerischen Rundschau als den „von materialistisch orientierter Seite [...] bedeutendste[n]" Versuch eines Gegenentwurfs zu Spenglers pessimistischem „Untergang des Abendlandes“432.

Andere Kritiker stießen sich zwar an der sprachlichen Unzugänglichkeit der Bauhütte, zeigten sich jedoch stark beeindruckt von ihrem Inhalt. So etwa der österreichische Schriftsteller Hans von Dettelbach, der im Zweiten Weltkrieg mit dem Grazer Kunstpreis der Stadt der Volkserhebung ausgezeichnet werden sollte. ${ }^{433}$ Dettelbach bemängelte 1934 in den Alpenländischen Monatshefen zwar den „ungewohnten Wortgebrauch“ der Bauhütte und deren „Unwegsamkeit der Darstellung", gab sich aber insofern als gelehrsamer Schüler zu erkennen, als er betonte, mit der Bauhütte sei „eine Glaubensgewißheit, die lange Zeit unumschränkt geherrscht“ habe, „an ihr Ende gekommen“. Das entsprach ganz dem Selbstbild Kolbenheyers, der sich, wie eingangs zitiert, philosophiehistorisch betrachtet als der Überwinder des „Idealismus“ zugunsten des „Naturalismus“ verstand. Dementsprechend stilisierte es auch Dettelbach zu einer neuen „Kopernikanischen Tat", dass Kolbenheyer das „absolute Ich durch die plasmatische Entwicklungstheorie“ entthront habe: „Wie Kopernikus die Erde aus dem Mittelpunkt einer Weltanschauung gehoben hat, so hat ja Kolbenheyer das menschliche Ich als den archimedischen Festpunkt aller Erkenntnis erledigt" ${ }^{\text {"434 }}$.

Auch im privaten Briefverkehr Kolbenheyers fanden dessen philosophische Entwürfe mitunter euphorisches Lob von professoraler Seite. Verwiesen sei hier nur auf den Mathematiker Robert König, den mit Kolbenheyer eine enge Freundschaft aus gemeinsamen Tübinger Tagen verband. ${ }^{435}$ König, der schon im November 1922 aus seiner Affinität zu Kolbenheyer kein Geheimnis gemacht hatte, indem er seine Antrittsvorlesung an der Universität Münster mit dessen Gedicht Deutsches Leid beschloss ${ }^{436}$, sah es im Januar 1925 als seine „liebste Pflicht“, zu

431 Alker, Kolbenheyer, S. 387.

432 Ernst Alker, Eine materialistische Metaphysik, S. 879.

433 Vgl. Strallhofer-Mitterbauer, NS-Literaturpreise, S. $66 \mathrm{f}$.

434 Dettelbach, Gedanken, S. 293 f., 296.

435 König, 1885 im oberösterreichischen Linz geboren, lehrte seit 1914 als Extraordinarius Mathematik an der Universität Tübingen. 1922 folgte er einem Ruf als ordentlicher Professor an die Universität Münster, wo er bis 1927 lehrte. Anschließend wirkte König lange Jahre als Direktor des Mathematischen Instituts der Universität Jena, ehe er nach Ende des Zweiten Weltkriegs einen Ruf an die Universität München erhielt. Dort lehrte er als Ordinarius von 1950 bis 1955. König starb 1979 in München.

436 So die eigene Mitteilung Königs in: KAG, Robert König an Erwin Guido Kolbenheyer, 25. November 1922. Das 1919 verfasste Gedicht Deutsches Leid ist abgedruckt in: Kolbenheyer, Dichterischer Nachlass, S. 21 f. 
einer möglichst weiten Verbreitung von Kolbenheyers Gedankenwelt beizutragen, besonders unter den Studenten. Mit seiner Bauhütten-Philosophie, so König, habe Kolbenheyer „mir u[nd] jedem denkenden Deutschen eine neue Welt aufgeschlossen“; König wollte künftig „die Samenkörner ausstreuen, wo immer ich kann“437. Dass dies keine leeren Worte waren, zeigt ein Schreiben vom März 1927, in dem es König zu seiner „größte[n] Freude“ erklärte, seinen Studenten aus Kolbenheyers Bauhütte „vorzulesen“438. Wie stark sein eigenes Denken durch Kolbenheyer beeinflusst worden war und wie sehr ihn dessen Bauhütte beeindruckte, hob König in seinen Briefen mehrfach hervor. Besonders aufschlussreich ist ein Schreiben vom Dezember 1926, in dem er Kolbenheyer als „Philosoph auf jeder Seite, in jeder Zeile“ beschrieb, als „ein richtiger Weiser, der den Deutschen den Weg weist!“ Es müsse „ein unendlich glückliches, befriedigendes Gefühl sein, so ein Werk geschrieben zu haben“439.

Die „BAUHÜTTE“ IN DER NS-LiterATURWISSENSCHAFT - In der heterogenen Germanistenzunft des „Dritten Reichs“ waren es in erster Linie Heinz Kindermann ${ }^{440}$ und Franz Koch ${ }^{441}$, die sich an Modellen zu einer Modernisierung ihres Fachbereichs durch eine stärkere Berücksichtigung wissenschaftlicher Erkenntnisse aus dem Bereich der Biologie versuchten. Zur Orientierung griffen sie dabei jedoch nicht etwa auf die einschlägigen Lehr- und Handbücher ihrer Zeit zurück, sondern auf das angeblich „zeitgemäße“ Verständnis von Biologie, wie es Kolbenheyer in seiner Bauhütte entwickelt hatte.

Heinz Kindermann stellte in seiner programmatischen Studie Dichtung und Volkheit. Grundzüge einer neuen Literaturwissenschaft (1937) gar den „schöpferischen Vorgang des Dichtens“ selbst „als biologischen Vorgang, als einen Blutkreislauf der Seele und des Geistes“442 dar. Die Germanistik sah Kindermann vor die

437 KAG, Robert König an Erwin Guido Kolbenheyer, 20. Januar 1925.

438 KAG, Robert König an Erwin Guido Kolbenheyer, 1. März 1927. Die Gewohnheit Königs, seinen Studenten durch Lesungen mit Kolbenheyers Werk vertraut zu machen, lässt sich bis mindestens 1923 zurückverfolgen: „Wenn die Studenten abends zu mir kommen [...] dann nehme ich die eine oder andere Schrift von Ihnen, lieber Freund, u[nd] suche ihnen Ihr Denken zu erschließen“ (KAG, Robert König an Erwin Guido Kolbenheyer, 21. Oktober 1923).

439 KAG, Robert König an Erwin Guido Kolbenheyer, 28. Dezember 1926 (Herv. i. Orig.).

440 Heinz Kindermann (1894-1985) studierte an den Universitäten Wien und Berlin Germanistik, Romanistik und Skandinavistik. Nach seiner Habilitation 1924 war er Ordinarius für neuere Literaturgeschichte an der TH Danzig (1926-1936) und an den Universitäten Münster (bis 1942) und Wien (bis 1945). Von 1954 bis 1969 hatte er abermals den dortigen Lehrstuhl inne. Kindermann gründete das Wiener Institut für Theaterwissenschaften und war Mitglied der Österreichischen Akademie der Wissenschaften.

441 Franz Koch (1888-1969) arbeitete nach seiner Promotion 1912 zunächst an der Hofbibliothek Wien, ehe er sich 1925 an der Universität Wien in deutscher Literatur habilitierte. Zwischen 1932 und 1935 war er ebendort als außerordentlicher Professor für deutsche Sprache und Literatur tätig, ehe er 1935 einen Ruf als Ordinarius für Literatur- und Geistesgeschichte an die Friedrich-Wilhelm-Universität Berlin erhielt. Nach dem Ende des Zweiten Weltkriegs lehrte Koch ab 1946 bis 1952 an der Universität Tübingen.

442 Kindermann, Dichtung, S. 31. 
Aufgabe gestellt, der angeblich „biologische[n] Frage“ künftig mehr Aufmerksamkeit zu widmen, weshalb „unser Volk der Dichtkunst“ bedürfe und wie diese beschaffen sein müsse, „um der Selbstbehauptung und immer wiederkehrenden Erneuerung unseres Volkes zu dienen“. Nur durch die Berücksichtigung dieser Frage könne die Literaturwissenschaft zugleich „eine volkhafte Lebenswissenschaft" werden. Bei dieser Aufgabe, so prognostizierte Kindermann, werde sich „der Literaturhistoriker von morgen [...] an Kolbenheyer zu halten haben“443. Auch glaubte Kindermann, dass der gegenwärtigen Literaturwissenschaft „gerade [durch] die biologischen Grundlagen unserer neuen Wertbegriffe" gelehrt worden sei, die „Erlebnis-Echtheit der wirklichen Welt in der Dichtung [...] von der bloß theoretischen Buch- und Musealwelt der ,Literatur' [zu] unterscheiden“. Letztere habe ungeachtet ihres handwerklichen und künstlerischen Geschicks „an Bedeutung für unsere Wert-Auswahl verloren“444. In engere Beziehung mit Kolbenheyer war Kindermann schon in der zweiten Jahreshälfte 1932 getreten; die Bekanntschaft ging mindestens bis zum Sommer 1932 zurück, als Kindermann gegenüber Kolbenheyer das Bedürfnis nach einem engeren „Zusammenwirken“ der Literaturwissenschaft „mit den führenden Dichterpersönlichkeiten“445 zum Ausdruck brachte. Der Germanist blieb in der Folgezeit merklich um Beziehungspflege bemüht - insbesondere durch die immer wieder ausgesprochene Versicherung, Kolbenheyer in seinem universitären und außeruniversitären Arbeitsalltag bis hin zur Nachwuchsförderung intensiv zu behandeln und gebührend zu berücksichtigen. ${ }^{446}$

Stärker noch als Kindermann versuchte Franz Koch, die Philosophie der Bauhütte für die Germanistik nutzbar zu machen. Über bloßes Interesse ging das Engagement dabei weit hinaus; Kochs Arbeit als Literaturwissenschaftler lässt sich

443 Ebd., S. 55 f.

444 Ebd., S. 65.

445 KAG, Heinz Kindermann an Erwin Guido Kolbenheyer, 25. Juli 1932.

446 Schon im Dezember 1932 schrieb Kindermann an Kolbenheyer, „in der letzten Zeit“ zu seiner „Freude wieder allerlei zum Verständnis Ihres Werks“ getan zu haben. „Im Lauf des Januar kommen dann im Rahmen meines modernen Roman-Kollegs zwei gesonderte Kolbenheyer-Vorlesungen“ (KAG, Heinz Kindermann an Erwin Guido Kolbenheyer, 25. Dezember 1932). Im März 1935 berichtete er dann von einem eigenen „Kolbenheyer-Kolleg“ im kommenden Sommersemester (KAG, Heinz Kindermann an Erwin Guido Kolbenheyer, 2. März 1935). Und zum Jahresbeginn 1940 ließ er Kolbenheyer wissen: „Als ich im November im Auftrag des Auswärtigen Amtes und der Nord[ischen] Gesellschaft in Kopenhagen über die deutsche Dichtung seit dem Weltkrieg sprach, habe ich viel von Ihrem Lebenswerk berichten dürfen. Der Erfolg war überraschend groß. [...] In meinem Oberseminar lautet das Thema diesmal: Das deutsche Drama der Gegenwart. Darunter gibt's auch 3 Kolbenheyer-Referenten“ (KAG, Heinz Kindermann an Erwin Guido Kolbenheyer, 18. Januar 1940). Darüber hinaus ließ Kindermann das Werk Kolbenheyers auch von seinen Doktoranden bearbeiten, wie er wenige Wochen nach Ausbruch des Zweiten Weltkriegs berichtete: „Einer meiner besten Schüler hat eben eine Dissertation abgeschlossen über das Thema: Erwachen der sudetendeutschen Dichtung zur völkischen Sendung. Das Kapitel über Ihr Lebenswerk ist zu meiner Freude besonders geglückt" (KAG, Heinz Kindermann an Erwin Guido Kolbenheyer, 27. September 1939). 
sogar „in erster Linie als Propagandist der kolbenheyerschen Ideen und Texte“447 verstehen. Die Begeisterung des Germanisten entzündete sich dabei hauptsächlich an Kolbenheyers Bestreben, in seinen „historischen Romanen die blutmäßigen und geistigen Ursprünge ,deutscher Art' freizulegen“ und die ,philosophischnaturalistische Erfassung des Weltgeschehens“ zur „Basis seiner Kunst“448 zu machen. Eine herausragende Bedeutung sprach Koch Kolbenheyers „These von der ,plasmatischen Kapazität ' der Individuen und Völker“ zu, ebenso wie dessen Theorie, dass ,jede Individualitätsform funktionell abhängig sei von blutmäßigen und erbbiologischen Faktoren in Gestalt von Familie, Stamm, Volk und Rasse, dem überindividuellen Leben " 449 . Koch verband mit Kolbenheyer seit ihrer ersten Begegnung während des Ersten Weltkriegs eine enge Freundschaft. ${ }^{450}$ Entsprechend früh begann er damit, ausführliche Artikel über das literarische und philosophische Schaffen Kolbenheyers zu veröffentlichen. ${ }^{451}$ Koch war - zusammen mit Conrad Wandrey ${ }^{452}$ und Wilhelm Stapel - im hier interessierenden Untersuchungszeitraum der gelehrigste Schüler der Bauhütte. Kolbenheyer selbst schätzte Koch nebst Stapel als den besten Kenner seines Werks ${ }^{453}$, sodass sich dieser „mit Fug und Recht zu jenen zählen“ durfte, „die Kolbenheyers Thesen zum organischen Weltbild verstanden hatten" 454 .

Koch gab in dem 1941 erschienenen Aufsatz E. G. Kolbenheyers Bauhütte und die Geisteswissenschaften detailliert darüber Auskunft, wie er die Philosophie Kolbenheyers in seine eigene Arbeit einzubinden gedachte. ${ }^{455}$ Hinter Kochs Konzept der „biologistischen Literaturbetrachtung“456 stand immer auch der Wille, literaturwissenschaftliche Analyseverfahren durch eine Nutzbarmachung der Erkenntnisse der Biologie zu modernisieren. Auf diesem Weg sollte - ähnlich wie es die Lebensphilosophie seit dem ausgehenden 19. Jahrhundert eingefordert hatte „die Kluft zwischen Wissenschaft und ,Leben“" überwunden werden. Die von Koch angestrebte Fusion natur- und geisteswissenschaftlicher Perspektiven kannte bei alledem eine klare Hierarchie: Der Biologie war die Meister-, den Geisteswissenschaften die Lehrlingsrolle zugewiesen. Dafür, sich aus erster Hand über den biologischen Wissensstand seiner Zeit zu informieren, fehlte Koch jedoch stets die Muße. Stattdessen stützte er sich auf die Darstellungen Kolbenheyers, von dessen anmaßender Selbstdarstellung als Referenzbiologe er sich übertölpeln ließ. Nur vor diesem Hintergrund konnte die Bauhütte für Koch zur „,Brücke‘

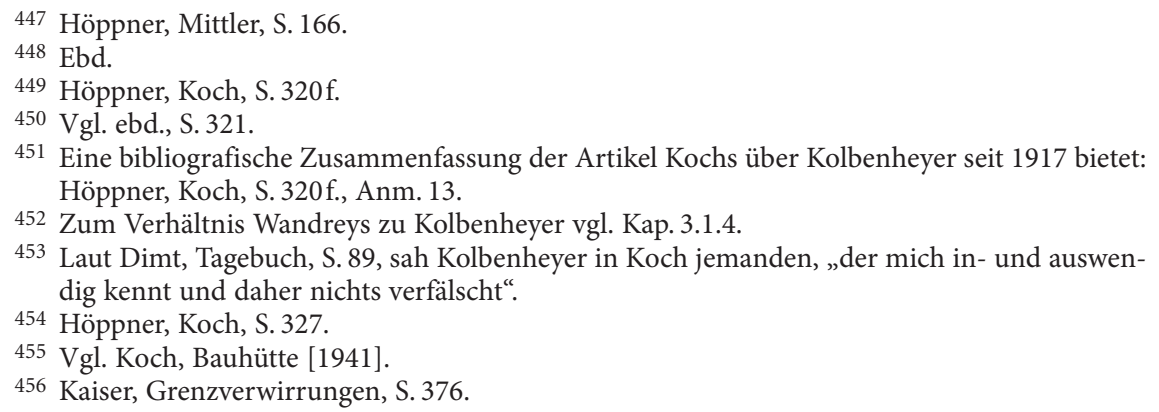


zwischen Geistes- und Naturwissenschaften“457 werden - eine Brücke, deren Tragfähigkeit er ebenso massiv überschätzte wie Kolbenheyer selbst.

Vor allem nach dem Antritt seines Ordinariats für Literatur- und Geistesgeschichte an der Friedrich-Wilhelm-Universität Berlin im Jahr 1935 wusste Koch die „ihm zur Verfügung stehenden akademischen und außerakademischen Multiplikationsfaktoren weidlich zu nutzen", um Kolbenheyers Weltanschauung zu popularisieren. „Themen wie E.G. Kolbenheyer oder Volkhafte Dichtung der Gegenwart" gehörten damals „zum Standardrepertoire“ seiner „Vorlesungen und Übungen am Germanischen Seminar“458. Die biologistische Literaturbetrachtung Kochs auf Basis der Bauhütten-Philosophie war jedoch auch im „Dritten Reich“ keineswegs unumstritten und konnte sich nicht als neues Paradigma durchsetzen. „Disziplinintern“, so hat Gerhard Kaiser vermutet, dürfte die „inszenatorische Referenzgröße Kolbenheyer“ vielen Germanisten letztendlich „als zu idiosynkratisch und von zweifelhafter, wissenschaftlicher Seriosität“ 459 erschienen sein.

Ein dritter Literaturwissenschaftler, der sich nachhaltig von der Philosophie der Bauhütte inspirieren ließ, war der Tübinger Ordinarius für Deutsche Sprache und Literatur, Hermann Schneider. ${ }^{460}$ Je weiter sich Schneider in das philosophisch-weltanschauliche Werk Kolbenheyers vertiefte, desto stärker gewann er den Eindruck, ein überlegenes, avantgardistisches Gedankengebäude vor sich zu haben. „Ernstlicher als früher“, so schrieb er im November 1934 an Kolbenheyer, habe er sich davon ,überzeugt, daß die Zukunft der großen deutschen Weltweisheit einer biologisch gerichteten Betrachtung " 461 gehöre. Diese Perspektive erfüllte den Germanisten indes nicht mit Trauer ob der geringeren Deutungsmacht seiner eigenen Disziplin. Vielmehr galt ihm diese Entwicklung als notwendig, damit „naturwissenschaftliche und geisteswissenschaftliche Weltanschauung“ nicht „ewig aneinander vorbeirede“; eine biologische Fundierung der Geisteswissenschaften hielt Schneider für unverzichtbar, damit diese nicht „weithin in bloßes subjektivistisches Gedankenspiel“ ${ }^{462}$ ausartete. Für seine literaturwissenschaftliche Arbeit gewann Schneider aus Kolbenheyers Bauhütte beispielsweise ein subjektiv befriedigendes Erklärungsmodell für das ihn beschäftigende „Problem des Neuen in der Literatur, Kunst und im Leben überhaupt ${ }^{\text {“463. }}$.

457 Ebd., S. 376, 382.

458 Ebd., S. 327 (Herv. i. Orig.).

459 Kaiser, Grenzverwirrungen, S. 390.

460 Zu Hermann Schneider (1886-1961) vgl. auch Kap. 3.1.2.

461 KAG, Hermann Schneider an Erwin Guido Kolbenheyer, 21. November 1934.

462 Ebd.

463 KAG, Hermann Schneider an Erwin Guido Kolbenheyer, 8. September 1935: „Eine besondere Art der Betrachtung danke ich Ihnen als Literaturhistoriker. Mich hat schon immer das Problem des Neuen in der Literatur, Kunst und im Leben überhaupt beschäftigt. [...] Der von Ihnen so exakt gefasste Begriff der Anpassung löst die Schwierigkeit. [...] Zugleich verschwindet eine mir lästige Doppelheit meiner bisherigen Betrachtungen: Ich pflegte [...] eine Zweiteilung vorzunehmen: entweder es liegt etwas in der Luft und wird von vielen aus der Menge zugleich empfunden und aufgegriffen, oder es kommt ein grosses Genie und weist für ein Jahrhundert einen Weg auf dem man ihm nur langsam nachkommt. In Ihrem Sinne wäre das eine verschiedene Art von Schnelligkeit und Ausgiebigkeit der Anpassung, 
Noch in einer Rede, mit der er am 15. Oktober 1945 als erster Rektor der Universität Tübingen nach dem Zweiten Weltkrieg den Lehrbetrieb wieder eröffnete, würdigte Schneider Kolbenheyers Philosophie als weltanschauliche Referenzgröße. ${ }^{464}$ In Schneiders Rede erscheint Kolbenheyer als Vertreter einer „moderne[n], biologisch gerichtete[n]“ Philosophie, mit deren Hilfe es den Deutschen gelingen könne, „zum ewig Anderen, zum Neuen durch[zu]stoßen“ und damit Wege aus der Krise und Bedrängnis der Gegenwart zu finden. Kolbenheyer habe es vermocht, „Geist und Natur in einer Ebene“ zusammenzuführen, wohingegen etwa Hegel in einseitiger Weise dem Geist „vor der ,langweiligen', sich ewig wiederholenden Natur den Vorrang einräumt" habe. Dabei sei es in Wirklichkeit doch stets „die Natur“, die „das Menschengeschlecht zugleich physisch und geistig durch Krisenzeiten“ führe und ihm „über ,Entwicklungsschwellen“ ' hinweg helfe, „die in ein neues, biologisch bedingtes Sein hineinführen und die überschritten sein wollen" ${ }^{465}$ - so Schneider in gelehrsamem Kolbenheyer-Jargon. Anlass zur Annahme, Schneider habe mit seinem Loblied auf Kolbenheyer einen „Nerv“ der Zeit getroffen, besteht indes keiner; eher dürften seine Ausführungen für Befremden gesorgt haben. Mit dem Ende des Zweiten Weltkriegs waren die Zeiten, in denen Kolbenheyer an deutschen Universitäten mit Gehör rechnen durfte, jedenfalls vorüber.

ANSCHLUSSFÄHIGKEIT DER „BAUHÜTTE“ JENSEITS DER GERMANISTIK - Kolbenheyers philosophische Entwürfe besaßen zwar in keinem Bereich des NS-Wissenschaftsbetriebs eine dominierende Rolle, gleichwohl stieß seine biologistische Denkweise auch jenseits der Literaturwissenschaft auf Interesse und erwies sich unter Vertretern sehr unterschiedlicher Fachbereiche als anschlussfähig.

1935 eruierte etwa der Ordinarius für Theoretische Physik an der Universität Rostock und spätere CDU-Bundestagsabgeordnete Pascual Jordan ${ }^{466}$ im Deutschen Volkstum das Potenzial einer stärkeren Interdisziplinarität von Physik und Biologie. In der Biologie glaubte er die „heute immer deutlicher zum zentralen Felde unseres Denkens“ werdende Wissenschaft, kurz: die künftige wissenschaftliche Leitdisziplin erkennen zu können. Diese Entwicklung belegte Jordan nicht nur mit dem Verweis auf eine „neuartige, für unsere Zeit charakteristische Bezugnahme politischen Denkens und Handelns auf biologische Begriffe und Gesetzlichkeiten“. Zugleich zeigte sich Jordan der wachsende Stellenwert der Biologie daran, dass diese auch „außerhalb des Politischen in die Werke der reifsten geisti-

das Genie hat die Gabe, den erfolgten Anpassungsvorgang ins Bewusstsein zu heben und die Lösung exemplarisch zu machen. Ists [sic!] nicht so?“.

464 Ein Teilabdruck der Rede, die sich dem Thema Entstehung, Träger und Wesen des Neuen in der Geschichte der Dichtkunst widmete, ist in einem 1963 veröffentlichten Beitrag der Tübinger Forschungen überliefert. Vgl. Müller, Bitte, S. 1.

465 Ebd.

466 Zum Werdegang Jordans vor und nach 1945 und zu seiner wissenschaftlichen Bedeutung vgl. Pascual Jordan (1902-1980). Mainzer Symposium zum 100. Geburtstag, hg. v. Max-PlanckInstitut für Wissenschaftsgeschichte, Berlin 2007. 
gen Vertreter unserer Zeit“ eingeflossen sei. Als Kronzeuge dieser Entwicklung diente dem jungen Physiker Kolbenheyer, dessen Denken er „erfüllt“ sah „von einer selbstgeschaffenen Biologie“ ${ }^{\text {467. }}$.

Wenige Monate nach Veröffentlichung des Artikels beschrieb Stapel Pascual Jordan, der schon 1930 unter dem Pseudonym „Ernst Domeier“ im Deutschen Volkstum publiziert hatte ${ }^{468}$, in einem Brief an Kolbenheyer denn auch als einen „bemerkenswert[en]“ weil „biologisch“ „ganz in der Richtung der ,Bauhütte““469 denkenden Physiker. Nötig war eine solche Vorstellung zum damaligen Zeitpunkt indes nicht mehr, war es doch schon im Frühjahr $1930 \mathrm{zu}$ einem ersten direkten Kontakt zwischen Kolbenheyer und Jordan gekommen. Anlass war hier Kolbenheyers Aufruf der Universitäten (1929) gewesen, von dem sich Jordan stark angesprochen fühlte. ${ }^{470}$

Nebst Jordan zeigte sich auch Siegfried Wendt, der Hauptschriftleiter der Akademischen Nachrichten der Handels-Hochschule Mannheim und spätere Professor für Volkswirtschaftslehre und Sozialpolitik, für Kolbenheyers Weltanschauung empfänglich. Besonders angetan war Wendt, seinem eigenen Fachbereich entsprechend, von Kolbenheyers Broschüre Arbeitsnot und Wirtschaftskrise biologisch gesehen (1935). ${ }^{471}$ Kolbenheyers „biologische Betrachtungsweise“, so Wendt im September 1935, habe ihm „eine ganze Reihe bedeutender Ausblicke erschlossen“. Insbesondere „der Gedanke von der Notwendigkeit eines biologischen Wehrerfordernisses, das allein Wachstum und Ausdifferenzierung der Art gewährleistet", gebe ihm die Möglichkeit, „bestimmte Erkenntnisse über die Ordnung des wirtschaftlichen Entwicklungsprozesses tiefer zu begründen" 472 . Wendt hatte bereits 1931 in seiner Zeitschrift auf Kolbenheyers Aufsatzsammlung Stimme hingewiesen und sie in den Lese-Kanon des deutschen Bildungsbürgertums zu hieven versucht: Mit Kolbenheyers Aufsätzen müsse sich ,jeder gebildete Deutsche befassen und auseinandersetzen“, da aus ihnen „die Stimme eines Führers“ spreche, „der Wesentliches, Entscheidendes über die Gestaltung des deutschen Lebens zu sagen" 473 habe.

Zu den Bewunderern Kolbenheyers zählte auch der in Tübingen lehrende Professor für Systematische Theologie und Mitbegründer des Reichsinstituts für Geschichte des neuen Deutschland, Gerhard Kittel. Im Juni 1935 pries Kittel insbesondere Kolbenheyers Aufsatz Arbeitsnot und Wirtschaftskrise biologisch ge-

467 Jordan, Perspektiven, S. 688f. (Herv. i . Orig.).

468 Dass sich hinter diesem Pseudonym Pascual Jordan verbirgt, ist durch einen Brief Wilhelm Stapels an Carl Schmitt vom 11. April 1944 verbürgt, abgedruckt in: Lokatis, Wilhelm Stapel und Carl Schmitt, S. 84.

469 KAG, Wilhelm Stapel an Erwin Guido Kolbenheyer, 24. Februar 1936.

470 Vgl. KAG, Pascual Jordan an Erwin Guido Kolbenheyer, 14. März 1930; zum Aufruf vgl. Kap. 3.5.

471 Erwin Guido Kolbenheyer, Arbeitsnot und Wirtschaftskrise biologisch gesehen, München 1935.

472 KAG, Siegfried Wendt an Erwin Guido Kolbenheyer, 20. September 1935.

473 Wendt, Kolbenheyer, S. 2. 
sehen als „eine der nicht bloß geistvollsten, sondern wirklichkeitsnahesten Darstellungen u[nd] Analysen unserer Situation“, die er "nicht nur sofort mit brennende $[\mathrm{m}]$ Interesse gelesen, sondern $[\ldots]$ inzwischen mehrfach verliehen $\mathrm{u}[\mathrm{nd}]$ verschenkt habe ${ }^{\text {"474 }}$. Weiterer Zuspruch von Seiten der Theologie - einer Disziplin, welcher er eigentlich denkbar fern stand - erhielt Kolbenheyer seiner Autobiografie zufolge im Jahr 1933 bei einer Unterredung mit Wilhelm Beye. Damals habe ihm Beye, der 1934 für kurze Zeit braunschweigischer Landesbischof werden sollte und zu den Gründungsmitgliedern der dortigen Gruppierung der Deutschen Christen gehörte, mitgeteilt, dass er „mit seinen Pfarrern seit Jahren Schulungskurse“ gehalten habe, „die auf meiner Bauhüttenphilosophie beruhten“ 475 .

Die zunehmende „Biologisierung des rechtsintellektuellen Denkens“ nach dem Ersten Weltkrieg, wie sie Niels Lösch am Beispiel der sich seit 1900 im Wissenschaftsbetrieb etablierenden Disziplinen Sozialanthropologie und Rassenhygiene dargestellt hat ${ }^{476}$, bot auch Kolbenheyer und seiner Bauhütte in den Jahren 19251945 einen vielversprechenden Rezeptionsrahmen. Selbst wenn nur sehr wenige Wissenschaftler die Bauhütten-Philosophie en détail verinnerlichten und den anmaßenden Alleingültigkeitsanspruch des Dichters ernst nahmen, gelang es Kolbenheyer doch, gegenüber zahlreichen akademischen Eliten den Anschein zu erwecken, neben seiner Berufung zum Dichter auch ein vermeintlich auf Höhe der biologisch-naturwissenschaftlichen Debatte stehender Naturphilosoph zu sein. Augenfällig ist hierbei, dass unter den Wissenschaftlern, die sich für Kolbenheyers Bauhütte interessierten und sich mitunter als gelehrsame Leser erwiesen, Geisteswissenschaftler eindeutig überwogen. Auch die oben angeführte, ausführliche Besprechung der Bauhütte durch den Tübinger Botanik-Professor Ernst Lehmann kann nicht darüber hinwegtäuschen, dass Kolbenheyers philosophisches Hauptwerk von naturwissenschaftlicher Seite, insbesondere von Seiten professioneller Biologen, auch schon vor dem Ende des Zweiten Weltkriegs weitgehend ignoriert wurde.

Die Reaktion von Seite der Geisteswissenschaftler verrät hingegen einiges über den sehr hohen Stellenwert, welcher der Biologie während der Zwischenkriegszeit in dieser Klientel zugesprochen wurde. Auf sie übte es einen nicht unerheblichen Reiz aus, sich an die Biologie als mutmaßlich avantgardistischer, zukunftsweisender Leitdisziplin anzulehnen und mit entsprechenden Kenntnissen zu glänzen. Dass die Rezeption der Bauhütte hier nur einen kleinen Ausschnitt eines sehr viel größeren Zusammenhangs darstellt, versteht sich von selbst.

474 KAG, Gerhard Kittel an Erwin Guido Kolbenheyer, 10. Juni 1935.

475 Kolbenheyer, Sebastian Karst, Bd. 3, S. $191 \mathrm{f}$.

476 Lösch, Biologisierung. 


\title{
3.4 Zum Stellenwert Grimms und Kolbenheyers an den Universitäten Göttingen und Tübingen
}

\begin{abstract}
Tübingen ist seit einer Reihe von Jahren Kolbenheyers Wahlheimat; Stadt und Landschaft sind ihm vertraut geworden [...]. Möge Tübingen immer mehr lernen, ihm mit gleich gutem Willen und mit gleicher Wärme entgegen zu kommen. Denn es geziemt sich, daß man sagen kann: Kolbenheyer wird nirgends besser verstanden und nirgends mehr geliebt als in Tübingen. 477
\end{abstract}

Angesichts der hohen Bedeutung, die Hans Grimm und Erwin Guido Kolbenheyer der Resonanz ihrer Arbeiten gerade unter deutschen akademischen Eliten zusprachen, überrascht es nicht, dass beide Autoren um gute Beziehungen zu den ihnen geografisch nächstgelegenen Universitäten bemüht waren. Besonders stark ausgeprägt war dieses Bedürfnis bei Kolbenheyer, den zeit seines Lebens auch eine enge emotionale Bindung mit der Universität Wien verband, wo er studiert und promoviert hatte. Demgegenüber hatte Grimm sein Studium erst im Alter von fast 40 Jahren abgeschlossen, inmitten einer längst begonnenen publizistischen und schriftstellerischen Karriere. ${ }^{478}$ Bei Grimm ist daher weniger von einer tiefen emotionalen Verbundenheit zum akademischen Leben auszugehen als von einer sehr hohen, vorauseilenden Hochachtung gegenüber Hochschullehrern.

Kolbenheyers erste Berührung mit dem akademischen Leben Tübingens war indes wenig vielversprechend verlaufen. In seiner Autobiografie ist die Rede von einer Zusammenkunft einiger namentlich nicht erwähnter Professoren, zu der er 1919 gemeinsam mit seiner Gattin unmittelbar nach ihrem Umzug von Wien nach Tübingen geladen wurde, offenbar aus Neugierde über die Neuankömmlinge. Hierbei seien rasch deutliche politische Differenzen zu Tage getreten, namentlich als anwesende Professoren das Gespräch auf die angebliche „politische Kunst der Franzosen und Engländer" gebracht und das Fehlen eines deutschen Pendants zu dem französischen Staatsmann George Clemenceau bedauert hätten. ${ }^{479}$ Seiner Gegenrede, das von den „Vertragsdiktatoren“ geschaffene Versailler System sei ein „Torenspiel“, da es keine politische Stabilität aufweisen werde, sei dabei mit dem „taktvollen Schweigen der Betretenen“ begegnet worden; man habe, so glaubte Kolbenheyer, „den Neuling weiter nicht abschrecken“ und dessen „Unverstand

477 Schneider, Kolbenheyer [1928].

478 Vgl. Kap. 2.1.

479 Kolbenheyer, Sebastian Karst, Bd. 2, S. 327. George Clemenceau hatte sich während des Ersten Weltkriegs durch viel beachtete, patriotische Reden in Frankreich zur „Verkörperung des nationalen Willens" stilisiert, „den Krieg unter allen Umständen siegreich zu beenden“" (Leonhard, Büchse, S. 726). Während der Pariser Friedenskonferenz (1919) trat Clemenceau als schroffer Hardliner gegen das Deutsche Reich auf und geriet so in einen Gegensatz zu dem gemäßigten US-Präsidenten Woodrow Wilson. Vgl. Sedlmaier, Deutschlandbilder, passim. 
nicht erst zurechtweisen“ wollen, ihn insgeheim jedoch zu einem „besessenen Nationalisten“ gestempelt, der letztlich „doch unbelehrbar wäre“480.

Diese Episode kann zwar, wie dieses Kapitel zeigen wird, keinesfalls als repräsentativ für das Verhältnis Kolbenheyers zur Universität Tübingen gelten, sie ermahnt jedoch dazu, die Anschlussfähigkeit des Dichters im akademischen Leben seiner neuen Wahlheimat nicht zu überschätzen. Innerhalb des Lehrkörpers der Universität Tübingen fanden sich emphatische Anhänger Kolbenheyers ebenso wie entschiedene Gegner und Personen, die dem Dichter indifferent gegenüberstanden. Dasselbe gilt für Grimms Stellung und Ansehen an der Universität Göttingen. Angesichts der eindeutigen und einseitigen ideologischen Aufladung ihrer Werke sowie der natürlichen Mannigfaltigkeit des politischen Denkens innerhalb der großen Lehrkörper jener Universitäten kann es nicht überraschen, dass sich das Verhältnis der beiden Autoren zu ,ihren“ Universitäten nicht auf einen einfachen und einheitlichen Nenner bringen lässt. Dass es an beiden Hochschulen indes eine erhebliche Anzahl von Professoren gab, die sich Grimm und Kolbenheyer persönlich verbunden fühlten, steht außer Frage. Dies lässt sich zunächst an den Ehrendoktorwürden veranschaulichen, die den beiden Dichtern im Jahr 1927 verliehen wurden.

Die Verleihung Der EhrendoktorwÜRde an Grimm - Den äußeren Anlass zur Verleihung der Ehrendoktorwürde an Hans Grimm durch die Philosophische Fakultät der Universität Göttingen bot der 100. Geburtstag Paul de Lagardes (18271891), eines der Säulenheiligen der völkischen Bewegung des wilhelminischen Kaiserreichs. ${ }^{481}$ Den entscheidenden Anstoß zur Verleihung des Titels hatte der Germanistikprofessor Edward Schröder gegeben ${ }^{482}$, mit dem Grimm bereits seit Anfang der 1920er Jahre freundschaftlich verbunden war. Im November 1922 hatte Schröder - beeindruckt von der Lektüre der Südafrikanischen Novellen $(1913)^{483}$ - den Kontakt mit Grimm gesucht. ${ }^{484}$ Als Beleg für das langanhaltende freundschaftliche und vertrauensvolle Verhältnis zwischen Schröder und Grimm mag der Hinweis genügen, dass Grimm dem Göttinger Germanisten im Februar 1931 sein Manuskript des Essaybands Der Schriftsteller und die Zeit anvertraute -

480 Ebd.

$481 \mathrm{Zu}$ Person und Nachwirkung Paul de Lagardes vgl. Paul, Lagarde; Sieg, Prophet.

482 Edward Schröder (1858-1942) studierte als Sohn eines Tabakfabrikanten Germanistik und Anglistik in Straßburg und Berlin. Nach seiner Habilitation (1883) ging Schröder 1887 als Extraordinarius nach Berlin, ehe er 1889 zum ordentlichen Professor der Germanistik nach Marburg berufen wurde. Seit 1902 lehrte er in Göttingen. Schröder gab von 1891 bis 1938 die Zeitschrift für Deutsches Altertum heraus und war von 1908 bis 1934 Hauptverantwortlicher für die Arbeit am Grimmschen Wörterbuch. - In dem Protokollbuch der Philosophischen Fakultät der Universität Göttingen findet sich über eine am 18. Oktober 1927 abgehaltene Fakultätssitzung die Information, dass die Fakultät die Entscheidung „auf Antrag“ Schröders und eines Fakultätskollegen sowie „nach Berichten durch Schröder, [Rudolf] Unger und dem Dekan“ traf. Für die Bereitstellung dieser Information danke ich Herrn Dr. Ulrich Hunger, Universitätsarchiv Göttingen.

483 Vgl. zu diesem Frühwerk Grimms: Gümbel, Volk, S. 48-55.

484 Vgl. DLA, A:Grimm, Edward Schröder an Hans Grimm, 20. November 1922. 
mit der Bitte um eine komplette Korrekturlektüre. ${ }^{485}$ Schröder kam dieser Bitte gerne nach.

Die Verleihung der Ehrendoktorwürde an Grimm erfolgte am 2. November 1927. Da Grimm zum damaligen Zeitpunkt in Südwestafrika weilte, wo er in einem mehrmonatigen Aufenthalt seine ersten größeren literarischen Publikationen seit Volk ohne Raum vorbereitete ${ }^{486}$, nahm seine Gattin das Ehrendoktordiplom entgegen. Der damalige Dekan der Philosophischen Fakultät und Ordinarius für englische Philologie, Hans Hecht ${ }^{487}$, begründete die Ehrung des Dichters dem organisatorischen Rahmen entsprechend - mit einer Parallelisierung des Wirkens von Grimm und Paul de Lagarde: Sowohl Grimm als auch Lagarde hätten den „prophetischen Geist“ besessen, „in Unabhängigkeit von allen Parteien aber im Glauben an die geschichtliche Sendung unseres Volkes und die reine Kraft seiner Jugend die deutsche Nationalität in der Einheit eines neuen Ideals aller Deutschen" 488 zu suchen. Die Verleihung des Ehrentitels galt zugleich ausdrücklich dem „Schöpfer des Epos von Volk ohne Raum, der mit demselben leidenschaftlichen Herzen für die Größe Deutschlands sein Schicksal mit der seherischen Gewalt des Dichters sichtbar gemacht" und der deutschen „Jugend die Zukunft eines freien und adeligen deutschen Lebens $[\ldots]$ in die Seele gezeichnet" ${ }^{\star 489}$ habe.

Nach Grimms Rückkehr aus Südwestafrika veranstaltete die Philosophische Fakultät am 8. Dezember 1928 zu Ehren des Dichters ein gemeinsames Essen, bei dem Grimm eine „Tischrede“ hielt, die auf Bitte des Professors für Mittlere und Neuere Geschichte, Arnold Oskar Meyer, alsbald in den Mitteilungen des Göttinger Universitätsbunds veröffentlicht wurde. ${ }^{490}$ Grimm und Meyer blieben bis zum Tod des Historikers im Jahr 1944 in regem Kontakt. ${ }^{491}$ Meyer schätzte die Werke des Dichters nicht nur wegen ihrer literarischen, sondern zugleich wegen ihrer angeblichen historiografischen Qualitäten. Insbesondere für Das deutsche Südwester-Buch (1929) sah Meyer die Historikerzunft Grimm zum Dank verpflichtet; ${ }^{492}$ in Einzelfragen zur Kolonialgeschichte ließ sich der Professor von

485 Vgl. DLA, A:Grimm, Hans Grimm an Edward Schröder, 7. Februar 1931.

4861928 erschien Die dreizehn Briefe aus Deutsch-Südwest-Afrika, ein Jahr später Das deutsche Südwester-Buch.

487 Zum Werdegang Hans Hechts (1876-1946) vgl. Schäfer-Richter/Klein, Bürger, S. $91 \mathrm{f}$.

488 Der Wortlaut ist belegt in: Schröder, Lagarde, S. 14.

489 Ebd.

490 DLA, A:Grimm, Arnold Oskar Meyer an Hans Grimm, 11. Februar 1929.

491 Der erstmalige briefliche Kontakt zwischen Grimm und Arnold Oskar Meyer (1877-1944) geht auf eine (von dem Dichter sogleich bewilligte) Bitte Meyers zurück, Grimm in Lippoldsberg persönlich aufsuchen zu dürfen, vgl. DLA, A:Grimm, Arnold Oskar Meyer an Hans Grimm, 30. Dezember 1928. Besonders dicht war der Briefwechsel in den Jahren 1934 bis 1937. Hauptthema der Korrespondenz waren die deutsch-englischen Beziehungen. Ebenso wie Grimm galt auch Meyer ein Krieg zwischen England und dem Deutschen Reich als eine "Schicksalstragödie der weißen Rasse“ (DLA, A:Grimm, Arnold Oskar Meyer an Hans Grimm, 24. September 1942).

492 Vgl. DLA, A:Grimm, Arnold Oskar Meyer an Hans Grimm, 22. September 1929: „Es ist deutsche Kolonial- und zugleich ein Ausschnitt aus der Weltgeschichte, was Sie bieten. [...] 
Grimm „gern belehren“493. In anderen, jenseits der Kolonialgeschichte liegenden Fragestellungen stimmte Meyer den Auffassungen Grimms freilich nicht immer zu. ${ }^{494}$

Grimm betonte in seiner „Tischrede“, dass der Ehrendoktortitel für ihn „ein Stück erfüllter Tradition“ bedeute. Zur Begründung verwies er auf seine kaufmännische Lehre, die er schweren Herzens nach seinem Abitur anstelle eines Studiums angetreten habe - unter Abkehr einer „drei Jahrhunderte langen theologischen, philosophischen, juristischen " und also akademischen Tradition seines „Geschlechts“495. Zu diesem Traditionsbruch sei es aufgrund eines „dunklen, unruhigen Gefühl[s]“ seines Vaters gekommen, der ihn nach seiner Schulzeit darauf hingewiesen habe,

„daß wir alten bürgerlichen Familien nach einer Zeit, in der wir in unserer Blickrichtung, höfisch' statt, völkisch' geworden waren, jedenfalls neu an das Leben heran müssten, wenn unsere so demütige wie leidenschaftliche Sachlichkeit $[\ldots]$ noch wirkliche, noch politische Bedeutung für die ungewisse Zukunft der rascher ziehenden deutschen Nation haben sollte und also wir selbst uns nicht überholt und [aus dem Volk] ausgeschieden erklären wollten“496.

Demnach nahm Grimm die Ehrendoktorwürde als Rückbindung an verlorene, innerfamiliäre akademische Traditionen wahr, an die anzuknüpfen ihm als Heranwachsenden durch eine gleichsam antiakademische Impulshandlung seines Vaters verwehrt geblieben war. Im gleichen Atemzug versicherte Grimm jedoch, seinen kaufmännischen Werdegang und seine durch ihn bedingte Auswanderung nach Südafrika rückblickend nicht zu bedauern. Nur durch seine Erfahrungen als Auslandsdeutscher sowie durch seine späteren Erlebnisse als Soldat im Ersten Weltkrieg habe er „erfahren“, dass der Einzelne „vor dem Zusammenhange [...] gering“ sei, dass das „Schicksal durch den Zusammenhang und im Zusammenhange mit dem Leben des eigenen Volkes“ den entscheidenden „Gegenstand unserer Zeit“ darstelle. Gegenüber der Schicksalsverbundenheit von Individuum und Volk müsse „alles andere“ als sekundäre „Folge“ zurückstehen. Dieses völkische Erweckungserlebnis lehrte Grimm, dass es die „Pflichtaufgabe“ des Schriftstellers ebenso wie des Gelehrten und Akademikers sei, „Synthese“, „Zusammen-

Als Gesamteindruck bleibt eine ungemeine Lebendigkeit des Landes und seiner Bewohner, des südlichen Himmels und des nordisch harten Menschen, die es erschlossen haben (wenn das Wort ,hart' auch nicht für alles gilt). Es ist Tat, Kraft, Nüchternheit und Lebenswille in dem Buch, dazu grausame Tragik. Grauenvoll die Rechtlosigkeit des Deutschen und die Schamlosigkeit des Engländers“.

493 DLA, A:Grimm, Arnold Oskar Meyer an Hans Grimm, 24. November 1929. In diesem Fall ging es um die Frage des „Erwachens des Farbigen in Afrika und des Reichspatriotismus der Buren“ - Themen, zu denen er "kein eigenes Urteil“ habe.

494 Während Grimm und Meyer in ihren außenpolitischen Betrachtungen zu England weitestgehend d'accord gingen, lehnte Meyer etwa die These Grimms, dass „,es im Mittelalter kein Deutschland“" gegeben habe, als „anachronistisch“ und „unannehmbar“ ab: „Die Deutschen des Mittelalters in Ihrer großen Zeit waren ein Herrenvolk, wie es nur je eines in der Geschichte gegeben hat, und wurden von den anderen mit Ingrimm als solches empfunden" (DLA, A:Grimm, Arnold Oskar Meyer an Hans Grimm, 4. Juni 1931).

495 Grimm, Ansprache, S. 22.

496 Ebd. 
denken“ und „Beziehung“ in die „ringende Nation“ hineinzutragen. Ob er diese Aufgabe gut erfüllt habe und noch erfülle, wollte Grimm nicht selbst beantworten; das Schicksal aber habe ihn dazu „gezwungen“, sie „zu erkennen“497.

An die Verleihung der Ehrendoktorwürde schlossen sich in den folgenden Jahren einige gemeinsame Unternehmungen Grimms mit dem Lehrkörper der Göttinger Universität an, die als Geselligkeitsformen in ihrer Bedeutung für den Stellenwert des Dichters an der Universität nicht unterschätzt werden sollten. Im Juni 1929 erreichte Grimm die von dem Geografieprofessor und damaligen Prorektor der Universität, Wilhelm Meinardus, unterzeichnete Einladung, die Göttinger Professorenschaft bei ihrem gemeinsamen Ausflug nach Carlshafen zu begleiten. ${ }^{498}$ Für den 19. Juli 1930 ist zudem ein Ausflug der Philosophischen Fakultät nach Lippoldsberg belegt. ${ }^{499}$ Eine Erinnerung an diesen Besuch ließ Grimm in eine seiner zahlreichen nach 1945 verfassten autobiografischen Schriften einfließen. Demzufolge waren insgesamt fast „sechzig Mann“500 der Fakultät zu einem Aufenthalt und gemeinsamen Abendessen nach Lippoldsberg gekommen. Bei der Zusammenkunft saß Grimm neben dem Historiker Karl Brandi, der bereits seit 1902 in Göttingen lehrte und im Namen der Fakultät Dank- und Grußworte an Grimm richtete, für die sich der Dichter mit einer Lesung seines kurz zuvor verfassten autobiografischen Aufsatzes Heimat und Ahnen ${ }^{501}$ revanchierte. Rückblickend zeigte sich Grimm mit der Qualität seiner Lesung recht unzufrieden; die Ehrfurcht gegenüber den versammelten Professoren habe ihn befangen gemacht. ${ }^{502}$

Die Verleihung der Ehrendoktorwürde an Kolbenheyer - Auch bei Kolbenheyer boten Jubiläumsfeierlichkeiten den äußerlichen Rahmen und Anlass zur Verleihung der Ehrendoktorwürde. An Aufwand und Umfang wurden die Feierlichkeiten in Göttingen zu Ehren Paul de Lagardes dabei jedoch weit in den Schatten gestellt: Im Juli 1927 feierte die Universität Tübingen den 450. Jahrestag ihrer Gründung - ein Ereignis, welches „mit Bildseiten und Sonderbeilagen in

497 Ebd., S. 23.

498 Vgl. DLA, A:Grimm, Georg-August-Universität Göttingen an Hans Grimm, 15. Juni 1929.

499 Rundschreiben des Dekans der Philosophischen Fakultät Herman Nohl an die Mitglieder der Fakultät vom 9. Juli 1930, als Abschrift überliefert in: DLA, A:Grimm, Herman Nohl an Hans Grimm, 15. Juli 1930.

500 Grimm, Suchen [1960], S. 44. Grimm dürfte mit dieser Zahlenangabe nicht übertrieben haben. Im Vorfeld des Besuchs betonte der mit der Organisation des Ausflugs beauftragte Ordinarius für Pädagogik und Philosophie, Herman Nohl (1879-1960), beinahe klagend die „schauderhafte Bereitwilligkeit der Fakultät nach Lippoldsberg zu kommen“. Nohl, der „kaum Absagen erhalten“ hatte, lagen zu jenem Zeitpunkt bereits 40 Zusagen vor, er harrte jedoch noch einiger Rückmeldungen. Vgl. DLA, A:Grimm, Herman Nohl an Hans Grimm, 15. Juli 1930.

501 Vgl. Grimm, Heimat [1930].

502 Vgl. Grimm, Suchen [1960], S. 44: „Kam gar eine Gemeinschaft von Universitätsprofessoren als Hörer in Frage, so fühlte ich mich, der in geistigen Dingen tief ehrerbietige Sohn seines Vaters, erst recht befangen, galt doch noch bis dahin unerschüttert - auch scheinbar unerschüttert durch Versailles - bei mir um die unantastbare Freiheit, um den königlichen Rang, um den unvergleichlichen Adel der deutschen Universität“. 
überregionalen deutschen Tageszeitungen dokumentiert“ und „auch im Hinblick

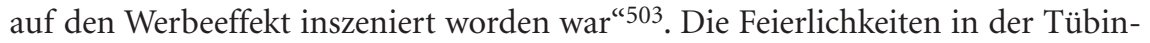
ger Stiftskirche wurden - damals alles andere als eine Selbstverständlichkeit - sogar „vom Rundfunk live übertragen“504.

Im Kontext der Feierlichkeiten wurde Kolbenheyer nicht etwa, wie man zunächst vermuten würde, durch die Philologische, sondern durch die Medizinische Fakultät der Ehrendoktortitel verliehen. Ausschlaggebend für die hohe Wertschätzung des Dichters in jener Fakultät war die literarische Bearbeitung der Figur des Arztes und Philosophen Theophrastus Bombastus von Hohenheim ${ }^{505}$ in Kolbenheyers Paracelsus-Trilogie. Neben der bloßen Wahl des literarischen Gegenstands war auch die im Roman angelegte weltanschauliche Aufladung506 mit entscheidend für das Votum der Fakultät. Die Verleihung des Ehrendoktortitels an Kolbenheyer durch den Ordinarius für Pathologische Anatomie und damaligen Dekan der Medizinischen Fakultät, Alexander Schmincke, galt konkret dem „hervorragenden deutschen Manne, der nicht nur in bewunderungswürdiger Weise in den Geist der Medizin“ eingedrungen sei und dabei „die Gestalt und das Schaffen eines der größten deutschen Ärzte“ und eindringlichsten „Verkünder[s] ärztlicher Ethik“ habe wiederauferstehen lassen, sondern dessen Schrifttum zudem ganz „im Dienste der seelischen und geistigen Gesunderhaltung unseres Volkes“507 gestanden habe.

Einige Wochen nach der 450-Jahr-Feier veröffentlichte Kolbenheyer einen offiziellen Dank für die Verleihung des Ehrendoktor-Titels, dessen Wortlaut sein tiefes Verbundenheitsgefühl mit den beteiligten Hochschullehrern anschaulich illustriert: „Erschüttert vor Dankbarkeit und Freude“ habe er seine Ernennung zum Ehrendoktor durch Tübingens „berühmte Ärztefakultät“ entgegengenommen. Bei der Entscheidung, ihm den Ehrendoktortitel zu verleihen, hätten die Beteiligten vielleicht empfunden, „welch innere Erhebung und welch eine Bekräftigung“ es für eine Dichter bedeuten müsse, „wenn sein letztes Streben: deutsche Art aus ihren eigenen Lebenstiefen zu fördern und aufzurichten - durch ein so weithin sichtbares Beifallszeichen " anerkannt und gutgeheißen werde. Das in der Entscheidung der Fakultät zum Ausdruck kommende Gespür, welches über ihn als Dichter „hinaus in das innere Wachstum unseres Volkes“ reiche, mache ihm die „hohe Auszeichnung zu einer Angelegenheit, der auch ich nur dienstbar untergeordnet bleiben kann" 508 .

Mit Blick auf die in der Begründung des Ehrendoktortitels so stark hervorgehobene Paracelsus-Trilogie bemerkte Kolbenheyer, die Wahl auch deshalb mit

503 Paletschek, Erfindung, S. 140.

504 Kotowski, Universität, S. 277.

505 Zum Wirken von Paracelsus als Mediziner vgl. Pagel, Weltbild; Benzenhöfer, Studien.

506 Vgl. die Hinweise in Kap. 2.3.1.

507 Die Feier des 450-jährigen Bestehens der Eberhard-Karls-Universität Tübingen vom 24. bis 26. Juli 1927, Stuttgart 1928, zitiert nach: Kotowski, Universität, S. 277.

508 Die auf den 10. September 1927 datierte Danksagung Kolbenheyers ist überliefert in: Kolbenheyer, Kämpfer [1978], hier S. 308. 
Freude anzunehmen, da durch sie dem zeitgenössisch sträflich verkannten Protagonisten seiner Trilogie gleichsam späte Gerechtigkeit widerfahren sei: Die „Unbill der Ärztefakultäten früherer Zeiten gesühnt zu haben“, so Kolbenheyer, bleibe das dauerhafte „Verdienst“ der medizinischen Fakultät. ${ }^{509}$ Die aus diesen Zeilen sprechende, tiefe Dankbarkeit Kolbenheyers war keine leere, aufgesetzte Geste, sondern spiegelt sein Gefühlsleben authentisch wider. Noch nach dem Zweiten Weltkrieg betonte der Dichter, die damalige Verleihung der Ehrendoktorwürde „wie ein[en] Segen“510 empfunden und empfangen zu haben. Die hohe Wertschätzung von Seiten der Universität war für Kolbenheyer also keineswegs selbstverständlich, sondern von erheblicher emotionaler Bedeutung. Entsprechend kommt auch in den Briefen an Stapel mehrfach die Freude zum Ausdruck, in der Tübinger Professorenschaft Anschluss und Wertschätzung gefunden zu haben. Nachdem der Rektor der Universität ${ }^{511}$ anlässlich des 50 . Geburtstags des Dichters am 30. Dezember 1928 „eine wirklich schöne Rede“ auf ihn gehalten hatte, konnte sich der ergriffene Dichter bei seiner Antwort „schließlich [...] doch kaum halten" 512 .

Die hohe Bedeutung, die Kolbenheyer der Auszeichnung zusprach, welche ihm durch die Universität zuteil geworden war, drückte sich in der Folgezeit auch darin aus, dass er mit Argusaugen verfolgte, wer nach ihm in den Kreis der Tübinger Ehrendoktoren aufgenommen werden sollte. Bei Kandidaten, die der Auszeichnung in seinen Augen nicht würdig waren, scheute er nicht davor zurück, gegenüber Vertretern der Universität Kritik anzumelden. So wandte sich Kolbenheyer im Frühjahr 1931 mit seinen Bedenken an den Tübinger Ordinarius für Deutsche Sprache und Literatur, Hermann Schneider ${ }^{513}$, nachdem ihm zu Ohren gekommen war, dass dem schwedischen Literaturwissenschaftler Fredrik Böök (1883-1961) eine Ehrendoktorwürde verliehen werden sollte. An der Argumentation des Antwortschreibens Schneiders lässt sich ablesen, worin die Vorbehalte Kolbenheyers konkret bestanden hatten: Es sei nicht zutreffend, so Schneider, dass Bööks Frau Jüdin sei; sie gleiche vielmehr geradezu dem „Urbild einer Germanin“514. Auch Kolbenheyers Behauptung, Bööks Arbeiten seien von „Philo-

509 Ebd., S. 309.

510 Kolbenheyer, Sebastian Karst, Bd. 2, S. 470.

511 Zum damaligen Zeitpunkt hatte der Professor der Evangelischen Theologie Gustav Anrich (1867-1930) dieses Amt inne.

512 DLA, A:Stapel, Erwin Guido Kolbenheyer an Wilhelm Stapel, 12. Januar 1929.

513 Hermann Schneider (1886-1961) ging nach dem Studium der deutschen Philologie in München und Berlin (Promotion 1909) 1915 zunächst als außerordentlicher Professor an die Universität Berlin, ehe er 1921 zum Ordinarius für deutsche Sprache und Literatur nach Tübingen berufen wurde, wo er bis 1954 lehrte. Schneider, der unter anderem Mitglied der Bayerischen Akademie der Wissenschaften war, trat als Mitherausgeber der Schiller-Nationalausgabe sowie als Herausgeber der Bibliothek des Literarischen Vereins (seit 1925) und der Tübinger Germanistischen Arbeiten (seit 1926) hervor. Im öffentlichen Leben Tübingens nahm Schneider vor allem als Redner, aber auch aufgrund seiner Tätigkeit als Vorsitzender des Vereins für das Deutschtum im Ausland eine prominente Stellung ein. Vgl. Kotowski, Universität, S. 239, Anm. 293.

514 KAG, Hermann Schneider an Erwin Guido Kolbenheyer, 15. Februar 1931. 
semitismus“ gekennzeichnet, relativierte Schneider und verwies - gleichsam zur Beruhigung des Dichters - auf Bööks Werk Reise nach Friedrichsruh ${ }^{515}$ aus dem Jahr 1930. Böök spreche darin

„von der letzten Reichstagswahl in Berlin und von dem Antisemitismus der Nationalsozialisten, und schließt ab: ,Es ist ja auch leider in Deutschland eine ganze Menge vorgekommen, von Kurt Eisner und Maximilian Harden bis auf Barmat und Sklarek, was den Antisemitismus begreiflich macht'. Was wollen Sie mehr? Seien Sie überzeugt, daß Sie sich auch sonst dieses Ehrend[okto]r Kollegen nicht zu schämen haben. “516

Schneider verteidigte Böök also gegen die Vorwürfe Kolbenheyers, aufgrund eines Mangels an antisemitischer Gesinnung kein passender Kandidat für eine Ehrendoktorwürde an der Universität Tübingen zu sein. Damit pflichtete Schneider freilich zugleich der Auffassung des Dichters bei, dass Judenfeindschaft als Grundvoraussetzung für die Verleihung einer Ehrendoktorwürde zu gelten habe. Entsprechend vergaß es Schneider auch nicht zu erwähnen, dass ihn Kolbenheyers Hinweise sehr „betroffen“ gemacht hätten und dass er dessen „Anregungen“ „natürlich“ vor dem „endgültigen Antrag auf Bööks Ehrenpromotion [...] nachgegangen" $" 517$ sei. Kolbenheyer dankte Schneider sogleich für dessen Recherchen, kündigte allerdings an, der Sache selbst noch weiter nachgehen zu wollen. ${ }^{518}$ Nach vierwöchiger Detektivarbeit konnte der Dichter schließlich halbe Entwarnung geben: Ein von ihm kontaktierter „Gewährsmann“ in Schweden, so Kolbenheyer, habe seine Informationen über Bööks angeblich jüdische Frau mittlerweile korrigiert; es habe ein Missverständnis vorgelegen. An den Bedenken gegen Böök charakterliche Eignung zum Erhalt der Ehrendoktorwürde hatte der „Gewährsmann“ jedoch festgehalten ${ }^{519}$, sodass sich auch Kolbenheyers Zweifel nicht völlig zerstreut hatten.

Bei dem „Gewährsmann“ handelte es sich um den damals an der Universität Uppsala tätigen Germanisten und späteren Ordinarius für Altertumskunde und Philologie an der Universität Kiel, Otto Höfler. Dieser hatte Böök Anfang der 1920er Jahre während eines zweisemestrigen Studiums an der Universität Lund in Augenschein genommen. „Alle Leute“, so versicherte Höfler in einem Brief an Kolbenheyer vom 24. Februar 1931, „die für so etwas überhaupt einen Blick“ hätten, „erklärten B[öök] für einen Judenstämmling“. Böök habe diesen Eindruck überdies mit seinem ganzen „Wesen [und] Aussehen bestätig[t]“. Von der Frage, ob Böök „zu einem Viertel Mischling“ sei oder doch „zu einem größeren oder geringeren Bruchteil“, zeigte sich jedoch selbst Höfler überfordert und ließ sie un-

515 Zum Entstehungshintergrund sowie zur politisch-ideologischen Aufladung dieses schwärmerischen Bismarck-Büchleins vgl. Hannemann, Böök. Hannemann skizziert Böök darin als widerspruchsvollen „konservative[n] Kleinbürger“ und „intellektuelle[n] DeutschlandSchwärmer" sowie als einen „vom Zionismus faszinierte[n] Antisemit[en] und von Marx beseelte[n] Antisozialist[en]“ (ebd., S. 10).

516 KAG, Hermann Schneider an Erwin Guido Kolbenheyer, 15. Februar 1931.

517 Ebd.

518 Vgl. KAG, Erwin Guido Kolbenheyer an Hermann Schneider, 16. Februar 1931 (Durchschlag).

519 KAG, Erwin Guido Kolbenheyer an Hermann Schneider, 12. März 1931 (Durchschlag). 
beantwortet. ${ }^{520}$ Zur Ehefrau Bööks bemerkte Höfler in einem weiteren Schreiben vom März 1931, dass er „sie gar nicht [kenne]. Und Bekannte, bei denen ich mich nun nochmals erkundigte, sagten, sie sei weder Jüdin noch werde sie für eine gehalten“521.

Eine weitere Reaktion Schneiders ist nicht belegt, auch scheint Kolbenheyer nach seinem zweiten Brief in der Angelegenheit nicht weiter nachgehakt zu haben. Anlass dazu, das Schweigen Schneiders als eine diskrete Kritik an der - um mit Kurt Tucholsky zu sprechen - „Judenriecherei“522 Kolbenheyers zu interpretieren, besteht indes nicht. Schneider gehörte zu jenen Professoren der Universität Tübingen, zu denen Kolbenheyer in eine besonders enge und freundschaftliche Beziehung trat. ${ }^{523}$ Schneider hatte bereits 1928 anlässlich des 50. Geburtstags Kolbenheyers in der Tübinger Chronik eine Würdigung des Dichters veröffentlicht, die mit den eingangs dieses Kapitels zitierten Sätzen schloss und in der Schneider die Werke Kolbenheyers in Sonderheit für das in ihnen verwobene „Weltbild“ lobte. ${ }^{524}$ Schneider gehörte darüber hinaus zu jenen Literaturwissenschaftlern, die sich in ihrer Arbeit deutlich von Kolbenheyers biologistischer Philosophie beeindrucken und beeinflussen ließen. ${ }^{525}$

Zur Reaktion der Universität TÜbingen auf den Umzug Kolbenheyers - 1931 fällte Kolbenheyer die Entscheidung, Tübingen zu verlassen. Im Herbst desselben Jahres kaufte er „in Solln bei München [...] eine ruhig gelegene, wohlausgestattete Villa" 526 , die er, rund 13 Jahre nach seinem Umzug von Wien nach Tübingen, mit seiner Familie im Frühjahr 1932 bezog. Anlässlich des Umzugs fand am 3. Februar 1932 auf Einladung des damaligen Rektors der Universität, dem seinerzeit berühmten Chirurgie-Professor Martin Kirschner ${ }^{527}$, im Silchersaal der Tübinger Museumsgesellschaft eine offizielle Verabschiedung Kolbenheyers statt. Zu diesem

520 KAG, Otto Höfler an Erwin Guido Kolbenheyer, 24. Februar 1931.

521 KAG, Otto Höfler an Erwin Guido Kolbenheyer, 9. März 1931.

522 Tucholsky münzte den Begriff auf Adolf Bartels und dessen antisemitische Literaturhistorik, vgl. Ignaz Wrobel, Herr Adolf Bartels, in: Die Weltbühne, 23. März 1922, Nr. 12, S. 291.

$523 \mathrm{Zu}$ dem Kreis der ihm in seinen Tübinger Jahren besonders nahestehenden Professoren zählte Kolbenheyer neben Hermann Schneider zudem den Philosophieprofessor Erich Adickes (1866-1928), den Mediziner Walter Birk (1880-1954), den Ordinarius für Religionswissenschaften und Indologie und Begründer der Deutschen Glaubensbewegung Jakob Wilhelm Hauer (1881-1962) sowie schließlich den Geologie- und Paläontologie-Professor Edwin Hennig (1882-1977). Vgl. Kolbenheyer, Sebastian Karst, Bd. 2, S. 470.

524 Schneider, Kolbenheyer [1928]: „Höher noch als die Form, die uns eine neue Klassizität der Prosadichtung heraufzuführen verspricht, steht uns aber ein anderes: Das Weltbind [sic!] des Kolbenheyerschen Romans und der Geist der es durchdringt. [...] Männer eigenen Schlags und Sinns, Strebende, Kämpfer sind seine Helden, sie gehen den Weg, den nur sie gehen konnten. Aber der Denker, der vor allem im Erkennen biologischer Zusammenhänge tief geschult ist, reiht sie als notwendige Glieder in ein ewiges Weltgeschehen ein und läßt sie zumal erscheinen als Symbole deutschen Volkstums und notwendige Durchgangsstadien deutschen, sich emporringenden Wesens".

525 Vgl. Kap. 3.3.1 und 3.3.2.

526 Kolbenheyer, Sebastian Karst, Bd. 3, S. 103.

527 Zum Lebensweg Kirschners (1879-1942) vgl. Hörmann, Kirschner. 
Anlass meldete sich nach Ansprachen von Kirschner, Hermann Schneider und Vertretern der Studentenschaft auch Kolbenheyer selbst zu Wort ${ }^{528}$ und versuchte, den Anwesenden einerseits seine tiefe Verbundenheit mit Tübingen zum Ausdruck zu bringen, andererseits die Gründe seines Umzugs plausibel zu machen: An „wohlwollender Anerkennung, unvergesslicher Freundschaft" und einem durch die ,edle Landschaft und hochgesinnte menschliche Umgebung“ bedingten „Arbeitsfrieden“ verdanke er Tübingen „so viel“, dass er von der Stadt in Wahrheit „überhaupt nicht Abschied nehmen“ könne. Tübingen, so Kolbenheyer, sei untrennbar Bestandteil seines Lebens geworden, der mit ihm gehe, „wohin ich mich auch immer wenden wollte "529. Dass er dennoch die Entscheidung zum Umzug nach München getroffen hatte, erklärte Kolbenheyer mit der „Möglichkeit einer eindringlicheren Wirkung“, die er sich durch „die unmittelbare Nähe einer zentraler gelegenen Großstadt"versprach; von München aus könne sein Werk „stärker und leichter [...] an irgendeine Stelle der deutschen Lebensmitte“ dringen, als dies von Tübingen aus möglich sei. 530

Das Streben nach höchstmöglicher Wirkung sah Kolbenheyer als eherne Pflicht insbesondere der „geistig Arbeitende[n]“ an, denen in seinen Augen „im Volke eine bildnerische, ordnende Funktion zugewiesen" war. Seinen Umzug stilisierte er zu einem persönlichen Opfer, das ihm durch das Ethos seines Berufs aufgenötigt worden sei. Er versuchte dabei zugleich, allen Anwesenden ihre persönliche Verpflichtung sinnstiftend vor Augen zu führen:

„Wir stehen in einem gewaltigen Endkampf, der das neue Europa bringen wird; und darin muss Deutschland den gebührenden Platz wiedererhalten, wenn nicht das Weltherrentum der weißen Rasse verloren sein soll. Kann auch kaum angenommen werden, daß meine Generation [...] den Ausgang dieses Kampfes erleben wird, so sind wir doch an der Reihe, die Art des Ausganges wesentlich mitzubestimmen. Wenn wir uns defaitistisch [...] aufgeben, dann wird die Welt derer, die auf uns folgen, wirklich verspielt sein. Ein jeder prüfe sein Leistungsvermögen! Den Geschlechtern, die nach uns kommen, ist ein scharfes Richtschwert in die Hand gegeben; sie werden unser Andenken unerbittlich zur Verantwortung ziehen, und ein Wicht, der da sagt, es läge ihm nichts daran" 531 .

Sein akademisches Publikum versuchte Kolbenheyer besonders dadurch aufzurütteln, dass er den Universitäten in dem skizzierten „Endkampf“ eine Hauptrolle

528 Der Wortlaut der „Rede des Herrn Dr. Kolbenheyer beim Abschiedsabend am 3. Februar 1932 im Museum" ist überliefert in: UAT, Medizinische Fakultät, Nr. 125/224,17, Ehrenpromotionen: Kolbenheyer, Guido Dr. phil.; ein Abdruck der Rede erfolgte in der Tübinger Hochschulzeitung, aus der dann die Tübinger Chronik einen Abdruck publizierte. Vgl. Kolbenheyers Abschied von Tübingen, in: Tübinger Chronik und Steinlachbote, 17. Februar 1932.

529 „Kolbenheyers Abschied von Tübingen“, in: Tübinger Chronik und Steinlachbote vom 17. Februar 1932. Dass diese Bemerkung Kolbenheyers keine leere Floskel war, mag an der eineinhalb Jahrzehnte später erfolgten, spontanen Äußerung Kolbenheyers gegenüber Hermann Schneider abzulesen sein, derzufolge er, Kolbenheyer, „noch immer halb u[nd] halb in meiner Tübinger Zeit" verharre. „Sie alle sind mir noch so vertraut wie ehemals“ (UAT, Nachlass Hermann Schneider, 185/199: Briefkarte Kolbenheyers an Hermann Schneider vom [?] Dezember 1928).

530 Ebd.

531 Ebd. 
zusprach: „Von keinem Teile unseres Volkes“ könnten „die Kräfte der Erneuerung und Wiederaufrichtung stärker strömen als von den Universitäten“. Von ihnen aus müsse „ein zwingender und tiefer Ausdruck der inneren Volksnot und des Volkswillens vor die verantwortlichen Leiter des Staates gelangen“. Sollten die Universitäten in dieser Aufgabe gehemmt oder gehindert werden, wäre damit „der empfindlichste Teil des völkischen Lebens in seiner arterhaltenden Funktion bedroht“532. Kolbenheyer selbst fühlte demnach die Verantwortung und „Verpflichtetheit vor dem Leben“, dorthin zu ziehen, wo er seine Kräfte möglichst effektiv einsetzen konnte. Diesem „Appell“ müsse er folgen, wolle er nicht „vor seinem Gewissen zugrunde gehen “533.

Die enorme Bedeutung, die Kolbenheyer den deutschen Universitäten in seiner Ansprache zuschrieb, stand in deutlicher Kontinuität zu den bereits vorher unternommenen Versuchen des Dichters, seinen Teil zu einem völkischen „Erwachen“ der Hochschullehrer beizutragen. Wie das folgende Kapitel zeigen wird, fiel Kolbenheyers Wortwahl und Argumentation hierbei sehr viel schärfer aus als bei seiner Verabschiedung aus Tübingen.

\title{
3.5 Kolbenheyers „Aufruf der Universitäten“ und seine Resonanz
}

\subsubsection{Kerninhalte des „Aufrufs" und Motive Kolbenheyers}

\author{
Nie waren Lärm, Angebot und Verbrauch des- \\ sen, was sich der Kunstmittel bedient, um \\ niedere Leidenschaft anzureizen, so brutal und \\ hemmungslos, und nie sind so gewandte Federn \\ [...] wie heute dieser Volkszertrümmerung zu \\ Gebote gestanden [...]. Nie war die Kunst so \\ sehr gefährdet und verraten wie heute. Nie sind \\ die Meister verlassener gestanden. ${ }^{534}$
}

Im Sommer 1929 fasste Kolbenheyer den Entschluss, die geisteswissenschaftlichen Professoren aller deutschsprachigen Universitäten in einem flammenden Appell an ihre vermeintlich vernachlässigten Pflichten gegenüber der zeitgenössischen Literatur zu erinnern - jedenfalls soweit Kolbenheyer diese Literatur als der deutschen „Volksart“ entsprechend und als „wertschöpfend“ betrachtete. Der aus dieser Motivation heraus entstandene Aufruf der Universitäten basierte auf der Überzeugung Kolbenheyers, dass infolge des Ersten Weltkriegs „Rohheit, Maß-

\footnotetext{
532 Ebd.

533 Ebd.

534 Kolbenheyer, Aufruf [1930], S. 116. Kolbenheyers „Aufruf der Universitäten“ wird im Folgenden nicht nach seiner Erstpublikation (vgl. Der Kunstwart. Monatshefte für Kunst, Literatur und Leben 43 (1929/30), S. 81-85) zitiert, sondern nach seinem unveränderten, um ein Nachwort Kolbenheyers erweiterten Wiederabdruck in der Zeitschrift Deutsche Sängerschaft.
} 
losigkeit und Sensationslüsternheit" in das deutsche Kunstleben eingedrungen seien und dieses gleichsam mit „undeutschem" Geist kontaminiert hätten; die von dem Krieg hervorgerufenen „Erschütterungen“ seien derart „ungeheuer“ gewesen, dass „die Lösung des Überdruckes“ gerade auch auf kulturellem Gebiet unnatürliche „Entladungen und Spannungszustände“ habe hervorbringen müssen. Das „volkseigene Kunstempfinden und Kunstverlangen“ sei infolgedessen schlicht „überrannt worden“"535.

Folglich durften in den Augen Kolbenheyers die auf dem Weimarer Kunst- und Literaturmarkt beobachtbaren „Entladungen“ - konkret gemeint waren hier die Erfolge linksliberaler, häufig jüdischer Autoren - keineswegs als ein organisches „Wachstum“ verstanden werden. Dieser Gedanke entbehrte insofern nicht der unfreiwilligen Ironie, als Kolbenheyer selbst zu jenen Autoren zählte, die erst vor dem Hintergrund der Kriegsniederlage und der von ihr evozierten nationalen Wiederaufstiegswünsche und erhöhten gesellschaftlichen Anschlussfähigkeit völkischen Denkens einem breiteren Publikum bekannt geworden war - ein Sachverhalt, den der Dichter aufgrund seiner immerwährenden, identitätsstiftenden Überzeugung, ein „totgeschwiegener“ Autor zu sein, freilich weit von sich gewiesen hätte. ${ }^{536}$

In der von ihm skizzierten Notlage sah Kolbenheyer die deutsche Professorenschaft vor die Pflicht gestellt, der als „artgemäß“ definierten und auf die Moral des besiegten deutschen Volks nicht zerstörerisch („devastierend“) wirkenden Gegenwartsliteratur konkrete Schützenhilfe zu leisten. Dieser Forderung lag ein sozialdarwinistisch konnotiertes Kunstverständnis zugrunde: Die „Lebenskräfte“ der Natur, zu denen Kolbenheyer Kunst und Literatur rechnete, bedürften nach dem „Gesetz biologischer Wirksamkeit“ der „selbstbewahrenden Behauptung “537. Das Naturgesetz des Kampfes mache vor Kunst und Literatur keinen Halt. ${ }^{538}$ Nur durch eine professorale Unterstützung, so folgerte Kolbenheyer, könne es der „artgemäßen“ Literatur gelingen, die notwendige und ihr gebührende, führende Stellung zurückzuerlangen. Ohne eine aktive „Betätigung“ von Seiten der Professoren müsse sie hingegen „zerrüttet [und] vernichtet“539 werden. Für die Zeit seit 1918 zog Kolbenheyer eine für das deutsche Volk verheerende, für die akademischen Bildungseliten aber beschämende Bilanz: Niemals zuvor hätten „Angebot und Verbrauch“ der zur Anreizung „niedere[r] Leidenschaften“ verwendeten „Kunstmittel“ derart „brutal und hemmungslos [...] zu Gebote gestanden“ wie in der auf „Volkszertrümmerung“ ausgerichteten „Massenliteratur“ der Gegenwart.

535 Kolbenheyer, Aufruf [1930], S. 115.

536 Vgl. Kap. 3.1.1.

537 Kolbenheyer, Aufruf [1930], S. 115.

538 Vgl. ebd.: „Das Leben hat keinen anderen Sinn, als seinen Bestand durchzusetzen. [...] Selbstbehauptung aber ist Kampf der einzelnen Lebensmächte und Überwindung alles dessen, was sich in diesem Kampfe zu widersetzen sucht, bis zu dem Grade, daß der Bestand des einen neben dem Bestande des andern möglich ist oder das eine durch das andere ausgetilgt wird." Für weitere Hinweise zum Kunstverständnis Kolbenheyers vgl. Kap. 2.2.1.

539 Kolbenheyer, Aufruf [1930], S. 115 (Herv. i. Orig.). 
Deren „zersetzende, parasitäre Funktion“ habe gerade seit 1918 in der Zerrüttung des Volks „durch seelisches Leid und physischen Zwang“ einen idealen „Nährboden gefunden" 540 .

Als Folge und Signum dieser Entwicklung galt Kolbenheyer die fortschreitende „Verniggerung“ der deutschen Kultur. Die „devastierenden“ Kräfte, die der Wirkung ,artgemäßer“ Kunstwerke im Volk entgegenstünden, sah Kolbenheyer in der Figur des „Niggers“ kulminiert. Sie symbolisierte für Kolbenheyer „die Vorherrschaft des primitiv Geschlechtlichen“ sowie „des primitiv Alimentären im wörtlichen und übertragenen Sinne“. Eine form- und maßlose Überbetonung „der Sexualität, des Abenteuers, der sozialen Hetze“ stehe „unerreicht im Ausmaße ihrer Wirkungsmasse“ den eigentlichen „Meistern der Kunst entgegen“. Die „werkgeheiligten Mittel der Musik, Dichtung und Darstellung“ würden schamlos und in völliger Vergessenheit ihrer „innere[n] Bindung an das ruhmvoll Errungene und Behauptete der deutschen Kunst“ missbraucht werden. Niemals, so Kolbenheyers zusammenfassende Wehklage, sei die Kunst daher „so sehr gefährdet und verraten [worden] wie heute“. Nie auch seien „die Meister verlassener gestanden“ “541.

Mit seiner Forderung einer organisierten Abwehr der angeblichen „Verniggerung" des deutschen kulturellen Lebens befand sich Kolbenheyer im Mainstream der kulturpolitischen Ordnungsvorstellungen der deutschen Rechten. Nur wenige Monate vor der Veröffentlichung des Aufrufs der Universitäten hatte etwa auch Hitler in seiner ersten großen Rede nach der Aufhebung seines Redeverbots in Preußen am 16. November 1928 im Berliner Sportpalast scharf die angebliche „Vernegerung“ der deutschen Kultur angeprangert. ${ }^{542}$ Dass dieses triviale Denken auch in Parlamentsdebatten Einzug hielt, zeigt das Beispiel des DNVP-Abgeordneten Karl Koch, der im April 1930 im Preußischen Landtag vor einem bedrohlich „negroiden Zug unserer Zeit“ warnte und lautstark die in Deutschland einfallenden „Niggerrythm[en]“, „Niggerrevuen“ und „Niggersongs übelster Art“ beklagte. Nicht zufällig verfügte Wilhelm Frick, nachdem er 1930 für die NSDAP als thüringischer Innen- und Volksbildungsminister vereidigt worden war, in einer seiner ersten Amtshandlungen die Herausgabe eines Erlasses „,wider die Negerkultur, für deutsches Volkstum“"; in ihm wurde die Polizei angewiesen, „Jazz, ,Negertänze` und ähnliche die ,sittlichen Kräfte` des Volkes umwühlenden, ,fremdrassigen Einflüsse [...] zu verbieten“"544.

540 Ebd., S. 116.

541 Alle Zitate: Ebd.

542 Vgl. Kershaw, Hitler, Bd. 1, S. 389.

543 Vgl. Saldern, Überfremdungsängste, S. 217-212.

544 Büttner, Weimar, S. 301. Der hierin zum Ausdruck kommenden Wechselwirkung von Rassismus, Jazzmusik und neuen Formen des Tanzes wurde in der Forschung bis dato nur wenig Aufmerksamkeit geschenkt (Rippey, Rationalisation; Vollhardt, Notbund). Eine systematische Aufarbeitung dieses Themas wäre indes vielversprechend. Die vorhandene Forschung zum Weimarer Diskurs über die „Schwarze Schmach“, d. h. über den Einsatz afrikanischer Kolonialsoldaten im Rheinland nach 1918 (vgl. Wigger, „Schwarze Schmach am Rhein" sowie die breiter angelegte Studie: Koller, Diskussion), deutet auf eine erhebliche Virulenz des Themas für die Kultur- und Mentalitätsgeschichte der Weimarer Republik hin. 
In seinem Aufruf bezichtigte Kolbenheyer die deutschen Hochschullehrer, ihrer Verantwortung nicht gerecht geworden zu sein, dem mit „Verniggerung“ bezeichneten kulturellen „Niedergang“ des deutschen Volks seit 1918 durch ihre Lehrtätigkeit entgegenzuwirken. Statt die „artgerechte“ Literatur ihrer Gegenwart durch eine Berücksichtigung im Lehrbetrieb zu unterstützen, habe man sie ignoriert und dadurch gedankenlos dem „lauten, breiten Tagesurteil“ und dem „Lärm des Literaturmarktes“ überlassen und ausgeliefert. Infolgedessen sei es gerade für junge Menschen immer schwieriger geworden, Werke zu finden, die ihnen eine „Lebenshilfe" bieten könnten. Stattdessen gehe der deutschen Jugend zunehmend das Bewusstsein verloren, dass in der Kunst überhaupt „wesentliche Lebenshilfen ruhen“ würden. Auf diese Weise sei die Jugend, die später den schweren „Kampfe um die Wiederaufrichtung des deutschen Volkes" ${ }^{\text {"545 }} \mathrm{zu}$ bestehen habe, mit unabsehbaren Folgen einer ihrer bedeutendsten seelischen und moralischen Stützen beraubt worden. Kolbenheyers konkrete Forderung ging letztendlich dahin, dass jede Universität pro Semester „ein Kolleg und ein Seminar über Literatur der Gegenwart in ihrem Verhältnis zur volkseigenen Literaturentwicklung“ anbieten müsse. Ergänzend dazu sollten „die Lektorate für Vortragskunst, Musik und bildende Künste ausgebaut“ und den Studenten „die Beteiligung an einem der drei Lektorate obligat gemacht" 546 werden.

Die Motive, die Kolbenheyer nach außen hin mit seinem Aufruf der Universitäten verfolgte, lassen sich dem Anschreiben entnehmen, das den Einzelexemplaren seines an alle deutschen Universitätsrektorate abgesandten Texts beigelegt war. Ein Exemplar des Anschreibens hat sich in dem vom Universitätsarchiv Tübingen aufbewahrten Nachlass Hermann Schneiders erhalten. ${ }^{547}$ Kolbenheyer adressierte die „Führer der Universitäten“ demzufolge „,in ernstester Stunde seelischer Volksgefährdung und Volksnot“. Nicht ohne Effekthascherei appellierte er an die hohe moralische Verantwortung der Professorenschaft. Sie mache es in dieser „Lebensstunde des deutschen Volkes“ notwendig, „daß kein Mittel unversucht, kein Weg unbeschritten bleibe“, durch welche „das schwer gefährdete Gefühlsleben dieses ringenden Geschlechtes [ge]klärt, [ge]stärkt" und gehoben werden könne. Aus diesem Grunde sei es „hohe Zeit geworden, daß man handle, auch für die Universitäten " 548 .

Den erwarteten Einwand seitens der Professoren, dass „schon längst über neuere Literatur gelesen werde“, versuchte Kolbenheyer vorauseilend mit dem Argument zu entkräften, dass es angesichts der zutiefst krisenhaften Lage des

545 Kolbenheyer, Aufruf [1930], S. $117 f$.

546 Ebd., S. $118 f$.

547 Siehe das „Dossier Kolbenheyer“, in: UAT, Nachlass Hermann Schneider. Es handelt sich hierbei um eine standardisierte Vorlage des an alle deutschen Universitätsrektorate abgegangenen Schreibens, in dem nur noch das Datum und der Name der Universität handschriftlich nachgetragen werden musste. Da das im Nachlass Schneiders überlieferte Exemplar mit keinen handschriftlichen Einträgen versehen ist, handelt es sich offenbar um ein überschüssiges Exemplar.

548 Ebd. 
deutschen Volks in den entsprechenden Vorlesungen nicht mehr lediglich um „darstellende Vermittlung eines auch absolut faßbaren Kenntnisstoffes" gehen dürfe. Aufgabe einer zeitgemäßen und verantwortungsbewussten Vermittlung „artgerechter“ Gegenwartsliteratur müsse es vielmehr sein, „einer bedrängten Generation“ eine „helfende Führung des emotionellen Lebens“ zu bieten. Die Grenzen der einzelnen Fachbereiche transzendierend gehe es überdies darum, das „innerste Ethos aller Lehrgebiete der Universität“ zu pflegen, welches darin bestehe, auf die „Grundlagen [d]er Lebenshaltung“ der von ihr berührten Menschen einzuwirken. ${ }^{549}$

In seiner Autobiografie gab Kolbenheyer als Motiv seines Aufrufs an, er habe einen Anstoß dazu geben wollen, die Universitäten „aus ihrer teilnahmslosen Haltung gegenüber den emotionalen Wirkungen der Kunst und besonders der Literatur“ herauszuführen. Demnach sollte „innerhalb ihres literatur- und kunstwissenschaftlichen Lehrgebietes“ den „biologischen Entwicklungswerten der Kunst nicht nur Beachtung, sondern aufklärende und förderliche Hilfe geboten werden " 550 . Neben einer erzieherischen Wirkung auf ihre Studenten erhoffte sich Kolbenheyer von den Professoren zugleich politische Impulse. Kolbenheyer war davon überzeugt, dass die „Kräfte der Erneuerung und Wiederaufrichtung“ von keinem Volksteil „stärker strömen“ könne „als von den Universitäten“. Hieraus leitete er die Verpflichtung der Hochschullehrer ab, „Volksnot“ und „Volkswillen“ auch gegenüber den „verantwortlichen Leiter[n] des Staates“ ${ }^{\text {} 551} \mathrm{zu}$ vertreten. Mit der Forderung, eine Begünstigung der „dem sogenannten Volkscharakter angemessenen Kunst“ durch gezielte „kulturpolitische Intervention“ zu erreichen, befand sich Kolbenheyer dabei ganz auf der Linie der „völkischen Kunstkritik“ des wilhelminischen Kaiserreichs.

Über die Motive Kolbenheyers bietet jedoch weder das zeitgenössische Anschreiben des Dichters noch die retrospektive Zusammenfassung der Autobiografie ein vollständiges Bild. Dass Kolbenheyer die Sorge um den Zustand der deutschen Literaturwissenschaft ebenso umtrieb wie die Sorge um die Chancengleichheit seiner Werke auf dem von der akademischen Jugend mitbestimmten literarischen Absatzmarkt, ist offensichtlich und vor dem Hintergrund seines

549 Ebd. Dass die in dem Anschreiben zum Ausdruck kommende Zuversicht in die Fähigkeit der Professoren, „üußere Schwierigkeiten“ und „Bedenklichkeiten“ überwinden zu werden, aufgesetzt war, geht aus mehreren brieflichen Äußerungen Kolbenheyers hervor, in denen er schon frühzeitig der Überzeugung Ausdruck gab, dass er mit seinem Aufruf an die Universitäten auf Granit beißen werde. Gegenüber dem Journalisten und Kunstkritiker Josef Hofmiller (1872-1933) betonte er im Dezember 1929, dass „alle Fachleute“ nunmehr „eifrig bemüht sein“ würden, „meine Forderung als undurchführbar darzustellen“. Die Professoren seien allesamt mit „sekundären Geschäftigkeiten“ derart „gewichtig vollgestopft, daß den meisten wohl kaum ein blinzelnder Blick für die Gefahr bleibt, die ich ihnen angemerkt habe" (DLA, A:Hofmiller, Erwin Guido Kolbenheyer an Josef Hofmiller, 20. Dezember 1929).

550 Kolbenheyer, Sebastian Karst, Bd. 3, S. 42.

551 Zitiert aus der Rede Kolbenheyers zum Abschied aus Tübingen in: Tübinger Chronik und Steinlachbote, 17. Februar 1932. Vgl. Kap. 3.4.

552 Hein, Kunstkritik, S. 617. 
Selbstbilds als „totgeschwiegener“ Autor leicht erklärbar. ${ }^{553}$ Zugleich wollte es Kolbenheyer der deutschen Professorenschaft jedoch unmöglich machen, sich mit Blick auf ihre angeblichen Versäumnisse im Umgang mit der zeitgenössischen Literatur in einer künftigen, nationalistischeren Zeit hinter der Schutzbehauptung zu verstecken, niemals auf die Thematik aufmerksam gemacht worden zu sein. Noch vor der erstmaligen Publikation des Aufrufs bemerkte Kolbenheyer gegenüber Stapel: „Man muß endlich die Universitäten einmal angehen. [...] Die sollen einmal nicht sagen, daß sie nicht gemahnt worden seien" 554 .

Zugleich war die Entscheidung zur Versendung des Aufrufs an die Universitätsrektorate aber auch von der Vorstellung geprägt, dass die deutsche Professorenschaft von dem mutmaßlich anti-nationalistischen Gepräge des Weimarer Literaturmarkts eingeschüchtert sei. Man müsse, so schrieb Kolbenheyer im Oktober 1929 an Stapel, „den Universitätsprofessoren Mut machen - Mut zum lesenden Volk, Mut zu jener Literatur, die nicht von den Juden erfolgreichst propagiert wird, Mut zum Volk überhaupt "555. Ein weiteres Motiv Kolbenheyers bestand in der Selbstvergewisserung, das Seinige getan zu haben, insbesondere die als unzulänglich empfundene deutsche Germanistik aufzurütteln. Dass Kolbenheyer den Aufruf auch um seiner selbst willen und zur Beruhigung seines eigenen Gewissens veröffentlichte, geht aus einer Mitteilung an Stapel bezüglich des „Widerhall[s]“ seines Aufrufs vom November 1929 hervor: „Nat[ürlich] verspreche ich mir nicht allzu viel davon. Aber es soll nichts unterlassen sein. Ich will mir nicht vorwerfen, eine Möglichkeit versäumt zu haben“"556.

\subsubsection{Vervielfältigung und Rezeption des „Aufrufs“}

Erstmalige Vervielfältigung auf dem Salzburger Philologen-Kongress - Kurz vor der erstmaligen Publikation des Aufrufs an die Universitäten gelang es Kolbenheyer, seine Broschüre an die Teilnehmer der im September 1929 abgehaltenen 57. Versammlung deutscher Philologen und Schulmänner in Salzburg als Beilage des offiziellen Veranstaltungsprogramms verteilen zu lassen. Zu diesem Zweck hatte er im Juli Richard Meister kontaktiert, den Wiener Ordinarius für Pädagogik und ersten Vorsitzenden des vorbereitenden Ausschusses des Philologenkongresses. In seinem Schreiben, dem ein Exemplar des Aufrufs ${ }^{557}$ beilag, fragte Kolbenheyer, ob sich „ein Mittel finden“ lasse, seine Anregungen „den Besuchern der Tagung zu Gehör oder Gesicht zu bringen“"558. Meister begrüßte diese Idee und pflichtete der Argumentation des Aufrufs entschieden bei; die von Kolbenheyer skizzierten Probleme seien „nur zu wahr“. Meister schlug vor, dass Kolbenheyer Sonderdrucke seiner Broschüre an einen der auf dem Kongress ausstellenden Ver-

553 Zur Beschaffenheit und Korrektur dieses Selbstbilds vgl. Kap. 3.1.1.

554 DLA, A:Stapel, Erwin Guido Kolbenheyer an Wilhelm Stapel, 14. September 1929.

555 Ebd. (Herv. i. Orig.).

556 DLA, A:Stapel, Erwin Guido Kolbenheyer an Wilhelm Stapel, 26. November 1929.

557 Der Text trug zu diesem Zeitpunkt noch den Titel Wo bleiben die Universitäten?.

558 KAG, Erwin Guido Kolbenheyer an Richard Meister, 8. Juli 1929 (Durchschlag). 
lage senden solle, um sie anschließend „in Kommission zu verkaufen“. Gelegenheit dazu, „,in der pädagogischen oder germanistischen Sektion“ des Kongresses auf den Aufruf hinzuweisen, werde „sich leicht ergeben“. Für den Fall, dass Kolbenheyer mit keinem der ausstellenden Verlage zusammenarbeiten wolle, bot Meister an, „die Ausstellung Ihrer Separate durch die die ganze Ausstellung leitende Firma, den österr[eichischen] Bundesverlag, zu vermitteln“559.

Da der Verkauf von Sonderdrucken nicht möglich war - der Erstdruck des Aufrufs im Kunstwart erfolgte erst nach der Salzburger Tagung -, machte Kolbenheyer den Gegenvorschlag, der Aufruf könne gegebenenfalls auch „als Beilage zu den Drucksachen gedruckt" werden, „die den Besuchern der Tagung eingehändigt “560 würden. Meister stimmte diesem Vorschlag sogleich $\mathrm{zu}$ und versprach, die Verbreitung des Aufrufs unter den Teilnehmern der Sektionen für Philosophie, Pädagogik, Deutsche Philologie, Geschichte, Kunstgeschichte, Musikwissenschaft, Kunsterziehung und Sprecherziehung zu veranlassen. Für die Druckkosten in Höhe von 60 Reichsmark kam Kolbenheyer persönlich auf. Insgesamt wurden 980 der 1000 gedruckten Exemplare verteilt, wie Meister im Anschluss an den Kongress mitteilte. ${ }^{561}$ Damit ist freilich noch nichts über die Wirkung gesagt, die von dem Aufruf in Salzburg ausging. Insgesamt wird sie gering geblieben sein, zumal die Kongressteilnehmer nach ihrer Anreise wohl anderes und als wichtiger empfundenes zu tun hatten, als einen ihnen ankündigungslos in die Hände gedrückten, vorwurfsvollen Aufruf zu studieren. Ironisch genug war es denn auch eben die Salzburger Versammlung deutscher Philologen und Schulmänner, auf die der an der dortigen Gewerbeschule tätige, Kolbenheyer emotional eng verbundene ${ }^{562}$ Lehrer und Schriftsteller Hans Deißinger in einem Brief vom 15. Dezember 1929 verwies, um exemplarisch die von Kolbenheyer angemahnten Missstände $\mathrm{zu}$ illustrieren. ${ }^{563}$

559 KAG, Richard Meister an Erwin Guido Kolbenheyer, 27. Juli 1929.

560 KAG, Erwin Guido Kolbenheyer an Richard Meister, 8. September 1929 (Durchschlag).

561 KAG, Richard Meister an Erwin Guido Kolbenheyer, 6. Oktober 1929.

562 Vgl. KAG, Hans Deißinger an Erwin Guido Kolbenheyer, [?] März 1929: „Seit Jahren gehe ich in der Schar Ihrer stillen Schuldner und nichts kann mich von dieser Verbundenheit, von diesem inneren Verpflichtetsein lösen. Sie wollen keine Worte. So möge sich doch einmal die Hand, die so oft die ,goldene Schale‘ zu Ihnen erhob, ausstrecken dürfen, die Ihrige in Dankbarkeit zu drücken. Bleiben Sie mir noch lange, Mensch, Dichter und Führer, durch die Schatten, die aus der Zeit bedrängen, in eine gesicherte, in eine immer neu zu führende Zukunft hinüber!“

563 Vgl. KAG, Hans Deißinger an Erwin Guido Kolbenheyer, 15. Dezember 1929: Kolbenheyer habe ausgesprochen, „was viele von uns schon längst bewegt“, der Aufruf erfülle die entsprechenden Kreise daher „mit ungewöhnlicher Genugtuung“. Ereignisse wie die „Tagung deutscher Philologen u[nd] Schulmänner vom Herbst dieses Jahres“ hätten „,in der Tat die Überzeugung“ hervorgerufen, dass „unsere Hochschulen merkwürdig beziehungslos [...] den lebendigen Fragen der Zeit, den Mächten geistiger Zuchtlosigkeit und Zersetzung gegenüberstehen“. Die naheliegende Vermutung, dass Deißinger als Teilnehmer der Salzburger Versammlung erstmalig mit Kolbenheyers Aufruf in Berührung gekommen sei, trifft nicht zu. Deißinger verweist in seinem Brief explizit auf die Veröffentlichung des Aufrufs im Kunstwart. 
ERSTE SCHÜTZENHILFE UND KRITIK - Im November 1929 reagierte Hans Hauske, ein „Alter Herr“ der Berliner Burschenschaft „Arminia“, in den Burschenschaftlichen Blättern auf die Erstveröffentlichung des „Aufrufs“ im Kunstwart. Hauske pflichtete dem Kerngedanken Kolbenheyers bei und spitzte dessen kulturkritische Diagnose der „Verniggerung“ sogar weiter zu: Man müsse „noch weitergehen“, als es Kolbenheyer getan hatte, dem als Dichter „nur das ihm naheliegende Teilgebiet“, die Literaturwissenschaft, vor Augen gestanden habe. In Wirklichkeit sei jedoch das „ganze nationale Geistesleben“ mit der „Gefahr der Auflösung und des Untergangs" konfrontiert. Hauske wollte Kolbenheyers Kritik also in einen deutlich breiteren Kontext gestellt wissen. Der „Einsatz der Hochschulen für den Kampf um Nation und Reich“ sei eine generelle, weit über die Germanistik hinausgehende „Forderung der Stunde“ ${ }^{\text {564 }}$.

Ablehnend reagierte Hauske auf die nach seiner Auffassung pauschalisierenden Vorwürfe Kolbenheyers gegen die Professorenschaft. Entgegen der Darstellung des Aufrufs fänden sich in den Lehrkörpern der deutschen Universitäten sehr wohl ehrlich engagierte, national denkende Hochschullehrer. Es sei eine „oft gehörte, aber in der Verallgemeinerung falsche Behauptung, daß die Hochschule

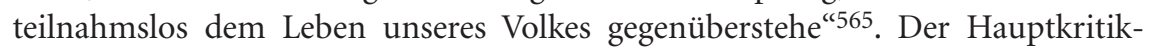
punkt Hauskes richtete sich jedoch gegen Kolbenheyers Begriff von Wissenschaftlichkeit. Hauske warb für Verständnis, dass sich die Hochschulen seit 1918 noch „in dem Stadium der Erörterung der Deutungsmöglichkeiten der herrschenden Kulturtendenzen“ befänden. Ein größerer „Abstand von der Zeit“ sei nötig, „um ein Urteil mit wissenschaftlicher Treue“ fällen zu können. Die Zurückhaltung vieler Wissenschaftler gegenüber der zeitgenössischen Literatur liege in der nachvollziehbaren und lobenswerten Absicht begründet, „sich in intellektueller Redlichkeit die [Ü]berschau zu bewahren“566. Dem Willen der Hochschulen, „ihre Wirkung [...] nur mittelbar ausüben“ zu wollen, namentlich „durch die Wissenschaft selbst, die wissenschaftliche Leistung [...] und durch die wissenschaftliche Bildung“, müsse mit mehr Nachsicht begegnet werden, als sie Kolbenheyer an den Tag gelegt habe. Hauske bilanzierte: „Den Vorwurf, die Universitäten versagen im Kampf der deutschen Kunst (Kolbenheyer) und überhaupt im Kampf der Weltanschauungen und der Politik (so die junge Generation aller Lager)“, könne nur von jenen erhoben werden, die von der Wissenschaft anstelle „entscheidende[r] Erkenntnisse“ primär „ethische Entscheidungen“ verlangten. Die Jugend, die „mit Kolbenheyer von den Hochschulen eine Aktivierung ihres politischen Willens“ fordere, verstoße damit „,in gleicher Weise gegen den Sinn der heutigen Wissenschaft" wie die „katholische oder marxistische Jugend oder wie der Staat“, die allesamt, jeweils auf ihre Weise, „die Universität für sich in Besitz nehmen“ wollten. Kolbenheyers Forderungen, so Hauskes Fazit, basierten zwar auf einem löblichen

564 Hauske, Wissenschaftskrisis, S. $121 \mathrm{f}$.

565 Ebd., S. 121.

566 Ebd. 
„nationalen, sittlichen Ethos“, ohne dabei jedoch „der Strukturwirklichkeit des Wesens Wissenschaft gerecht ${ }^{\text {“567 }} \mathrm{zu}$ werden.

Eine solche die Notwendigkeit der Trennung von (Partei-)Politik und Wissenschaft anmahnende Erwiderung musste Kolbenheyer, der ganz in dem illusorischen Selbstbild als „unpolitischer“ Intellektueller aufging, zur Gegenrede reizen. In einem auf seine eigene Initiative zurückgehenden ${ }^{568}$ Wiederabdruck des Aufrufs in der von Erich Kröning ${ }^{569}$ herausgegebenen Zeitschrift Deutsche Sängerschaft ${ }^{570}$ erhielt Kolbenheyer Gelegenheit, Hauskes Kritik in einem Nachwort zu kommentieren. Kolbenheyer stellte darin klar, dass sich sein Aufruf keineswegs gegen die „autonome Wissenschaftlichkeit" wende. Ebenso unbegründet sei Hauskes Warnung vor einer Vermengung von Wissenschaft und Politik: Was in dem Aufruf gefordert werde, sei vielmehr „das Gegenteil einer heute allgemein geübten Wertung der Kunst nach kultur- und parteipolitischen Gesichtspunkten“. Mit seinem Anliegen habe er sich „gerade deshalb an die Universitäten“ gewendet, weil von diesen „am ehesten erwartet werden“ könne, dass „durch aufklärende wissenschaftliche Objektivität einer Entartung der Kunst und ihrer parteilichen Radikalisierung Widerhall geboten werde“. Diese Aufgabe sei durchaus mit „der ,indirekt[en] kulturellen Mission der Hochschulen“" vereinbar, jedenfalls „wenn man sie richtig "571 erfasse.

„Richtig erfassen“ bedeutete hier freilich: sie nach den Grundannahmen und Wertvorstellungen der Bauhütten-Philosophie verstehen. Sehr wohl, so Kolbenheyer, könne von den Literaturhistorikern „verlangt werden“, in ihren Arbeiten die „Motive der Kunstwerke“ anhand „ihrer biologischen Wirksamkeit" herauszuarbeiten, und zwar nach lebens- und weltanschaulichen Grundsätzen, die durchaus auf wissenschaftlicher Erkenntnis beruhen" würden. Gerade in der „Zeit eines Volksnotstandes“ müsse gefordert werden, „daß die Universitäten ihre Jugend der Kunst, dem bedeutsamsten Gestaltungsmittel des Gefühlslebens,

567 Ebd., S. 122.

568 Verweisend auf den bis dato nur sehr zähen Fortschritt seiner Bemühungen hatte Kolbenheyer im März 1930 an die moralische Verpflichtung der von Kröning repräsentierten national gesinnten Studentenschaft appelliert, ihn bei der Verbreitung des Aufrufs zu unterstützen. Es sei endgültig an der Zeit für die sich „der Kunst besonders zugetan“ fühlenden studentischen Kreise mitzuarbeiten, „um Wandel und Besserung zu schaffen“ (DLA, A:Kröning, Erwin Guido Kolbenheyer an Erich Kröning, 12. März 1930).

569 Erich Kröning (1897-1973) war als Alter Herr der Sängerschaften Arion Leipzig, Zollern Tübingen sowie der Prager Universitäts-Sängerschaft Barden, vor allem aber aufgrund seiner Tätigkeit als Schriftleiter der Zeitschrift Deutsche Sängerschaft zwischen 1927 und 1933 eine der zentralen Persönlichkeiten in der deutschen Sängerschafts-Bewegung der Weimarer Republik. Vgl. Lönnecker, Boden, S. 130.

570 Gegenüber Hans Grimm beschrieb Kröning das Programm seiner Zeitschrift wie folgt: „Sie ist nur eine studentische Verbandszeitschrift, hat aber 9000 Akademiker zu Lesern. Diese große Gelegenheit möchte ich nicht mit klein-studentischen Wichtigtuereien versäumen. Darum habe ich mich bemüht, unsere Jung- und Altakademikerschaft immer wieder in die große Front des deutschen Aufbruches hinein rufen zu lassen und ihnen Ehre und Notwendigkeit auch ihres Standes zu zeigen“ (DLA, A:Kröning, Erich Kröning an Hans Grimm, 9. Dezember 1932).

571 Kolbenheyer, Aufruf [1930], S. $119 f$. 
durch Forschung und Lehre inniger verbinden“, um der Jugend, die später „unter dem Notstand des Volkes zu kämpfen haben“ werde, auf diese Weise „durch Steigerung des Kunsterlebens bei wissenschaftlicher und sinnbildnerischer Arbeit einen emotionalen Rückhalt" 572 für ihre künftigen Aufgaben zu bieten. Wer freilich die Auffassung des Dichters nicht teilte, dass Literatur eine konkrete biologische Wirkung besitze, die zumal objektiv bestimmbar sei, musste in der Auseinandersetzung Hauske zustimmen.

Die Bemühungen Erich Krönings um KolbenheYers „Aufruf“ - Erich Krönings Bereitschaft zur Unterstützung des „Aufrufs“ blieb nicht lediglich auf den Wiederabdruck des Texts in der Deutschen Sängerschaft beschränkt. ${ }^{573}$ Abermals auf Initiative Kolbenheyers leistete Kröning zugleich den uneigennützigen Freundschaftsdienst, ein Rundschreiben seines Verbands an alle deutschen Universitäten zu organisieren. Entsprechend der Vorstellung und impliziten Handlungsanweisung Kolbenheyers sollten sich die „Studentenschaft und [...] Altherrenschaft“ in ihrem Schreiben mit dem „Aufruf einig“ erklären und dessen „dringliche Behandlung in positivem Sinne“574 einfordern. „Nichts“ könne „den bereitwilligen Professoren zur größeren Stütze dienen“ als eine solche Stellungnahme von studentischer Seite. Die hierfür nötigen „Unterschriften der einzelnen Sängerschaften“, so Kolbenheyer, „dürften wohl zu beschaffen sein“. Kolbenheyer setzte Kröning detailliert auseinander, wie eine solche „Kundgebung“ aufzuziehen sei, und empfahl zunächst eine „Einleitung, in der sich die ,Deutsche Sängerschaft" mit dem Aufruf einverstanden“ erklären und dessen „dringliche Behandlung “575 einfordern sollte. Anschließend sollte der „Aufruf“ - einschließlich Kolbenheyers „Erwiderung“ auf die Kritik Hans Hauskes - wiederabgedruckt werden, gefolgt von den Unterschriften der einzelnen deutschen Sängerschaften.

Kröning erwies sich als eifriger wie beflissener Helfer. Auf Kolbenheyers Wünsche ging er "gerne“ ein und kündigte an, sich „unverzüglich“ an die „Sängerschaften und deren Alt-Herrenverbände“ wenden zu werden, um für die erbetene Unterstützung des „Aufrufs“ zu werben. Anschließend werde er sich um „die Eingabe bei den Universitäten " 576 kümmern. Kröning hielt beide Versprechen. Ein Exemplar der von Kröning verfassten und vom Bundesvorsitzenden der Deutschen Sängerschaft Rudolf Urlaß sowie dessen Stellvertreter Otto Wenn unterzeichneten Anschreiben hat sich in den Beständen des Universitätsarchivs Tübingen erhalten.

572 Ebd., S. $120 \mathrm{f}$.

573 Auch der Wiederabdruck war freilich keine reine Dienstleistung Krönings, musste doch die Möglichkeit, den zum damaligen Zeitpunkt innerhalb der Weimarer Rechten bereits prominenten Kolbenheyer zu den Mitarbeitern seiner Zeitschrift zählen zu dürfen, für Kröning selbst verlockend sein.

574 DLA, A:Kröning, Erwin Guido Kolbenheyer an Erich Kröning, 2. April 1930.

575 Ebd.

576 KAG, Inv. Nr. 154: Bitten um Beiträge, 1930: Erich Kröning an Erwin Guido Kolbenheyer, 3. April 1930. 
Den Fingerzeigen Kolbenheyers entsprechend ist Krönings Text ganz im Geiste einer völligen Solidarisierung mit dem Aufruf verfasst. Das Schreiben beginnt jedoch zunächst mit der zurückhaltenden Aussage, die Deutsche Sängerschaft erhebe nicht den „Anspruch, das was Herr Dr. Kolbenheyer tadelt oder anstrebt, vom Blickpunkt der Hochschulen aus zureichend beurteilen zu können“. Aus Perspektive „des deutschen Studenten“, der „in der Wirrnis der Gegenwart“ stehe, könne indes kein Zweifel bestehen, dass Kolbenheyers „Forderungen [...] erhoben werden müssen“. Zu dieser Mitteilung fühle sich die Deutsche Sängerschaft deshalb berechtigt und verpflichtet, da sie „vor anderen studentischen Verbänden ihren besonderen Auftrag darin“ erblicke, „durch die Bindekräfte deutscher Kunst das Leben in ihren studentischen Gemeinschaften zu formen“. Nur „was rein und stark aus der Tiefe unseres Volkstums quillt“, könne „deutsche Menschen bilden“. Im Gegensatz dazu lasse sich jedoch täglich beobachten, wie „das Kunstwesen der deutschen Gegenwart“ zunehmend „entwurzelt“ werde und dadurch „entarte“. Diese Situation sei umso prekärer, als „dem deutschen Volke durch eine unverantwortliche Geschäftigkeit“ unentwegt „die ihnen wesensgemäßen Gefühle verwirrt“ und „die rechten Maßstäbe des Urteils zerstört" würden. Umso dringender sei es daher, den „Gedanken Kolbenheyers eingehende Beachtung [zu] schenken" 577 .

Kolbenheyer zeigte sich mit Krönings „ausgezeichnet abgefaßt[em]“ Schreiben vollauf zufrieden, mahnte mit Blick auf die zu erwartenden Ergebnisse jedoch zu Geduld: „Man stößt auf Gummiwände“ 578 . Auch Kröning müsse sich darauf einstellen, dass seine Zuschrift zunächst „abgefertigt“ werde, „beruhigend, zurechtweisend, als sei schon so vieles geschehen“. In Wahrheit würden die germanistischen Lehrstühle die zeitgenössische Literatur jedoch sträflich missachten und stattdessen reine Literaturhistorie betreiben. Damit würden sie ihrer Aufgabe, die um einen Aufbau der Volkskräfte bemühten Autoren der Gegenwart zu fördern, nicht gerecht, was sich in einer Zeit, in der „das deutsche Volk [...] seelisch niedergehalten“ werde „wie nie in seinem Leben“, umso verheerender auswirken müsse. Kolbenheyer bewahrte sich jedoch auch in dieser Situation seinen charakteristischen Zweckoptimismus: Letzten Endes vertraue er „auf die Akademiker“, denn sie seien „in ihrer Mehrzahl dem Aufbauwillen zugewandt“579.

PRIVATE Und ÖFFENTLICHE REAKTIONEN AUf DEN „AUfRUF“ - Im April 1930 zeigte sich Kolbenheyer von der „nicht unbeträchtlichen Korrespondenz" mit „einzelnen Universitätsprofessoren“, die sich an den Aufruf angeschlossen hatte, durchaus zufrieden. Auch „Rektoren des Vorjahres“ hätten sich unter die „Wohlwollenden“ eingereiht. Kolbenheyer leitete daraus die „Gewißheit“ ab, dass „viele Universitätslehrer Verständnis für die volksbiologische Dringlichkeit“ des Aufrufs

577 UAT, Sachakten des Rektoramtes, 117/161, Akten betr. Deutsche Universitäten und andere höhere Lehranstalten: Brief der Bundesleitung der Deutschen Sängerschaft an Rektor und Senat der Universität Tübingen, 29. April 1930.

578 DLA, A:Kröning, Erwin Guido Kolbenheyer an Erich Kröning, 30. April 1930.

579 Ebd. 
hätten. Öffentliche Stellungnahmen im größeren Stil erwartete er indes nicht: „Leider dürften diese Herren weniger in dem Kreise der Referenten zu suchen sein" ${ }^{580}$. In der Tat finden sich im Nachlass Kolbenheyers mehrere Zuschriften, die eine mindestens bedingte Anschlussfähigkeit des „Aufrufs“ unter Hochschullehrern belegen. Einige Beispiele seien aufgeführt:

Der Tübinger Ordinarius für Klassische Philologie, Johannes Mewaldt, sah die Universitätsrektoren durch Kolbenheyers Aufruf ultimativ vor die Pflicht gestellt, „sich zu entscheiden, wie sie den Niedergang deutschen Geistes zu steuern gedenken". Viel Vertrauen in seine Kollegen besaß Mewaldt allerdings nicht. An befähigten „Persönlichkeiten“, um die von Kolbenheyer gestellten Aufgaben „in Angriff zu nehmen“, werde es vermutlich „,weithin fehlen“. Trotzdem gab sich Mewaldt kämpferisch: Verlangt werden müssten Kolbenheyers Forderungen „trotz allem!“ Womöglich würden die Philosophischen Fakultäten doch „aufgerüttelt" werden und „ihre Mitglieder aus der Träumerei der Nabelschau erwachen“581.

Sehr ähnlich fiel die Redaktion des Erlanger Professors für Deutsche Sprachkunst, Ewald Geißler ${ }^{582}$, aus. Auch er stimmte den Aussagen des „Aufrufs“ zu, machte Kolbenheyer bezüglich der offiziellen Reaktion seiner Universität jedoch wenig Hoffnung: Der „hohe Senat“ tendiere leider dazu, „Lebensfragen in Aktenschränken [zu] vergraben“. Daher stehe auch „eine große Programmwirkung kaum [zu] erwarten“583. Da Geißler nicht Mitglied des Senats war, sah er für sich selbst an dieser Stelle keine direkten Einflussmöglichkeiten. Nicht gelten ließ er jedoch den pauschalen Vorwurf Kolbenheyers, die deutsche Hochschullehrerschaft habe kollektiv darin versagt, der ,artgerechten “ Gegenwartsliteratur die ihr gebührende Förderung zuteilwerden zu lassen. Sichtlich persönlich herausgefordert, bemühte sich Geißler, diese Kritik zu widerlegen: Unter dem, was an der Universität Erlangen ,an Erziehung geschafft“ werde, finde sich in Wirklichkeit "gewiß mancherlei in deutsch-aufbauendem Sinn Gediegenes“. Im Hinblick auf seine eigenen Wirkungsmöglichkeiten gestand Geißler zwar ein, dass noch Handlungsspielraum nach oben bestehe, die Art und Weise der Beschreibung jenes Spielraums implizierte jedoch eine klare Zurückweisung der Kollektivschuldthese Kolbenheyers gegen die deutschen Germanisten: Er „persönlich“ könne „nichts anderes tun“, als im kommenden Sommersemester „wieder einmal“ über „Dichtung der Gegenwart“ zu referieren, wie er es schon in der Vergangenheit getan

580 DLA, A:Kröning, Erwin Guido Kolbenheyer an Erich Kröning, 2. April 1930.

581 KAG, Johannes Mewaldt an Erwin Guido Kolbenheyer, 9. Dezember 1929.

582 Ewald Geißler, am 18. Januar 1880 in Dresden geboren, war nach seinem Studium der Theologie, Germanistik und Philosophie in Heidelberg, Berlin, Leipzig und Erlangen (Promotion 1904) seit 1906 als Lektor für Vortragskunst an der Universität Halle angestellt. 1925 folgte seine Habilitation für „Deutsche Sprachkunst“ (Rhetorik, Phonetik, Metrik, Stilistik, Ästhetik) an der Universität Erlangen, wo er seit 1922 als Lektor für Stimmbildung und deutsche Sprachkunst gearbeitet hatte. Seit 1932 war er im selben Fachbereich als außerordentlicher Professor tätig. Ab 1936 arbeitete Geißler, seit 1937 NSDAP-Mitglied, als „Weltanschauungsund Kulturreferent" der SA. Am 26. Januar 1946 nahm sich Geißler zusammen mit seiner Frau in Erlangen das Leben. Vgl. Wendehorst, Geschichte, S. 220.

583 KAG, Ewald Geißler an Erwin Guido Kolbenheyer, 1. Juli 1929. 
habe und auch „in den Ferienkursen zu Jena u[nd] Marburg tun“ werde und wie er es „im übrigen auch in allen sonstigen Vorlesungen u[nd] Übungen bei jeder Gelegenheit u[nd] Angelegenheit tue “584.

Das waren keine leeren Worte. Stapel, der Kolbenheyers Aufruf selbst als „sehr überzeugend und anregend" empfand, unterrichtete Kolbenheyer im Anschluss an eine von Max Wundt organisierte Tagung in Weimar im Oktober 1929 darüber, dass Geißler in seinem Vortrag den Aufruf namentlich „an[ge]führt“ habe. ${ }^{585}$ Auch Grimm, dem ein Sonderdruck des Aufrufs von Kröning zugespielt worden war, betonte im Juli 1930, dass er „selbstverständlich der Meinung Kolbenheyers“ ${ }^{586}$ sei, soweit er den Text richtig verstanden habe. Öffentlich wollte sich Grimm zu dieser Sache jedoch nicht äußern. Stattdessen verwies er auf seinen thematisch verwandten Aufsatz Der Schriftsteller und die Zeit, den er Kröning zum Wiederabdruck in der Deutschen Sängerschaft anbot - ein Angebot, das der Schriftleiter sogleich dankend annahm. ${ }^{587}$

Weitere positive Reaktionen folgten: Der seinerzeit berühmte, an der Universität Wien lehrende Literaturhistoriker Josef Nadler, den mit Kolbenheyer seit Anfang der 1920er Jahre eine freundschaftliche, von wechselseitigem Respekt getragene Beziehung verband ${ }^{588}$, verwies im September 1932 anlässlich einer öffentlichen Feier zum 60-jährigen Bestehen des Allgemeinen Deutschen Buchhandlungsgehilfenverbands auf Kolbenheyers Aufruf als eine Mahnung „von besonderem Gewicht“589. „Rückhaltlos beizustimmen“ sei insbesondere der Kritik, die Universitäten hätten viel zu wenig unternommen, um der „volksgefährdende[n] Wirkung“ der zeitgenössischen „Kunstverlotterung entgegenzutreten“. D’accord ging Nadler auch mit der Forderung Kolbenheyers, pro Semester „ein Kolleg und ein Seminar über Literatur der Gegenwart in ihrem Verhältnis zur volkseigenen Literaturentwicklung“ zu veranstalten. „Die Universität, an der sich die kommenden geistigen Führer der Nation auf ihre hohen Pflichten vorbereiten“, habe „von ihrer eigenen Pflicht im Kampfe um unsere nationale Literatur den Vorstreit zu führen, nur ungenügend Gebrauch gemacht “ 590 .

Auch innerhalb der Volkskunde traf Kolbenheyer einen kulturkritischen Nerv. Ein 1930 in der Oberdeutschen Zeitschrift für Volkskunde veröffentlichter Beitrag

584 Ebd.

585 KAG, Wilhelm Stapel an Erwin Guido Kolbenheyer, 16. Oktober 1929.

586 DLA, A:Kröning, Hans Grimm an Erich Kröning, 9. Juli 1930.

587 Vgl. Deutsche Sängerschaft. Zeitschrift der Deutschen Sängerschaft und des Verbandes Alter Sängerschaftler 35 (1930), S. 183-186.

588 Die gute Beziehung war nicht nur einseitig von der hohen Wertschätzung getragen, die Nadler den Werken Kolbenheyers gegenüber empfand und die ausgiebig in seinen literaturhistorischen Werken dokumentiert ist. Kolbenheyer war demgegenüber ein Anhänger von Nadlers literaturhistorischen Herangehensweisen: Im November 1926 versicherte er Nadler, dass er wisse, „daß Ihre Einstellung dem Standpunkte der modernen Biologie nahekommt, nach welchem auch in der Literaturgeschichte von der Geschichte der Familiennamen wird abkommen und die Geschichte des Blutes wird ins Recht gesetzt werden müssen“ (DLA, A:Nadler, Erwin Guido Kolbenheyer an Josef Nadler, 16. November 1926).

589 Nadler, Buchhandel, S. 34.

590 Ebd. 
betonte, Kolbenheyers Mahnungen an die Akademiker, „der Volksgemeinschaft unmittelbar zu dienen“, erinnere an die Aufgaben, wie sie schon „Fichte und W[ilhelm] v[on] Humboldt oder [Paul de] Lagarde [...] aus volkhaftem Gewissen heraus“591 den Deutschen anheimgestellt hätten. „Ihrer hohen Stellung im deutschen Geistesleben entsprechend“ müssten die deutschen Hochschulen daher in der von Kolbenheyer vorgebrachten Angelegenheit „führend vorangehen“. Kolbenheyer habe „die Hüter der Literatur an den Universitäten“ mit vollem Recht „Zu verantwortlicher Stellungnahme gegenüber der zeitgenössischen Dichtung aufgerufen“. Der Autor ließ es sich dabei nicht nehmen, Kolbenheyers Diagnosen und Forderungen speziell auf seinen eigenen Fachbereich anzuwenden: „Um wieviel mehr“ verlange „das deutsche Volkstum nach der Aufmerksamkeit der Fachkenner in Volkskunde und Volksgeschichte!“592

Dieses kleine Panorama der Rezeption des Aufrufs an die Universitäten soll gleichwohl nicht implizieren, die Reaktionen wären ausnahmslos wohlwollend ausgefallen. Es gab sehr wohl auch Gegenstimmen. Scharf ablehnend beantwortete etwa der Heidelberger Literaturhistoriker Friedrich Gundolf die Zusendung des Aufrufs durch die Deutsche Sängerschaft. ${ }^{593}$ Im Fall Gundolfs ist indes zu bedenken, dass dessen Verhältnis zu Kolbenheyer bereits insofern vorbelastet war, als Gundolf nach der Publikation einer eigenen „Paracelsus“-Monografie (Berlin 1927) von Stapel im Deutschen Volkstum polemisch und persönlich verletzend angegriffen worden war. Konkret hatte Stapel - verweisend auf die angeblich ungleich höhere schöpferische Kraft Kolbenheyers - Gundolf die Fähigkeit abgesprochen, sich aufgrund seiner jüdischen Abstammung über die Figur des Paracelsus ein verständiges und ernst zu nehmendes Urteil bilden zu können. ${ }^{594}$ Stapel hatte es sich nicht nehmen lassen, Gundolf einen Abdruck seiner Glosse persönlich zu übersenden, dem Germanisten war die gehässige Kritik an seiner Person also bekannt. ${ }^{595}$ Wie stark sie seine Sicht auf Kolbenheyer beeinflusst hat, lässt sich indes nicht genau sagen.

Beirren freilich ließ sich Kolbenheyer von ablehnenden Reaktionen auf seinen Aufruf nicht; als ihm Gundolfs Urteil zu Ohren kam, behandelte er es gegenüber Erich Kröning vielmehr als weiteren Beleg seines biologistischen Weltbilds: Es sei „eine der Hilfen des Lebens“ für jene Menschen, welche die Zeichen der Zeit bio-

591 Schumacher, Volkskunde, S. 91.

592 Ebd.

593 Siehe die knappe Bemerkung Kolbenheyers in: DLA, A:Stapel, Erwin Guido Kolbenheyer an Wilhelm Stapel, 24. Juni 1930: „Pfarrer [Erich] Kröning, der sich im Rahmen der ,Deutschen Sängerschaft' sehr tapfer für meinen Aufruf d[er] Universitäten einsetzt, hat mir geschrieben[,] das [sic!] Gundolf an diese sehr verbreitete akad[emische] Organisation einen sehr heftigen Brief gegen mich, d.h. meinen Aufruf, geschrieben hat. Noch habe ich die Abschrift nicht. Glaube mir, die Leute wissen, dass ich ihnen an die Nerven greife. Sie hatten die deutsche Kultur schon so schön eingewickelt!“ (Herv. i. Orig.).

594 Vgl. Deutsches Volkstum. Monatsschrift für das deutsche Geistesleben 10 (1928), S. $81 \mathrm{f}$.

595 Vgl. KAG, Wilhelm Stapel an Erwin Guido Kolbenheyer, 8. Januar 1928: „Die Glosse habe ich Gundolf angestrichen zugesandt. [...] Der Mann soll seine Freude an uns erleben. Man müsste es soweit bringen, daß ein Jude, der auf sich hält, es nicht mehr wagt, sich leichtfertig an deutsche Dinge mit Gift zu machen“. 
logisch zu deuten verstünden, „daß unsere Gegner sich immer wieder mit unserer volksbiologischen Artung verrechnen.“ In ihrer „rassemäßig festgelegt[en]“ „rationalistischen Befangenheit“ seien sie nicht in der Lage, diese „zu erkennen“. Nur für kurze Zeit lasse sich daher „Geistesmode über uns hinwegtreiben“, anschließend aber - Kolbenheyers Vorfreude ist nicht zu überhören - komme „die Stunde der Abrechnung“ 596 .

ERINNERUNGEN AN DEN „AUfRUF“ IM „DritTen ReICH“ - Die Rezeption von Kolbenheyers Aufrufblieb im Wesentlichen auf die Jahre 1929 bis 1931 konzentriert. Auf privater und publizistischer Ebene finden sich in den Folgejahren zwar noch vereinzelt Bemerkungen über Kolbenheyers Initiative, als Ausnahmen der Regel können sie jedoch nicht darüber hinwegtäuschen, dass der Aufruf ab 1932 rasch in Vergessenheit geriet. Am intensivsten war nach 1933 der enge Freund Kolbenheyers und prominente NS-Germanist Franz Koch ${ }^{597}$ darum bemüht, die Erinnerung an den Aufruf am Leben zu erhalten, indem er immer wieder dessen Relevanz für eine „neue“ deutsche Literaturwissenschaft betonte. Ganz im Sinne Kolbenheyers stellte Koch die „Wissenschaft von der Dichtung der Gegenwart“ in einem 1935 publizierten Forschungsbericht als eine besonders sträflich vernachlässigte universitäre Disziplin heraus. Als Maßgabe zur Korrektur dieses Defizits verwies Koch auf den orientierungsstiftenden Charakter des Aufrufs, in dem der Germanistenzunft die „Pflicht“ gegenüber der Gegenwartsliteratur „nachdrücklichst“ vor Augen gestellt und damit „das Gewissen geschärft“ worden sei. Die Literaturgeschichte werde es in Zukunft als ihre „selbstverständliche Aufgabe betrachten müssen, ihr Mittlertum in den Dienst volkhaften Aufbauwillens zu stellen“598. Noch zehn Jahre nach dessen erstmaliger Publikation würdigte Koch den Aufruf als eine visionäre Vorwegnahme der im „Dritten Reich“ vollzogenen Abkehr der Literaturwissenschaft von der Vergottung „des Individuums, das heißt richtig des Individualismus“. Im Rückblick erschien es Koch als hohes „Glück, daß hier einer am Werke war, der [...] von je, zu einer Zeit, wo andere noch tief verhangen waren in den Regungen ihres, ach, so interessanten Ichs, dieses Ich von der anderen Seite her erlebte, von den überindividuellen Bindungen der Familie, der Sippe, des Volkes her" ${ }^{\text {599. }}$.

An die Vorbildfunktion von Kolbenheyers Aufruf für die Wissenschaft glaubte auch der spätere Ordinarius für Philosophie an der Universität Wien Friedrich Kainz. In einer 1935 in der Zeitschrift für Ästhetik und allgemeine Kunstwissenschaft publizierten Besprechung von Hans Eibls Schrift Vom Sinn der Gegenwart. Ein Buch von deutscher Sendung schrieb Kainz:

„Die klaren und besonnenen Ausführungen Eibls zeigen wieder einmal, wie nötig es stets von neuem ist, die Meinungen der Tageskritik, die zwischen verständnisloser Unaufgeschlossenheit

596 DLA, A:Kröning, Erwin Guido Kolbenheyer an Erich Kröning, 18. Juni 1930.

597 Zur Karriere Kochs vgl. Höppner, Germanist.

598 Koch, Umbruch, S. 47.

599 Ders., Kolbenheyer [1939], S. 85. 
für das Neue und einem ebenso verständnislosen Verhimmeln jedes Verkrampften Versuchs nur selten die Mitte zu halten weiß, durch eine wissenschaftliche Betrachtung der Kulturleistungen ständig zu überwachen und zu korrigieren - aus der Erkenntnis der hohen Verantwortung, welche die Wissenschaft für das Kulturschaffen der Volksgemeinschaft zu tragen hat. Auf diese Pflicht hat vor einigen Jahren E. G. Kolbenheyer mit den mahnenden Worten seiner denkwürdigen Schrift ,Wo bleiben die Universitäten' nachdrücklich hingewiesen."600

Von einer bedeutenden Rolle des Aufrufs an die Universitäten für die Neuausrichtung der Germanistik nach 1933 kann insgesamt jedoch keine Rede sein. Wie aber fiel der Umgang mit dem Aufruf innerhalb der 1929 direkt adressierten Universitätsleitungen aus?

\subsubsection{Der Amtsweg als Sackgasse - Zum universitätsinternen Umgang mit Kolbenheyers "Aufruf"}

[Es kann] nicht erwartet und nicht als ersprießlich angesehen werden, daß über so schwierige Fragen, wie Kolbenheyer sie zur Erörterung stellt und mit starkem Temperament $z u$ ihnen Stellung nimmt, von dem großen Lehrkörper einer Hochschule im Wege der Abstimmung und durch Mehrheitsbeschluß Stellung genommen wird. ${ }^{601}$

Kolbenheyers Skepsis im Hinblick auf die Erfolgsaussichten einer direkten Adressierung der Universitätsleitungen erwies sich als berechtigt. Seinen Handlanger Erich Kröning hatte der Dichter schon im April 1930 über sein „weiteste[s] Zweifelsgefühl“ hinsichtlich der bevorstehenden "offiziellen amtlichen Behandlung“ des Aufrufs informiert. Überall - so Kolbenheyers, wie das Fallbeispiel Leipzig zeigen wird, Fehlannahme - sei „dem ersten germanistischen Fachmann das Referat anvertraut worden", ausgerechnet jenen Personen also, von denen er in seinem Aufruf verlangt hatte, „mit der gewohnten, bequemeren [Ü]bung ihrer Lehrtätigkeit“ zu brechen und endlich ihrer Mitverantwortung für das „emotionale Leben des Volkes und dessen Aufbau“ gerecht zu werden. Unter diesen Umständen erwartete Kolbenheyer, dass ,alle möglichen Ausreden genommen werden “602 würden, damit die Angelegenheit im Sande verlaufe, schon um der zusätzlichen Arbeitsbelastung aus dem Weg zu gehen.

In den meisten Fällen schuf die Zusendung des Aufrufs in den Universitäten aber erst gar keine Situation, in der sich die Germanistik-Professoren in der von Kolbenheyer beschriebenen Weise aus der Verantwortung hätten stehlen müssen. Generell ist vielmehr davon auszugehen, dass der Aufruf in den Rektoraten lediglich kurz zur Kenntnis genommen und alsbald ad acta gelegt wurde, es also nur

600 Kainz, Eibl, S. 273.

601 UAT, Sachakten des Rektoramtes, Nr. 117/161, Akten betr. Deutsche Universitäten und andere höhere Lehranstalten: Enno Littmann an den Bundesvorstand der Deutschen Sängerschaft, 29. Juli 1930.

602 DLA, A:Kröning, Erwin Guido Kolbenheyer an Erich Kröning, 2. April 1930. 
vereinzelt zu ernsthaften Debatten über dessen Inhalte kam. Offizielle Stellungnahmen von Seiten der Universitäten blieben dementsprechend die Ausnahme. ${ }^{603}$ Kolbenheyers Initiative versandete auf dem Amtsweg meist spur- und wirkungslos. Die Enttäuschung, die hierdurch trotz allen vorauseilenden Pessimismus hervorgerufen wurde, evozierte in Kolbenheyer und seinem engen persönlichen Umfeld untypisch scharfe Ressentiments gegen eine nun als engstirnig, feige und verschlafen wahrgenommene Professorenschaft. Ende Januar 1930 kommentierte Stapel das Schweigen der Universitäten süffisant damit, dass es sich bei den Universitätsrektoren letztendlich nur um reine „Fachmenschen“ und stur „arbeitsteilig“ agierende „Erkenntnispräzisionsgehirnmaschinen“ handle, von denen „wenig zu wollen" 604 sei. Kurze Zeit später versuchte Stapel, Kolbenheyer auf weitere Enttäuschungen hinsichtlich der zu erwartenden offiziellen Stellungnahmen der Universitäten vorzubereiten: „Große Menschen“ seien „unter den Professoren so selten wie anderswo“. Mehrheitlich seien sie bloße „Techniker der Erkenntnis in engen Grenzen“. Gegen alles, „was von außen komm[t]“, reagierten sie instinktiv „höflich“, aber „abwehrend“ 605 .

Kolbenheyer selbst resümierte in seiner Autobiografie ungewöhnlich selbstkritisch, er habe mit seiner direkten Wendung an die Universitätsleitungen „die Sache beim falschen Ende angefaßt " 606 . Sinnvoller und zielführender wäre es gewesen, sich an die ungleich aufnahmefähigere akademische Jugend zu wenden, anstatt den durch professorale Trägheit und schwierige universitätsinterne Konsensfindungsverfahren steinigen Umweg über die Senate zu wählen. Wie zutreffend dieses Resümee war, geht exemplarisch aus Akten des Universitätsarchivs Leipzig hervor. Der nicht unerhebliche Aufwand, der in Leipzig beim Umgang mit dem Aufruf betrieben wurde, war, wie schon angedeutet, an sich bereits un-

${ }^{603}$ Diese Schlussfolgerung ergibt sich zum einen aus der zeitgenössischen Enttäuschung Kolbenheyers über die Quantität und Qualität der universitären Reaktionen. Da sich eine solche Enttäuschung indes auch bei einer durchaus respektablen Resonanz hätte einstellen können, sind die Rückmeldungen ausschlaggebender, die ich von Seiten zahlreicher Universitätsarchive auf meine Anfrage über mögliche den Aufruf betreffende Überlieferungen in ihren Beständen (Senatsprotokolle/Rektoratsakten) erhalten habe. Aus ihnen ging in den meisten Fällen hervor, dass der Aufruf, insofern er überhaupt Spuren in den Akten hinterlassen hat, rasch wieder in Vergessenheit geriet. In anderen Fällen erlaubt die Vernichtung von Archivbeständen durch Bombenangriffe in der Endphase des Zweiten Weltkriegs keine Aussagen über mögliche universitätsinterne Debatten. Für die freundlichen Rückmeldungen danke ich Frau Katharina Becker (Universitätsarchiv Frankfurt/M.), Herrn Thomas Becker (UA Bonn), Herrn Andreas Freitäger (UA Köln), Frau Angela Hartwig (UA Rostock), Herrn Marcus Holtz (UA Würzburg), Herrn Ulrich Hunger (UA Göttingen), Frau Karin Keller (UA Halle), Herrn Carsten Lind (UA Marburg), Herrn Lars Nebelung (UA Hannover), Frau Barbara Peters (UA Greifswald), Herrn Clemens Wachter (UA Erlangen-Nürnberg) und Herrn Alexander Zahoransky (UA Freiburg/Br.). Für die Universität Innsbruck ist belegt, dass der Aufruf von dem Rektor der Universität im Januar 1930 zwar „sanktioniert und verteilt", von dem dortigen Ordinarius für Neuere deutsche Sprache und Literatur, Moritz Enzinger, jedoch „ignoriert“ wurde. Vgl. Holzner, Positivismus, S. 101.

${ }^{604}$ KAG, Wilhelm Stapel an Erwin Guido Kolbenheyer, 30. Januar 1930 (Herv. i. Orig.).

605 KAG, Wilhelm Stapel an Erwin Guido Kolbenheyer, 10. Februar 1930.

606 Kolbenheyer, Sebastian Karst, Bd. 3, S. 42. 
gewöhnlich. Umso anschaulicher unterstreicht die in ihren einzelnen Etappen unfreiwillig komisch wirkende Versandung des Aufrufs an der Universität Leipzig, welche Sackgasse Kolbenheyer mit dem offiziellen Amtsweg beschritt. Dabei hatte es vergleichsweise vielversprechend begonnen.

Das Fallbeispiel der Universität LeipZig - Als Außenstehendem drängte sich dem in Leipzig lebenden Erich Kröning im Frühjahr 1931 der Eindruck auf, der Aufruf habe innerhalb der dortigen Universität Anlass zu hitzigen, kontroversen Debatten gegeben. Ein „Kreis von Professoren“ habe sich „gebildet, der von den Fakultäten beschickt“ worden sei, um „die Anregungen Ihres Aufsatzes im Vorlesungsplan [zu] berücksichtigen“. Näheres zu sagen schien Kröning noch nicht möglich zu sein, jedoch waren die „Gemüter“, wie Kröning aus unbekannter Quelle vernommen hatte, „sehr erhitz[t]“607. Studiert man die Rektoratsakten jenes Zeitraums, drängt sich indes der Eindruck sehr viel kühlerer Temperaturen auf. Zwar war der Aufruf zum damaligen Zeitpunkt in der Tat Gesprächsthema an der Universität, von einer erregten Debatte konnte jedoch keine Rede sein. Vielmehr lässt sich beispielhaft nachverfolgen, wie der äußerlich zum Diskussionsgegenstand erhobene Aufruf in kürzester Zeit inhaltlich derart verwässert und weichgespült wurde, dass in den nominell aufgrund des Aufrufs einberufenen Sitzungen schon bald über allerlei gesprochen wurde, nur nicht über die von Kolbenheyer konkret erhobenen Vorwürfe und Forderungen.

Die unfreiwillige Komödie, den die Behandlung des „Aufrufs“ an der Universität Leipzig im Rückblick darstellt, nahm Anfang Dezember 1930 ihren Ausgang, als der damalige Rektor der Universität, der Veterinärmediziner Hermann Baum, an den berühmten Kriminalbiologen und -soziologen Franz Exner ${ }^{608}$ „in Sachen des von dem Dichter Kolbenheyer verfassten ,Aufrufs der Universitäten' [...] mit der Bitte“ herantrat, „für die für den Januar n[ächsten] J[ahres] in Aussicht genommene Kommissionssitzung das Referat zu übernehmen"609. Exner entsprach dieser Bitte, sodass am 16. Januar 1931 eine erste Sitzung der gebildeten Senatskommission einberufen wurde, in der eine offizielle „Stellungnahme zu dem Aufruf des Dichters Erwin Guido Kolbenheyer" 610 diskutiert werden sollte; diese Sitzung wurde jedoch um eine Woche vertagt. In der Sitzung am 22. Januar ergab die sich an Exners Vortrag „anknüpfende Diskussion“ das Ergebnis, dass „man über die Wiedereinführung einer Sammelvorlesung über das deutsche Volkstum $\mathrm{u}[\mathrm{nd}]$ von Vorlesungen der von Kolbenheyer gedachten Art geteilter Meinung “611

607 DLA, A:Kröning, Erich Kröning an Erwin Guido Kolbenheyer, 21. Februar 1931.

$608 \mathrm{Zu}$ Biografie und wissenschaftlicher Bedeutung Exners vgl. Sebald, Kriminalbiologe.

609 UAL, Rektor (1409-1951), Rep. I/III/062, Lauf. Nr. 47: Rektor Hermann Baum an Franz Exner, 8. Dezember 1930.

610 Ebd., Lauf. Nr. 52. Die Kommission konstituierte sich dem Schreiben zufolge nebst Baum und Exner aus den Leipziger Professoren Leo Bruhns (Kunstgeschichte), Theodor Kroyer (Musikwissenschaft), Heinrich Junker (Vergleichende Sprachwissenschaft), Theodor Litt (Philosophie/Pädagogik), Alfred Dedo Müller (Praktische Theologie) und Horst Emil Stephan (Systematische Theologie).

611 Ebd., Lauf. Nr. 59. 
sei. Dies konnte kaum überraschen: Dass es einer aus einem Veterinärmediziner, einem Strafrechtler, einem Kunsthistoriker, einem Musikwissenschaftler, einem Sprachwissenschaftler, einem Philosophieprofessor und zwei Theologen - kurioserweise aber keinen Germanisten, an die sich der Aufruf im Besonderen gewandt hatte - zusammengesetzten Kommission gelang, sich auf eine einhellige, gemeinsame Stellungnahme zu einigen, stand kaum zu erwarten.

Bereits an dieser ersten Sitzung war bezeichnend, dass sich die Diskussion nicht etwa um konkrete Einzelforderungen und -thesen Kolbenheyers, sondern nur vage um eine mögliche Gemeinschaftsvorlesung zum Thema „Deutsches Volkstum" drehte, deren Zusammenhang mit den Inhalten des Aufrufs schon zu diesem Zeitpunkt unklar blieb. Letztendlich einigten sich die Professoren darauf, den Gedanken einer entsprechenden Gemeinschaftsvorlesung „nicht gänzlich fallen [zu] lassen“, und bewiesen ihre Entschlussfreude, indem sie die Bildung einer „kleinere[n] Kommission“ anstießen, die sich aus jenen Professoren zusammensetzen sollte, „die sich aus Überzeugung für die Sache einsetzen können“ - also jene, die der vage angedachten Ringvorlesung über „Deutsches Volkstum“ ausreichendes Interesse entgegenbrachten, um eigene Arbeitszeit für sie zu investieren. Eine solche Kommission, so die Hoffnung, würde „eher in der Lage“ sein, „konkrete Vorschläge zu machen, die der Rektor dem Senat unterbreiten könnte“. Mit diesem Entschluss trat der „tagende Ausschuss außer Funktion“612.

Da es offenbar nicht gelang, aus dem Kreis der Versammelten ausreichend viele entsprechende Interessenten zu finden, wurden in die anschließend einberufene „vorberatende engere Kommission" 613 neben den bereits am 22. Januar anwesenden Hermann Baum, Franz Exner und Horst Emil Stephan zwei neue Gesichter gewählt. Dieses Schicksal ereilte keine Geringeren als den Kulturhistoriker und Nachfolger Karl Lamprechts, Walter Goetz, sowie den Ordinarius für Nationalökonomie, Kurt Wiedenfeld. Das erste Treffen der neu zusammengesetzten Kommission „in Sachen der Wiedereinführung einer Sammelvorlesung über das deutsche Volkstum im Anschluss an den von Kolbenheyer erlassenen Aufruf "614 wurde auf den 12. Februar 1931 anberaumt. Beschlüsse von ihr sind jedoch erst für den 6. März belegt. Konkretes oder Verbindliches gab es indes auch weiterhin nicht zu vermelden und das Ergebnis der „eingehende[n] Aussprache“ nahm sich ausgesprochen bescheiden aus: Die neue Kommission beschloss, dem Senat zum Vorschlag zu bringen, dass „die Frage [...] weiter verfolgt werden“615 möge. Dass sich die Debatte mittlerweile von den Inhalten des „Aufrufs“ völlig abgekoppelt hatte, geht aus dem Vermerk hervor, dass eine mögliche Ringvorlesung über „Deutsches Volkstum“ auf eine „breitere Basis“ gestellt werden sollte. So könnten „Hörer aller Fakultäten über allgemein interessierende Fragen eingeführt“ werden. Über die mögliche „offizielle Benennung“ einer solchen Vorlesungsreihe

612 Ebd.

613 Ebd.

614 Ebd., Lauf. Nr. 60.

615 Ebd., Lauf. Nr. 61. 
oder gar die Frage, „an welcher Stelle im Vorlesungsverzeichnis“616 sie angekündigt werden könnte, wollte sich die Kommission keine Stellungnahme erlauben. Für Entscheidungen solcher Tragweite erbat sie stattdessen die Unterstützung durch ein neu hinzuzuziehendes Kommissionsmitglied, wobei der spätere Nobelpreisträger für Chemie, Peter Debye, als Wunschkandidat genannt wurde. Wodurch sich Debye ausgerechnet als Experte für „Deutsches Volkstum“ qualifizierte, blieb offen.

Die Idee einer allgemein gehaltenen, interdisziplinären Vorlesung wurde anschließend an die Dekane aller Fakultäten mit der Bitte um Stellungnahme weitergeleitet. Einen Bezug auf den Aufruf sucht man in dem Rundschreiben vergeblich; die ursprünglich von Kolbenheyer angestoßene universitätsinterne Debatte hatte zu diesem Zeitpunkt nichts mehr mit den Ideen und Vorschlägen des Dichters zu tun. Auch die Reaktionen der Fakultäten, die zum Teil mit monatelanger Verzögerung eingingen, trugen nicht dazu bei, der Idee einer Ringvorlesung über „Deutsches Volkstum“ in naher Zukunft hohe Priorität zu verleihen.617 Gleichwohl lud Rektor Hermann Baum die Professoren Exner, Goetz, Stephan und Wiedenfeld am 15. Juli abermals „,in Sachen der Veranstaltung allgemeiner Universitätsvorträge“ zu einer Kommissionssitzung618, um zu klären, „in welcher Form der Vortragszyklus abgehalten werden“ könne und an „welcher Stelle im Vorlesungsverzeichnis auf ihn hinzuweisen"619 sei.

Das Desinteresse, das inzwischen selbst im harten Kern der Causa Kolbenheyer Einzug gehalten hatte, zeigt sich am anschaulichsten darin, dass sich nicht weniger als drei der vier geladenen Professoren (Exner, Stephan und Wiedenfeld) entschuldigen ließen und dem Treffen fernblieben. Den grotesken Schlusspunkt der Behandlung des Aufrufs an der Universität Leipzig stellte schließlich die Empfehlung der verbliebenen Rumpfkommission dar, in der Angelegenheit ein noch kleineres „Gremium von 2 Herren, etwa Geh[eim]Rat Goetz und Prof. Exner selbst“

616 Ebd.

617 Von Seiten der Philosophischen Fakultät erfolgte am 18. Mai die Stellungnahme, dass man sich von „Allgemeine[n] Universitätsvorlesungen [...] keinen großen Gewinn“ verspreche. Sollte eine solche Vorlesungsreihe jedoch veranstaltet werden, werde die Teilnahme oder Nichtteilnahme an ihr „dem Belieben jedes einzelnen Fakultätmitgliedes“ überlassen bleiben (ebd., Lauf. Nr.66). Die veterinärmedizinische Fakultät erhob am 1. April zwar keine prinzipiellen Bedenken, verwies aber darauf, dass „Vorlesungen für Hörer aller Fakultäten über allgemein interessierender [sic!] Fragen [...] bereits gehalten“ würden und „im Vorlesungsverzeichnis aufgeführt“ seien (ebd., Lauf. Nr. 68). Der Dekan der Theologischen Fakultät berichtete am 14. April „ergebenst [...], daß nur ein Teil der Mitglieder meiner Fakultät einen Versuch dieser Art vorbehaltlos“ empfehle, „während andere grundsätzliche Bedenken dagegen haben“. Im Übrigen sei diese Mitteilung „der akademischen Ferien wegen [...] als vorläufig zu betrachten“ (ebd., Lauf. Nr. 69). Am 11. Juni 1931, nach etwas mehr als drei Monaten also, bequemte sich schließlich auch die Medizinische Fakultät zu einer offiziellen Stellungnahme und ließ in phlegmatischem Tonfall mitteilen, man habe grundsätzlich "gegen den Gedanken der Abhaltung von Vorträgen für Hörer aller Fakultäten nichts einzuwenden“ (ebd., Lauf. Nr. 75). Vorbehaltslose Unterstützung des Vorlesungsplans wurde lediglich von der Juristischen Fakultät signalisiert (ebd., Lauf. Nr. 67).

618 Ebd., Lauf. Nr. 76.

619 Ebd., Lauf. Nr. 77. 
einzurichten, das „bis Mitte Oktober 1931“ eine „Zusammenstellung der in Frage kommenden Vorlesungen und Dozenten"620 erarbeiten sollte. Dass auch diese Idee im Sande verlief, verrät die letzte Spur, die sich in den Rektoratsakten zu der Angelegenheit findet: Ein auf den 28. Oktober 1931 datierender Senatsbeschluss besagt, dass die „Frage der Veranstaltung allgemeiner Universitätsvorträge (in Fluss gekommen durch den Aufruf des Dichters Kolbenheyer) [...] zu erneuter Beratung der Kommission überwiesen"621 werden solle.

Zum Umgang mit DeM „Aufruf“ AN DeR Universität TÜBIngen - Als Beispiel einer zwar ebenfalls auf dem Amtsweg steckengebliebenen, für Kolbenheyer jedoch ungleich erfreulicheren Behandlung des Aufrufs lohnt ein Blick auf die Universität Tübingen. Entscheidend war hier der Standortvorteil des seit 1919 in Tübingen lebenden Dichters: Einige der mit Kolbenheyer bekannten und befreundeten Professoren waren sichtlich darum bemüht, den Ehrendoktor ${ }^{622}$ ihrer Universität nicht durch Untätigkeit vor den Kopf zu stoßen. Eine Erfolgsgeschichte lässt sich, was den Amtsweg anbetrifft, zwar auch für Tübingen nicht bilanzieren - eine gemeinsame, offizielle Erklärung zugunsten Kolbenheyers im Namen der gesamten Universität blieb auch hier zu jedem Zeitpunkt illusorisch -, gleichwohl lässt der Umgang mit dem Aufruf in Tübingen auf eine im Vergleich zu Leipzig bei Weitem höhere Anschlussfähigkeit schließen.

Im Mai 1930 beauftragte der Tübinger Universitätsrektor Enno Littmann den mit Kolbenheyer befreundeten Dekan der Philosophischen Fakultät Johannes Mewaldt ${ }^{623}$ damit, eine Antwort auf die Zusendung des Aufrufs durch die Bundesleitung der Deutschen Sängerschaft zu verfassen. Littmann, der Wind davon bekommen hatte, dass sich Mewaldt „mit dem vor einigen Monaten versandten Aufruf des Herrn Dr. Kolbenheyer" bereits „eingehender beschäftigt" und dem

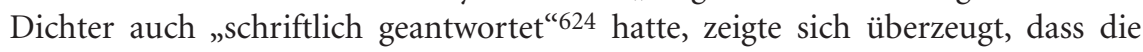
Universität „nicht achtlos an diesen Kundgebungen vorübergehen“ dürfe. Eine „richtige Antwort darauf zu finden“"werde jedoch „schwer“. Littmann beauftragte

620 Vgl. ebd. Anwesend war hingegen der in der Ankündigung unerwähnte Oberregierungsrat Flade.

621 Ebd., Lauf. Nr. 79.

622 Vgl. Kap. 3.4.

623 Die Freundschaft zwischen Mewaldt und Kolbenheyer bezeugen die Briefe und Postkarten des Philologen im Nachlass Kolbenheyers aus dem Zeitraum 1928 bis 1931 - jenem Jahr, in dem Mewaldt von der Universität Tübingen an die Universität Wien berufen wurde. Mewaldt gab in mehreren Schreiben seine Bewunderung für Kolbenheyers künstlerisches Werk wie auch für dessen politische Publizistik zu erkennen. Kolbenheyers Aufsatz Die volksbiologische Grundlage des deutsch-österreichischen Anschlussgedankens kommentierte Mewaldt im März 1928 mit den Worten: „Mich haben Ihre Beweisgründe sehr aufgerüttelt. Möge es auch bei vielen anderen so sein, an deren Ohr Ihre Stimme klingt!" Und auch zu Kolbenheyers Bühnenwerk Die Brücke fand Mewaldt im Oktober 1929 „kein Ende des Rühmens“. Vgl. KAG, Johannes Mewaldt an Erwin Guido Kolbenheyer, 14. März 1928 und 4. Oktober 1929.

624 UAT, Sachakten des Rektoramtes, Nr. 117/161, Akten betr. Deutsche Universitäten und andere höhere Lehranstalten: Enno Littmann an Johannes Mewaldt, 6. Mai 1930. 
Mewaldt darüber hinaus, „in der Sitzung des kleinen Senats am nächsten Donnerstag [den 8. Mai 1930] einmal Ihre Ansicht vorzutragen"625.

Aus Gründen, die im Detail nicht mehr rekonstruierbar sind, übermittelte Mewaldt an Littmann jedoch erst mit über zweimonatiger Verspätung, am 22. Juli 1930, den Entwurf eines offiziellen Antwortschreibens der Universität an die Deutsche Sängerschaft. In diesem Schreiben wird zwar selbstkritisch die sachliche Berechtigung des Aufrufs und dessen Unterstützung durch die Deutsche Sängerschaft betont, eine darüber hinausgehende, verbindliche Aussage jedoch bewusst vermieden: „Mit vollem Recht“, so Mewaldt, werde „von den Besten der deutschen Jugend $[\ldots]$ gefühlt und erkannt, daß das Kunstwesen der deutschen Gegenwart weithin entwurzelt und entartet" sei. ${ }^{626}$ Die deutsche Jugend empfinde „hierin ganz instinktiv richtig und tiefer als der größte Teil der gegenwärtig an den Universitäten lehrenden Philologen- und Historikergeneration". Diese stehe den „geistigen Nöten und Gefahren der Gegenwart“ häufig „ahnungslos oder hilflos“ gegenüber, sei es „aus rein verstandesmäßigem, kühlen Betrachten der Vergangenheit", sei es „aus Vorkriegserinnerungen“, sei es „auch nur aus liebgewordener Gewohnheit des Lehrbetriebs". Aus diesem Grund bestehe zwischen Professoren und Studenten nur selten „eine innere geistige Gemeinschaft über die Fragen des alle umfassenden deutschen Kulturinteresses“. In dieser Situation „auf einen großen Mangel des heutigen Universitätslagebetriebes hingewiesen zu haben“, sei „das Verdienst Kolbenheyers“, dessen Forderungen bei „den Versuchen, die deutsche Universität aus der Krisis zu retten“, eine „bedeutende Rolle“ spielen würden. ${ }^{627}$

Littmann pflichtete dem von Mewaldt vorgelegten Text bei und übernahm ihn wortwörtlich in seinem Antwortschreiben an den Bundesvorstand der Deutschen Sängerschaft. Damit unterstrich er eindrücklich die in Tübingen vorhandenen Sympathien für Kolbenheyers Aufruf, der, so versicherte Littmann, „den Lehrkörper unserer Universität stark beschäftigt" habe. Kolbenheyer sei nicht nur den meisten Professoren und Dozenten „persönlich bekannt“, er werde „von uns verehrt" - wie auch an der Verleihung der Ehrendoktorwürde abgelesen werden könne. Der Lehrkörper sei sich demnach bewusst, dass Kolbenheyer „etwas zu sagen" 628 habe. Zugleich kommt in Littmanns Schreiben jedoch auch unmissverständlich die Aussichtslosigkeit einer einhelligen Solidarisierungserklärung von Seiten der gesamten Universität zum Ausdruck: Von der Deutschen Sängerschaft

625 Ebd. In dem Protokoll der nämlichen Sitzung des Kleinen Senats am 8. Mai 1930 findet sich leider kein Vermerk darüber, dass Mewaldt (der als Teilnehmer der Sitzung belegt ist) zum Fall Kolbenheyer vorgetragen hätte, siehe: UAT, Sachakten des Rektoramtes, Nr. 47a/2: Protokolle über die Verhandlungen des Kleinen Senats der Universität Tübingen vom 3. November 1927-16. Dezember 1935, S. 85-88.

626 UAT, Sachakten des Rektoramtes, Nr. 117/161, Akten betr. Deutsche Universitäten und andere höhere Lehranstalten: Johannes Mewaldt an Enno Littmann, 22. Juli 1930.

627 Ebd.

628 UAT, Sachakten des Rektoramtes, Nr. 117/161, Akten betr. Deutsche Universitäten und andere höhere Lehranstalten: Enno Littmann an den Bundesvorstand der Deutschen Sängerschaft, 29. Juli 1930 . 
werde schwerlich „erwartet“ und wohl auch nicht „als ersprießlich angesehen“ werden, dass „über so schwierige Fragen, wie Kolbenheyer sie zur Erörterung stellt und mit starkem Temperament zu ihnen Stellung nimmt, von dem großen Lehrkörper einer Hochschule im Wege der Abstimmung und durch Mehrheitsbeschluß Stellung genommen " 629 werde. Littmann solidarisierte sich also persönlich mit Kolbenheyer und den Inhalten des Aufrufs, erklärte eine offizielle, einheitliche Verlautbarung der Universität jedoch mit einem Federstreich zu einem Ding der Unmöglichkeit.

Um alle Missverständnisse zu vermeiden, hob Littmann ergänzend hervor, dass sein Schreiben nicht als repräsentativ für die Ansichten des gesamten „Senats oder der Universität Tübingen" angesehen werden dürfe. Er spiegele lediglich die Auffassung „derjenigen Gruppe von Dozenten“ wider, „die Dr. Kolbenheyer zustimmen und gewillt sind, im Sinne seines Aufrufs zu handeln". Für den Fall, dass die Deutsche Sängerschaft in Erwägung ziehe, seine Stellungnahme in ihrer Zeitschrift zu publizieren, wollte Littmann unmissverständlich klarstellen, dass sie keine universitätsoffizielle sei, sondern lediglich „aus Universitätskreisen“630 stamme. 